\title{
Role of Adaptor Proteins in MPR sorting
}

\author{
Dissertation \\ zur Erlangung des Doktorgrades \\ der Mathematisch-Naturwissenschaftlichen Fakultäten \\ der Georg-August-Universität zu Göttingen
}

\author{
vorgelegt von \\ Guruprasad Medigeshi Ramarao \\ aus Bangalore (Indien)
}

Göttingen 2003 
D7

Referent:

Prof. Dr. Kurt von Figura

Korreferent:

Prof. Dr. Gerhard Braus

Tag der mündlichen Prüfung:

08.05.2003 
To

My Parents... 



\section{Contents}

\section{Abbreviations}

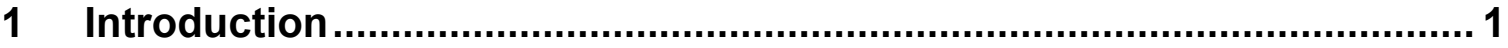

$1.1 \quad$ Vesicular transport processes .................................................. 1

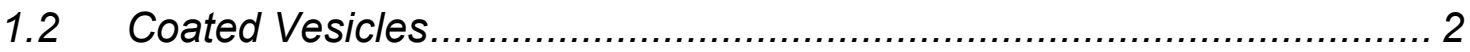

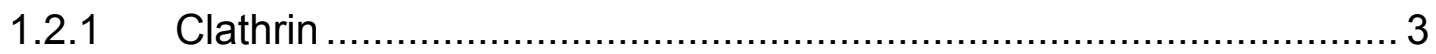

1.2.2 Adaptor Protein Complexes................................................. 4

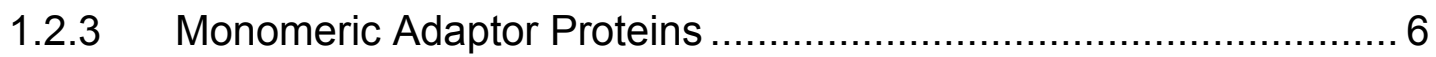

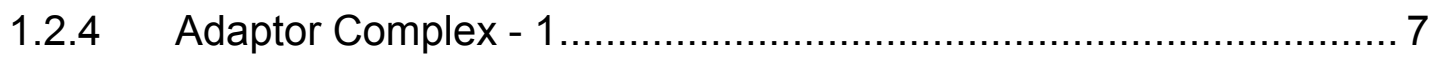

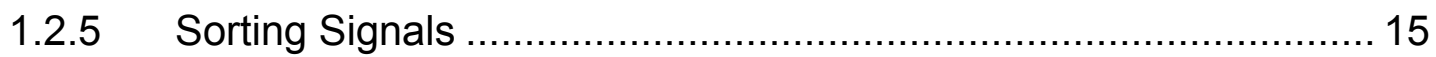

1.2.6 Cargo molecules of AP-1 ............................................... 16

1.2.7 Formation of CCVs: Initiation, Budding and Uncoating................ 21

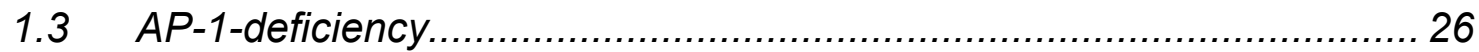

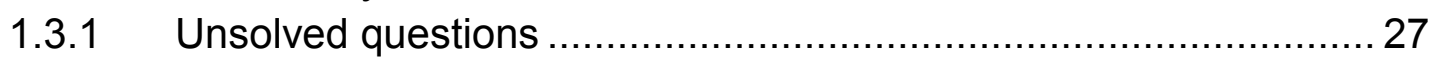

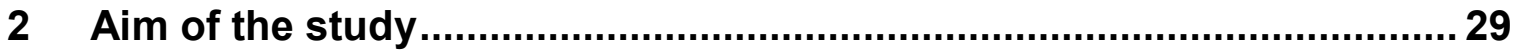

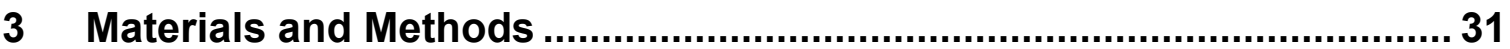

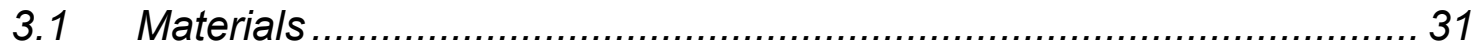

3.1.1 Equipments used for molecular biology and biochemical work ..... 31

3.1.2 Materials for molecular biology and biochemical experiments....... 33

3.1.3 Materials for Western Blotting........................................... 34

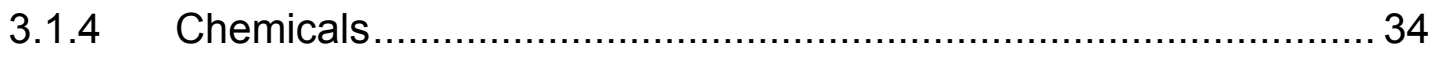

3.1.5 Detergents ....................................................................... 36

3.1.6 Enzymes, Substrates and Nucleotides ...................................... 36

3.1.7 Proteins, Protease inhibitors and Protein standards .................... 37

3.1.8 Vectors and DNA standards ............................................. 37

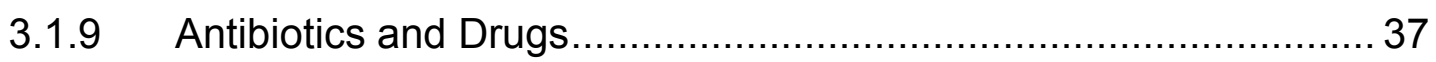

3.1.10 Radioactive substances.................................................... 38

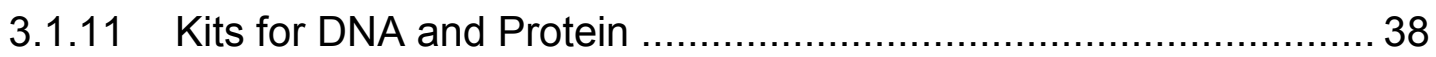

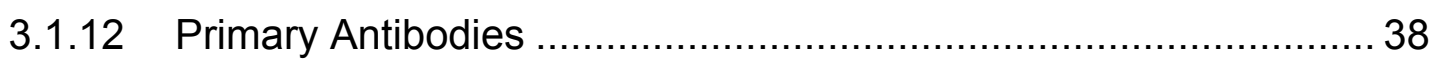

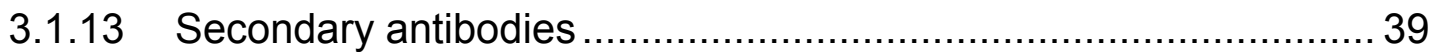

3.1.14 Bacterial strains and Fibroblast cell lines................................... 39

3.1.15 Media and Solutions for Cell culture ....................................... 40

3.1.16 Stock solutions and buffers............................................. 40

3.1.17 Computing facilities used................................................. 41

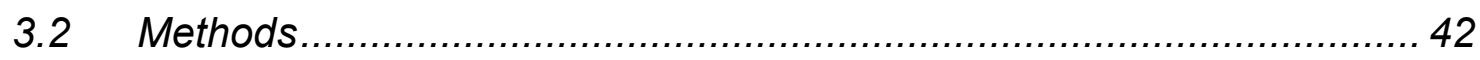

3.2.1 MOLECULAR BIOLOGY METHODS .................................... 42 


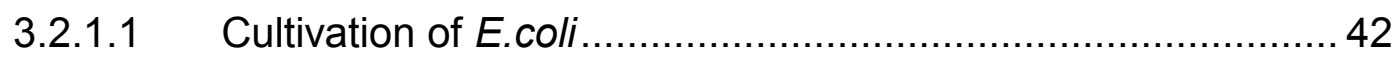

3.2.1.2 Preparation of competent E. coli cells .............................. 42

3.2.1.3 Transformation of E.coli competent cells.......................... 43

3.2.1.4 Preparation of electrocompetent cells .............................. 43

3.2.1.5 Transformation of the electrocompetent cells.....................43 43

3.2.1.6 Glycerol stocks of bacterial strains .................................. 44

3.2.1.7 Mini preparation of plasmid DNA .................................... 44

3.2.1.8 Determining the concentration of DNA .............................. 45

3.2.1.9 Restriction endonuclease digestion of DNA ....................... 45

3.2.1.10 Agarose gel electrophoresis of DNA ............................... 46

3.2.1.11 Cloning of full length and antisense GGA cDNA ................ 47

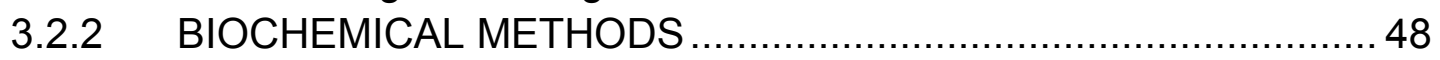

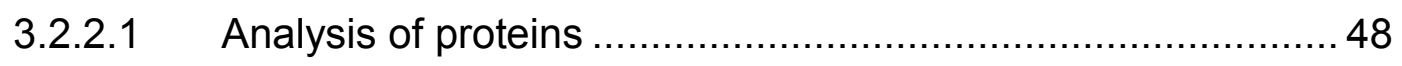

3.2.2.1.1 Estimation of protein content using the BIORAD reagent... 48

3.2.2.1.2 Solubilisation of proteins ......................................... 48

3.2.2.1.3 SDS Poly-Acrylamide Gel Electrophoresis (SDS-PAGE) ... 48

3.2.2.1.4 Coomassie blue staining of Polyacrylamide gels ..............50

3.2.2.1.5 Western blot analysis (semi dry method) ...................... 50

3.2.2.1.6 Detection techniques.................................................. 52

3.2.2.1.7 Stripping the antibody from the membrane ...................... 53

3.2.2.2 Expression and Purification of GST-Vti1a from E.coli ............ 53

3.2.2.2.1 Raising polyclonal antibodies against $\mathrm{Vti} 1 \mathrm{a} \ldots \ldots \ldots \ldots \ldots \ldots . \ldots . \ldots 55$

3.2.2.2.2 Purification of IgG from Vti1a polyclonal antisera................56

3.2.2.2.3 Purification of IgG from VAMP4 polyclonal serum by

VIVASPIN buffer-exchange and MONO-S mini columns ....56 56

3.2.2.3 TCA precipitation of proteins ....................................... 57

3.2.2.4 Gel filtration of cytosol to obtain adaptor enriched fraction ..... 57

3.2.2.5 Indirect Immunoflorescence ...................................... 59

3.2.2.5.1 Fixing cells by Methanol/Methanol-Acetone ..................... 59

3.2.2.5.2 Fixing cells by para formaldehyde ............................... 60

3.2.2.6 Transferrin endocytosis ................................................ 61

3.2.2.7 Metabolic labeling of cells with [35S]-Methionine/Cysteine ....61 61

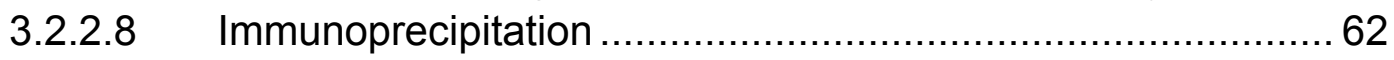

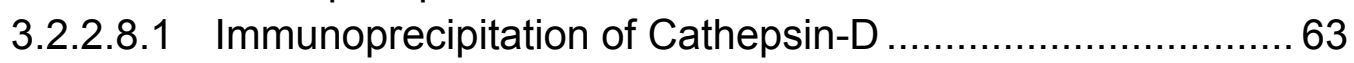

3.2.2.8.2 Immunoprecipitation of MPR46 .................................. 65

3.2.2.9 Preparation of membrane and cytosol fractions for western blot analysis ........................................................ 66

3.2.3 In vitro MPR retrograde transport assay ................................6 67

3.2.3.1 Synthesis and purification of ${ }^{35} \mathrm{~S}-\mathrm{Phosphoadenosine}$ phosphosulfate (PAPS).

3.2.3.1.1 Preparation of Yeast extract.........................................6 67

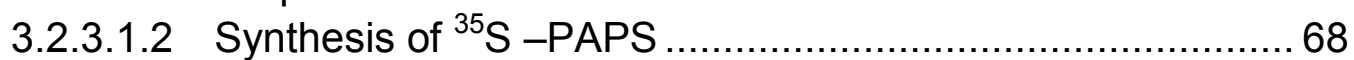

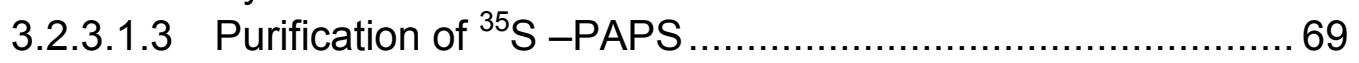


3.2.3.2 Preparation of semi-intact cell membranes for in vitro transport assay ................................................... 70

3.2.3.3 Preparation of cytosol for the in vitro assay....................... 72

3.2.3.4 In vitro Endosome-to-TGN transport assay ....................... 73

3.2.3.4.1 Assay to verify the intactness of compartments during in vitro reaction ......................................................... 75

3.2.3.5 CELL BIOLOGICAL METHODS ...................................... 76

3.2.3.6 Cell Culture.............................................................. 76

3.2.3.7 Passaging of cells by trypsinization ................................ 76

3.2.3.8 Freezing cells for stock maintenance ............................. 77

3.2.3.9 Thawing cells from liquid nitrogen ................................ 77

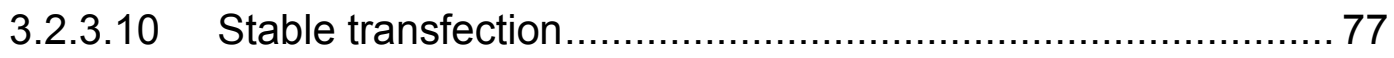

3.2.3.10.1 By Calcium-phosphate coprecipitation ....................... 77

3.2.3.10.2 Transfection with Effectene transfection reagent (Quiagen)........................................................ 78

3.2.3.10.3 Transfection with FuGENE 6 transfection reagent (Roche Diagnostics) .......................................................... 79

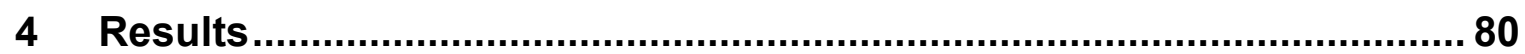

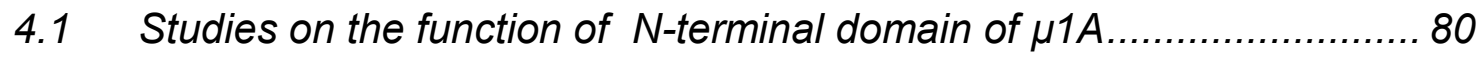

$4.1 .1 \quad \mu 2 / \mu 1$ chimeras .......................................................... 80

4.1.2 Expression of Chimera I in transfected cells............................ 82

4.1.3 AP-1 complex formation in the cells expressing Chimera I.............83 83

4.1.4 Steady-state localization of AP-1 and MPRs in Chimera I expressing cells ................................................................ 84

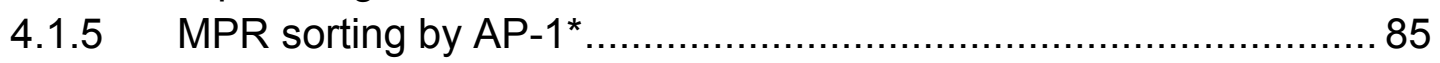

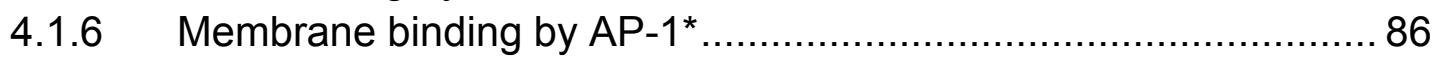

4.2 In vitro assay to measure the retrograde transport of MPR46 ............ 89

4.2.1 Generation of Cell lines ................................................... 90

4.2.2 Steady-state localization of HMY-MPR46 ............................... 91

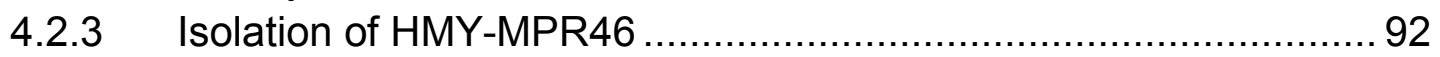

4.2.4 In vivo ${ }^{35}$ S-sulfate labelling of HMY-MPR46 ............................. 93

4.2.5 Synthesis and purification of ${ }^{35}$ S-PAPS ..................................... 94

4.2.6 In vitro endosome-to-TGN transport assay ............................. 95

4.2.7 Standardization of assay conditions ...................................... 96

4.2.7.1 Time course .............................................................. 96

4.2.7.2 Dependence on cytosolic protein concentration ..................... 97

4.2.7.3 Temperature dependence ............................................ 98

4.2.7.4 Assay to verify compartment intergrity ............................ 99

4.2.7.5 ATP dependence....................................................... 100

4.2.7.6 GTP and CAMP dependence ....................................... 101

4.2.8 Analysis of the HMY-MPR46 endosome-to-TGN transport ......... 103 
4.2.8.1 Effect of Primaquine on the in vitro endosome-to-TGN transport............................................................... 103

4.2.8.2 Transferrin endocytosis and immunofluorescence .............. 104

4.2.8.3 SNARE proteins involved in the in vitro retrograde transport reaction................................................................... 105

4.2.8.4 Rab dependence of in vitro transport reaction ..................... 106

4.2.8.5 Effect of AP-1-deficient cytosol on the retrograde transport of MPR46 .......................................................... 108

4.2.8.6 Estimation of membrane association of adaptors ................ 109

4.2.8.7 Effect of BFA on the in vitro transport reaction .................... 110

4.2.8.8 Effect of AP-3-deficiency on the retrograde transport of MPR46................................................................ 112

4.2.8.9 Effect of pre-treatment of membranes with BFA................. 114

4.2.8.10 AP-1 and AP-3 membrane association during the assay .... 115

4.2.8.11 TIP47 dependence .................................................... 117

4.2.9 Assays with AP-1-deficient membranes ................................ 118

4.2.9.1 AP-1 and AP-3-depencence........................................ 119

4.2.9.2 Membrane-associated AP-1 .......................................... 120

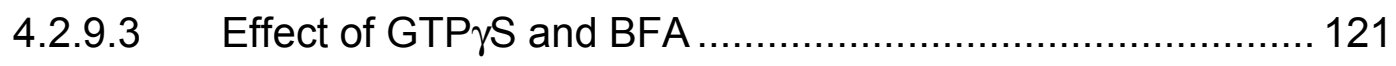

4.2.9.4 Membrane Mixing assay....................................... 122

4.3 Role of GGA proteins in MPR transport........................................ 124

4.3.1 Generation of cell lines ................................................ 124

4.3.2 Cathepsin D sorting ..................................................... 126

4.3.3 Steady-state localization of cathepsin D............................. 129

4.3.4 Steady-state localization of MPRs ................................... 131

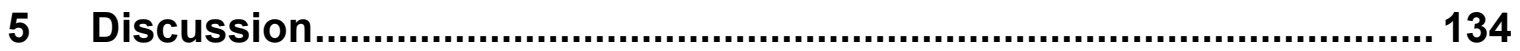

5.1 Studies on the function of $N$-terminal domain of $\mu 1 A$..................... 134

5.2 Establishment of an in vitro transport assay for MPR46 retrograde transport .................................................................... 137

5.2.1 Assay characteristics ................................................... 138

5.2.2 Evidence for an early-endosome-to-TGN transport of MPR46 ... 140

5.2.3 Involvement of Adaptor complex-1 and 3 in the retrograde transport of MPR46......................................................... 142

5.2.4 TIP47 in retrograde MPR46 transport................................. 146

5.2.5 Effect of AP-1-deficiency on MPR46 retrograde transport........... 146

5.3 Preliminary analysis of GGA function in MPR sorting ..................... 150

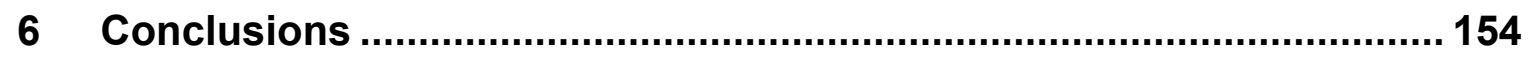

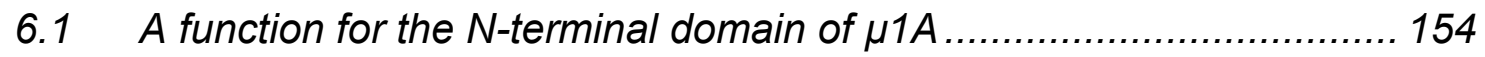

6.2 In vitro MPR46 retrograde transport assay ............................... 154 
6.3 Analysis of the function of GGAs in MPR sorting............................ 156

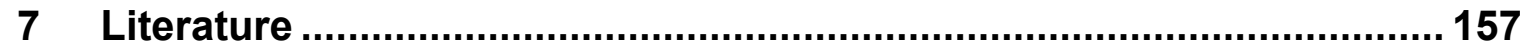




\section{Abbreviations}

\begin{tabular}{|c|c|}
\hline AA & Amino acid \\
\hline Amp & Ampicillin \\
\hline AP & Adaptor Protein \\
\hline APS & Ammoniumperoxodisulfate \\
\hline ARF & Adenosine 5'-diphosphate Ribosylation Factor \\
\hline ATP & Adenosine 5'-triphosphate \\
\hline BFA & Brefeldin A \\
\hline BSA & Bovine Serum Albumin \\
\hline cAMP & Adenosine 3',5'- cyclic monophosphate \\
\hline CCV & Clathrin-coated Vesicle \\
\hline cDNA & complementary DNA \\
\hline $\mathrm{CHC}$ & Clathrin Heavy Chain \\
\hline CLC & Clathrin Light Chain \\
\hline $\mathrm{CHO}$ & Chinese Hamster Ovary \\
\hline COP & Coat Protein \\
\hline ct & Control \\
\hline $\mathrm{ddH}_{2} \mathrm{O}$ & double distilled water \\
\hline DMSO & Dimethylsulfoxide \\
\hline DNA & Deoxyribonucleicacid \\
\hline dNTPs & Deoxynucleosidetriphosphate (dATP, dGTP, dCTP, dTTP) \\
\hline DTT & Dithiothreitol \\
\hline E. coli & Escherichia coli \\
\hline EDTA & Ethylenediamintetraacetate-Disodium salt \\
\hline EGF & Epidermal Growth Factor \\
\hline EGTA & Ethylenglycol-bis-( $\beta$-Aminoethylether)-N,N,N',N'-Tetraacetate \\
\hline ER & Endoplasmic Reticulum \\
\hline $\mathrm{EtOH}$ & Ethanol \\
\hline GAP & Guanosine 5'-triphosphatase activating protein \\
\hline GEF & Guanine nucleotide exchange factor \\
\hline
\end{tabular}




\begin{tabular}{ll} 
Abbreviations & \\
\hline GDP & Guanosine 5'-diphosphate \\
GGA & Golgi localized Gamma ear domain-containing ARF binding \\
& proteins \\
GST & Glutathione-S-Transferase \\
GTP & Guanosine 5'-triphosphate \\
h & Hour \\
HEPES & N-2-Hydroxyethylpiperazin-N'-2-ethanesulfonic acid \\
HeLa & Henrietta Lacks \\
HRP & Horseradish-Peroxidase \\
IgG & Immunoglobulin G \\
IPTG & Isopropyl-a-D-Thiogalactopyranoside \\
kb & Kilobase \\
kDa & Kilodalton \\
I & Liter \\
LB & Luria Bertani \\
M & Molar \\
mA & Milliampere \\
Man 6-P & Mannose 6-phosphate \\
MEF & Mouse Embryonic Fibroblasts \\
mg & Milligram \\
min & Minute \\
ml & Milliliter \\
mM & Millimolar \\
MPR & Mannose 6-phosphate receptor \\
nm & Nanometer \\
NSF & N-ethylmaleimide Sensitive Factor \\
PAGE & Poly-acrylamide gel electrophoresis \\
PAPS & Phosphoadenosine phosphosulfate \\
PCR & Polymerase chain reaction \\
pH & Negative logarithm of $H^{+}$concentration \\
PKA & Protein Kinase A \\
PIP & Phosphatidyl inositol phosphate \\
\hline
\end{tabular}




\begin{tabular}{ll}
\hline PM & Plasma Membrane \\
PMSF & Phenylmethylsulfonylfluoride \\
RNA & Ribonucleicacid \\
RT & Room Temperature \\
S. cerevisiae & Saccharomyces cerevisiae \\
SDS & Sodium Dodecyl Sulfate \\
Sec & Seconds \\
SNARE & Soluble N-ethylmalimide Attachment protein Receptor \\
TAE & Tris-Acetate-EDTA-Buffer \\
TCA & Trichloroaceticacid \\
TE & Tris-EDTA-Buffer \\
TEMED & N,N,N',N'-Tetramethylethylenediamine \\
TGN & trans-Golgi network \\
Tris & Tris-(hydroxymethyl)-aminomethane \\
U & Unit \\
UV & Ultraviolet \\
V & Volt \\
v/v & (volume/volume) \\
Vti1a & Vps10p interacting \\
w/v & (weight/volume) \\
WT & Wild type \\
$\mu$ & Micro \\
\hline
\end{tabular}




\section{Introduction}

\subsection{Vesicular transport processes}

Vesicle-mediated protein trafficking is an essential component of eukaryotic cells. Proteins destined for both secretory and endosomal-lysosomal pathways traverse along the Golgi stacks to reach the trans-Golgi network (TGN). They undergo compartment specific post-translational modifications both during their transit through Golgi stacks and in the trans-Golgi network. Proteins take specific routes from the TGN to reach their target destinations. Post-TGN transport of proteins is mediated by coated vesicles and this process involves participation of defined set of proteins that confer specificity to the transport events (Le Borgne et al., 1998; Scales et al., 2000; Schu, 2001)

The outline of a round of vesicular transport is as follows: coat proteins are recruited from a cytosolic pool to specialized sites on the donor membrane on activation of a specific small GTP-binding protein by its donor membrane-bound GTP exchange factor (GEF). Cargo molecules are concentrated at this bud site although the sequence of these events is not known. Cargo molecules may recruit coat constituents, cargo may be recruited into emerging bud sites, or cargo and coat may be recruited coordinately. Coat protein subunits have been shown to interact with sorting signals on cargo molecules and receptors, ensuring the efficient and selective packaging of the cargo into the newly emerging transport vesicle. This packaging leads to the formation of a coated bud and the bud pinches off to form a coated vesicle. The transport of this vesicle is facilitated by motor proteins along cytoskeletal filaments over long distances. Uncoating of the vesicle coat components allows the vesicles to dock to their target membrane through the binding of specific v-SNARE and t-SNARE (Soluble N-ethylmalimide Attachment protein Receptor) proteins and the cargo is delivered into the acceptor compartment. 


\subsection{Coated Vesicles}

Two classes of coated vesicles are characterized to date namely: Clathrin-coated vesicles (CCVs) and COPI-coated vesicles. Clathrin-coated vesicles (CCVs) were the first discovered and remain the most extensively characterized transport vesicles. They are involved in the sorting and selective transport of membranebound proteins for several pathways of intracellular membrane traffic. They are responsible for receptor-mediated endocytosis at the plasma membrane and sorting of proteins at the TGN during the biogenesis of lysosomes and secretory granules (Brodsky et al., 2001; Kirchhausen, 2000). The important components of CCVs are clathrin and adaptor protein complexes. Clathrin forms the outermost layer, adaptors serve to link clathrin to the membrane. Adaptor complexes are a family of heterotetrameric complexes consisting of four members named AP-1 to AP-4. While AP-1 and clathrin coordinate trafficking from the TGN to the endosomal/lysosomal pathway, AP-2 is involved in internalization of extracellular ligands at the plasma membrane by CCVs. AP-3 and AP-4 function in a clathrin independent manner and hence belong to a distinct class of coated vesicles that contain adaptors but lack clathrin (Fig. 1.1).

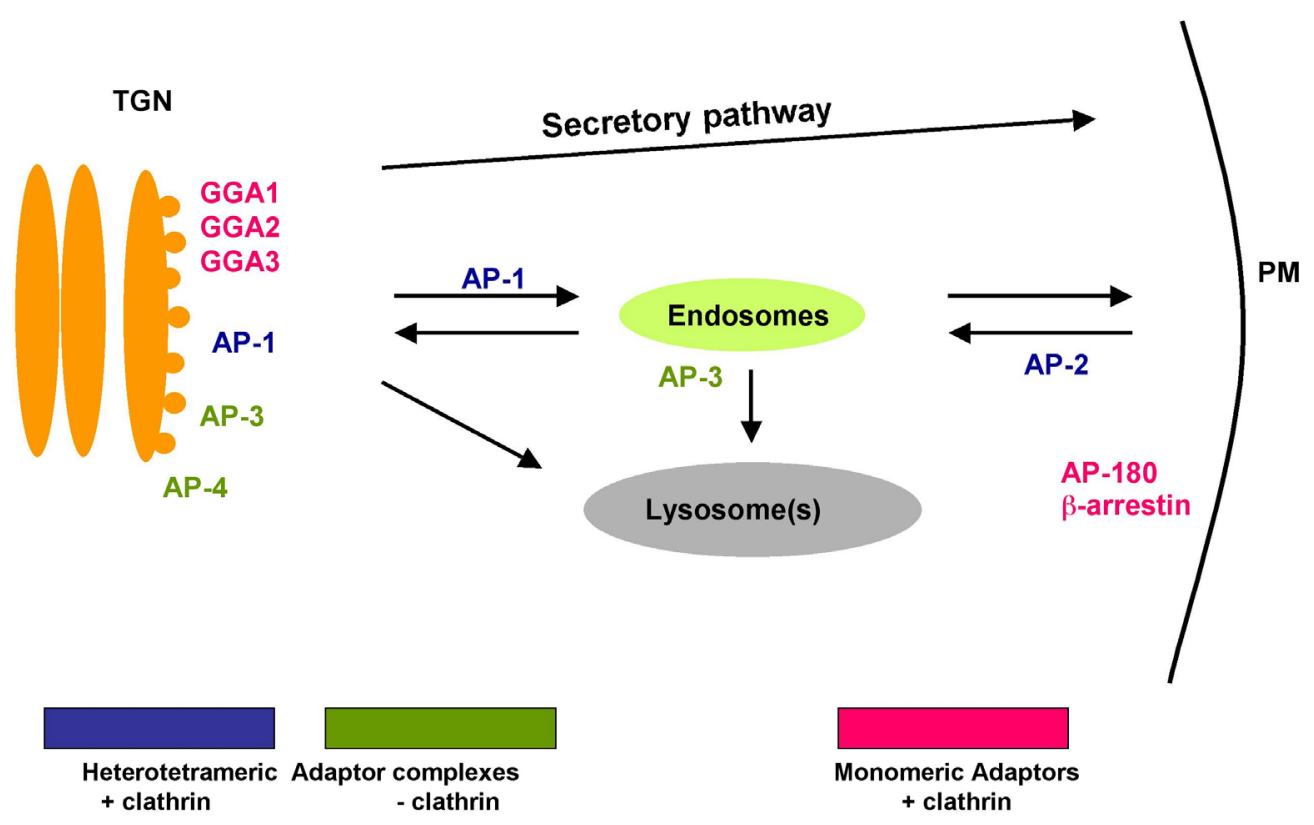

Figure 1.1: A schematic representation of the vesicular transport processes beyond the trans-Golgi network (Schu, 2001). 
COPI-coated vesicles are involved in the retrograde transport of proteins from Golgi to endoplasmic reticulum (ER) and there is considerable evidence for its role in the anterograde transport from ER-to-Golgi, hence it is believed that COPIcoated vesicles might function in either direction (Hosobuchi et al., 1992; Schekman and Mellman, 1997). The coat of COPI-coated vesicles consists of coatomer, which is a complex of seven subunits $\alpha, \delta, \zeta, \gamma, \beta, \beta$ ' and $\varepsilon$ called COPs (coat proteins), which makes up the COPI coat. The $\beta$-, $\delta$-, and $\zeta$-cop subunits are similar in size and show weak homology to some domains of $\beta, \mu, \sigma$ subunits of clathrin adaptor complexes respectively, implying that these domains are important for general aspects of coat function. COPII coats are made up of Sec23p/Sec24p complex, Sec13p/Sec31p complex and the small GTPase Sar1p. COPII-coated vesicles are mainly shown to bud from the ER and are involved in the ER-to-Golgi transport (Kuehn et al., 1998).

\subsubsection{Clathrin}

CCVs contain clathrin as their outermost coat layer and this coat protein provides structural stability to the vesicle. Clathrin consists of three $180 \mathrm{kDa}$ heavy chains (HCs) each bound to either of two $\sim 30 \mathrm{kDa}$ light chains, LCa or LCb. This complex is called a triskelion based on its three-legged appearance when viewed by negative stain or rotary shadowing. Triskelions are the assembly units of the polygonal lattice composed of hexagons and pentagons that demarks the bud site and eventually encases the transport vesicle (Fig. 1.2). Clathrin triskelia are capable of spontaneous self-assembly to form polyhedral structure called clathrin cages, which look like polygonal lattices on the vesicles under an electron microscope. Clathrin heavy chains are trimerized at their $\mathrm{C}$-terminal end with their bent arm extending radially from the vertex. One clathrin LC is non-covalently bound along each HC arm, proximal to the vertex. Clathrin HCs and LCs are thought to interact in a coiled-coil fashion, mediated by heptad repeats contained within both proteins (Nathke et al., 1992). In mammalian cells one major clathrin $\mathrm{HC}$ gene and two clathrin LC genes have been identified, whereas yeast has only one LC gene. 
The crystal structures of clathrin N-terminal 495 residues and a segment of the clathrin proximal leg ( 316 residues) has been solved (ter Haar et al., 1998; Ybe et al., 1999). These two structures together effectively yield a picture of most of the molecule. The terminal domain is a seven-blade $\beta$-propeller and the linker is a zigzag of $\alpha$-helices which continues throughout the leg. The $\mathrm{N}$-terminal domain projects inward towards the membrane, where it probably directs incorporation of specific cargo through interaction with appropriate adaptors (Gallusser and Kirchhausen, 1993). The $\beta$-propeller appears to be a particularly favourable kind of protein interaction domain for mediating multiple specific interactions.

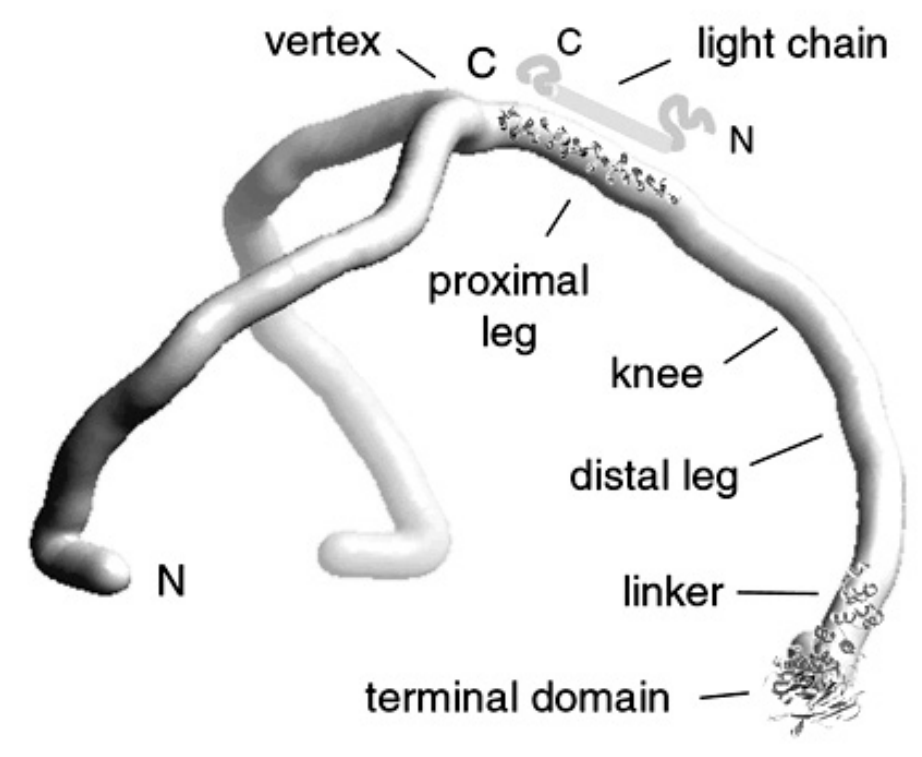

Figure 1.2: The three dimensional shape of a Clathrin triskelion (Kirchhausen, 2000).

\subsubsection{Adaptor Protein Complexes}

Adaptor complexes constitute a family of large heterotetrameric protein complexes of $\sim 300 \mathrm{kDa}$ in size, which are found in all eukaryotes. They play an important role in the protein sorting events at different intracellular compartments. There are at least four classes of adaptor complexes in mammalian cells which are designated as AP-1, AP-2, AP-3 and AP-4 (Boehm and Bonifacino, 2001; 2002; Kirchhausen, 1999; Robinson and Bonifacino, 2001). Yeast has only three adaptor complexes and lacks AP-4. 


\section{i) Composition and Function}

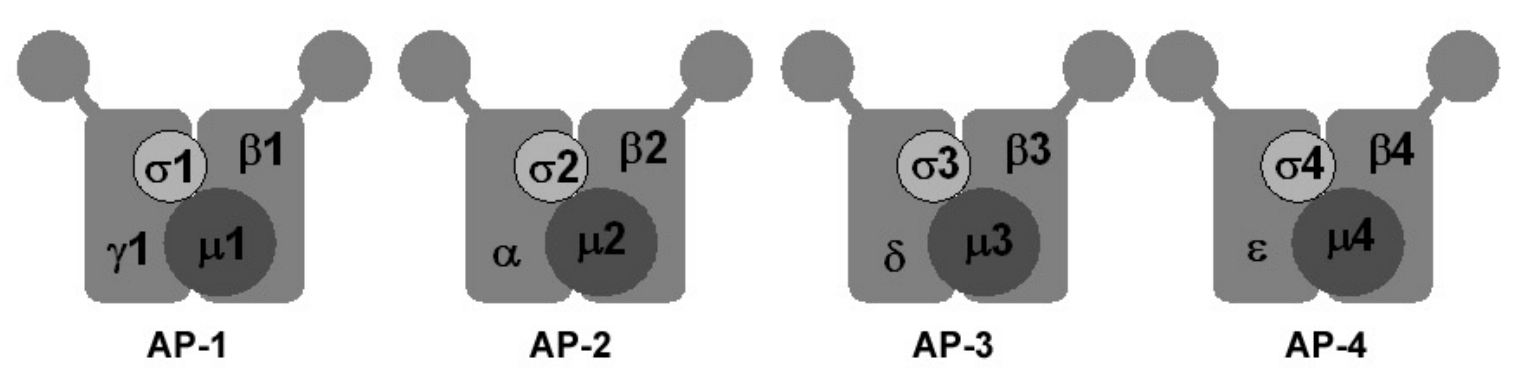

Figure 1.3: Domain organization of Adaptor Complexes.

Each adaptor complex consists of two large subunits (one each of $\gamma / \alpha / \delta / \varepsilon$ and $\beta 1-4$ respectively, 90-130 kDa), one medium ( $\mu 1-4, \sim 50 \mathrm{kDa}$ ) and one small ( $\sigma 1-$ 4, $\sim 20 \mathrm{kDa}$ ) subunit. The four subunits are closely associated and cannot be dissociated without the use of harsh denaturants. They are collectively referred to as adaptins. The analogous $\beta, \mu$, and $\sigma$-adaptins of the four AP complexes are homologous to one another (21-83\% identity at the amino acid level), which indicates that their primary structure is highly conserved (see Fig. 1.3). In contrast, the $\alpha, \gamma, \delta$ and $\varepsilon$ chains diverge significantly from each other with only $25 \%$ overall sequence identity. Many of the adaptins occur in two or more isoforms encoded by distinct genes. Most of the isoforms are expressed ubiquitously and some are expressed only in specialized tissues for eg. $\mu 1 \mathrm{~B}$ (Folsch et al., 1999), which is specifically expressed in polarized epithelial cells and exocrine cells, $\beta 3 \mathrm{~B}, \mu 3 \mathrm{~B}$ and $\sigma 3 \mathrm{~B}$ which are expressed only in neuronal tissues (Newman et al., 1995; Pevsner et al., 1994).

Each AP complex functions at a distinct intracellular compartment(s) and is involved in cargo selection, vesicle formation and budding processes. AP-1 and AP-2 are established components of clathrin-coated vesicles and are involved in the initiation of clathrin-coated vesicle formation and cargo selection (for incorporation into the vesicles) at the TGN and plasma membrane respectively.

AP-1 is part of clathrin-coated machinery that functions at the trans-Golgi network and is involved in the sorting of lysosomal enzymes from the TGN to the endosomes. It may also be required for the transport of proteins from the endosomes to the TGN (Meyer et al., 2000). A GTPase named ARF1 (Adenosine 
5'-diphosphate Ribosylation Factor 1) is required for the recruitment of AP-1 onto the membranes (Stamnes and Rothman, 1993). AP-2 specifically functions at the plasma membrane and is involved in the internalization of extracellular ligands by endocytosis through clathrin-coated vesicles. AP-3 is present both at the TGN and on the endosomes and is specialized in the targeting of specific membrane proteins destined to lysosomes or related organelles like melanosomes. AP-4 also functions at the TGN and is involved in the basolateral sorting of proteins from the TGN (Dell Angelica et al., 1999a; Simmen et al., 2002). Both AP-3 and AP-4 may require ARF for their membrane recruitment (Boehm et al., 2001; Drake et al., 2000; Ooi et al., 1998).

\subsubsection{Monomeric Adaptor Proteins}

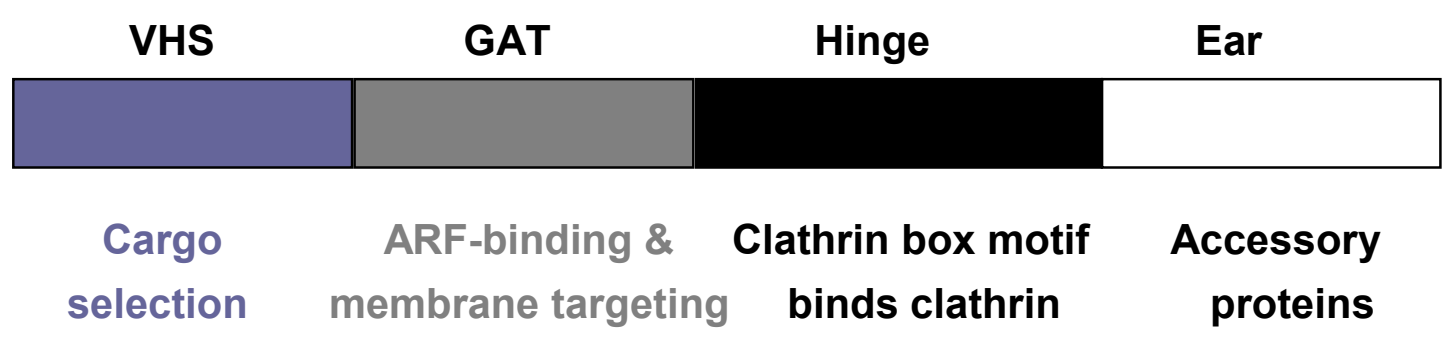

Figure 1.4: Schematic representation of the domain organisation of GGAs.

Domains and their respective functions are indicated above and below the diagram respectively. VHS, GAT and "Ear" domains are highly conserved between the family members, whereas hinge region is divergent.

Golgi localized, $\gamma$-ear containing, ADP-ribosylation factor binding proteins (GGAs) are a family of monomeric adaptor proteins named GGA1, -2 and -3 (Puertollano et al., 2001a; Takatsu et al., 2001; Zhu et al., 2001). They are involved in the sorting of mannose 6-phosphate receptors (MPRs) from the TGN to the endosomes. They are modular proteins with four domains: an N-terminal $\underline{\text { VPS-27, }}$ Hrs, and STAM (VHS) domain, a coiled-coil GGA and TOM domain (GAT domain), a connecting hinge segment and a $\mathrm{COOH}$-terminal $\gamma$-adaptin ear (GAE) domain which is homologous to the AP-1 $\gamma$-appendage and is thought to bind the same accessory factors as AP-1 $\gamma$-appendage (Liu et al., 2003) (Fig. 1.4). The GAT domain binds ARF-GTP complexes and mediates recruitment of the protein from the cytosol onto the TGN (Dell Angelica et al., 2000; Puertollano et al., 2001b; Zhdankina et al., 2001). The VHS domain of all three GGAs interacts 
specifically with the acidic cluster-dileucine (AC-LL) motif in the cytoplasmic tails of the MPRs (Misra et al., 2002; Shiba et al., 2002a). Mutations in the AC-LL motif impair lysosomal enzyme sorting and decrease binding of the MPRs to the GGAs but not to AP-1, indicating that the GGAs have a major role in the sorting process (Chen et al., 1997; Hoening et al., 1997). It has been proposed based on the biochemical studies that GGAs and AP-1 cooperate in packaging MPRs at the TGN. Both AP-1 and GGAs are associated close together on buds and CCVs at the TGN. All three GGAs interact with the $\gamma$-ear domain of AP-1 (Doray et al., $2002 b)$. The hinge and the ear domain of the GGAs interact with clathrin but GGAs are not present in clathrin-coated vesicles purified from mammalian cells (Costaguta et al., 2001; Hirst et al., 2000; Puertollano et al., 2001b).

MPR binding to the VHS domains of GGA1 and GGA3 is regulated by competitive binding of an AC-LL motif in the hinge segment. This binding requires casein kinase-II (CK-II)-mediated phosphorylation of a serine located three residues upstream of the acidic cluster (Doray et al., 2002a). It has been proposed that cargo release by GGA1 and GGA3 is initiated by an AP-1 associated CK-II that phosphorylates the GGAs resulting in autoinhibition. GGAs are then thought to be released into the cytosol and hence are not detectable in isolated clathrin-coated vesicles. Recent findings indeed show that cytosolic GGAs are phosphorylated and the membrane-bound GGAs are dephosphorylated. Protein phosphatase $2 \mathrm{~A}$ has been proposed to be the phosphatase that dephosphorylates the GGAs (Ghosh and Kornfeld, 2003b).

\subsubsection{Adaptor Complex - 1}

Clathrin-coated vesicles at the TGN contain AP-1 as their adaptors akin to AP-2 at the PM. Both humans and mice express two $\gamma(\gamma 1$ and $\gamma 2)$, one $\beta(\beta 1)$, two $\mu$ $(\mu 1 \mathrm{~A}$ and $\mu 1 \mathrm{~B})$ and three $\sigma(\sigma 1 \mathrm{~A}, \sigma 1 \mathrm{~B}$ and $\sigma 1 \mathrm{C})$ adaptins (Hirst and Robinson, 1998; Kirchhausen, 1999). However, the classical AP-1 which has been well characterized, consists of the subunits $\gamma 1, \beta 1, \mu 1 \mathrm{~A}$ and $\sigma 1 . \mu 1 \mathrm{~B}$ replaces $\mu 1 \mathrm{~A}$ in the complex (AP-1B) that mediates basolateral sorting in polarized epithelial cells (Folsch et al., 2001; Ohno et al., 1999; Eskelinen et al., 2002; Gan et al., 2002; 
Sugimoto et al., 2002). All other AP-1 subunits are ubiquitously expressed and the functional importance of $\gamma 2$ and $\sigma$ isoforms is not well understood.

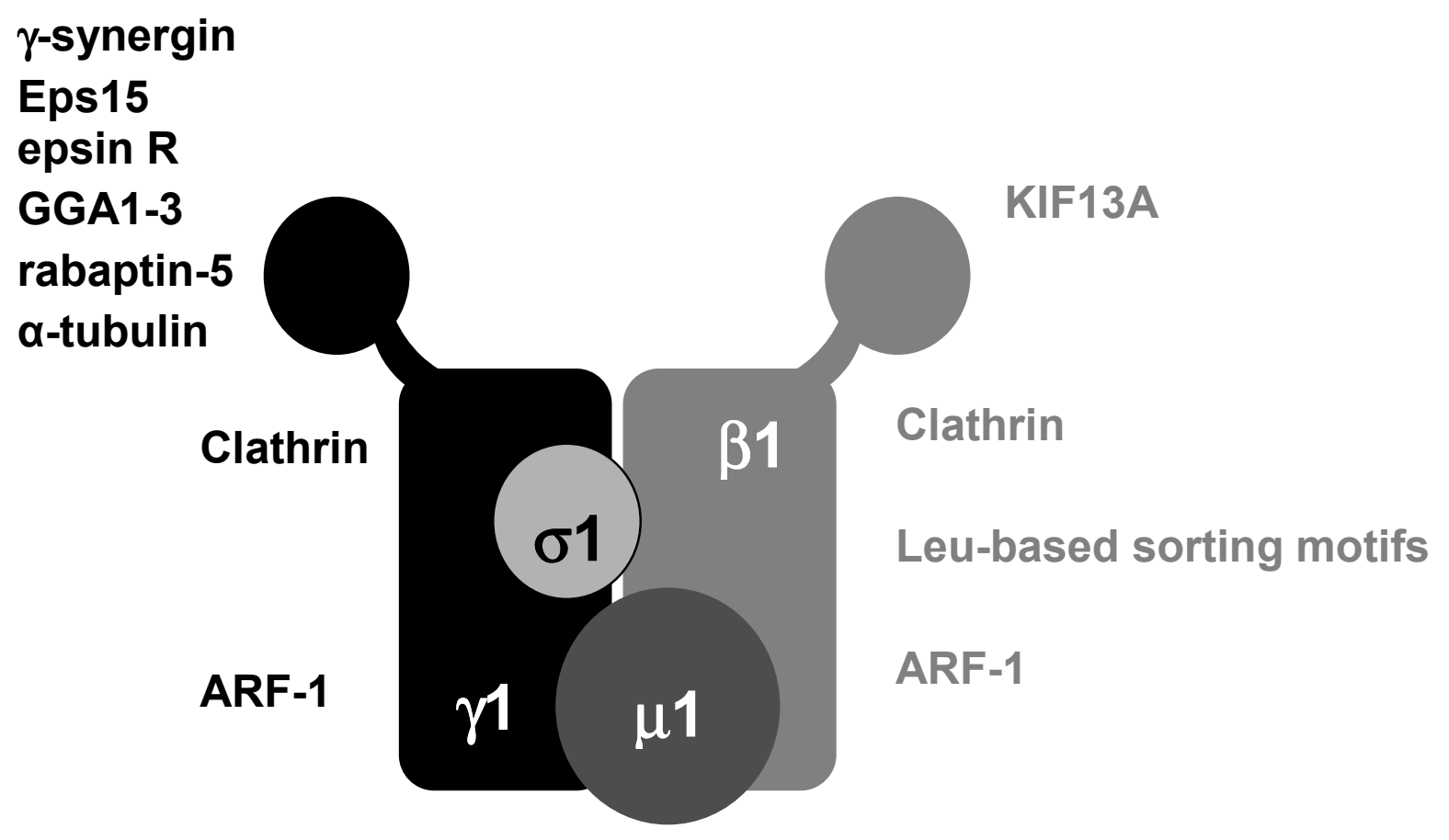

\section{Tyr-based sorting motifs}

Figure1.5: Subunit organization of the Adaptor Complex-1

\section{i) Structure}

The structural details of adaptor complexes are mainly derived from studies on AP-2 which is the most well characterized adaptor complex both from the functional and structural point of view. AP-1 and AP-2 are closely related to each other, therefore the structural details of AP-2 can be extrapolated to AP-1. Earlier structural studies were done by rotary shadowing of isolated AP-2 and it was shown to consist of a globular core or head flanked by two appendages or ears. The ears are connected to the head by a flexible, protease sensitive hinge region (Heuser and Keen, 1988). Upon proteolysis, the ear and head domains separate and it was shown by this approach that the ear domain corresponds to the $\mathrm{C}$ terminus of the large chains, whereas the head contains the remaining $\mathrm{N}$-terminal two thirds of the large chains plus the medium and small chains (Kirchhausen et al., 1989; Zaremba and Keen, 1985). 
The $\mathrm{x}$-ray crystallographic structure of the $\alpha$ and $\beta$ ear domains and also of the entire core region of AP-2 has been solved in the last couple of years (Collins et al., 2002; Owen et al., 1999; Owen et al., 2000; Traub et al., 1999). The ear domain of $\alpha$-subunit is divided into two subdomains, the $\mathrm{N}$-terminal subdomain is a nine-stranded $\beta$-sandwich and the C-terminal subdomain is made up of five stranded $\beta$-sheet. Mutational analysis and pull down experiments revealed that the $\mathrm{C}$-terminal subdomain of the appendage domain of $\alpha$-adaptin serves to coordinate spatially and temporally the recruitment of components of the endocytic machinery and consequently plays a pivotal role in the formation of clathrin-coated vesicles. The $\beta 2$-appendage domain has a overall bilobal structure similar to the $\alpha$-appendage domain despite a very low sequence identity between them. The hydrophobic patch in the $\beta 2$-appendage $\mathrm{C}$-terminal subdomain binds to a subset of $\mathrm{D} \phi \mathrm{F}$ motif-containing proteins that are bound by the $\alpha$-adaptin appendage domain (epsin, AP180, eps15, AAK, auxilin, synaptojanin etc.). The binding site residues are also conserved in $\beta 1$-adaptin from AP-1, so this homologue would be predicted to bind the same ligands as $\beta 2-$ appendage. It has been shown that in addition to binding accessory proteins, the $\beta 2$-appendage domain along with the hinge region binds to clathrin. The "clathrin box" motif $L \Phi D / E \Phi D / E$ (where $\Phi$ is a bulky hydrophobic residue), which has been shown to bind to the $\mathrm{N}$-terminal $\beta$-propeller of clathrin heavy chain, is present both in the hinge and the platform domain of the 32 -appendage (ter Haar et al., 2000). The hinge domain of $\beta 1$ also contains a clathrin-binding motif conforming to the consensus $L(L, I)(D, E, N)(L, F)(D, E)$ (Kirchhausen, 2000). This interaction with clathrin seems to drive the clathrin cage formation under physiological conditions.

The structure of the ear domain of $\gamma$-adaptin has been resolved by $x$-ray crystallography (Kent et al., 2002; Nogi et al., 2002). The structure shows that the $\gamma$-ear domain forms an immunoglobulin-like $\beta$-sandwich fold composed of eight $\beta$ strands with two short $\alpha$-helices. The topology of the entire $\gamma$-ear domain is similar to those of the $\mathrm{N}$-terminal subdomains in the $\alpha$-appendage with which it has $12 \%$ 


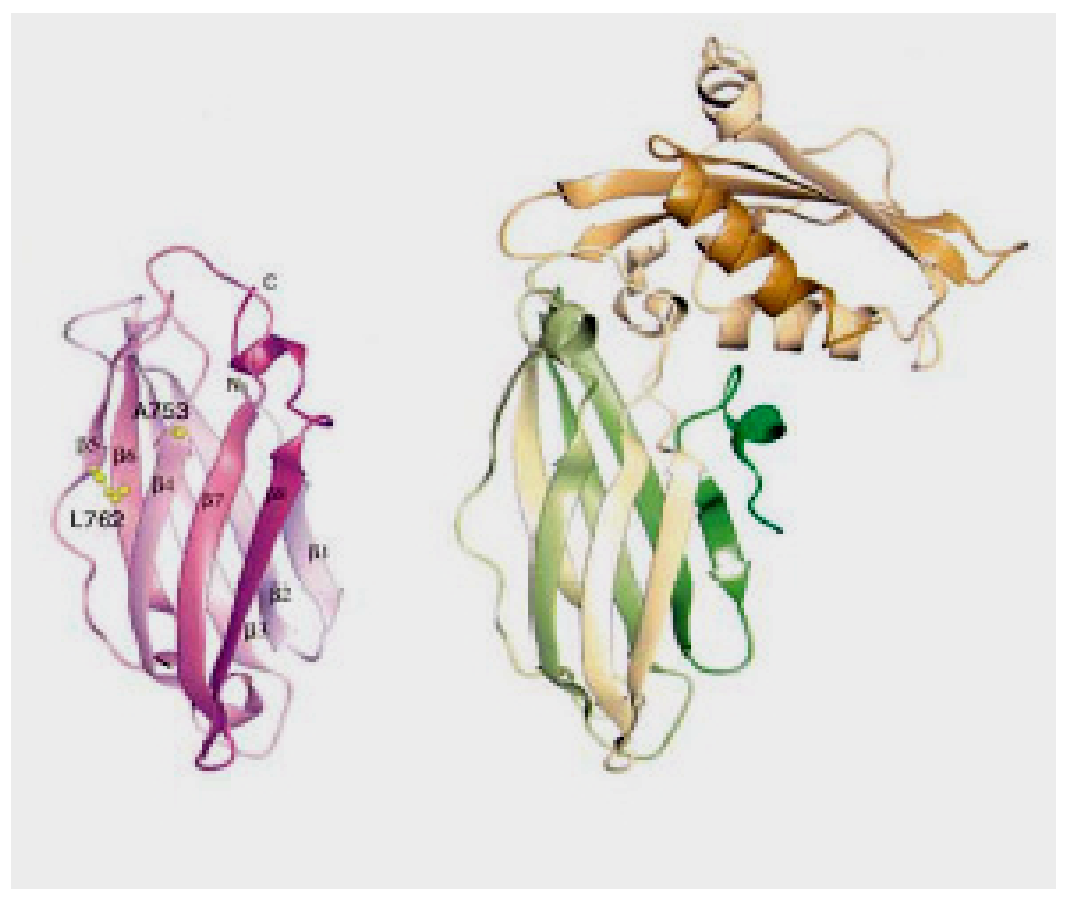

A

B

Figure 1.6: Comparison of the structure of $\gamma$-appendage domain (A) with that of $\alpha$ appendage domain (B) (Kent et al., 2002).

(A) Schematic representation of the $\gamma 1$ appendage domain. Point mutations that abrogate binding to $\gamma$-synergin and Eps 15 are shown in yellow in ball and stick representation.

(B) Schematic representation of the $\alpha$ appendage domain. The $\mathrm{N}$-terminal subdomain is in green and the C-terminal subdomain in gold.

sequence identity on the basis of a structural alignment. In the $\alpha$-appendage this domain has no function assigned to it other than correctly presenting the Cterminal protein binding "platform" subdomain, and yet in the $\gamma$-appendage it performs the protein recruitment role. Structure-based mutational analysis has revealed the residues critical for binding to the accessory proteins $\gamma$-synergin, Eps15 and rabaptin-5. $\gamma$-synergin contains an EH (Eps15 homology) domain, which suggests the potential to interact with the NPF motif found in proteins implicated in vesicle formation at the PM. The binding site on the $\gamma$-appendage for these ligands is situated where the two sheets of the sandwich meet.

The hinge domains of the large chains are the least conserved regions between the large subunits of different adaptor complexes. These regions are rich in serine residues which are presumed to be the potential sites for phosphorylation. 
$\beta 1$ subunit has been shown to be phosphorylated in vivo like $\beta 2$ and it suggests that phosphorylation influences adaptor-clathrin interactions (Ghosh and Kornfeld, 2003a; Wilde and Brodsky, 1996).

The structure of AP-2 "core" ( $\alpha$-trunk, $\beta 2$-trunk, $\mu 2$ and $\sigma 2$ ) complexed with polyphosphatidylinositol has been resolved recently by $\mathrm{x}$-ray crystallography (Collins et al., 2002). It was shown that every subunit makes at least some contact with a portion of every other subunit. The most extensive subunit interactions are between the trunk domains of $\alpha$ and $\beta 2$ with their respective, small, homologous subunits $\sigma 2$ and the $\mathrm{N}$-terminal domain of $\mu 2(\mathrm{~N}-\mu 2)$. The $\alpha-$ and $\beta$-trunks are mainly composed of $\alpha$-helical solenoids, while the smaller domains are mixed $\alpha / \beta$ structures. The small $\sigma 2$ subunit and the homologous $N$ $\mu 2$ domains are buried in the curvature caused by the changes in the orientation of the helices of $\alpha$ and $\beta$ along the length of the superhelix. $30 \%$ of the total surface area of the small subunits is buried in the hydrophobic interfaces of the large subunits. The $\alpha / \beta$ and $\sigma 2 / \mathrm{N}-\mu 2$ subunit pairs each form a tight heterodimer which together form a shallow dish in which the $\mathrm{C}-\mu 2$ domain sits. The folds of the $\sigma 2$ subunit and $\mathrm{N}$-terminal domain of $\mu 2$ resemble each other as do the folds of the two trunk domains. The structure suggests that the $\mathrm{N}-\mu 2$ and $\sigma 2$ domains perform a predominantly structural role, stabilizing the core of the tetrameric complex. It is suggested that there are two potential binding sites for phosphoinositides per complex. One site is located at the $\mathrm{N}$-terminus of $\alpha$ and the other on the surface of $\mathrm{C}-\mu 2$. The all- $\beta$ sheet $\mathrm{C}-\mu 2$ is exposed on the surface of the core and is joined to the buried $\mathrm{N}-\mu 2$ by a disordered 23-residue linker. This linker region contains the major site of phosphorylation in the AP-2 core $(\mu 2 \mathrm{Thr}$ 156) (Conner and Schmid, 2002; Ricotta et al., 2002). The C- $\mu 2$ binding site for Yxx $\Phi$ endocytic motifs (see section 1.2.5) is blocked by residues from the $\beta 2$ trunk, explaining the observation that the unphosphorylated complex has a low affinity for $Y \times x \Phi$ signals (Fingerhut et al., 2001; Ricotta et al., 2002). Phosphorylation of $\mu 2$ leads to a large conformational change ("open" conformation) which dislodges $\mathrm{C}-\mu 2$ from the rest of the core complex. This conformational change allows $\mathrm{C}-\mu 2$ to bind to the endocytic $\mathrm{Yxx} \Phi$ motifs in the cytoplasmic tails of its cargo molecules. A similar mechanism has been proposed 
to occur with $\mu 1$ during cargo recognition (Ghosh and Kornfeld, 2003a). The hinges are approximately 100 residues long and do not possess any significant secondary structure.

It has been shown that the trunk domain of the $\alpha$ subunit can bind phosphatidylinositol-4,5-bisphosphate (PIP2) or phosphatidyl-inositol-3,4,5-trisphosphate headgroups (PIP3) and that this interaction is important for targeting AP-2 to the plasma membrane (Subtil et al., 1999). The structure of AP-2 further narrowed down the residues involved in this binding. It was suggested that a patch of basic residues in the $\mathrm{C}-\mu 2$ domain also binds to inositol-polyphosphates. It was shown recently by mutagenesis studies that this patch of basic residues indeed binds to PIP2 and regulates clathrin-mediated endocytosis (Rohde et al., 2002).

\section{ii) Subunit composition and functions}

\section{a) The large subunits $\gamma$ and $\beta 1$}

$\gamma$ and $\beta 1$ are the large subunits of AP-1 and are similar in structure and function to the $\alpha$ and $\beta 2$ subunits of AP-2. They show a similar domain organization and consist of an $\mathrm{N}$-terminal trunk domain, a variable hinge region and a $\mathrm{C}$-terminal ear/appendage domain which is involved in the recruitment of accessory proteins. Sequence conservation is least between the $\gamma$ and the a subunits (25\% identity) whereas the $\beta$ subunits have the most sequence similarity ( $\beta 1$ is $84 \%$ identical to $\beta 2)$.

$\gamma$-adaptin "knock-out" studies in mice provided first evidence for the importance of AP-1 for viability as the disruption of this gene was embryonic lethal at the blastocyst stage (Zizioli et al., 1999). It was shown that this subunit is essential for the stability of the AP-1 complex as the lack of $\gamma$-adaptin led to degradation of remaining subunits of the complex.

AP-1 binds to clathrin mainly through interaction of the $\mathrm{N}$-terminal domain of clathrin with the clathrin box motif in the hinge region of $\beta 1$ (Gallusser and Kirchhausen, 1993). $\gamma$-hinge region has two copies of a "variant" clathrin-box 
motif, LLDLL, which has also been shown to bind to the terminal domain of the clathrin heavy chain by GST-pulldown assays (Doray and Kornfeld, 2001).

$\gamma$-adaptin from the cytosol co-immunoprecipitates with $\alpha$-tubulin and microtubule associated protein of type 1a (Map1a). An earlier study has shown that the $\gamma$ adaptin ear domain interacts with Map1a (Hirst et al., 2000). Thus AP-1 also plays a role in loading of AP-1 coated vesicles onto appropriate microtubule tracks. Molecular motors generate force required for the delivery of the vesicles to the appropriate destination. KIF13A, a plus end-directed microtubule-dependent motor protein has been shown to associate with the ear domain of $\beta 1$-adaptin thus providing another link between AP-1 and microtubule-dependent molecular motor (Nakagawa et al., 2000).

SNARE proteins play an important role in membrane fusion events. Vesicle associated membrane protein 4 (VAMP4), a SNARE protein predominantly localized to the TGN, with a notable portion found in endosomes was shown to interact with AP-1 from CCVs. This interaction links the vesicle budding machinery with membrane fusion events (Peden et al., 2001).

Recruitment of AP-1 onto the Golgi membranes requires small GTP-binding protein ADP-ribosylation factor-1 (ARF-1). The structural determinants required for the ARF-mediated binding of cytosolic AP-1 onto the Golgi membranes are contained within the adaptor core, that is, in the N-terminal trunk region of $\gamma$ and $\beta 1$ (Traub et al., 1995).

The trunk domain of $\beta 1$ interacts with the di-leucine-based sorting signals (see section 1.2.5) in the cargo molecules that are included in the CCVs at the TGN (Rapoport et al., 1998).

\section{b) The medium and small subunits $\mu 1 \mathrm{~A}$ and $\sigma 1$}

Medium chains of AP-1 and AP-2 ( $\mu 1$ and $\mu 2)$ and small chains of AP-1 and AP-2 ( $\sigma 1$ and $\sigma 2$ ) share $40 \%$ amino acid identity with each other. Mouse "knock-out" 
studies of $\mu 1 \mathrm{~A}$-adaptin from our lab have further enhanced our understanding of AP-1 function in the biogenesis of lysosomes. Targeted disruption of $\mu 1 \mathrm{~A}$ gene is embryonic lethal and further confirms the absolute necessity of AP-1 for mammalian development (Meyer et al., 2000). $\mu 1 \mathrm{~A}$-deficient cells have trimeric $\gamma 1 / \beta 1 / \sigma 1$-complexes and dimeric $\gamma 1 / \beta 1$-complexes, but these are not able to bind to membranes in vivo and in vitro. This indicated that the $\mu 1$-subunit and thus the cargo binding is essential for membrane recruitment of AP-1. These cells missort a large fraction of lysosomal enzymes to the medium and the steady-state localization of the AP-1 cargo, mannose 6-phosphate receptors (MPRs), is shifted to early endosomes at the expense of the TGN. It was demonstrated that there is block in the retrograde transport of MPRs from the early endosome to the TGN, thus proposing a new function for AP-1 in this pathway.

Not much is known about the functional role of $\sigma 1$ subunits except for their requirement to maintain the stability of the complex (Collins et al., 2002). Recently, a new protein called PACS-1 (phosphofurin acidic cluster sorting protein), implicated in the active retrieval of MPRs from endosomes to the TGN, has been shown to interact directly with AP-1 via binding to $\mu 1$ and $\sigma 1$ (Crump et al., 2001).

The sequences of the $\mu$-adaptins of AP-1 and AP-2 are $37 \%$ identical. Secondary structure predictions for formation of $\beta$-sheets, helices and surface probability also show a high degree of homology between these adaptins. Both have been shown to bind to sorting motifs present in the cytoplasmic domains of transmembrane proteins by yeast-two-hybrid analysis, 'pull-down' experiments and by co-crystallization of $\mu 2$-adaptin from AP-2 with sorting motif peptides (Boll et al., 1996; Ford et al., 2001; Heilker et al., 1996; Hoening et al., 1996; Kongsvik et al., 2002; Rodionov and Bakke, 1998). The residues identified in $\mu 2$-adaptin to bind to $Y x x \phi$-based sorting motifs are conserved in $\mu 1 \mathrm{~A}$-adaptin, but differences are found in surface areas next to the Yxxф-binding site. $\mu 2$-adaptin has a phosphatidylinositol-4,5-bisphosphate binding domain, which supports AP-2 binding to the plasma membrane. Sorting motif-binding and lipid-binding domains are formed by the C-terminal 145-449 amino acids. No function has been 
attributed to the $\mathrm{N}$-terminal amino acids. Interestingly, despite having no sequence homology, $\sigma 2$ and the $N$-terminal 159 amino acids of $\mu 2$ form almost identical ternary structures.

The sequence homology between $\mu 1 \mathrm{~A}$ and $\mu 2$ is highest in the domain facilitating cargo binding, which is formed by amino acids 150-449. This domain is also evolutionarily highly conserved and is conserved in the $\mu 3$ - and $\mu 4$-adaptins of the homologous AP-3 and AP-4 adaptor-protein complexes. The PI-4,5- $\mathrm{P}_{2}$ binding motif of $\mu 2$ is not conserved in $\mu 1 \mathrm{~A}$, even though AP-1 binding to synthetic membranes is stimulated by $\mathrm{Pl}-4,5-\mathrm{P}_{2}$ (Crottet et al., 2002).

\subsubsection{Sorting Signals}

Targeting of the cargo proteins to different compartments of the endocytic and late secretory pathways is largely dependent upon sorting signals contained within their cytosolic domains. The interaction of signals with their recognition molecules is thus considered to be the key event leading to selective recruitment of cargo transmembrane proteins into the nascent transport intermediates. Sorting signals are short structural motifs which are typically of 4-6 amino acids. They can be classified into two types:

i) the $\mathrm{Yxx} \Phi$ motif, where $\mathrm{Y}$ is tyrosine, $\mathrm{x}$ is any amino acid and $\Phi$ is a bulky hydrophobic residue (Leu, lle, Met or Phe).

Most tyrosine-based signals conform to the consensus motif $\mathrm{Yx} \Phi$ and are found within the cytosolic domains of all types of transmembrane proteins, including type I (e.g., lamp-1, mannose 6-phosphate receptors), type II (e.g., transferrin receptor) and multi-spanning (e.g., CD63) and also within the cytosolic domains of some signalling receptors (e.g., epidermal growth factor (EGF) receptor) and retroviral envelope glycoproteins (e.g., HIV-1 gp41). The $\mu$ subunit recognizes the $Y x x \Phi$ motif in the membrane proteins that are sorted into clathrin-coated pits (Boll et al., 1996; Ohno et al., 1995).

A second type of tyrosine based sorting motif NPXY (N, P and $Y$ are asparagine, proline and tyrosine, $X$ is any amino acid) is present uniquely in the proteins 
belonging to the LDL receptor family (Chen et al., 1990). It has been shown that $\mu 2$ binds to NPVY and YxxФ sorting signals at distinct sites (Boll et al., 2002).

ii) the "dileucine" motif (-)xxxLL, where (-) is often a negatively charged residue (aspartic or glutamic acid) and $\mathrm{x}$ is usually a polar residue, is present in a number of trafficking proteins, including the mannose 6-phosphate receptor, Limp-II, tyrosinase, Glut-4 transporter etc. (Gallusser and Kirchhausen, 1993; Rapoport et al., 1998; Rodionov and Bakke, 1998; Shih et al., 1995). Phage display, surface plasmon resonance and peptide cross-linking studies have identified both $\mu$ and $\beta$ as the subunits that bind to the di-leucine based sorting signals (Greenberg et al., 1998; Hoening et al., 1998; Rapoport et al., 1998).

\subsubsection{Cargo molecules of AP-1}

A number of cargo proteins have been shown to interact with AP-1 at the TGN and are transported from the TGN to the endosomes by AP-1-mediated clathrincoated vesicle assembly. Most prominent among them are the MPRs (Hille Rehfeld, 1995), lysosomal membrane glycoproteins (LGP85 or LIMPII), invariant chain of MHC class II complexes (Rodionov and Bakke, 1998), furin (Molloy et al., 1999; Teuchert et al., 1999), gp48 (Reusch et al., 2002), HIV-1 Nef (Erdtmann et al., 2000) etc.

MPRs are the best known example of the transmembrane proteins sorted into the clathrin coats found on the TGN. They are selectively sorted at the TGN and exit this compartment in AP-1 containing clathrin-coated vesicles. MPRs are significantly enriched in purified clathrin-coated vesicle preparations (Le Borgne and Hoflack, 1997). Electron microscopic analysis have shown that both the MPRs and AP-1 or clathrin colocalize on budding profiles at the TGN (Klumperman et al., 1993; Klumperman et al., 1998). There is a direct interaction between the sorting signals in cytosolic domain of the MPR300 and AP-1 (Glickman et al., 1989; Hoening et al., 1997; Johnson and Kornfeld, 1992a; b). AP-1-mediated sorting ensures that newly synthesized lysosomal hydrolases, bound to MPRs, are segregated from the molecules destined for constitutive transport to the plasma membrane and are delivered efficiently to the lysosomes 
via an intracellular route. However, since the GGA-proteins appear to have the same properties, the function of these two coat structures in TGN-to-endosome sorting is not clear (see section 1.2.3)

\section{A) Mannose 6-phosphate-dependent transport}

Mannose 6-phosphate-dependent transport of soluble lysosomal enzymes is a crucial step in the biogenesis of lysosomes. Newly synthesized lysosomal enzymes are carried from the endoplasmic reticulum, through the Golgi complex and via endosomes to the lysosomes by vesicular transport. After translocation across the membrane of the ER, lysosomal hydrolases receive high mannose, asparagine linked oligosaccharides, and their oligosaccharide side chains are then selectively modified. Soluble lysosomal enzymes acquire Man-6-P residues that enable their binding to MPRs within the trans-Golgi network and inclusion into clathrin-coated buds (Campbell and Rome, 1983; Geuze et al., 1985; Lemansky et al., 1987; Schulze Lohoff et al., 1985). CCVs containing MPRs and their ligands bud from the TGN and fuse with endosomal membranes, where the receptors release the lysosomal enzymes due to the acidic $\mathrm{pH}$ and recycle back to the TGN to perform several rounds of transport (von Figura and Hasilik, 1986).

\section{B) Functions of MPRs}

Mammalian cells express two distinct, but related MPRs. Both are involved in sorting of lysosomal enzymes. They are referred to as mannose 6-phosphate receptor MPR300 and mannose 6-phosphate receptor MPR46, according to their molecular mass.

\section{i) Mannose 6-phosphate-dependent intracellular sorting of newly synthesized lysosomal enzymes}

The role of MPRs in intracellular sorting of lysosomal enzymes has been initially discovered by investigation of cultured human fibroblasts from patients with I-cell disease (mucolipidosis II) and pseudo Hurler polydystrophy (mucolipidosis III). In these patients, most of the newly synthesized soluble lysosomal enzymes are 
secreted due to an inherited deficiency of one of the enzymes involved in the synthesis of the Man-6-P sorting signal.

Several independent observations suggested that MPR300 is more efficient in intracellular sorting of newly synthesized lysosomal enzymes than MPR46 (Gabel et al., 1983; Kyle et al., 1988; Lobel et al., 1989). The function of MPR46 in lysosomal enzyme transport was made clear by studies on mouse models with a mutated MPR46 gene. This approach demonstrated that the MPR46 also performs an essential function in intracellular transport of lysosomal enzymes (Koster et al., 1993; Ludwig et al., 1993). The biological importance of the two MPRs is illustrated by the phenotype of primary embryonic fibroblasts devoid of these two proteins (Ludwig et al., 1994; Pohlmann et al., 1995). These fibroblasts secrete most of their newly synthesized lysosomal enzymes and consequently accumulate undigested substrates in their lysosomes. This phenotype is strikingly similar to that of fibroblasts from patients with I-cell disease (Neufeld, 1991).

The MPRs exhibit complementary functions. Each MPR mediates the intracellular transport of different, but overlapping subsets of lysosomal enzymes. This view is supported by several observations. First, the overexpression of MPR46 in cells lacking MPR300 does not permit the complete targeting of lysosomal enzymes (Johnson and Kornfeld, 1992a). The overexpression of MPR46 or MPR300 receptor in MPR negative cells does not totally correct secretion of lysosomal enzymes (Munier Lehmann et al., 1996). In vitro binding experiments have also shown that purified MPRs exhibit preferred affinities for given phosphorylated ligands (Chen et al., 1997). This explains the reason for the expression of two different, but related receptors in mammalian cells.

\section{ii) Endocytosis of Mannose 6-phosphate-containing ligands}

Exogenous mannose 6-phosphate-containing ligands undergo receptor-mediated endocytosis. This process is inhibited by antibodies against the luminal domains of MPR300, but not against MPR46 (Stein et al., 1987). Under physiological conditions, endocytosis of mannose 6-phospate containing ligands is most likely exclusively mediated by MPR300. In general MPR300 may recapture endogenous, 
newly synthesized lysosomal enzymes that have escaped sorting from the TGN (Koster et al., 1994) or that have been actively exported by MPR46 (Chao et al., 1990). MPR300 is a bifunctional protein which has also the capability to bind insulinlike growth factor-II (IGF-II) and hence this receptor is referred to as the Man 6P/IGF-II receptor. In addition MPR300 is most likely responsible for the clearance of extracellular IGF-II and therefore is an important component of the machinery which regulates the concentration of the hormone in circulation.

\section{C) Trafficking of MPRs}

\section{i) Recycling pathways}

The trans-Golgi network is the site where MPRs and their bound ligands are sorted away from the secretory pathway (Kornfeld and Mellman, 1989). MPRs recycle between the TGN and endosomes to sort the newly synthesized lysosomal enzymes (Duncan and Kornfeld, 1988). These two compartments are the main location of both MPRs, whereas lysosomes are devoid of MPRs (Geuze et al., 1984). Electron microscopic and morphological studies have shown that clathrincoated buds on the TGN and the clathrin-coated vesicles often observed in its vicinity, contain the MPRs (Klumperman et al., 1993). Therefore the current view is that the MPRs are packaged into clathrin-coated vesicles at the TGN and that these vesicles transport the MPRs to endosomes. At the plasma membrane the interaction of the MPRs with AP-2 allows their endocytosis via a clathrin-dependent pathway for subsequent delivery to endosomes. The vesicular transport intermediates, which carry the MPRs out of the endosomes either to the plasma membrane or to the TGN have not been characterized yet. After delivery to endosomal membranes ligands dissociate and intermix with material of the endocytic pathway. The $\mathrm{pH} 5.8$ of endosomal compartments allows dissociation of ligands already in early endosomes. Comparison of the crystal structure of the ligand-bound MPR46 with ligand-free receptor revealed that the MPR46 undergoes a dramatic change both in its quaternary structure and in the positioning of a loop involving residues glutamine and cysteine upon ligand binding (Olson et al., 1999; Roberts et al., 1998). MPRs have been shown to be physically separated from their ligands within endosomal membranes by immunoelectron microscopy. The lysosomal enzymes were mainly found in the lumen of the endosomes and were essentially excluded from tubular 
extensions containing MPR300 (Geuze et al., 1985). These and other findings suggest that MPRs are segregated into tubular extensions of endosomal membranes for return to the TGN whereas lysosomal proteins are transported from the luminal part of the endosome to dense lysosomes. It has been proposed that the tubular extensions, which contain MPRs are involved in selective recycling of MPRs from endosomes back to the TGN.

\section{ii) Sorting Signal mediated MPR trafficking}

As many transmembrane proteins, the MPRs contain multiple sorting determinants in their cytoplasmic tails, in particular tyrosine- and di-leucine based motifs. Mutagenesis studies of the MPR300 tail demonstrated that the major sorting determinant is a conserved casein kinase II phosphorylation site followed by a dileucine motif $\left({ }^{157} \mathrm{DDSDEDLL}^{164}\right)$. Aspartate 160 was shown to be the most critical residue for the normal sorting function of the receptor (Chen et al., 1997). The dileucine motif in MPR46 tail was also shown to be important for sorting of the receptor in endosomes (Tikkanen et al., 2000). The endocytosis of MPR300 requires two distinct motifs: a phenylalanine-containing sequence (FPHLAF) and a YRGV sequence, which function as dominant and weak determinants respectively (Johnson and Kornfeld, 1992a). The determinants that are essential for the sorting of the MPRs at the TGN or in endosomes have been identified by mutation of putative signal sequences and studying the internalization of these mutant receptors. These results have shown that a carboxyl-terminal di-leucine motif (LLHV sequence) and, to a minor extent the tyrosine-based endocytosis motif (YKYSKV sequence) are essential for efficient intracellular transport of lysosomal enzymes. In case of MPR46 it has been shown that the carboxyl-terminal di-leucine based motif (HLLPM sequence) is crucial for efficient targeting of newly synthesized lysosomal enzymes (Chen et al., 1997; Johnson and Kornfeld, 1992b; Lobel et al., 1989).

Serine 56 in the MPR46 tail is phosphorylated by casein kinase-II and this phosphorylation is shown neither essential for the stability nor for cell-surface expression of MPR46 (Hemer et al., 1993; Korner et al., 1994). This phosphorylation site was also proposed to mediate high affinity binding to AP-1 but this remains controversial (Le Borgne et al., 1993). Surface plasmon resonance studies have 
identified two stretches of residues (34-43 and 49-67) in the MPR46 tail important for binding to AP-1. The canonical di-leucine-based and tyrosine based sorting signals were shown to bind to AP-2 ( Hoening et al., 1997).

In addition to these sorting signals, there are other critical residues in the MPR tail, which play crucial role in the trafficking and functioning of the receptor. Cysteine ${ }^{34}$ of the MPR46 is reversibly palmitoylated which leads to anchoring of the receptor to the lipid bilayer and is essential for the normal trafficking and lysosomal enzyme sorting function of the receptor. A di-aromatic residue, $\mathrm{F}^{18} \mathrm{~W}^{19}$, in the cytoplasmic tail of MPR46 was identified as a determinant necessary to prevent MPRs from entering the degradatory pathway to lysosomes (Schweizer et al., 1996; 1997). Very recently, a novel protein named TIP47 (Tail Interacting Protein of $\underline{47} \mathrm{kDa}$ ), was shown to recognize this motif and mediate retrograde transport of MPRs from late endosomes to the TGN in CHO cells. A late endosomal GTPase, Rab 9, was shown to be required for this transport step (Carroll et al., 2001; Diaz and Pfeffer, 1998). Another cytosolic protein called PACS-1 (phosphofurin acidic cluster sorting protein) was also shown to recognize the acidic cluster motif in the MPR tail and mediate its retrieval from early endosomes to the TGN (Crump et al., 2001; Wan et al., 1998). Cholesterol requirement for MPR300 exit from the multivesicular late endosomes to the Golgi was demonstrated in a recent study (Miwako et al., 2001).

\subsubsection{Formation of CCVs: Initiation , Budding and Uncoating}

The mechanism of clathrin-coated vesicle formation and the events that follow thereafter have been extensively studied for AP-2 in the synaptic vesicle recycling and endocytic pathway. There is a significant variation in this mechanism at the TGN. It has been shown in vitro that adaptors bind to the terminal domain of clathrin and addition of $\mathrm{N}$-terminal fragment of the $\beta 2$-chain, comprising the hinge and the ear domain, will stimulate clathrin assembly (Shih et al., 1995). The entire process of clathrin lattice assembly has been reconstituted in an in vitro assay with fragments of clathrin and adaptors (Greene et al., 2000). The presence of two binding sites in one $\beta$-chain suggests that adaptors could potentially crosslink two $\mathrm{CHCs}$ to orient them in a conformation favourable for assembly. It has also been shown that phosphorylation of the $\beta$-chains plays an important 
regulatory role in CCV formation (Ghosh and Kornfeld, 2003a; Wilde and Brodsky, 1996). The hinge region of the $\beta$-chains is phosphorylated in the cytosol and hence cannot bind clathrin. When membrane-bound, $\beta$-chains are dephosphorylated and can interact with clathrin to stimulate assembly. However, the kinetics of phosphorylation-dephosphorylation cycles with respect to the CCV formation is not well understood. Owing to the differences in the nature of the donor membrane at the PM and TGN (flat and cholesterol rich versus tubulated), one can expect distinct differences between CCV formation at these sites.

\section{A) Initiation}

Hexagonal lattices of clathrin have been observed at the plasma membrane by electron microscopy. This suggested that there is a potential need for lattice rearrangement to form a pentagon and introduce a curvature during the formation and growth of $\mathrm{CCV}$. Initiation of the CCV formation occurs by the inward deformation of a flat array as a result of massive membrane reorganization (see Fig. 7, step 1). The factor that determines the location and initiation of coat assembly remains unknown. Adaptors serve to link clathrin to the membrane and to coordinate the structural assembly of the coat with the selection of cargo proteins and lipids. A number of proteins, in addition to the adaptors, contain clathrin-box sequences and any of these in principle could recruit clathrin. In addition to a clathrin scaffold, a membrane, cargo, and cargo adaptors, coated vesicles must include molecules that determine the destination and ultimate fusion of the vesicle. The identities of these targeting and fusion molecules are largely undetermined. They probably include soluble $\mathrm{N}$-ethylmaleimide sensitive factor (NSF) attachment protein receptors (SNAREs) and Rab proteins.

Binding of AP-1 to the TGN requires the formation of ARF1-GTP and its interaction with additional unknown factor(s) (Dittie et al., 1996; Robinson and Kreis, 1992; Stamnes and Rothman, 1993). This activation step for coat formation is shared by other coats in the Golgi region but is not a feature of CCV formation at the PM. ARF1-GTP formation in turn depends on guanine nucleotide-exchange factors (GEFs) of two classes. The high-molecular-weight class includes yeast Sec7p, Gea1p and Gea2p and mammalian p200, BIG1, BIG2 and GBF1, all 
localized in the Golgi region. All but GBF1 are inhibited by fungal metabolite brefeldin A (BFA). The low-molecular-weight GEFs include ARNO, cytohesin-1, cytohesin-4 and GRP1. They all are insensitive to BFA. ARFs and some GEFs bind phosphatidyl inositol-phosphates (PIPs), and their recruitment to TGN membrane is responsive to PI3-kinase activity. In addition, ARF1-GTP stimulates phospholipase D (PLD) activation, potentially resulting in increased PIP synthesis and increased sites of ARF and GEF recruitment, which could serve as a positive feedback loop for coat component recruitment. It has been recently shown that overexpression of BIG2, an ARF-GEF, blocks BFA-induced redistribution from membranes of ARF1 and the AP-1 complex, but not that of the COPI complex indicating that BIG2 is involved in association of AP-1 onto the membranes (Shinotsuka et al., 2002b).

The assembly of clathrin-coated buds is aided by an array of mostly cytosolic proteins, often referred to as "accessory proteins", that form a dynamic network of protein-protein interactions by associating with multiple partner proteins during different stages of endocytosis. Candidate proteins include Eps15 and amphiphysin I. Both molecules interact with clathrin and adaptors. Eps15 binds to AP-2 adaptor directly and clathrin via its binding partner epsin, a protein that also binds AP-2 (Rosenthal et al., 1999). It has been shown recently that epsin drives the formation of a curvature during the growth of clathrin-coated pits (Ford et al., 2002). Lipids play a very important role in the nucleation of vesicle formation at both PM and TGN. A number of proteins associated with PM CCVs, including the $\alpha$-subunit of AP2, dynamin, amphiphysin I, AP 180 and epsin have been shown to bind phosphatidyl-inositol polyphosphates (PIPs) (Cremona and De Camilli, 2001; Ford et al., 2001; Itoh et al., 2001; Jost et al., 1998). These modular proteins interact with lipids and contribute to membrane deformation during budding and vesicle scission. Clathrin binds a class II PI3-kinase through its Nterminal domain and thereby stimulates PIP formation, amplifying binding sites of coat proteins at both the PM and TGN (Gaidarov et al., 2001). 


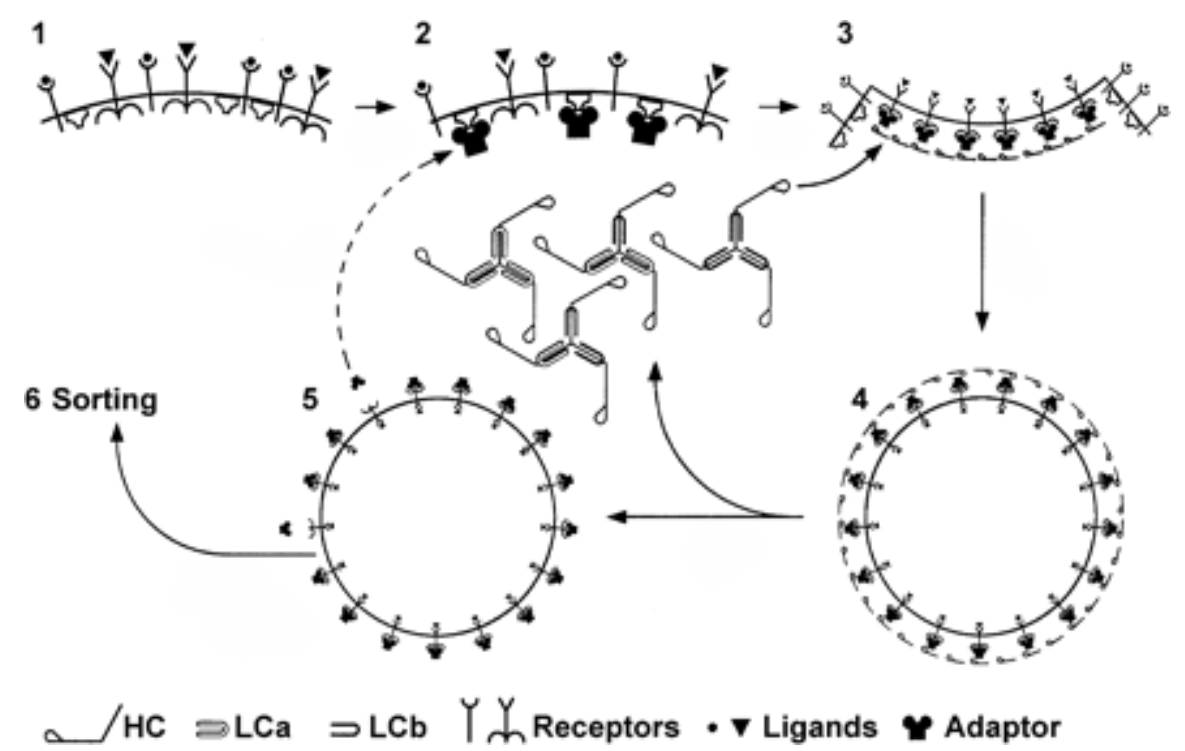

Figure1.7: Basic steps in the nucleation, budding, scission, and uncoating of a clathrin-coated vesicle (CCV) from either the plasma membrane or the trans-

Golgi network. 1."Hot spots" of CCV formation, sites which have the necessary receptors and vesicle formation machinery that influence adaptor localization 2. Binding of Adaptors to the putative receptors with high affinity. 3. Cargo recognition, clathrin recruitment and triggering of clathrin lattice assembly. 4. Budding and fission of the fully formed coated CCV. 5. Uncoating 6. Fusion with the acceptor compartment (Brodsky, 2001).

\section{B) Budding and Vesicle detachment}

Once the growing buds (see Fig. 7, step 2 and 3) at the sites of assembly are completely formed, they need to detach from the donor membrane as a vesicle and travel a certain distance in order to deliver their contents to the target organelle. Detachment of the coated vesicles from the plasma membrane requires the activity of a GTPase, dynamin (Hinshaw and Schmid, 1995; van der Bliek et al., 1993). Two of the proteins recruited to a dynamin proline-rich region through their SH3 domains are amphiphysin and endophilin. Amphiphysin in turn interacts with synaptojanin. Synaptojanin is an inositol 5-phosphatase. Endophilin has lysophosphatidic acid acyltransferase activity (Huttner and Schmidt, 2000). This reaction generates phosphatidic acid potentially causing a change in membrane curvature and contributing to budding and scission. The activity of synaptojanin would favour release of dynamin by dephosphorylation of the head groups that recruit it. This suggests that PIP binding is a critical interaction 
stabilizing an assembled coat and that a inositide-specific phospholipase may play a role in vesicle uncoating (Cremona et al., 1999).

Both isoforms of dynamin (Dynamin $1 \& 2$ ) have been shown to be involved in the formation of transport vesicles at the TGN hinting at similarities in the vesicle scission mechanism with plasma membrane CCVs (Jones et al., 1998; Kreitzer et al., 2000).

\section{C) Uncoating}

The uncoating of the CCVs is facilitated by the dissociation of the coat proteins from lipid bilayers of the membranes. An in vitro clathrin-uncoating activity was attributed to a cytoplasmic member of the Hsc70 family (Schlossman et al., 1984). Hsc70 is an ATP-dependent chaperone, which binds relatively hydrophobic peptides or exposed protein sequences. It is involved in modulating the folding state of intracellular proteins for their translocation across ER, mitochondrial and lysosomal membranes. ATP hydrolysis by hsc70 is required for removing the clathrin triskelion from the vesicle and ADP stabilizes the hsc70clathrin complex that is released (Prasad et al., 1994). Hsc70 proteins are drawn to specific targets by proteins that contain $\mathrm{J}$ domains (named after DnaJ, the partner of the E.coli Hsp70, DnaK). The coated vesicle protein Auxilin contains such a $\mathrm{J}$ domain. The recently defined role in cellular CCV disassembly for auxilin also strengthens the implication of hsc70 as a regulator of clathrin disassembly (Lemmon, 2001; Ungewickell et al., 1995). The phosphatase activity associated with auxilins could conceivably destabilize coat protein-PIP interaction. The recruitment of hsc70 to CCVs by auxilin followed by ATP binding and hydrolysis by hsc70 may cause a conformational change in assembled clathrin, triggering disassembly. It is not clear how lipid dissociation processes are coupled to disassembly of the clathrin lattice. Hsc70 releases clathrin, but not adaptors, from the isolated coated vesicles (Heuser and Keen, 1988; Schlossman et al., 1984), which hinted that clathrin and adaptor dissociation are separate events. It was indeed shown that clathrin and adaptors dissociate from CCVs in separate steps (Hannan et al., 1998) but very little is known about how adaptors are released 
from the membranes. The regulatory events involved in sensing the completion of formation of the vesicle and initiating the uncoating reaction still remain a puzzle.

Earlier studies had reported the requirement of a cytosolic factor in the uncoating process at the TGN which was also shown to require ATP and Hsc70 (Hannan et al., 1998). Recently it was shown that protein phosphatase 2A (PP2A) treatment of phosphorylated AP-1 from CCVs abolished binding to the tail peptides and released adaptors from CCVs to the cytosol. Hence PP2A was shown to be the cytosolic co-factor required in adaptor uncoating of CCVs at the TGN (Ghosh and Kornfeld, 2003a).

\subsection{AP-1-deficiency}

Disruption of $\gamma$-adaptin gene in mice turned out to be embryonic lethal. The $\gamma$ adaptin-deficient embryos developed until day 3.5 post coitus and died during the prenidation period (day 4.5), revealing that AP-1 is essential for viability (Zizioli et al., 1999). Heterozygous mutant mice exhibited a $50 \%$ decrease in the amount of intracellular $\gamma$-adaptin protein and were growth-retarded when compared to their wild type litter-mates. The absence of any free $\beta 1, \sigma 1$ or $\mu 1$ subunits led to the conclusion that the free subunits are unstable in the absence of $\gamma$. This argues for an essential role of AP-1 during the development of a multicellular organism, which was further strengthened by studies on $\mu 1 \mathrm{~A}$-deficient mice. Targeted disruption of $\mu 1 \mathrm{~A}$ gene in mice again turned out to be embryonic lethal, but in this case the embryos developed till mid-organogenesis (day 13.5) and hence cell lines could be established for further studies on the effect of $\mu 1 \mathrm{~A}$ gene disruption. Although no free $\gamma 1, \beta 1$ or $\sigma 1$ subunits are present in the fibroblasts, a $\gamma 1-\beta 1-\sigma 1$ trimeric subcomplex is detected. This trimeric complex is non-functional as only a weak perinuclear staining and diffuse cytosolic staining of $\gamma$-adaptin are observed by immunoflorescence. Clathrin staining at the perinuclear region is also lost. Furin and MPRs which are the cargo receptors of AP-1 at the TGN have a more dispersed distribution and MPR46 is shown to colocalize with early endosomal marker EEA1. It was shown that in these cells, the MPRs fail to return back to the TGN and thus the steady-state distribution of MPRs is shifted to early endosomes at the expense of the TGN. Lack of functional AP-1 in these cells led to impaired 
sorting of lysosomal enzyme cathepsin-D, bulk of which is secreted into the medium in its Golgi precursor form. There is also an enhanced endocytosis rate of MPR300 at the plasma membrane and increased recycling of this receptor between endosomes and plasma membrane (Meyer et al., 2001; Meyer et al., 2000). The block in retrograde transport of MPRs was surprising as all previous evidences implicated AP-1 function at the TGN. Hence a new role for AP-1 in the retrograde transport of MPRs was proposed.

\subsubsection{Unsolved questions}

i) The exact mechanism by which AP-1 is recruited onto the membranes is still poorly understood. There is evidence that the cargo proteins play a role in recruitment of their adaptors. Overexpression of major histocompatibility complex (MHC) class II molecules, an $\alpha \beta$ dimer associated with the li chain, promotes the recruitment of AP-1 on Golgi membranes (Salamero et al., 1996). Similar results were obtained by overexpression of varicella-zoster virus glycoprotein I (Alconada et al., 1996). In cells that lack MPRs, the total amount of AP-1 binding to the TGN is reduced by $\sim 25 \%$, while cells overexpressing MPRs show increased AP-1 binding (Le Borgne and Hoflack, 1997; Le Borgne et al., 1993). But this concept has been challenged by studies with Golgi membranes devoid of mannose-6-phosphate receptors where no significant changes in the affinity of AP-1 for such membranes was observed (Zhu et al., 1999b). Yet, it has been proposed that some cytosolic and peripheral membrane factors are to be involved in the binding of AP-1 to the membranes (Dittie et al., 1996; Mallet and Brodsky, 1996; Zhu et al., 1999a). The AP-1 complexes lacking the cargo-binding subunit $\mu 1$ do not bind to the membranes, supporting the model that cargo-proteins are essential for high-affinity membrane binding.

None of these factors have been further characterized to implicate their role in AP-1 recruitment onto the membranes. What are the cytosolic and membrane factors required for AP-1 binding onto the membranes ? Is there a receptor for AP-1 on the membranes ? Are there specific regions in adaptor subunits which could play a regulatory role in this event? 
ii) Binding of AP-1 to the TGN requires the formation of ARF1-GTP and its interaction with additional unknown factor(s). The link between the activation of ARF1 and recruitment of AP-1 onto the membranes is unknown. This activation step for coat formation is shared by other coats in the Golgi region but is not a feature of $\mathrm{CCV}$ formation at the PM. Therefore it is unlikely that ARF1 contributes to the specificity of AP-1 binding to the TGN. What is the factor that determines the specificity of membrane recruitment of AP-1 to the TGN or endosomes?

iii) While AP-1 has been implicated in the anterograde transport of MPRs, why is there a block in the retrograde transport of MPRs in AP-1-deficient cells ? Several studies have shown that a significant amount of AP-1 and MPRs are present on peripheral endosomal structures (Futter et al., 1998; Shiba et al., 2002b; Waguri et al., 2003). What is the role of AP-1 on these endosomes ? Does AP-1 mediate vesicle formation and budding on these structures ? Is Clathrin involved in this event? What other factors are involved and how is it regulated?

iv) The recently discovered GGA proteins are proposed to function in a cooperative manner with AP-1 in the transport of MPRs from TGN to the endosomes. Do GGAs have an independent function at all ? Are they capable of forming their own transport vesicles and mediate sorting of MPRs in the presence or absence of AP-1 ? 


\section{Aim of the study}

\section{Project 1: Analysis of the role of N-terminal domain of $\mu 1 \mathrm{~A}$ in the AP-1 function}

$\mu$ subunits in the adaptor complexes are involved in the selection of cargo by recognizing the sorting signals on the cargo proteins. The sequences of the $\mu$ adaptins of AP-1 and AP-2 are $37 \%$ identical. Secondary structure predictions for formation of $\beta$-sheets, helices and surface probability also show a high degree of homology between these adaptins. The C-terminal two-thirds of the $\mu$-adaptin subunits are involved in cargo recognition. Crystal structure analysis of AP-2 indicated that their $\mathrm{N}$-terminus serves as an anchor domain, linking $\mu$ to the $\beta$ adaptin. Our aim was to analyze the functions of $\mu 1$-adaptin domains for protein sorting by constructing chimeras between $\mu 1 \mathrm{~A}$ and $\mu 2$ adaptins and expressing them in $\mu 1 \mathrm{~A}$-deficient fibroblasts to study AP-1 complex formation, cargo (MPR) distribution and lysosomal sorting functions.

\section{Project 2: Establishing an in vitro assay to measure the retrograde transport of MPR46 in MEFs}

$\mu 1 \mathrm{~A}$-deficiency is lethal in mice. AP-1 exists as a non-functional trimeric complex and its cargo mannose 6-phosphate receptors are redistributed to early endosomal structures at the expense of the TGN. This redistribution is due to the inability of the receptors to return back to the TGN from the endosomes. This indicates that AP-1 function is required for the retrograde transport of MPRs from endosomes to the TGN. We wanted to address this issue by establishing an in vitro transport assay to measure the retrograde transport of MPR46 in both wild type and $\mu 1 \mathrm{~A}$-deficient mouse embryonic fibroblasts. Such an assay would be useful to test if the block in retrograde transport of MPRs in $\mu 1 \mathrm{~A}$-deficient cells is a direct or an indirect effect of AP-1-deficiency. 


\section{Project 3: Analysis of the function of GGA proteins in the presence or absence of a functional AP-1 complex}

GGAs are a recently identified family of monomeric adaptor proteins which are involved in the trafficking of mannose 6-phosphate receptors from the TGN to the endosomes. GGAs and AP-1 are proposed to work in a cooperative manner at the TGN to mediate this sorting event. However, it is not clear if GGAs can function independently and form coated vesicles at the TGN on their own without any mediation by AP-1. In order to address this issue, we decided to take an antisense approach to knock-down GGA1 and GGA2 expression in both control and $\mu 1 \mathrm{~A}$-deficient mouse embryonic fibroblasts and analyze the phenotype with respect to MPR distribution, trafficking and lysosomal enzyme transport. 


\section{$3 \quad$ Materials and Methods}

\subsection{Materials}

\subsubsection{Equipments used for molecular biology and biochemical work}

\begin{tabular}{|c|c|}
\hline $\begin{array}{l}\text { Analytical weighing balance } \\
\text { Type } 1602 \text { MP and M5P }\end{array}$ & Sartorius, Göttingen \\
\hline $\begin{array}{l}\text { Weighing Machine Type } \\
1264 \mathrm{MP} \text { and } 1265\end{array}$ & Sartorius, Göttingen \\
\hline Autoclave Type Tecnoclav 50 & $\begin{array}{l}\text { Tecnorama, Zürich, } \\
\text { Switzerland }\end{array}$ \\
\hline ELISA reader, TECAN SPECTRA & SLT Instruments, Germany \\
\hline $\begin{array}{l}\text { Electrophoresis Power Supplies: } \\
\text { POWER PAC } 300 \\
\text { EC250-90 }\end{array}$ & $\begin{array}{l}\text { Bio-Rad, USA } \\
\text { E-C Apparatus Corporation, USA }\end{array}$ \\
\hline Freezer $-20^{\circ} \mathrm{C}$ & Liebherr \\
\hline$-85^{\circ} \mathrm{C}$ Ultra Low Freezer & $\begin{array}{l}\text { New Brunswick Scientific Co, Inc., } \\
\text { Edison, USA }\end{array}$ \\
\hline $\begin{array}{l}\text { Film developing machine } \\
\text { Gevamatic } 60\end{array}$ & Agfa-Gevaert, Leverkusen \\
\hline Gel documentation system & Hitachi, Japan \\
\hline Gel drier & Bio-Rad, USA \\
\hline Gradient Former & $\begin{array}{l}\text { Bethesda Research Laboratories } \\
\text { New Isenberg, Germany }\end{array}$ \\
\hline Heating block 5320 & Eppendorf, Hamburg \\
\hline Ice Machine & Ziegra, Isernhagen \\
\hline Incubator for bacterial plates & Heraeus, Osterode \\
\hline $\begin{array}{l}\text { Incubator for bacterial liquid } \\
\text { cultures }\end{array}$ & $\begin{array}{l}\text { New Brunswick Scientific Co, Inc., } \\
\text { Edison, USA }\end{array}$ \\
\hline $\begin{array}{l}\text { Incubators for mammalian cells. } \\
\text { STERI:CULT incubator }\end{array}$ & Forma Scientific, Ohio \\
\hline $\begin{array}{l}\text { Liquid Nitrogen tanks } \\
\text { Biosafe Chronos }\end{array}$ & $\begin{array}{l}\text { Messer Griesheim, } \\
\text { Frankfurt/M }\end{array}$ \\
\hline $\begin{array}{l}\text { Liquid Scintillation Counter } \\
\text { LS } 6500\end{array}$ & Beckman, USA \\
\hline $\begin{array}{l}\text { Luminescent Image Analyzer } \\
\text { Fujifilm LAS-1000 plus }\end{array}$ & Fuji photo film Co. Ltd., Japan \\
\hline $\begin{array}{l}\text { Lyophiliser } \\
\text { Model Alpha 1-4 and Delta 1A }\end{array}$ & Christ, Osterode \\
\hline $\begin{array}{l}\text { Magnetic stirrer Ika-Combimag } \\
\text { Ret }\end{array}$ & Janke \& Kunkel, Staufen \\
\hline $\begin{array}{lll}\text { Microflow } & \text { Biological } & \text { Safety } \\
\text { Cabinet } & & \end{array}$ & Nunc, Wiesbaden \\
\hline
\end{tabular}




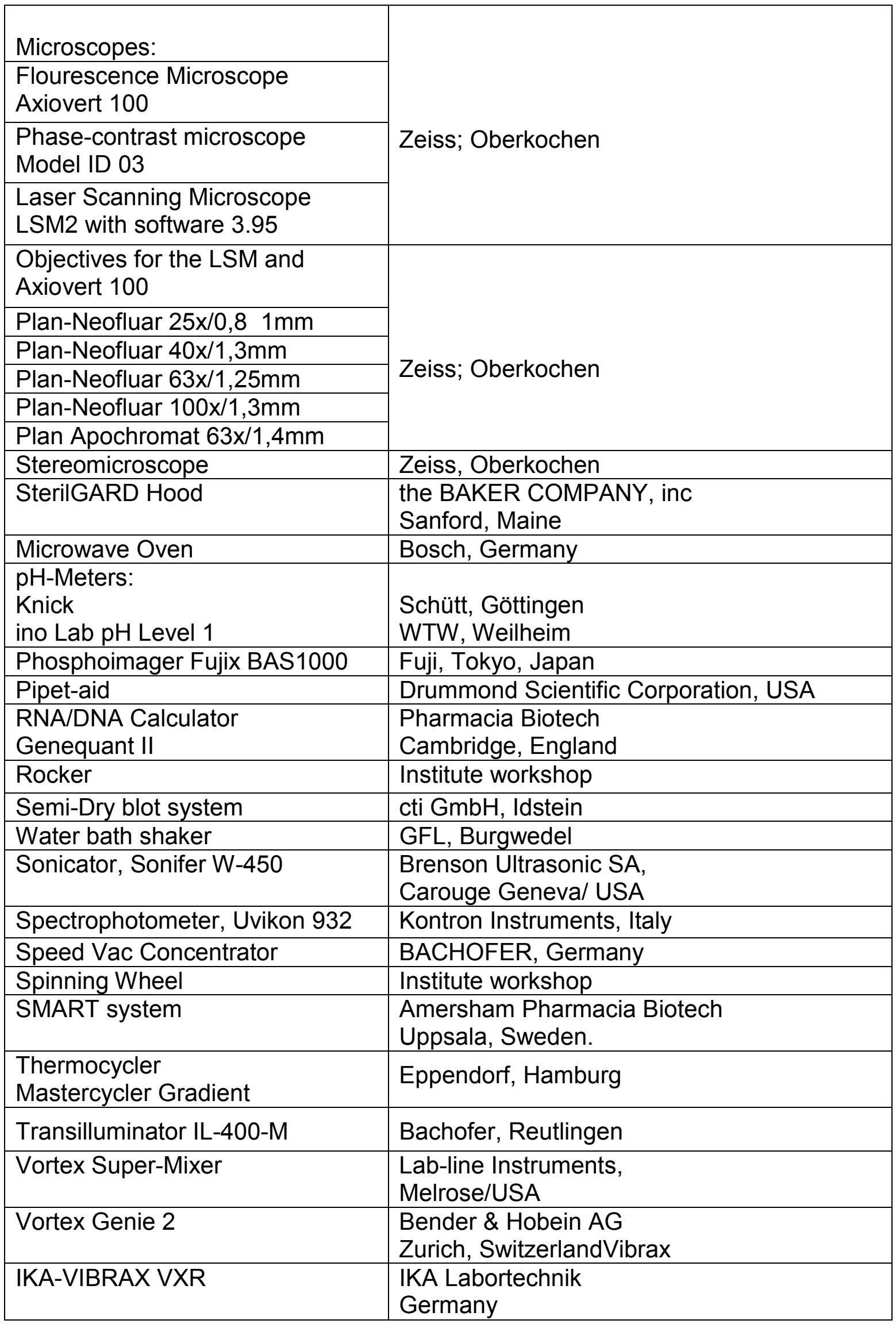




\begin{tabular}{|l|l|}
\hline Centrifuges: & \multirow{2}{*}{$\begin{array}{l}\text { Heraeus Sepatech, } \\
\text { Osterode/ Harz }\end{array}$} \\
\cline { 1 - 2 } $\begin{array}{l}\text { Babofuge A } \\
\text { Biofuge Fresco }\end{array}$ & Eppendorf, Hamburg \\
\hline $\begin{array}{l}\text { Eppendorf centrifuges: } \\
5414,5415 \text { \& 5804R }\end{array}$ & Beckman, München \\
\hline $\begin{array}{l}\text { Refrigerated centrifuge J2-MC } \\
\text { Table top Ultracentrifuge TL-100 }\end{array}$ & \\
\hline $\begin{array}{l}\text { Rotors for cooling centrifuges and } \\
\text { ultracentrifuge: } \\
\text { (g values are for } r_{\text {max }} \text { ) }\end{array}$ & \\
\hline JA-10 rotor, upto $17,680 \mathrm{~g}$ & Beckman, München \\
\hline JA-20 rotor, upto $48,300 \mathrm{~g}$ & Beckman, München \\
\hline TLA 45 upto $125,000 \mathrm{~g}$ & Beckman, München \\
\hline TLA 100.3 upto $541,000 \mathrm{~g}$ & Beckman, München \\
\hline
\end{tabular}

\subsubsection{Materials for molecular biology and biochemical experiments}

Autoclave bags

Bottle top filters

Cell Culture plates:

4 well NUNCLON

6 well, 24 well \& 96well CELLSTAR

Centrifuge tubes:

JA-10 Polypropylene tube

JA-20 Polypropylene tube

Columns for chromatography

Glass Econo-column

Culture flasks for bacteria

Culture flasks for mammalian cells

25 and $75 \mathrm{~cm}^{2}$

Dialysis bags (12,000 Da cut-off)

Glass pipettes

Microscope slides

Immersion oil 518C

Needles for syringes

Nunc cryotube ${ }^{T M}$ vials

Parafilm

Pasteur pipettes

Culture dishes for mammalian cells

3,$5 ; 6 ; 10 ; 15 \mathrm{~cm} \mathrm{\varnothing}$
Sarstedt, Nümbrecht

Sarstedt Inc., Newton, USA

Nalge Nunc International

Denmark

Greiner bio-one, Frickenhausen

Nalgene, München

Nalgene, München

Biorad, München

Schott, Mainz

Greiner bio-one, Frickenhausen

Biomol, Hamburg

Schütt, Göttingen

Menzel-Glaser

Zeiss, Oberkochen

B.Braun Melsungen AG,

Melsungen

Nalge Nunc International

Denmark

American National Can ${ }^{\mathrm{TM}}$

Chicago

Schütt, Göttingen

Greiner bio-one, Frickenhausen 
Pipette tips

Polyethyleneimine-cellulose $\mathrm{F}$

(TLC sheets)

Plastic tubes 10, 15 and $50 \mathrm{ml}$

Polycarbonate ultracentrifuge tubes $1,5 \mathrm{ml}$

Reaction tubes:

$0.2,0.5,1.5 \& 2 \mathrm{ml}$

Scintillation Cocktail

LUMASAFE PLUS

Scintillation Vials:

MINIS 2000

Spin columns

Sterile filters:

$0.45 \mu \mathrm{M} ; 0.2 \mu \mathrm{M}$

Superdex 200 column

Syringes:

$1 \mathrm{ml}$ and $2 \mathrm{ml}$

5, $10 \& 20 \mathrm{ml}$ Ecoject

\subsubsection{Materials for Western Blotting}

Nitrocellulose membrane $0.2 \mu \mathrm{M}$

PVDF membrane, $0.2 \mu \mathrm{M}$

Whatman GB002 paper

Whatman GB003 paper extra thick

X-ray films XAR-5

Supersignal Chemiluminiscent Substrtate

Luminol and p-coumaric acid

\subsubsection{Chemicals}

Acetic acid

Acetone

Acrylamide/ Bisacrylamide (30\%/ 0.8\%)

Agar

Agarose

$\varepsilon$-Ammonium caproic acid

Ammonium chloride

Ammonium peroxide disulphate (APS)

Bacto tryptone

Bio-Gel P-6 DG (Desalting gel)

Bromophenol blue

Calcium chloride

Citric acid
Sarstedt, Nümbrecht

Merck, Darmstadt

Sarstedt, Nümbrecht

Beckman, München

Sarstedt, Nümbrecht

Lumac LSC B.v., The Netherlands

Zinsser Analytic, Germany

Vivascience, Göttingen

Heinemann Labortechnik GmbH

Amersham Pharmacia Biotech

Uppsala, Sweden.

B.Braun Melsungen AG, Melsungen

Dispomed Witt OHG, Gelnhausen

Schleicher and Schüll, Dassel

Schleicher and Schüll, Dassel

Schleicher and Schüll, Dassel

Schleicher and Schüll, Dassel

Kodak, Stuttgart

Pierce, Illinois/ USA

Sigma

Roth

Merck

Roth

Roth

Roth

Sigma

Sigma

Merck

Roth

Bio-rad

Merck

Merck

Merck 
Coomassie, Serva Blue $\mathrm{R}$

DAKO (Fluorescent mounting medium)

DEAE-Sephacel

Dimethylsulfoxide (DMSO)

Disodiumhydrogenphosphate

Dipotassiumhydrogenphosphate

Dithiothreitol (DTT)

Ethanol

Ethidium bromide

Ethylenediamine tetra acetic acid

-sodium salt (EDTA)

Glucose

Glutathione

Glycerol

Glycine

HEPES (N-2-Hydroxyethylpiperazin-N'-

2-ethanesulfonic acid)

Hydrochloric acid

Imidazole

IPTG

(Isopropyl $\beta$-D-Thiogalactopyranoside)

Isobutanol

Isopropyl alcohol

Lithium chloride

Liquid Nitrogen

Magnesium acetate

Magnesium chloride

Manganese chloride

Mannose-6-phosphate (di Sodium salt)

2-Mercaptoethanol

Methanol

MOPS

(3-[N-Morpholino]propanesulfonic acid)

Nickel-NTA agarose

Para-formaldehyde (PFA)

Perhydrol $\left(30 \% \mathrm{H}_{2} \mathrm{O}_{2}\right)$

Ponceau S $(0.2 \%$ solution in $3 \%$ TCA $)$

Potassium acetate

Potassium chloride

Potassium hydroxide

Protamine sulfate

Rubidium chloride

Sodium acetate

Sodium azide

Sodium bicarbonate

Sodium citrate

Sodium chloride

Sodium chlorate
Serva

Dako Corporation

Sigma

Merck

Merck

Merck

Diagnostic Chemicals Ltd

Roth

Serva

Merck

Merck

Amersham Pharmacia

Roth

Roth

Roth

Roth

Merck

Serva

Merck

Merck

Sigma

Messer Griesheim, Seigen

Merck

Merck

Merck

Sigma

Merck

Roth

Serva

Qiagen

Sigma

Merck

Serva

Merck

Merck

Merck

Sigma

Merck

Merck

Sigma

Merck

Merck

Roth

Merck 
Sodium dihydrogenphosphate

Merck

Sodium hydroxide

Merck

Sodium sulphate

Merck

Sucrose

Merck

TEMED

(N'N'N'N Tetramethylethylenediamine)

Serva

Trichloroacetic acid

Triethanolamine

Tris-base

Urea

Water (HPLC-grade)

Merck

Merck

ICN Biomedicals, Aurora/ USA

Serva

Yeast extract

Mallinckrodt Baker

Roth

All the chemicals were of analysis grade.

\subsubsection{Detergents}

NP-40

Serva

Saponin

Sigma

Sodium deoxycholate

Serva

Sodium dodecyl sulphate (SDS)

Sigma

Triton X-100

Serva

Tween-20

Serva

\subsubsection{Enzymes, Substrates and Nucleotides}

Adenosine 5'-triphosphate (ATP)

Sigma

8-(4-Chlorophenylthio)adenosine

3':5'-cyclic monophosphate sodium salt

(pCPT-cAMP)

Creatine kinase (from Rabbit muscle)

Sigma

Endoglycosidase $\mathrm{H}$

Sigma

Guanosine 5'-triphosphate (GTP)

Roche Diagnostics

Guanosine 5'-O-(3-thiotriphosphate),

Tetralithium Salt (GTP $\gamma$ S)

Calbiochem

Hexokinase

Calbiochem

Phosphoadenosine phosphosulfate (PAPS)

Phosphocreatine

Restriction endonucleases

Trypsin from Bovine Pancreas (for assay)

Roche Diagnostics

Calbiochem

Sigma

New England Biolabs

Trypsin inhibitor from egg white (for assay)

Sigma

Sigma 


\subsubsection{Proteins, Protease inhibitors and Protein standards}

Aprotinin

Bovine Serum Albumin (BSA)

Glutathione-sepharose

lodoacetamide

Leupeptin

Lysozyme

PANSORBIN cells, Standardized

(Heat inactivated Staphylococcus aureus

cell suspension)

Protein A sepharose

Protein $\mathrm{G}$ agarose

Pepstatin A

Phenylmethylsulfonylfluoride (PMSF)

Prestained protein molecular

weight markers

\subsubsection{Vectors and DNA standards}

pGK Hygro

pME18S-HMY-MPR46

pMPSV-EH- $\mu 1 \mathrm{~A}$ (Clone7)

pUB/Bsd

1-kb DNA ladder

\subsubsection{Antibiotics and Drugs}

Ampicillin

Blasticidin-S Hydrochloride

Brefeldin-A

Cycloheximide

Hygromycin

Neomycin (Gentamycin sulfate or G418)

Penicillin/Streptomycin

$(100 x=10,000 \mathrm{U} / \mathrm{ml})$

Primaquine

Wortmannin

Nocodazole
Biomol

Serva

Amersham-Pharmacia

Sigma

Biomol

Merck

Calbiochem

Amersham-Pharmacia

Calbiochem

Biomol

Serva

Biorad

Invitrogen life technologies

Itin et al., 1997

Meyer et al., 2000

Invitrogen life technologies

Gibco BRL

Serva

Invitrogen life technologies

Calbiochem \& Sigma

Sigma

Calbiochem

Gibco

Gibco

Sigma

Sigma

Calbiochem 
Cytochalasin-D

Bafilomycin-A
Calbiochem

Calbiochem

\subsubsection{Radioactive substances}

[35s]-Methionine, $10 \mathrm{mCi} / \mathrm{ml}$

[35s]-Sulphate

(Sulphate in aqueous solution), $36.7 \mathrm{mCi} / \mathrm{ml}$

Purchased from Hartmann Analytic and Amersham Pharmacia Biotech, UK respectively.

\subsubsection{Kits for DNA and Protein}

Bio-Rad Protein Assay

Effectene Transfection kit

Fugene Transfection reagent

HiSpeed plasmid midi kit

Invisorb Spin Plasmid Mini kit

QIAquick Gel extraction kit
Bio-Rad

Qiagen

Roche

Qiagen

Invitek, Berlin

Qiagen

\subsubsection{Primary Antibodies}

\begin{tabular}{|c|c|c|c|c|}
\hline Name & Type & Antigen & $\begin{array}{c}\text { Immunized } \\
\text { Species }\end{array}$ & Reference \\
\hline MSC 1 & Polyclonal & $\begin{array}{l}\text { tail peptide of } \\
\text { MPR46 }\end{array}$ & Rabbit & $\begin{array}{l}\text { (Klumperman et } \\
\text { al., 1993) }\end{array}$ \\
\hline KII5 & Polyclonal & human MPR46 & Rabbit & \\
\hline 9E10 & Monoclonal & c-myc & Mouse & $\begin{array}{c}\text { Santa Cruz } \\
\text { Biotechnology, } \\
\text { Inc. }\end{array}$ \\
\hline$\gamma$-adaptin & Monoclonal & $\begin{array}{l}\text { Mouse } \gamma \text {-adaptin } \\
\text { hinge region }\end{array}$ & Mouse & $\begin{array}{l}\text { Transduction } \\
\text { laboratories }\end{array}$ \\
\hline$\alpha$-adaptin & Monoclonal & $\begin{array}{c}\text { Mouse } \alpha_{A} \text {-adaptin } \\
N \text { - terminus }\end{array}$ & Mouse & $\begin{array}{l}\text { Transduction } \\
\text { Laboratories }\end{array}$ \\
\hline $\begin{array}{c}\mu 1 \mathrm{~A} \\
\text { antibody }\end{array}$ & Polyclonal & $\begin{array}{c}\text { Synthetic peptide } \\
\text { of mouse } \mu 1 \mathrm{~A} \text { aa } \\
295-310\end{array}$ & Rabbit & $\begin{array}{l}\text { (Meyer et al., } \\
\text { 2000) }\end{array}$ \\
\hline SII9, S10 & Polyclonal & $\begin{array}{c}\text { Mouse } \\
\text { cathepsin-D }\end{array}$ & Rabbit & $\begin{array}{c}\text { (Pohlmann et al., } \\
\text { 1995) }\end{array}$ \\
\hline
\end{tabular}




\begin{tabular}{|c|c|c|c|c|}
\hline 15 & Polyclonal & Rat MPR-300 & Rabbit & $\begin{array}{c}\text { (Claussen et al., } \\
\text { 1995) }\end{array}$ \\
\hline $\begin{array}{c}\text { Anti } \\
\text { VAMP-4 }\end{array}$ & Polyclonal & $\begin{array}{c}\text { Rat GST-VAMP4 } \\
\text { (aa } 1-117 \text { ) }\end{array}$ & Rabbit & $\begin{array}{c}\text { (Kreykenbohm et } \\
\text { al., 2002) }\end{array}$ \\
\hline AKP7 & Polyclonal & $\begin{array}{l}\text { AA 1-187 of } \\
\text { mouse Vti 1a }\end{array}$ & Rabbit & $\begin{array}{c}\text { (Antonin et al., } \\
2000)\end{array}$ \\
\hline $\begin{array}{c}\text { Anti- } \\
\text { Syntaxin } 6 \\
\text { Clone } \\
\text { 3D10 }\end{array}$ & Monoclonal & $\begin{array}{c}\text { Rat-syntaxin } 6 \text { - } \\
\text { GST- fusion } \\
\text { protein }\end{array}$ & Mouse & $\begin{array}{c}\text { StressGen } \\
\text { Biotechnologies } \\
\text { Corporation }\end{array}$ \\
\hline Anti TIP47 & Polyclonal & $\begin{array}{c}\text { Synthetic peptide } \\
\text { of TIP47 amino } \\
\text { terminus }\end{array}$ & Guinea pig & Progen Biotechnik \\
\hline p47A & Monoclonal & $\begin{array}{c}\text { Rat } \mu 3 \mathrm{~A} N- \\
\text { terminus }\end{array}$ & Mouse & $\begin{array}{l}\text { Transduction } \\
\text { laboratories }\end{array}$ \\
\hline S48 & Polyclonal & $\begin{array}{l}\text { Human } \delta \text {-adaptin } \\
\text { (aa 784- 802) }\end{array}$ & Rabbit & $\begin{array}{c}\text { Dr. Stefan } \\
\text { Hoening }\end{array}$ \\
\hline
\end{tabular}

Table 1: List of antibodies used in this study.

\subsubsection{Secondary antibodies}

Goat anti-rabbit Horseradish peroxidase conjugate

Goat anti-mouse Horseradish peroxidase conjugate

Goat anti-guinea pig Horseradish peroxidase conjugate

Goat anti-rabbit Flourescein isothiocyanate conjugate

Goat anti-mouse Flourescein isothiocyanate conjugate

Goat anti-rabbit Texas Red conjugate

Goat anti-mouse Texas Red conjugate

Goat anti-mouse Cy3 conjugate

All secondary antibodies were purchased from Dianova, Hamburg.

\subsubsection{Bacterial strains and Mouse embryonic fibroblast cell lines}

\section{Escherichia coli:}

\begin{tabular}{|c|c|c|}
\hline Strain & Genotype & Firm \\
\hline DH5a & $\begin{array}{l}\text { supE44, thi-1, recA1, relA1, hsdR17(rK-mK+), } \\
\text { thi-1, } \Delta \text { lacU169 ( } \$ 80 \text { lacZ } \Delta M 15) \text {, endA1, gyrA } \\
\left(\mathrm{Nal}^{\mathrm{r}}\right)\end{array}$ & $\begin{array}{l}\text { Gibco BRL, } \\
\text { Eggenstein }\end{array}$ \\
\hline XL1-Blue & $\begin{array}{l}\text { recA1, end } A 1, \text { gyrA96, thi-1, hsdR17, supE44, } \\
\left.\text { relA1, lac [F', proAB, lacl }{ }^{q} Z \Delta M 15, T n 10\left(\text { Tet }^{r}\right)\right]^{c}\end{array}$ & $\begin{array}{l}\text { Stratagene, } \\
\text { Heidelberg }\end{array}$ \\
\hline $\begin{array}{l}\text { BL21- } \\
\text { (D3)-RIL }\end{array}$ & 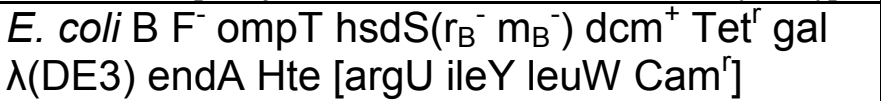 & $\begin{array}{l}\text { Stratagene, } \\
\text { Heidelberg }\end{array}$ \\
\hline
\end{tabular}


$\mu 1 \mathrm{~A}$-deficient mouse embryonic fibroblasts (MEFs) (Meyer et al., 2000)

$\mu 1 \mathrm{~A}$-deficient MEFs stably retransfected with $\mu 1 \mathrm{~A}$ cDNA (Meyer et al., 2000)

Mocha cells, which were natural AP-3-deficient mouse fibroblasts, were the kind gift of Dr. Stefan Hoening.

HeLa cells stably transfected with TIP47 anti-sense construct (Kind gift of Dr.

Stefan Hoening)

\subsubsection{Media and Solutions for Cell culture}

PBS (Sterile for cell culture)

$150 \mathrm{mM} \mathrm{NaCl}$

$120 \mathrm{mM} \mathrm{KCl}$

$10 \mathrm{mM} \mathrm{Na} 2 \mathrm{HPO}_{4} / \mathrm{KH}_{2} \mathrm{PO}_{4}, \mathrm{pH} 7.4$

Dulbecco's Modified Eagles Medium

(DMEM)

Gibco-Invitrogen

Fetal Calf Serum

PAA laboratories $\mathrm{GmbH}$, Austria

Trypsin-EDTA solution (1x)

$0.5 \mathrm{~g} / \mathrm{L}$ Trypsin

$0.2 \mathrm{~g} / \mathrm{L}$ EDTA

in Puck's Salt Solution A without $\mathrm{Ca}^{2+}$

and $\mathrm{Mg}^{2+}$

Gibco

L-Glutamine $(100 \mathrm{x})$

Gibco

(200 mM)

Sulfate-free DMEM powder

PAN Biotech GmbH

\subsubsection{Stock solutions and buffers}

$1 \mathrm{M}$ Sodiumphosphate buffer $1 \mathrm{M}$ solution of sodium di-hydrogen phosphate was slowly added to $1 \mathrm{M}$ di-sodium hydrogen phosphate solution with constant mixing on a magnetic stirrer till the $\mathrm{pH}$ came down to 7.4.

$10 \times$ PBS

$100 \mathrm{mM}$ sodium phosphate buffer $\mathrm{pH} 7.4$

$9 \%$ sodium chloride

Dissolved in $800 \mathrm{ml}$ water, volume was made up to $1000 \mathrm{ml}$ and autoclaved. Stored at room temperature. 
$\underline{1 \times \text { TBS }}$

$10 \mathrm{mM}$ Tris/ $\mathrm{HCl} \mathrm{pH} \mathrm{7,4}$

$150 \mathrm{mM}$ Sodium chloride

$\underline{1 \times \mathrm{TAE}}$

0.04 M Tris-acetate

$1 \mathrm{mM}$ EDTA (pH 8.0)

$\underline{50 \times \mathrm{TAE}}$

$242 \mathrm{~g}$ Tris base

$57.1 \mathrm{~g}$ glacial acetic acid

$100 \mathrm{ml}$ of $0.5 \mathrm{M}$ EDTA (pH 8.0)

Dissolved in water and the final volume was made upto one litre.

$\underline{\text { TE Buffer }}$

$10 \mathrm{mM}$ Tris/ $\mathrm{HCl} \mathrm{pH}$ 7,5

1 mM EDTA

\subsubsection{Computing facilities used}

\section{Hardware}

Samsung VM8000 Series Notebook

Apple Macintosh 7600/132

Samsung Electronics

Apple Computers Inc

Apple Macintosh Performa 630

Apple Computers Inc

Laser Jet $4050 \mathrm{~N}$

Hewlett Packard, Palo Alto (USA)

Scanner ScanJet 4C/T

$$
\text { Hewlett Packard, Palo Alto (USA) }
$$

Software

Acrobat Reader 5.0

Adobe System Inc

Photoshop 6.0

Adobe System Inc

Aida image analyzer

raytest

Image gauge

Fuji

Image reader

Fuji

Kaleidagraph

Synergy software

Word for Windows XP

Microsoft Corporation

Image Reader LAS-1000

(Pro Vers. 2.1)

raytest, Straubenhardt 


\subsection{Methods}

\subsubsection{MOLECULAR BIOLOGY METHODS}

\subsubsection{Cultivation of E.coli}

Luria Bertani(LB) medium

$10 \mathrm{~g}$ Bacto-Tryptone

$5 \mathrm{~g}$ Bacto-yeast extract

$5 \mathrm{~g} \mathrm{NaCl}$

Dissolved in $900 \mathrm{ml}$ distilled water, $\mathrm{pH}$ adjusted to 7.0 with $10 \mathrm{~N} \mathrm{NaOH}$, made up the volume to one liter, sterilized by autoclaving and stored at room temperature.

\section{LB-Ampicillin Agar Plates}

$1.5 \%$ of Agar was added to the LB medium and autoclaved. After autoclaving, the medium was let to cool down to $55^{\circ} \mathrm{C}$ and ampicillin was added to a final concentration of $100 \mu \mathrm{g} / \mathrm{ml}$. This medium was poured into $10 \mathrm{~cm}$ petriplates in the hood and left undisturbed for about $30 \mathrm{~min}$ to solidify. LB-Agar plates were stored in the cold room.

\subsubsection{Preparation of competent $E$. coli cells}

Buffers

TFB I

$30 \mathrm{mM}$ Calcium acetate, $\mathrm{pH} 5.8$

100 mM Rubidium chloride

$10 \mathrm{mM}$ Calcium chloride

$50 \mathrm{mM}$ Manganese chloride

$15 \%$ Glycerol (w/v)

TFB II

$10 \mathrm{mM}$ MOPS, pH 6.5

$75 \mathrm{mM}$ Calcium chloride $10 \mathrm{mM}$ Rubidium chloride $15 \%$ (w/v) Glycerol

A 2-3 $\mathrm{ml}$ bacterial pre-culture was grown in LB medium at $37^{\circ} \mathrm{C}$ overnight. $1 \mathrm{ml}$ of the pre-culture was then inoculated into $99 \mathrm{ml}$ of LB medium and grown at $37^{\circ} \mathrm{C}$ to an O.D600 of $0.4-0.6$. Cells were pelleted at $3,000 \mathrm{rpm}$ for $5 \mathrm{~min}$ at $4^{\circ} \mathrm{C}$, resuspended in 0.2 culture volume of TFB I and incubated on ice for $5 \mathrm{~min}$. Cells were centrifuged at $3000 \mathrm{rpm}$ for $5 \mathrm{~min}$ at $4{ }^{\circ} \mathrm{C}$, the pellet was resuspended in 
0.04 culture volume of TFB II and incubated on ice for $30 \mathrm{~min}$. Aliquots of $50 \mu \mathrm{l}$ were frozen at $-80^{\circ} \mathrm{C}$.

\subsubsection{Transformation of E.coli competent cells}

50-100 ng of DNA was added to each $50 \mu$ aliquot of competent cells and incubated on ice for $30 \mathrm{~min}$. Cells were subjected to heat shock by incubating at $42^{\circ} \mathrm{C}$ for $2 \mathrm{~min}$ and incubated on ice for $1-2 \mathrm{~min}$. $0.9 \mathrm{ml}$ of LB medium was added to the cells followed by incubation at $37^{\circ} \mathrm{C}$ in the shaker for 1 hour. Cells were plated on LB-agar plates containing appropriate antibiotic. For blue-white selection, cells were plated on plates containing IPTG (Isopropyl-ß-Dthiogalactopyrahoside; $40 \mu \mathrm{l}$ of $100 \mathrm{mM}$ solution in water) and X-Gal (40 $\mu \mathrm{l}$ of $4 \%$ solution in dimethylformamide).

\subsubsection{Preparation of electrocompetent cells}

$10 \%(\mathrm{v} / \mathrm{v})$ Glycerol : $1 \mathrm{ml}(1.26 \mathrm{~g})$ of glycerol in $10 \mathrm{ml}$ sterile water

A single $E$. coli colony was inoculated into $5 \mathrm{ml}$ of LB media and allowed to grow overnight at $37^{\circ} \mathrm{C}$ in a shaker incubator. $2.5 \mathrm{ml}$ of this pre-culture was inoculated into $500 \mathrm{ml}$ LB media and allowed to grow to an OD600 of $0.5-0.7$ at $37^{\circ} \mathrm{C}$. Cells were pre-chilled on ice for $15 \mathrm{~min}$ and then pelleted at $5000 \mathrm{rpm}$ for $15 \mathrm{~min}$ at $4^{\circ} \mathrm{C}$. Pellet was resuspended in $500 \mathrm{ml}$ of ice cold water and centrifuged as described above. This washing was repeated one more time. To the pellet an equal volume of water was added and resuspended, aliquots of $100 \mu \mathrm{l}$ was stored at $-80^{\circ} \mathrm{C}$.

\subsubsection{Transformation of the electrocompetent cells}

SOC medium

$0.5 \%$ Yeast extract

$2 \%$ Bacto-tryptone

$10 \mathrm{mM}$ Sodium chloride

2,5 mM Potassium chloride

$10 \mathrm{mM}$ Magnesium sulfate

$10 \mathrm{mM}$ Magnesium chloride

$20 \mathrm{mM}$ Glucose 
For each electroporation $40 \mu$ of the electrocompetent cells were used. $0.5 \mu \mathrm{g}$ of DNA was added to the cells and the contents were transferred into a pre-chilled electroporation cuvette. The cuvette was placed in the electroporater and pulse was applied. SOC medium was added to the cells and they were allowed to recover in sterile tubes for $30 \mathrm{~min}$ at $37^{\circ} \mathrm{C}$ in a shaker incubator. Cells were plated on LB plates containing appropriate antibiotic.

\subsubsection{Glycerol stocks of bacterial strains}

Bacterial cultures were grown overnight at $37^{\circ} \mathrm{C}$ in a shaker-incubator. $0.3 \mathrm{ml}$ of sterile $100 \%$ glycerol was taken in freezing vials to which $700 \mu$ of the overnight culture was added. The contents were gently mixed, shock frozen on dry ice and stored at $-80^{\circ} \mathrm{C}$.

\subsubsection{Mini preparation of plasmid DNA}

Plasmid DNA was isolated from E.coli cultures using the kit provided by Qiagen. Isolation was done as follows according to the instructions of the manufacturer.

$\begin{array}{ll}\text { Buffer P1 } & 50 \mathrm{mM} \text { Tris/ } \mathrm{HCl} \mathrm{pH} 8,0 \\ & 10 \mathrm{mM} \text { EDTA } \\ & 100 \mu \mathrm{g} / \mathrm{ml} \text { RNase A } \\ \text { Buffer P2 } & 0.2 \mathrm{M} \mathrm{NaOH} \\ & 1 \% \mathrm{SDS}\end{array}$

Buffer P3 3 M Potassium acetate $\mathrm{pH} 5.5$

A single E. coli colony was inoculated into $3 \mathrm{ml}$ of LB medium containing 100 $\mu \mathrm{g} / \mathrm{ml}$ of antibiotic and grown overnight at $37^{\circ} \mathrm{C}$ in a shaker incubator. Cells were pelleted in a table-top centrifuge at 3,000 rpm for $5 \mathrm{~min}$. Cell pellet was resuspended in $250 \mu \mathrm{l}$ of buffer P1 and $250 \mu \mathrm{l}$ of buffer P2 was added, mixed by gently inverting the tube 4-6 times. To this, $350 \mu$ of buffer P3 was added and gently mixed and centrifuged for $10 \mathrm{~min}$ at 13,000 rpm in a table-top eppendorf centrifuge. The supernatant was applied onto a QIAprep spin column and centrifuged for $1 \mathrm{~min}$ at 13,000 rpm. Flow through was discarded, the column was washed with $0.75 \mathrm{ml}$ of buffer PE and centrifuged again for $1 \mathrm{~min}$. Flow through was discarded and the column was centrifuged for an additional $1 \mathrm{~min}$ to remove 
any residual wash buffer. The column was placed in a clean eppendorf tube and $50 \mu \mathrm{l}$ of double distilled water was added directly to the centre of the column . The column was let to stand for $1 \mathrm{~min}$ and DNA was eluted by centrifuging at $13,000 \mathrm{rpm}$ for $1 \mathrm{~min}$.

\subsubsection{Determining the concentration of DNA}

DNA concentration was determined using a spectrophotometer at $260 \mathrm{~nm}$. DNA was diluted in water and the absorbance was measured at $260 \mathrm{~nm}$.

Absorbance or optical density (OD) of 1 at $260 \mathrm{~nm}$ corresponds to $\sim 50 \mu \mathrm{g} / \mathrm{ml}$ of double stranded DNA or $\sim 40 \mu \mathrm{g} / \mathrm{ml}$ of single stranded DNA and RNA or $\sim 20$ $\mu \mathrm{g} / \mathrm{ml}$ of oligonucleotides. The ratio between the readings at $260 \mathrm{~nm}$ and $280 \mathrm{~nm}$ $\left(O D_{260} / O D_{280}\right)$ provides an estimate of the purity of the nucleic acid. Pure preparations of DNA and RNA have $\mathrm{OD}_{260} / \mathrm{OD}_{280}$ values of 1.8 and 2.0, respectively. Any contamination with proteins or phenol would yield values less than mentioned above.

\subsubsection{Restriction endonuclease digestion of DNA}

The activity of restriction enzymes is measured in terms of 'Units' (U).

One unit of restriction enzyme is the amount of enzyme required to completely digest $1 \mu \mathrm{g}$ substrate DNA in $1 \mathrm{~h}$.

Plasmid DNA $\quad 0.5-1 \mu \mathrm{g}$

$10 \times$ buffer $\quad 2 \mu l$

Restriction enzyme $\quad 1-2 \mathrm{U}$

BSA

$1 \mu \mathrm{g} / \mu \mathrm{l}$ (added where essential)

Water was added to a final volume of $20 \mu \mathrm{l}$. Reaction mix was incubated at $37^{\circ} \mathrm{C}^{*}$ for 2 hours.

*Incubation temperatures were set as recommended by the manufacturer (New England Bio Labs Beverly U.S.A.) which varies from enzyme to enzyme. Reaction mix was analyzed on an agarose gel (0.8 to $2 \%$ depending on the size of the DNA of interest)

The buffers and enzymes used were all from New England Biolabs. 
The composition of the buffers is as follows:

NEB 1: $10 \mathrm{mM}$ Bis Tris Propane- $\mathrm{HCl}\left(\mathrm{pH}\right.$ 7.0), $10 \mathrm{mM} \mathrm{MgCl}_{2}, 1 \mathrm{mM}$ DTT

NEB 2: $10 \mathrm{mM}$ Tris- $\mathrm{HCl}$ (pH 7.9), $10 \mathrm{mM} \mathrm{MgCl}$, $50 \mathrm{mM} \mathrm{NaCl}, 1 \mathrm{mM}$ DTT

NEB 3: 50 mM Tris- $\mathrm{HCl}$ (pH 7.9), $10 \mathrm{mM} \mathrm{MgCl} 2,100 \mathrm{mM} \mathrm{NaCl}, 1 \mathrm{mM}$ DTT

NEB 4: $20 \mathrm{mM}$ Tris-acetate (pH 7.9), $10 \mathrm{mM}$ Magnesium acetate, $1 \mathrm{mM}$ DTT, $50 \mathrm{mM}$ Potassium acetate

\subsubsection{Agarose gel electrophoresis of DNA}

The size and purity of DNA is analyzed by agarose gel electrophoresis. Concentration of agarose used for analysis is inversely proportional to the size of the DNA of interest, that is, the larger the DNA the lower the concentration of agarose.

\begin{tabular}{|c|c|}
\hline Agarose concentration (\%) & DNA size $(\mathrm{kb})$ \\
\hline 0.7 & $20-1$ \\
\hline 0.9 & $7-0.5$ \\
\hline 1.2 & $6-0.4$ \\
\hline 1.5 & $4-0.2$ \\
\hline 2.0 & $3-0.1$ \\
\hline
\end{tabular}

\section{Gel loading buffer (10x)}

$0.25 \%(w / v)$ Bromophenol blue

$40 \%$ Saccharose in $1 \times$ TAE

Agarose was weighed and dissolved in $1 \times \mathrm{TAE}$ by boiling in microwave oven. The agarose solution was allowed to cool till about $60^{\circ} \mathrm{C}$ and ethidium bromide was added to a final concentration of $0.5 \mu \mathrm{g} / \mathrm{ml}$. This was poured into the agarose gel cassette and allowed to polymerize completely. The sample DNA was mixed with gel loading buffer and loaded into the lane. The gel electrophoresis was carried out at $100 \mathrm{~V}$. Ethidium bromide is a fluorescent dye which contains a planar group that intercalates between the stacked bases of the DNA. The fixed 
position of this group and its close proximity to the bases cause dye bound to DNA to display an increased fluorescent yield compared to that of the dye in free solution. Ultraviolet radiation at $254 \mathrm{~nm}$ is absorbed by the DNA and transmitted to the dye; radiation at $302 \mathrm{~nm}$ and $366 \mathrm{~nm}$ is absorbed by the bound dye itself. In both cases, the energy is re-emitted at $590 \mathrm{~nm}$ in the red orange region of the visible spectrum. and hence DNA can be visualized under a UV transilluminator. The gel was photographed using a gel documentation system.

\subsubsection{Cloning of full length and antisense GGA cDNA}

Full length mus musculus GGA cDNAs were cloned by RT-PCR using total RNA isolated by the RNAeasy method (Quiagen, Neuss, FRG) from mouse embryonic fibroblast cell lines and primers designed according to mouse genomic sequences. Amplified DNAs were cloned into pCR2.1 and sequenced (Invitrogen, Karlsruhe, FRG). A 2 kb Eco RI fragment of GGA1 and a $1.5 \mathrm{~kb} \mathrm{5'-Eco} \mathrm{RI}$ fragment of GGA2 were cloned in reverse orientation in the murine expression vector pMPSV. These plasmids were transfected in a $\mu 1 \mathrm{~A}$-deficient cell line derived from a mouse 'knock-out'. Stable transfectants were selected after cotransfection with vector encoding resistance to hygromycin B (Calbiochem, Schwalbach, FRG). Clones resistant for upto $500 \mu \mathrm{g} / \mathrm{ml}$ hygromycin were picked and cultured for further experiments. Absence of the GGA mRNA was tested by northern-blot using a probe of the homologous GGA sequence as positive control. $\mu 1 \mathrm{~A}$ cDNA cloned in the pMPSV was transfected as described in the GGA anti-sense cell lines to generate cell lines deficient only in GGA1 and GGA2 expression. 


\subsubsection{BIOCHEMICAL METHODS}

\subsubsection{Analysis of proteins}

\subsection{Estimation of protein content using the BIORAD reagent}

Bovine Serum Albumin (BSA) stock solution $1 \mathrm{mg} / \mathrm{ml}$

Concentration range : $2-16 \mu \mathrm{g} / \mu \mathrm{l}$

A standard curve was made using BSA in the range of $2-16 \mu \mathrm{g} .10 \mu \mathrm{l}$ of the sample was used for the protein estimation. The volume was made up to $800 \mu \mathrm{l}$ with water. $200 \mu$ of the BIORAD reagent was added and the samples were incubated for 3 - $5 \mathrm{~min}$ at room temperature, $200 \mu \mathrm{l}$ from each tube was pipetted into ELISA strips and optical density was measured at $595 \mathrm{~nm}$ in the ELISA reader.

\subsection{Solubilisation of proteins}

$2 \times$ Laemmli buffer 125 mM Tris-Cl, pH 6.8

$4 \%$ SDS

$0.004 \%$ Bromophenol blue

$20 \%(w / v)$ Glycerol

$20 \mathrm{mM}$ DTT

Proteins were resuspended in $1 \mathrm{x}$ Laemmli buffer. The resuspended proteins were boiled at $95^{\circ} \mathrm{C}$ for $5 \mathrm{~min}$, cooled on ice for $1 \mathrm{~min}$, centrifuged at 13,000 rpm for 2 min and resolved by SDS-PAGE.

\subsection{SDS Poly-Acrylamide Gel Electrophoresis (SDS-PAGE)}

Gel running buffers

Anode buffer $(5 \mathrm{x}) \quad 50 \mathrm{mM}$ Tris

192 mM Glycine

Volume was made up with double distilled water.

Cathode buffer $(1 \mathrm{x}) \quad 0.1 \%$ SDS in anode buffer

Volume was made up with double distilled water. 
Separating gel buffer $(4 \mathrm{x}) \quad 1.5 \mathrm{M}$ Tris- $\mathrm{Cl} \mathrm{pH} 8.8$

$$
\begin{aligned}
& 0.4 \% \text { SDS } \\
& 0.4 \% \text { APS }
\end{aligned}
$$

Volume was made up with double distilled water.

Stacking gel buffer (4x) $\quad 0.5 \mathrm{M}$ Tris- $\mathrm{Cl} \mathrm{pH} 6.8$

$$
0.4 \%(w / v) \text { SDS }
$$

Acrylamide Solution

$$
30 \% \text { (w/v) Acrylamide }
$$

$0.8 \%(w / v)$ Bisacrylamide

Ammonium per sulphate $10 \%(\mathrm{w} / \mathrm{v})$

Recrystallised ammonium peroxidisulphate (APS) was dissolved in double distilled water. This was prepared fresh every week.

Preparation of Acrylamide solution for SDS-PAGE: (for one minigel- 8ml) All volumes are in $\mathrm{ml}$ unless indicated otherwise.

\begin{tabular}{|c|c|c|c|c|c|}
\hline Gel (\%) & 5 & 10 & 12.5 & 15 & $\begin{array}{c}3 \text { ml Stacking } \\
\text { Gel }(4.5 \%)\end{array}$ \\
\hline $\begin{array}{c}\text { Acrylamide/ } \\
\text { Bis-acrylamide }\end{array}$ & 1.33 & 2.67 & 3.3 & 4 & 0.45 \\
\hline $\begin{array}{c}4 \text { x resolving gel } \\
\text { buffer }\end{array}$ & 2 & 2 & 2 & 2 & $\begin{array}{c}4 x \text { stacking } \\
\text { gel buffer } \\
0.45\end{array}$ \\
\hline Water & 4.58 & 3.2 & 2.6 & 1.9 & 1.77 \\
\hline Temed & $8 \mu \mathrm{l}$ & $8 \mu \mathrm{l}$ & $8 \mu \mathrm{l}$ & $8 \mu \mathrm{l}$ & $3 \mu \mathrm{l}$ \\
\hline $10 \%$ APS & $80 \mu \mathrm{l}$ & $80 \mu \mathrm{l}$ & $80 \mu \mathrm{l}$ & $80 \mu \mathrm{l}$ & $30 \mu \mathrm{l}$ \\
\hline
\end{tabular}

SDS-PAGE is a biochemical technique wherein proteins are separated based on their molecular weight. The gel is discontinuous in that it has a stacking gel which is present on top of the resolving gel. SDS-PAGE can be used to separate 
proteins based on their native size (native SDS-PAGE) or their sub unit size (reducing SDS-PAGE). Two clean glass plates were fixed together with a spacer of appropriate thickness (0.75-1.5 mM) using holders or clips. The resolving gel was poured and isobutanol was layered on top of it. The gel was allowed to polymerise for about $30 \mathrm{~min}$ and isobutanol was thoroughly washed off using double distilled water. The stacking gel was poured on top of the resolving gel and a comb, of appropriate size and appropriate number of wells, was placed in the stacking gel and left undisturbed for about $30 \mathrm{~min}$. After polymerisation of the stacking gel, the combs were removed and the wells were cleaned with double distilled water to wash off any unpolymerised acrylamide. Boiled and denatured protein samples were loaded into the wells, the gel was placed in a tank with electrophoresis buffer and run at $100-125 \mathrm{~V}$ for $2 \mathrm{~h}$.

\subsection{Coomassie blue staining of Polyacrylamide gels}

Coomassie blue stain $\quad 0.5 \%(w / v)$ Coomassie blue

$50 \%(\mathrm{v} / \mathrm{v})$ Methanol

$10 \%(v / v)$ Acetic acid

in double distilled water

Destaining solution $\quad 50 \%$ Methanol and $10 \%$ glacial acetic acid dissolved in double distilled water.

The gel was stained in Coomassie blue solution at room temperature for 1-2 hours and destained using the destaining solution overnight. After complete destaining the gel was washed with double distilled water for $15 \mathrm{~min}$ and then dried in a gel drier

\subsection{Western blot analysis (semi dry method)}

Semidry blot buffers

Cathode buffer $\quad 40 \mathrm{mM} \varepsilon$-Ammonium caproic acid

$20 \mathrm{mM}$ Tris/Cl

$20 \%$ Methanol 
Dissolved in water, $\mathrm{pH}$ set to 9.0 with free Tris base and volume was made up with water.

Anode buffer

$75 \mathrm{mM}$ Tris/Cl

$20 \%$ Methanol

Dissolved in water, $\mathrm{pH}$ set to 7.4 with $\mathrm{HCl}$ and volume made up with water.

TBS - Tween

TBS containing $0.1 \%$ Tween-20

Blocking buffer

TBST containing 5\% milk powder

\section{Primary antibodies}

anti-gamma adaptin

anti-alpha adaptin

anti- $\mu 1 \mathrm{~A}$ adaptin

anti-MPR46

anti-myc antibody

anti-Vti1a

anti-Syntaxin 6

anti-TIP47

anti-Vamp 4

anti-delta adaptin

anti- $\mu 3 \mathrm{~A}$

\section{Final concentration}

$1: 5,000$

$1: 5,000$

$1: 1,000$

$1: 1,000$

$1: 500$

$1: 1,000$

$1: 1,000$

$1: 500$

$1: 1,000$

$1: 500$

$1: 1000$

\section{Secondary antibody}

\section{Final concentration}

HRP (Horseradish peroxidase)

conjugated Goat anti-rabbit and

anti-mouse antibody

$1: 10,000$

Proteins separated by SDS-PAGE were transferred onto nitrocellulose or PVDF membranes for western blot analysis by chemiluminescence. 6 sheets of whatman paper were cut according to the size of the gel. Three sheets were 
immersed in the semidry anode buffer and placed in the chamber. A glass pipette was rolled on it to remove any air bubbles. Then the membrane dipped in the cathode buffer was placed on top of it and again the air bubbles were removed. The gel was also soaked in the cathode buffer before placing on the membrane. Another three whatman paper sheets were dipped in cathode buffer and placed on top of the gel. The glass pipette was again rolled on the set up to remove air bubbles. The proteins were transferred onto the membrane using current at 1 $\mathrm{mA} / \mathrm{cm}^{2}$ for $60-90 \mathrm{~min}$.

$3 \times$ whatman paper wet in

Cathode (-)

Cathode buffer

SDS-acrylamide gel

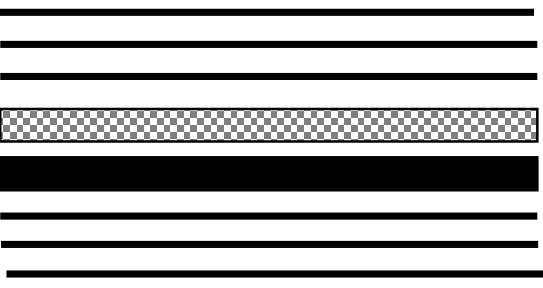

$3 \mathrm{x}$ whatman paper wet in

Anode buffer

Anode (+)

After the transfer, membrane was incubated in TBST containing $5 \%$ milk powder for 1 hour at room temperature to block all non-specific interaction sites on the membrane. After blocking, the primary antibody suitably diluted in blocking buffer, was added onto the membrane and incubated overnight in the cold room on a rocker. The non-specifically bound antibody was washed off by incubating the blot on a rocker with blocking buffer, changing the buffer once every 10 min for three times. The membrane was then incubated with the secondary antibody for 1 hour at room temperature and the membrane was washed 4 times, 10 min each, with TBST. The proteins were detected by chemiluminescence.

\subsection{Detection techniques}

\section{Chemiluminescent Substrate from PIERCE}

Enhancer and peroxide solutions were mixed in a 1:1 ratio and incubated at room temperature for $5 \mathrm{~min}$. The substrate was washed off and the membrane was wrapped in a polythene sheet and signals were detected using a CCD camera or an X-ray film. 


\section{Luminol Detection system}

Luminol

p-coumaric acid

Solution $1(10 \mathrm{ml})$

Solution $2(10 \mathrm{ml})$
$0.44 \mathrm{~g}$ was dissolved in $10 \mathrm{ml}$ of DMSO and aliquots were stored at $-20^{\circ} \mathrm{C}$

$0.15 \mathrm{~g}$ dissolved in $10 \mathrm{ml}$ DMSO, aliquots stored

at $-20^{\circ} \mathrm{C}$

$100 \mu \mathrm{l} 250 \mathrm{mM}$ Luminol

44 l 90 mM p-coumaric acid

$1 \mathrm{ml} 1 \mathrm{M} \mathrm{Tris} / \mathrm{Cl} \mathrm{pH} 8.5$

$8.9 \mathrm{ml}$ Water

$1 \mathrm{ml} 1 \mathrm{M} \mathrm{Tris} / \mathrm{Cl} \mathrm{pH} 8.5$

$6 \mu \mathrm{l}$ hydrogen peroxide (from $30 \%$ stock solution)

$9 \mathrm{ml}$ water

Solution 1 and solution 2 were mixed just before adding onto the blot.

Solutions were added onto the blot and incubated at room temperature for 1 min. The substrate was washed off and the membrane was wrapped in a polythene sheet and signals were detected using a CCD camera or an X-ray film.

\subsection{Stripping the antibody from the membrane}

The membrane was washed twice with water for 5 min each to wash off the chemiluminescent substrate. The membrane was stripped of the antibodies by washing with $0.2 \mathrm{~N} \mathrm{NaOH}$ for 10 min on a rocker. The membrane was again washed for 5 min with water, and 5 min with TBST, incubated in blocking buffer followed by antibody of interest for next round of chemiluminescence.

\subsubsection{Expression and Purification of GST-Vti1a from E.coli}

LB medium

Ampicillin Stock : $25 \mathrm{mg} / \mathrm{ml}$

Working concentration : $100 \mu \mathrm{g} / \mathrm{ml}$

IPTG Stock : $0.1 \mathrm{M}$

Working concentration : $0.3 \mathrm{mM}$ 
Lysis buffer $\quad 25 \mathrm{mM}$ Tris- $\mathrm{HCl} \mathrm{pH}$ 7.5, $0.5 \mathrm{mM}$ EDTA, $1 \mathrm{mM}$ DTT, 10\% Sucrose, $1 \mathrm{mM}$ PMSF, $5 \mathrm{mM}$ lodoacetamide, $1 \mu \mathrm{M}$ Pepstatin, $0.5 \mu \mathrm{g} / \mathrm{ml}$ Leupeptin

Binding buffer $\quad 25 \mathrm{mM}$ Tris- $\mathrm{HCl}$ pH 7.5, $0.5 \mathrm{mM}$ EDTA, 1 mM DTT, $1 \%$ Triton $\mathrm{X}-100$

Wash buffer $\quad 25 \mathrm{mM}$ Tris- $\mathrm{HCl}$ pH 7.5, $0.5 \mathrm{mM}$ EDTA, $1 \mathrm{mM}$ DTT

Elution Buffer $\quad 50 \mathrm{mM}$ Tris- $\mathrm{HCl} \mathrm{pH} \mathrm{8.0,25} \mathrm{mM} \mathrm{Glutathione}$

All centrifugations were perfomed at $4^{\circ} \mathrm{C}$.

A single E. coli colony overexpressing GST-Vti1a was inoculated into $3 \mathrm{ml}$ LB medium containing Ampicillin $(100 \mu \mathrm{g} / \mathrm{ml})$ and grown overnight at $37^{\circ} \mathrm{C}$ in a shaker-incubator. $3 \mathrm{ml}$ of this pre-culture was inoculated into $400 \mathrm{ml}$ of LB-Amp medium and the cells were grown till $\mathrm{OD}_{600}$ of $0.5-0.8$ at $37^{\circ} \mathrm{C}$. This log phase culture was induced by adding $0.3 \mathrm{mM}$ IPTG and incubated for further $3 \mathrm{~h}$ at room temperature.

Cells were harvested by centrifuging at $6,000 \mathrm{rpm}$ (JA10 rotor), $4^{\circ} \mathrm{C}$, for $15 \mathrm{~min}$. The supernatant was discarded completely, the pellet was resuspended in $20 \mathrm{ml}$ of cold PBS on ice and centrifuged as before. The supernatant was discarded and the pellet was resuspended in $4 \mathrm{ml}$ of lysis buffer and transferred to a JA20 centrifuge tube. After adding $4 \mathrm{ml}$ of lysis buffer containing $0.2 \mathrm{mg} / \mathrm{ml}$ lysozyme, the cell suspension was incubated on ice for $15 \mathrm{~min} .12 \mathrm{ml}$ of lysis buffer was added and sonicated twice, 30 secs each time. $10 \mu \mathrm{g} / \mathrm{ml}$ RNase and $5 \mu \mathrm{g} / \mathrm{ml}$ DNase were added and the lysate was incubated on ice for $15 \mathrm{~min} .2 \mathrm{ml}$ of $10 \%$ Triton X-100 was added and mixed well. The solubilized cell lysate was centrifuged for $15 \mathrm{~min}$ at $12,000 \mathrm{rpm}$ in a JA20 rotor. The supernatant containing soluble protein was transferred to a new falcon tube. The pellet was frozen at $20^{\circ} \mathrm{C}$ for SDS-PAGE analysis. An aliquot of the supernatant was also frozen for SDS-PAGE.

$260 \mathrm{ml}$ of GSH-sepharose beads (75\% solution in ethanol) were washed twice with wash buffer and twice with binding buffer ( $2 \mathrm{ml}$ of buffer was used for each). 
wash, and the centrifugations were performed at 2,000 rpm, for $5 \mathrm{~min}$ in a table top eppendorf centrifuge. The beads were resuspended in $2 \mathrm{ml}$ of binding buffer, added into the soluble cell lysate and incubated on a spinning wheel in the cold room overnight. This incubation mix was centrifuged at 3,000 rpm for $5 \mathrm{~min}$ and the supernatant was frozen for SDS-PAGE analysis. The beads were washed with binding buffer twice and with wash buffer twice by centrifuging at 2,000 rpm, for 5 min each with $2 \mathrm{ml}$ of buffer. Washes were collected in separate tubes for SDS-PAGE. The proteins bound to the GSH beads were eluted by incubating the beads three times with $200 \mu$ l of elution buffer for 10 min each on a spinning wheel in the cold room. After each elution, the beads were centrifuged and the eluate was transferred to a new tube and fresh elution buffer was added to the beads and incubated for next elution. After the last elution, $10 \mu \mathrm{l}$ of beads were boiled in SDS-PAGE sample buffer and loaded on a 10\% SDS-PAGE along with cell lysate, flow-through, wash fractions and eluate fractions. The gel was stained with coomassie to visualize proteins.

\subsection{Raising polyclonal antibodies against Vti 1a}

GST-Vti1a purified by GST-affinity chromatography was used as an antigen to raise polyclonal antibody in New Zealand white rabbit. $250 \mu \mathrm{g}$ of eluate-1 of GSTVti1a was made up to $400 \mu \mathrm{l}$ with PBS and mixed with $400 \mu \mathrm{l}$ of Specol. A homogenous emulsion was prepared by vigorously mixing antigen and specol solution in a leuer lock syringes connected by a capillary tube. This emulsion was injected into the rabbit, pre-immune serum was collected before injection to use as a negative control in western blots and immunoprecipitations. $100 \mu \mathrm{g}$ of the antigen was used for further booster injections. Booster injections were given once in two weeks and bleeds were collected two weeks after booster injections and analyzed by western blot analysis. The rabbit was sacrificed two weeks after the fourth booster injection.

After each bleed the blood was incubated at room temperature for 4 hours to allow for clot formation and centrifuged at $13,000 \mathrm{~g}$ for $15 \mathrm{~min}$ at $4^{\circ} \mathrm{C}$. The supernatant was carefully transferred into new tubes, prepared small aliquots and frozen at $-20^{\circ} \mathrm{C}$ or at $-80^{\circ} \mathrm{C}$ for long term storage. 


\subsection{Purification of IgG from Vti1a polyclonal antisera}

Binding buffer TBS

Elution buffer $\quad 0.1 \mathrm{M}$ Glycine- $\mathrm{HCl} \mathrm{pH} 2.8,0.15 \mathrm{M} \mathrm{NaCl}$

Neutralization buffer $2 \mathrm{M}$ Tris base

$250 \mu \mathrm{l}$ of Protein A-sepharose beads were washed with TBS and resuspended in $250 \mu \mathrm{l}$ of $2 \times$ TBS. $500 \mu \mathrm{l}$ of rabbit polyclonal Vti1a antiserum was added onto the beads and incubated on a spinning wheel in cold room for $1 \mathrm{~h}$. This was then poured into a small spin column with a frit. The column was placed in an Eppendorf tube and the flow-through was collected by centrifuging at 2,000 rpm for $2 \mathrm{sec}$ at $4^{\circ} \mathrm{C}$. The beads were washed three times with $400 \mu \mathrm{l}$ of TBS and centrifuged as above. Each wash fraction was collected in a new tube. 5 eppendorf cups were labelled from E1 through E5 and $3 \mu$ of $2 M$ Tris base was added to each tube to collect and neutralize the eluates. The IgGs bound to the beads were eluted by adding $200 \mu \mathrm{l}$ of elution buffer and centrifugation as above. The protein concentration was estimated in each of the fractions, IgG containing eluates were pooled, and frozen as small aliquots at $-20^{\circ} \mathrm{C}$.

\subsection{Purification of IgG from VAMP4 polyclonal serum by VIVASPIN buffer-exchange and MONO-S mini columns}

Equilibration/Binding buffer $\quad 50 \mathrm{mM}$ MES-NaOH pH 6.0

$20 \mathrm{mM} \mathrm{NaCl}$

Elution buffer 1

50 mM MES-NaOH pH 6.0

$0.5 \mathrm{M} \mathrm{NaCl}$

Elution buffer 2

50 mM MES-NaOH pH 6.0

$1 \mathrm{M} \mathrm{NaCl}$

$500 \mu \mathrm{l}$ of rabbit polyclonal anti-VAMP 4 antiserum was mixed with $500 \mu \mathrm{l}$ of equilibration buffer. $500 \mu \mathrm{l}$ each of this mix was loaded onto two VIVASPIN buffer exchange columns with a molecular weight cut off of $100 \mathrm{kDa}$. The columns were centrifuged at $12,000 \mathrm{rpm}, 10 \mathrm{~min}, 4^{\circ} \mathrm{C}$. The flow-through was transferred into new tubes. $500 \mu \mathrm{l}$ of fresh equilibration buffer was added into the columns and 
centrifuged as before. This step was repeated one more time to ensure complete buffer exchange. This dialysed serum was taken out of the column $(\sim 400 \mu \mathrm{l})$ and mixed with equal volume of binding buffer. $400 \mu \mathrm{l}$ of this sample was loaded onto each of the Mono-S Vivapure Mini-H columns (2 columns were used) which were pre-equilibrated with binding buffer. The column was centrifuged at 3,000 rpm, $4^{\circ} \mathrm{C}$, for $10 \mathrm{~min}$. The flow-through was transferred into a new eppendorf tubes and the column was washed twice with $400 \mu \mathrm{l}$ binding buffer each time. The bound proteins (IgGs) were eluted first with $400 \mu$ of elution buffer 1 and then with $400 \mu \mathrm{l}$ of elution buffer 2 . The protein concentration was estimated in all fractions, aliquots were prepared and frozen at $-20^{\circ} \mathrm{C}$.

\subsubsection{TCA precipitation of proteins}

Trichloroacetic acid (TCA) solution

$100 \mathrm{~g}$ of TCA crystals was weighed and the volume was made up to $100 \mathrm{ml}$ with water

$2 \%$ Sodium acetate in ethanol

$2 \mathrm{~g}$ of Sodium was dissolved in small amount of water and volume was made up to $100 \mathrm{ml}$ with ethanol

The proteins were precipitated by adding TCA to a final concentration of $10 \%$ and incubated on ice in the cold room overnight. The precipitated samples were centrifuged at $13,000 \mathrm{rpm}, 10 \mathrm{~min}, 4^{\circ} \mathrm{C}$. The supernatant was discarded and the pellets were washed $500 \mu \mathrm{l}$ of $2 \%$ sodium acetate solution in ethanol. The samples were again centrifuged as above, supernatant was discarded and the pellets were air-dried for 10-15 min at RT. The pellets were resuspended in 1x SDS-PAGE buffer, boiled and loaded on SDS-PAGE for further analysis.

\subsubsection{Gel filtration of cytosol to obtain adaptor enriched fraction}

Gel filtration is a chromatographic technique which separates proteins based on their relative size. The general principle of exclusion chromatography is quite simple and is performed using porous beads as the chromatographic support. A column of gel particles is in equilibrium with a suitable mobile phase for the 
molecules to be separated. Large molecules that are completely excluded from the pores will pass through the interstitial spaces and will elute first. Smaller molecules will be distributed between the mobile phase inside and outside the molecular sieve and will then pass through the column at a slower rate, hence elute later. The porosity of the gel particles and the size of the molecule to be seperated determine the quality of seperation. Adaptor proteins exist as large heterotetrameric complexes in the cytosol, and hence can be separated from the small molecular weight proteins by gel filtration to obtain a cytosolic fraction enriched with adaptor proteins.

A Superdex 200 column was installed in the SMART system and the column was equilibrated overnight with cytosol buffer. The column was calibrated using the following proteins as standards:

$\begin{array}{lc}\text { Protein Concentration } & \text { Mol. Wt }(\mathrm{kDa}) \\ \text { Blue dextran }(1 \mu \mathrm{g} / \mu \mathrm{l}) & 2,000 \\ \text { Thyroglobulin }(2.5 \mu \mathrm{g} / \mu \mathrm{l}) & 669 \\ \text { Ferritin }(0.7 \mu \mathrm{g} / \mu \mathrm{l}) & 440 \\ \text { Catalase }(2 \mu \mathrm{g} / \mu \mathrm{l}) & 232 \\ \text { Aldolase }(2 \mu \mathrm{g} / \mu \mathrm{l}) & 158 \\ \text { BSA }(1 \mu \mathrm{g} / \mu \mathrm{l}) & 67 \\ \text { Lysozyme }(1 \mu \mathrm{g} / \mu \mathrm{l}) & 14.3\end{array}$

$1 \mathrm{ml}$ of the solution containing above concentration of proteins was prepared and $10 \mu \mathrm{l}$ was injected into the column. A calibration curve was generated from the elution profile of the standard proteins.

The cytosol was prepared from mouse fibroblasts as described later in (3.2.3.3) except that the cytosolic fractions were not desalted when used for gel filtration experiments. $50 \mu \mathrm{l}$ of cytosol (200-350 $\mu \mathrm{g}$ protein) was injected into the superdex 200 pre-equilibrated with cytosol buffer. Fractions were collected after void volume of the column $(20 \mathrm{~min})$ at a flow rate of $40 \mu \mathrm{l} / \mathrm{min}$ and $50 \mu \mathrm{l} /$ fraction. The 
proteins were precipitated from the fractions by TCA precipitation as described in (3.3.15) and the samples were resolved on a 10\% SDS-PAGE and analyzed by western blotting with antibodies against the adaptors of interest.

Adaptor complexes usually eluted in fractions 6-12.

\subsubsection{Indirect Immunoflorescence}

\subsection{Fixing cells by Methanol/Methanol-Acetone}

Solutions

PBS

$10 \mathrm{mM} \mathrm{Na}_{2} \mathrm{HPO}_{4}, \mathrm{pH} 7.4,150 \mathrm{mM} \mathrm{NaCl}$

PBS/Glucose $\quad 5 \mathrm{mM}$ Glucose in PBS

$\mathrm{PBS} / \mathrm{FCS} \quad 5 \%$ Fetal calf serum in PBS

Methanol Cooled by storing at $-20^{\circ} \mathrm{C}$

Acetone $\quad$ Cooled by storing at $-20^{\circ} \mathrm{C}$

DAKO Mounting medium stored at $4^{\circ} \mathrm{C}$

Cells were plated on cover slips in a 24 well plate and grown till $50-70 \%$ confluency. Cells were washed twice with PBS/Glucose which was prewarmed to $37^{\circ} \mathrm{C}$. Solutions from the wells were sucked out using a tube connected to a vacuum pump and the following solutions were immediately added onto the cells. Cells were never let to dry up. The plate was placed on ice and incubated with cold PBS for $5 \mathrm{~min}$. The cells were fixed with methanol from $-20^{\circ} \mathrm{C}$ for 5 minutes or alternatively, fixed with cold methanol for 3 minutes followed with cold acetone for $30 \mathrm{sec}$. After fixation cells were washed twice with PBS/Glucose and twice with PBS at room temperature. Non-specific binding was blocked by incubating cells for $3 \times 5$ min with PBS/FCS. During this incubation, the primary antibody was diluted 1:100 in PBS/FCS. About $30-40 \mu$ of the antibody solution was added on to each cover slip and incubated for 45 - $60 \mathrm{~min}$. Care was taken not to disturb the plate during incubation with the antibodies. After incubation with the primary antibody cells were again washed $3 \times 5$ min with PBS/FCS and 30-40 $\mu$ l of 1:100 diluted (in PBS/FCS) FITC or Texas Red conjugated secondary antibody was added. The plate was covered with an aluminum foil and incubated for 45 60 min. After this incubation, cells were washed $3 \times 5$ min with PBS/FCS and $3 \times$ 
5 min with double distilled water. Meanwhile, clean glass slides were labelled and a drop of DAKO solution was added and kept aside. The cover slip was carefully taken out of the wells using syringe and a forceps, excess water was absorbed by gently touching it to a tissue paper and was placed on DAKO solution on the glass slide with the cell side facing the solution. These glass slides were incubated overnight at room temperature in dark. Next day, the border of the cover-slip was sealed with a nail-polish and after few minutes the cells were observed under fluorescence microscope. Slides were stored at $4^{\circ} \mathrm{C}$ for further analysis.

\subsection{Fixing cells by paraformaldehyde (PFA)}

Solutions

PBS $10 \mathrm{mM} \mathrm{Na}_{2} \mathrm{HPO}_{4}, \mathrm{pH} 7.4,150 \mathrm{mM} \mathrm{NaCl}$

PBS/PFA $3 \%$ paraformaldehyde in PBS

The desired amount of PFA was weighed and a small amount of PBS was added, heated to $60^{\circ} \mathrm{C}$ on a heating block with constant mixing and after 10 min, 1-2 drops of $1 \mathrm{~N}$ $\mathrm{NaOH}$ was added, solution gets cleared immediately and the volume was made up to the desired amount with PBS and the $\mathrm{pH}$ was adjusted to 7.4 with $\mathrm{HCl}$.

$\mathrm{PBS} / \mathrm{NH}_{4} \mathrm{Cl} \quad 50 \mathrm{mM} \mathrm{NH}_{4} \mathrm{Cl}$ in PBS

PBS/Saponin $\quad 0.5 \%$ saponin in PBS

DAKO Mounting medium stored at $4^{\circ} \mathrm{C}$

Cells were grown on sterile cover slips in a 24 well plate to $50-70 \%$ confluency, washed twice with PBS (pre-warmed at $37^{\circ} \mathrm{C}$ ) and fixed with $3 \%$ PFA for 30 min at room temperature. The fixed cells were washed twice with PBS (RT) and incubated with $50 \mathrm{mM} \mathrm{NH}_{4} \mathrm{Cl}$ in PBS for $10 \mathrm{~min}$ at room temperature to block non-specific interactions and washed twice with PBS. Cells were permeabilized with $0.5 \%$ Saponin in PBS for $3 \times 5$ min. Primary antibody was diluted 1:100 in Saponin/PBS solution and about 30-40 $\mu \mathrm{l}$ was added on each cover slip and incubated at RT for 45 - 60 minutes. Cells were washed again with saponin/PBS 
$3 \times 5 \mathrm{~min}$ and $30-40 \mu \mathrm{l}$ of $1: 100$ diluted FITC or Texas-Red conjugated antibodies were added and incubated at RT for 45 - 60 minutes. Cells were washed $3 \times 5$ min with Saponin/PBS and 3 times with double distilled water. Cells were analyzed as described in (3.2.2.5.1).

\subsubsection{Transferrin endocytosis}

Transferrin is endocytosed from the medium by the transferrin receptor at the plasma membrane. The internalized transferrin is then delivered to the intracellular compartments and the transferrin receptor recycles back to the plasma membrane for further rounds of sorting. The kinetics of transferrin endocytosis and recycling has been well characterized and hence they are widely used as markers of the early and recycling endosomes.

Control cells overexpressing the sulfatable MPR-46 were grown on coverslips to $50-60 \%$ confluency. Medium containing $10 \mu \mathrm{g} / \mathrm{ml}$ cycloheximide was added to the cells and incubated for one hour at $37^{\circ} \mathrm{C}$ in the incubator. The medium was replaced by a serum free medium containing $0.5 \%$ BSA (ultra pure), and $10 \mu \mathrm{g} / \mathrm{ml}$ cycloheximide and incubated for further one hour. $0.1 \mu \mathrm{M}$ of Cy3 conjugated mouse transferrin was added to the wells and mixed with a pipette for uniform concentration of transferrin in the medium and continued incubation at $37^{\circ} \mathrm{C}$ for $10 \mathrm{~min}$. This is the time required for the endocytosed transferrin to reach early endosomes. The cells were immediately shifted onto the ice and processed for immunoflorescence by PFA fixation as described in (3.2.2.5.2). The coverslips were incubated with polyclonal anti-MPR46 primary antibodies and FITCconjugated anti-rabbit secondary antibodies.

\subsubsection{Metabolic labeling of cells with [35S]-Methionine/Cysteine}

Solutions

dFCS

heat inactivated and dialyzed fetal calf serum

Starvation medium

DMEM without Methionine /Cysteine with $5 \%$ dFCS, $20 \mathrm{mM}$ Hepes- $\mathrm{NaOH}$ pH 7.4, 2 mM Glutamine

35S-Methionine/Cysteine $10 \mu \mathrm{Ci} / \mu \mathrm{l}$ 
Methionine/Cysteine $\quad 10 \mathrm{mg} / \mathrm{ml}$ in $\mathrm{ddH}_{2} \mathrm{O}$, sterile filtered

Labelling of starved cells with radioactive methionine and cysteine leads to the incorporation of these amino acids into newly synthesized proteins and helps in the detection of the protein of our interest. Cells were grown in normal DMEM medium till 70 - 80\% confluency. Before labeling, the cells were washed with PBS once or twice and incubated with starvation medium for one hour. The cells were again washed once with PBS and incubated with labeling medium (starvation medium containing nomally $100 \mu \mathrm{Ci} / \mathrm{ml}$ of 35S-Methionine/Cysteine) for required time periods. In pulse-chase experiments, after pulse period, the cells were chased by adding cold methionine and cysteine to the dishes in the dilution of 1:100. The labeled cells were processed as per the protocol for the desired experiments.

\subsubsection{Immunoprecipitation}

Solutions

Working concentration

Protease Inhibitors

(Stock solutions)

$500 \mathrm{mM}$ in water, $\mathrm{pH} 8.0$

$1 \mathrm{mM}$ EDTA

$200 \mathrm{mM}$ in DMSO

$1 \mathrm{mM}$ PMSF

$500 \mathrm{mM}$ in water

5 mM IAA

TBS

10 mM Tris- $\mathrm{Cl}, \mathrm{pH} 7.4$

$150 \mathrm{mM} \mathrm{NaCl}$

Lysis Buffer (for cathepsin-D)

$0.1 \%$ Triton-X-100 in TBS

with protease inhibitors

HP

0.1 M Sodium acetate $\mathrm{pH} 6.0$

0.2 M Sodium chloride

Protease inhibitors

TIN

$0.5 \%$ Triton-X-100

$50 \mathrm{mM}$ Imidazole $\mathrm{pH} 7.0$

$150 \mathrm{mM} \mathrm{NaCl} \&$ protease inhibitors 
Protamine sulfate

Immunomix (IMM)

Precipitation immunomix

(PIM)

Neufeld buffer

$2 \mathrm{M} \mathrm{KCl-IMM}$

$0.1 \times$ PBS

PANSORBIN

Washed PANSORBIN

Protein-A sepharose
$3 \% \mathrm{w} / \mathrm{v}$ in water (freshly prepared)

1\% Triton $\mathrm{X}-100$

$0.5 \%$ sodium deoxycholate

10 mM Sodium phosphate buffer, pH 7.4

0.15 M Sodium chloride

$10 \%$ BSA and $0.2 \%$ SDS in Immunomix with

protease inhibitors

10 mM Tris- $\mathrm{Cl}, \mathrm{pH} 8.5$

0.6 M Sodium chloride

$0.1 \%$ SDS

$0.05 \%$ NP- 40

$2 \mathrm{M} \mathrm{KCl}$ in IMM

1:10 diluted PBS

$1 \mathrm{mM}$ Sodium phosphate buffer, $\mathrm{pH} 7.4$

$15 \mathrm{mM} \mathrm{NaCl}$

Heat killed and inactivated Staphylococcus aureus cell suspension in PBS

Staphylococcus aureus Cells washed according to the protocol of (Lemansky et al., 1985).

Washed three times with water and three times with TBS and stored at $4{ }^{\circ} \mathrm{C}$ as a $50 \%$ solution

\subsection{Immunoprecipitation of Cathepsin-D}

Soluble lysosomal enzymes like cathepsin-D are delivered to lysosomes by MPRs, which bind to the mannose-6-phosphate residues on the enzymes at the trans-Golgi network and sort them to the lysosomes via endosomal compartments. Impairing the function or steady-state distribution of MPRs leads to defect in processing and sorting of lysosomal enzymes. The precursor form of lysosomal enzymes are missorted to the extracellular medium under such 
circumstances and studying this sorting is a direct functional analysis of MPRs at the TGN.

In order to study the sorting of lysosomal enzymes in different mouse fibroblasts the cells were metabolically labeled with 35S-Methionine/Cysteine. As metabolism of glutamine also induces secretion of lysosomal enzymes into the medium, glutamine was freshly added to the medium. Cells were grown in normal DMEM medium to $70-80 \%$ confluency. Before labeling, the cells were washed with PBS once or twice and incubated with starvation medium for one hour. The cells were again washed once with PBS and incubated with labeling medium containing 100 $\mu \mathrm{Ci} / \mathrm{ml}$ of $35 \mathrm{~S}-M e t h i o n i n e / C y s t e i n e$ for one hour. After this pulse period, the newly synthesised radioactive proteins in the cells were chased by adding cold methionine and cysteine to the dishes at a dilution of 1:100. After a four hour chase period, the dishes were kept on ice, the medium was collected into eppendorf tubes and centrifuged for $2 \mathrm{~min}$ at $13,000 \mathrm{rpm}, 4^{\circ} \mathrm{C}$. The supernatant was collected into new tubes. The cells in the dishes were washed with cold PBS twice (one $\mathrm{ml}$ each) and scraped with $400 \mu \mathrm{l}(200 \mu \mathrm{l} \times 2)$ of lysis buffer. Both medium and cells were either frozen at $-20^{\circ} \mathrm{C}$ at this step or were processed immediately as follows. Cells were sonicated three times for 10 s each and centrifuged for $2 \mathrm{~min}$ at $13,000 \mathrm{rpm}$, at $4^{\circ} \mathrm{C}$. The supernatant was transferred into new tubes. To these cell lysates, 0.8 volume of pre-immune mix and $1 / 100$ volume of $3 \%$ protamine sulfate (freshly prepared) was added and incubated on ice for $10 \mathrm{~min}$. This step precipitates histones which are in turn bound to genomic DNA and hence reduces contaminants in immunoprecipitates. The samples were centrifuged for $10 \mathrm{~min}$ at $13,000 \mathrm{rpm}, 4^{\circ} \mathrm{C}$ to remove the precipitated DNA. The supernatant were transferred to new tubes. 0.8 volume of pre-immunemix was added to the tubes containing medium. $3 \mu$ of rabbit pre-immune serum and $60 \mu \mathrm{l}$ of unwashed Pansorbin were added to all the samples and incubated on a spinning wheel in cold room for 5-6 hours to block binding of non-specific proteins. After this pre-clearing, samples were centrifuged for $30 \mathrm{~min}$ at 13,000 $\mathrm{rpm}, 4^{\circ} \mathrm{C}$. The supernatant was carefully transferred to new tubes, $3 \mu \mathrm{l}$ of rabbit anti-mouse cathepsin-D antibody was added to each tube and incubated on 
spinning wheel in cold room overnight for the formation of specific antigenantibody complexes. $60 \mu \mathrm{l}$ of washed Pansorbin or $40 \mu \mathrm{l}$ of washed Protein-G agarose (50\% solution in TBS) was added and the incubation was continued for another one hour. The samples were centrifuged for $2 \mathrm{~min}$ at $13,000 \mathrm{rpm}, 4^{\circ} \mathrm{C}$. Supernatants were collected in fresh tubes and were frozen at $-20^{\circ} \mathrm{C}$. The pellets were washed once with each of the following buffers:

\section{Neufeldbuffer \\ 2.Wash-immunomix \\ 3.Wash-immunomix containing $2 \mathrm{M} \mathrm{KCl}$ \\ 4.1/10 PBS}

$800 \mu \mathrm{l}$ of each of the above buffers (chilled on ice) was added to the pellets, resuspended in a resuspender (when Pansorbin was used) or vortexed on a vortex mixer (when Protein-G agarose was used) and centrifuged at 13,000 rpm for $2 \mathrm{~min}, 4^{\circ} \mathrm{C}$. After last wash, the supernatant was completely removed and 60 $\mu \mathrm{l}$ of $1 \mathrm{x}$ Laemmli buffer without DTT was added and boiled for $5 \mathrm{~min}$ at $95^{\circ} \mathrm{C}$, incubated on ice for few seconds and centrifuged for 2 min at 13,000 rpm, 2 min. The supernatant was loaded in a 10\% SDS-PAGE and the gel was run at 40-50 $\mathrm{mA}$ for about 3 - 4 hours (3.2.2.1.3). The gel was fixed in destaining solution for $20 \mathrm{~min}$, washed with water twice, for 5 min each, and dried in a BioRad gel drier and exposed onto the phosphoimager screen. The screen was scanned after two days of exposure and bands of interest were quantitated using Image Gauge software.

\subsection{Immunoprecipitation of MPR46}

Cells were metabolically labeled overnight as described earlier (3.2.2.7). After labeling, cells were washed twice with cold PBS, scraped into tubes in $1 \mathrm{ml}$ PBS $(500 \mu \mathrm{l} \times 2)$ and centrifuged for $5 \mathrm{~min}$ at $3,000 \mathrm{rpm}, 4^{\circ} \mathrm{C}$. The supernatant was discarded, the pellet was resuspended in HP buffer containing protease inhibitors and sonicated $3 \times 10$ s. After sonication the samples were incubated on vibrax for $10 \mathrm{~min}$ in cold room. This step dissociates ligands from the receptors and hence all the receptors will be available for binding to antibodies. The samples were centrifuged for $10 \mathrm{~min}$ at $13,000 \mathrm{rpm}, 4^{\circ} \mathrm{C}$. The supernatant is cytosol and was 
discarded. $400 \mu$ of TIN buffer was added to the pellets, sonicated $3 \times 10$ s and incubated on vibrax in cold room for $20 \mathrm{~min}$ to solubilise all membrane proteins. After solublilisation, the samples were centrifuged at $13,000 \mathrm{rpm}, 20 \mathrm{~min}, 4^{\circ} \mathrm{C}$. The supernatant was transferred to a new tube and the insoluble pellet was discarded. To the supernatants, 0.8 volume of PIM, $3 \mu$ l of rabbit pre-immune serum and $50 \mu \mathrm{l}$ of unwashed Pansorbin were added and incubated on a spinning wheel in cold room for 2 hours. After this pre-clearing of non-specifically interacting proteins, the samples were centrifuged at $13,000 \mathrm{rpm}, 10 \mathrm{~min}, 4^{\circ} \mathrm{C}$. Supernatant was carefully transferred to a new tube. $3 \mu \mathrm{l}$ of rabbit anti-MPR46 antibody was added to the samples and incubated in the cold room on the spinning wheel overnight. $20 \mu$ l of washed Protein-A sepharose beads were added ( $40 \mu$ l of $1: 1$ solution in TBS) and continued incubation for two hours in the cold room on a spinning wheel. The antigen-antibody complexes bound to the beads were pelleted at $3,000 \mathrm{rpm}, 2 \mathrm{~min}, 4^{\circ} \mathrm{C}$. Supernatant was discarded and the beads were washed with Neufeldbuffer, IMM, IMM containing $2 \mathrm{M} \mathrm{KCl}$, and 1/10 PBS. Washes were performed at 5,000 rpm, $4^{\circ} \mathrm{C}$ for $2 \mathrm{~min}$. After last wash, the supernatant was completely removed and $60 \mu \mathrm{l}$ of $1 \mathrm{x}$ Laemmli buffer with DTT was added and boiled for $5 \mathrm{~min}$ at $95^{\circ} \mathrm{C}$, incubated on ice for few seconds and centrifuged for $2 \mathrm{~min}$ at 13,000 rpm, $2 \mathrm{~min}$. The proteins were resolved on a $12.5 \%$ SDS-PAGE (Minigels) at 100-125 V for about 2 hours (3.2.2.1.3). The gel was fixed in destaining solution for $20 \mathrm{~min}$, washed with water twice, 5 min each, dried in a BioRad gel drier and exposed onto a phosphoimager screen. The bands were visualized by autoradiography.

\subsubsection{Preparation of membrane and cytosol fractions for western blot analysis}

Buffer-A

TBS containing protease inhibitors

1 mM EDTA

$1 \mathrm{mM}$ PMSF

5 mM IAA

Buffer-B Buffer A containing $0.1 \%$ Triton X-100 
Cells were grown to confluency in a $3 \mathrm{~cm}$ or $6 \mathrm{~cm}$ dish in normal medium. They were washed twice with cold PBS and scraped in lysis buffer A, sonicated $3 \times 10 \mathrm{~s}$ and centrifuged at $3,000 \mathrm{rpm}, 5 \mathrm{~min}$. The pellet was discarded and the supernatant was centrifuged at $100,000 \mathrm{~g}$ (45,000 rpm;TLA-45 rotor), $1 \mathrm{~h}, 4^{\circ} \mathrm{C}$. Supernatant was the cytosol and the pellet was the membrane fraction. For analysis of the membrane proteins, the pellet was resuspended in Buffer B (1-2 pellet volume), sonicated $3 \times 10$ s and kept on vibrax for 30 min in cold room for solubilization of membrane proteins. The sample was centrifuged and the soluble membrane fraction was transferred to a new tube and the insoluble pellet fraction was discarded. Protein concentration was estimated and $100 \mu \mathrm{g}$ of protein was loaded per lane on a SDS-PAGE (3.2.2.1.3).

\subsubsection{In vitro MPR retrograde transport assay}

\subsubsection{Synthesis and purification of ${ }^{35} \mathrm{~S}-\mathrm{Ph}$-sphoadenosine phosphosulfate (PAPS)}

\subsection{Preparation of Yeast extract}

Phosphate buffered saline (PBS)

$2 \mathrm{M}$ di-potassium hydrogen phosphate

1 M Acetic acid

Sodium Chloride

$2 \mathrm{M}$ Tris (free base)

Yeast extract is a very rich source of the enzymes, ATP sulfurylase and APS kinase, which are required for the synthesis of PAPS. Baker's yeast was bought from a local bakery. 420 grams of yeast cells were frozen in 1.6 liters of liquid nitrogen and kept in cold room for $10 \mathrm{~min}$. This frozen pellet was washed with 2 liters of PBS and centrifuged at $9,000 \mathrm{rpm}$ with a JA10 rotor for $10 \mathrm{~min}$ at $4^{\circ} \mathrm{C}$. Supernatant was discarded and the pellet was resuspended in $500 \mathrm{ml}$ of $50 \mathrm{mM}$ di-potassium hydrogen phosphate and kept overnight (approximately $16 \mathrm{~h}$ ) stirring in cold room. This cell suspension was then centrifuged at 9,000 rpm, $15 \mathrm{~min}, 4^{\circ} \mathrm{C}$ (JA 10 rotor). The pellet was discarded, the supernatant was transferred to a new bottle and $\mathrm{pH}$ was set to 5.0 with $1 \mathrm{M}$ acetic acid. The 
sample was centrifuged at $9,000 \mathrm{rpm}, 10 \mathrm{~min}, 4^{\circ} \mathrm{C}$. The supernatant was collected in a clean beaker and $128 \mathrm{~g}$ of sodium chloride was slowly added while stirring in cold room and after all the sodium chloride was dissolved, the solution was left stirring in the cold room overnight for precipitation of all proteins. Next day, the turbid solution was centrifuged at $9,000 \mathrm{rpm}, 10 \mathrm{~min}, 4^{\circ} \mathrm{C}$ to pellet the precipitate. The pellet was kept on ice and the supernatant was re-centrifuged as above. The supernatant was discarded and both the pellets were pooled by resuspending in $15 \mathrm{ml}$ of $20 \mathrm{mM}$ Tris (free base), The $\mathrm{pH}$ of the solution at this stage was around 6.5. About 3 - 4 drops of $2 \mathrm{M}$ Tris (free base) was added to get a final $\mathrm{pH}$ of 7.0. Protein concentration was estimated, (it was around $7.5 \mathrm{mg} / \mathrm{ml}$ ), the extracts were aliquoted $\left(500 \mu \mathrm{l}\right.$ each) and froze at $-80^{\circ} \mathrm{C}$. This extract had enzyme activity even after 2 years of storage.

\subsection{Synthesis of ${ }^{35} \mathrm{~S}$-PAPS}

${ }^{35} \mathrm{~S}-\mathrm{PAPS}$ is synthesized by a two step reaction as follows.

${ }^{35} S^{*}$-sulfate + ATP

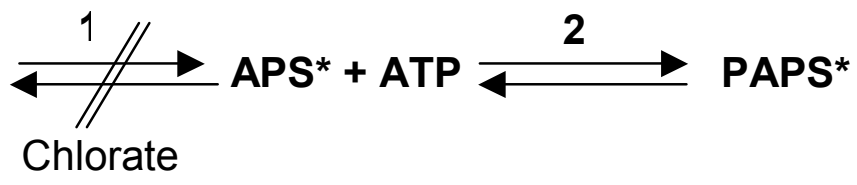

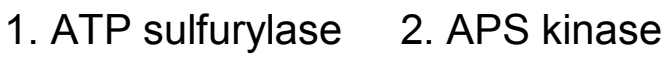

${ }^{35}$ S-sulfate was incubated with ATP and yeast extract as a source of the enzymes ATP sulfurylase and APS kinase required for the synthesis of the PAPS. In the first step of the reaction ATP combines with sulfate to form adenosine phosphosulfate (APS), a reaction is catalyzed by the enzyme ATP sulfurylase. Chlorate acts as a reversible inhibitor of this reaction. In the second step of the reaction, APS combines with excess of ATP present in the reaction to yield phosphoadenosine phosphosulfate (PAPS), this reaction is catalyzed by the enzyme APS kinase. 
A typical PAPS synthesis reaction was as follows:

$60 \mu \mathrm{l}$ of $1 \mathrm{M}$ Tris- $\mathrm{Cl} \mathrm{pH} 8.5$

$120 \mu$ of 200 mM ATP pH 7.0 (set with $\mathrm{NaOH}$ )

$16 \mu$ of $1 \mathrm{M} \mathrm{MgCl}_{2}$

$270 \mu \mathrm{l}$ of yeast extract

$1-1.5 \mathrm{mCi}$ of ${ }^{35} \mathrm{~S}$-sulfate

Volume made up to $500 \mu \mathrm{l}$ with water.

This reaction mix was incubated for $4 \frac{1}{2}$ hours at $37^{\circ} \mathrm{C}$ and after this incubation, $40 \mu \mathrm{l}$ of $200 \mathrm{mM}$ ATP was added to drive the reaction to completion. The samples were incubated for another $1 \frac{1}{2} \mathrm{~h}$ after adding ATP. During this incubation, a TLC sheet (Polyethyleneimine-cellulose F) was cut to appropriate size, rinsed with double distilled water and air-dried. A straight line was drawn about $0.5 \mathrm{~cm}$ above the edge of the sheet to mark as starting point of the sample. After incubation, about $0.5 \mu \mathrm{l}$ of the reaction mix was spotted on this line, the spot was air-dried and the sheet was placed in TLC chamber containing $0.9 \mathrm{M}$ Lithium chloride for resolution. After the solvent was run about $3 / 4$ th of the length of the TLC sheet it was taken out, air-dried, wrapped in a polythene sheet and exposed onto a phosphoimager screen. The reaction mixes were frozen at $-20^{\circ} \mathrm{C}$ till the result of autoradiography was obtained.

\subsection{Purification of ${ }^{35} \mathrm{~S}$-PAPS}

Solutions

Column matrix

DEAE-Sephacel

Equilibration buffer

$14 \mathrm{mM} \mathrm{NH}_{4} \mathrm{HCO}_{3}$

Gradient

$14-700 \mathrm{mM} \mathrm{NH}_{4} \mathrm{HCO}_{3}$

Wash buffer

$2 \mathrm{M}$ Ammonium bicarbonate

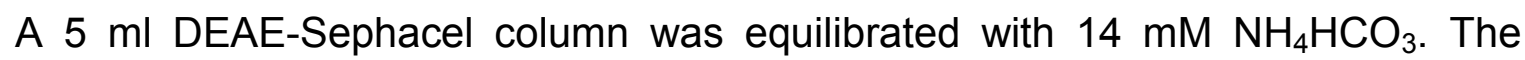
frozen PAPS reaction mixes were thawed and boiled for 2 min at $95^{\circ} \mathrm{C}$, cooled on ice for few seconds and centrifuged at $13,000 \mathrm{rpm}, 15 \mathrm{~min}, 4^{\circ} \mathrm{C}$. The supernatant was transferred to a new tube and the volume was made up to $2 \mathrm{ml}$ with water. This was loaded onto the column and the sample was allowed to enter 
completely into the column. Two column volumes of equilibration buffer was passed through the column and free sulfate and PAPS were separated by running a gradient of $14 \mathrm{mM}$ to $700 \mathrm{mM} \mathrm{NH}_{4} \mathrm{HCO}_{3}$ through the column. Fractions of $2 \mathrm{ml}$ were collected and $2 \mu \mathrm{l}$ of each fraction was counted in $1 \mathrm{ml}$ scintillation cocktail in a scintillation counter. Free sulfate eluted in fractions 12-18 and PAPS eluted in fractions 34-42. These fractions were pooled separately, frozen in liquid nitrogen and lyophilized overnight. The samples were repeatedly lyophilized (twice) by adding about $5 \mathrm{ml}$ of water to dissolve the lyophilized PAPS, and to get rid of ammonium salt as far as possible. After lyophilizing, the samples were dissolved in water and aliquots of $100 \mu \mathrm{l}$ containing $0.5 \mu \mathrm{Ci} / \mu \mathrm{l}$ were prepared. A tiny amount was spotted on TLC to estimate the amount of PAPS after lyophilization. The aliquots were frozen in dry ice and stored at $-80^{\circ} \mathrm{C}$.

The column was washed with 2 column volumes of $2 \mathrm{M} \mathrm{NH}_{4} \mathrm{HCO}_{3}$ to elute any radioactivity that is associated with the column. The column was equilibrated with $14 \mathrm{mM} \mathrm{NH}_{4} \mathrm{HCO}_{3}$ and stored at $4^{\circ} \mathrm{C}$.

\subsubsection{Preparation of semi-intact cell membranes for in vitro transport assay}

Solutions

KHM Buffer

$25 \mathrm{mM}$ Hepes-KOH, pH 7.4

$125 \mathrm{mM}$ Potassium acetate

$2.5 \mathrm{mM}$ Magnesium acetate

$1 \mathrm{mM}$ DTT

RB Buffer (10x)

$250 \mathrm{mM}$ Hepes-KOH, pH 7.2

$15 \mathrm{mM}$ Magnesium acetate

$250 \mathrm{mM} \mathrm{KCl}$

ATP Regeneration system 10 mM ATP, pH 7.0 (adjusted with $\mathrm{NaOH}$ )

$150 \mathrm{mM}$ Phosphocreatine

$210 \mathrm{U} / \mathrm{ml}$ Creatine phosphokinase

$0.4 \mathrm{mg} / \mathrm{ml}$ Aprotinin

$0.1 \mathrm{mg} / \mathrm{ml}$ Leupeptin 
$10 \mu \mathrm{M}$ Pepstatin-A

$20 \mathrm{mM} \mathrm{MgCl}_{2}$

2 M Sodium chlorate

10 mM PAPS (non-radioactive)

Sucrose

SEAT Buffer

Cycloheximide
$0.5 \mathrm{M}, 0.75 \mathrm{M}$ and $1 \mathrm{M}$ solutions

$10 \mathrm{mM}$ Triethanolamine

10 mM Acetic acid

1 mM EDTA

\subsection{Sucrose}

$\mathrm{pH}$ adjusted to 7.4 with $\mathrm{NaOH}$

Stock: $10 \mathrm{mg} / \mathrm{ml}$ in ethanol

Final concentration used: $10 \mu \mathrm{g} / \mathrm{ml}$

Wild type or $\mu 1 \mathrm{~A}$-deficient fibroblasts, overexpressing murine MPR 46 cDNA which was modified so as to contain a consensus sequence for tyrosine sulfation, were grown in sulfate-free medium containing $7.5 \%$ fetal calf serum and $20 \mathrm{mM}$ sodium chlorate. Cells were grown in $10 \mathrm{~cm}$ dishes $(4-6)$ to $90 \%$ confluency and were treated with $10 \mu \mathrm{g} / \mathrm{ml}$ cycloheximide for two hours before membrane preparation. Cycloheximide blocks protein synthesis and by this we deplete the biosynthetic pathway for any newly synthesized MPR46. All receptors that enter the TGN are presumably of endosomal origin in our in vitro assay. After cycloheximide treatment, the cells were placed on ice and washed once with cold KHM buffer, the buffer was completely drained out of the plates and they were placed on a metal plate cooled on dry ice. The plates were left on the metal plate for 30s after the cells froze and thawed at room temperature for $4 \mathrm{~min}$. The dishes were returned on ice and washed twice with KHM buffer to wash off all cytosol that would have leaked out of the cell due to lysis of the cells by freeze thawing. The buffer was completely drained out of the plate by placing the dish in a slanting position on ice for about a minute and sucking off all buffer that got collected. The cells were scraped from the dishes in $250 \mu$ of SEAT buffer using a cell scraper. A pre-incubation was set up as follows (given volumes are for cells from one $10 \mathrm{~cm} \Phi$ dish): 
Semi intact cells $\quad 250-300 \mu l$

Buffer RB (10 x) $80 \mu l$

$10 \times$ ATP mix $\quad 120 \mu l$

$2 \mathrm{M} \mathrm{NaClO}_{3} \quad 14 \mu \mathrm{l}$

$10 \mathrm{mM}$ PAPS $\quad 2.5 \mu \mathrm{l}$

0.75 M Sucrose $\quad 260 \mu l$

Volume was made up to $1 \mathrm{ml}$ with water.

This pre-incubation mix was incubated at $37^{\circ} \mathrm{C}$ on a heating block for $15 \mathrm{~min}$. This step serves to label all the TGN resident sulfatable MPRs with cold PAPS to get rid of the background labeling in the assay. During this incubation, a sucrose cushion was prepared as follows:

$20 \mu \mathrm{l}$ of $1 \mathrm{M}$ sucrose was added into an eppendorf tube and shock frozen on dry ice, $40 \mu \mathrm{l}$ of $0.5 \mathrm{M}$ sucrose was added on top of this and again frozen on dry ice. After the pre-incubation, the reaction mix was overlaid on sucrose cushion and the cushion was thawed on ice for $5 \mathrm{~min}$. Sample was centrifuged at 13,000 rpm for $7 \mathrm{~min}$ at $4^{\circ} \mathrm{C}$. The supernatant was removed down leaving about $100 \mu \mathrm{l}$ in the tube. The membranes were resuspended in this $100 \mu$ l using a cut yellow tip and the protein concentration was determined. Membrane concentration was usually between $3-5 \mu \mathrm{g} / \mu \mathrm{l}$. Suitable aliquots were made and frozen at $-80^{\circ} \mathrm{C}$.

\subsubsection{Preparation of cytosol for the in vitro assay}

Solutions

Cytosol Buffer

25 mM Hepes/KOH pH 7.6

$50 \mathrm{mM} \mathrm{KCl}$

$1 \mathrm{mM} \mathrm{MgCl} 2$

$0.5 \mathrm{mM}$ EDTA

Protease inhibitors (1x) $40 \mu \mathrm{g} / \mathrm{ml}$ Aprotinin

$10 \mu \mathrm{g} / \mathrm{ml}$ Leupeptin

$1 \mu \mathrm{M}$ Pepstatin-A

$2 \mathrm{M} \mathrm{KCl}$ 
Cytosol was always prepared fresh for the assay. Cells were usually grown in $4 \mathrm{x}$ $15 \mathrm{~cm} \varnothing$ dishes to confluency, washed three times with cytosol buffer on ice and buffer was drained completely. The cells were scraped using cell scraper into an eppendorf tube and immediately supplemented with protease inhibitors and resuspended. The cells were lysed by passing the suspension 10 times slowly through a $23 \mathrm{G}$ needle fixed to a $1 \mathrm{ml}$ syringe. The lysed cells were centrifuged at $3,000 \mathrm{rpm}$, for $5 \mathrm{~min}$, at $4^{\circ} \mathrm{C}$, the pellet was discarded and the supernatant was centrifuged at $13,000 \mathrm{rpm}$, for $10 \mathrm{~min}$, at $4^{\circ} \mathrm{C}$. The supernatant from this centrifugation was taken for ultracentrifugation at 45,000 rpm $(100,000 \mathrm{~g}$, TLA-45 rotor) for $1 \mathrm{~h}$ at $4^{\circ} \mathrm{C}$. During this centrifugation, a $5 \mathrm{ml}$ Bio-Gel P6 DG polyacrylamide Gel column was equilibrated with 2 column volumes of cytosol buffer (sterile filtered). The 100,000 g supernatant was loaded directly onto the column bed. The cytosol buffer was added onto the column immediately after the sample had entered completely into the column and five fractions of $1 \mathrm{ml}$ each were collected and protein was estimated from each fraction. Almost all of the desalted cytosol was usually present in the third fraction. The protein concentration was usually 3-5 $\mathrm{mg}$ per $\mathrm{ml}$. To this fraction, protease inhibitors and $0.5 \mathrm{mM}$ ATP was added and used in the assay at a final concentration of $1 \mathrm{mg} / \mathrm{ml}$ unless otherwise indicated.

The column was completely eluted of any proteins by adding two column volumes of $2 \mathrm{M} \mathrm{KCl}$ and washed with two column volumes of cytosol buffer. The column was equilibrated with fresh cytosol buffer before loading cytosol again for desalting.

\subsubsection{In vitro Endosome-to-TGN transport assay}

The in vitro transport assay makes use of the activity of the TGN resident enzyme tyrosine sulfotransferase. This enzyme adds sulfate groups on the tyrosine residues in the proteins that enter TGN which contain a consensus sequence for tyrosine sulfation.

Murine MPR 46 was modified so as to contain a consensus sequence for tyrosine sulfation. Cells were stably transfected with this receptor and membranes were prepared after growing cells in a sulfate-free medium in presence of sodium 
chlorate to inhibit in vivo sulfation. Cycloheximide treatment just before membrane preparation ensures that there is no contribution of receptors from the biosynthetic pathway and also the resident TGN receptors are chased to endosomes. In order to further reduce the background due to the sulfation of any resident TGN receptors, the membranes are pre-treated with non-radioactive PAPS to label all the resident TGN receptors with non-radioactive sulfate.

In a typical assay, membranes (or semi-intact cells) were incubated with cytosol, an ATP-regenerating system and ${ }^{35}$ S-PAPS which is a substrate for sulfation, for 2 hours at $37^{\circ} \mathrm{C}$. The assay reactions were set up was follows (given are the volumes for one assay reaction $=150 \mu \mathrm{l}$ )

A) Membrane mix

$10 \times$ RB buffer $\quad 8 \mu \mathrm{l}$

$10 \times$ ATP mix $12 \mu \mathrm{l}$

$2 \mathrm{M} \mathrm{NaClO}_{3} \quad 1.4 \mu \mathrm{l}$

${ }^{35}$ S-PAPS $(0.5 \mu \mathrm{Ci} / \mu \mathrm{l}) \quad 10 \mu \mathrm{l}$ (final $\left.5 \mu \mathrm{Ci}\right)$

SEAT buffer $\quad 14 \mu \mathrm{l}$

Membranes $25 \mu \mathrm{g}$

B) Cytosol mix

Cytosol $\quad$ x $\mu \mathrm{l}$ ( Final concentration $1 \mathrm{mg} / \mathrm{ml}$ )

Cytosol buffer $\quad 50-\mathbf{x} \mu \mathrm{l}$

$\mathrm{H}_{2} \mathrm{O} \quad \mathrm{A}+\mathrm{B}-150 \mu \mathrm{l}$

After calculating the volume of cytosol and membrane mixes the amount of water required to make up the volume to $150 \mu \mathrm{l}$ was added to the eppendorf tubes, followed by the cytosol mix. Membrane mix without membranes was prepared. A frozen aliquot of membrane was thawed at $37^{\circ} \mathrm{C}$ quickly, added to the membrane mix cocktail, resuspended to get a homogeneous solution and this was then added to the reaction tubes containing water and cytosol mix. Before starting the incubation at $37^{\circ} \mathrm{C}$ the reaction mixes were mixed with the yellow tips using a 200 $\mu l$ pipette. The reaction tubes were shifted to a $37^{\circ} \mathrm{C}$ heating block and incubated 
for 2 hours unless indicated otherwise. The reactions were always set up in duplicates.

After incubation the reaction tubes were shifted back on ice, $50 \mu \mathrm{l}$ of water and $200 \mu$ of $2 x$ TIN buffer was added and the MPR46 was immunoprecipitated as described (3.2.2.8.2). except that the beads were washed once with IMM, $\mathrm{IMM}+2 \mathrm{M} \mathrm{KCl}$ and twice with 1/10 PBS. Finally the samples were boiled in buffer containing DTT. Samples were resolved on a $12.5 \%$ SDS-PAGE, fixed in destain solution for $20 \mathrm{~min}$ and dried. Dried gels were exposed onto phosphoimager screens and scanned after 6-7 days of exposure.

\subsection{Assay to verify the intactness of compartments during in vitro reaction}

Solutions

Trypsin (from bovine pancreas)

$5 \mathrm{mg} / \mathrm{ml}$ dissolved in water

Trypsin inhibitor

$5 \mathrm{mg} / \mathrm{ml}$ in cytosol buffer

(type II-O, chicken egg white)

In order to verify if the transport reaction is indeed vesicle-mediated and if the sulfation is a compartment specific activity and not an in vitro artifact, the assay mixes were tested for the sensitivity to trypsin in the presence or the absence of detergent Triton X-100. If MPRs are enclosed in a vesicular compartment, only the cytoplasmic tail will be sensitive to trypsin and will be digested. This MPR46 without cytoplasmic tail can be visualized as a band of about $40 \mathrm{kDa}$ which is smaller than the full length MPR46. When trypsin digestion is performed in presence of a detergent, MPR46 is no more enclosed in a vesicle and will be completely sensitive to trypsin leading to its degradation.

The assay reactions were set up in duplicates as described (3.2.3.4). Either trypsin alone or both trypsin and Triton X-100 were added to the reactions after 1h-45' incubation and the samples were further incubated for 15'. A final concentration of $25 \mu \mathrm{g} / \mathrm{ml}$ trypsin and $0.5 \%$ Triton X-100 was used. After 
incubation, the trypsin was inactivated by adding $25 \mu \mathrm{g}$ of trypsin inhibitor. The detergent concentration was made equal in all the samples by adding same amount of detergent to the samples which were incubated without detergent and processed for immunoprecipitation.

\subsubsection{CELL BIOLOGICAL METHODS}

\subsubsection{Cell Culture}

All the cells were grown in a humidified incubator with $5 \% \mathrm{CO}_{2}$ at $37^{\circ} \mathrm{C}$. All solutions used for cell-culture were pre-warmed to $37^{\circ} \mathrm{C}$ in a water bath.

For culturing normal mouse embryonic fibroblasts (MEFs), Dulbecco's modified essential medium (DMEM) with $10 \%$ fetal calf serum (FCS) and $1 x$ Penicillin/Streptomycin was used.

For cells stably transfected with plasmids encoding Hygromycin resistance, the medium was supplemented with $200 \mu \mathrm{g} / \mathrm{ml}$ Hygromycin B.

For cells stably transfected with plasmids encoding Blasticidin resistance, the medium was supplemented with $5 \mu \mathrm{g} / \mathrm{ml}$ Blasticidin-S Hydrochloride.

\subsubsection{Passaging of cells by trypsinization}

Cells grown to confluency were routinely passaged by trypsinizing the cells and plating by diluting them appropriately in fresh medium. The medium from the confluent cells was sucked off and the cells were washed once with PBS. The cells were incubated with trypsin-EDTA solution on a $37^{\circ} \mathrm{C}$ metal platform in the hood for about $5 \mathrm{~min}$ and examined under the microscope for the effect of trypsin treatment. Trypsin was inactivated by adding fresh medium into the flask and the cells were resuspended in this medium. About $1 / 5^{\text {th }}$ to $1 / 10^{\text {th }}$ of the volume was left in the flask and the remaining cells were either used for experimental purposes or discarded. An appropriate volume of the medium was added to the flask and the cells were placed back in the incubator. 


\subsubsection{Freezing cells for stock maintenance}

Freezing medium : Cell culture medium containing $10 \%$ DMSO

The trypsinized cells were collected in a centrifuge tube and were centrifuged at $500 \mathrm{~g}$ for $5 \mathrm{~min}$ to pellet the cells. The supernatant was discarded and the pellet was resuspended in an appropriate volume of freezing medium and cell suspension was aliquoted into freezing vials and stored at $-80^{\circ} \mathrm{C}$ overnight. On the following day, the frozen vials were shifted to liquid nitrogen. Usually from one confluent $35 \mathrm{~cm}^{2}$ flask, four vials containing one $\mathrm{ml}$ each of the cell suspension were prepared.

\subsubsection{Thawing cells from liquid nitrogen}

The vial containing frozen cells of interest was taken out of liquid nitrogen carefully, the cap of the vial was loosened in the hood to release the pressure and tightened again and thawed in a beaker containing $70 \%$ prewarmed ethanol to $37^{\circ} \mathrm{C}$ in the waterbath. When the cells were thawed almost completely, the vial was taken into the hood and the cells were pipetted into a centrifuge tube containing chilled cell culture medium. This cell suspension was centrifuged for 5 $\min$ at $500 \mathrm{~g}$, the cell pellet was resuspended with prewarmed medium, transferred to a new culture flask and kept in the incubator. For transfected cells, on the next day, the medium was replaced with medium containing appropriate selection antibiotics.

\subsubsection{Stable transfection}

\subsection{By Calcium-phosphate coprecipitation}

Stock solutions:

Calcium chloride

$0.5 \mathrm{M}$

2x HBS:

$50 \mathrm{mM}$ Hepes

$1.5 \mathrm{mM} \mathrm{Na}_{2} \mathrm{HPO}_{4}$

$280 \mathrm{mM} \mathrm{NaCl}$

$\mathrm{pH}$ was adjusted to 7.13 using $\mathrm{NaOH}$ 
Cells were plated at a density of $2 \times 10^{5}$ cells per $6 \mathrm{~cm}$ dish and grown to $40-$ $50 \%$ confluency. The medium in the dish was replaced with fresh medium four hours before transfection. $5-20 \mu \mathrm{g}$ of specific DNA and $0.5-2 \mu \mathrm{g}$ of plasmid DNA encoding the selection marker were taken for co-transfection. The ratio of specific DNA to the selection marker DNA was kept at 10:1 for all transfections.

The DNA was mixed with $125 \mu \mathrm{l}$ of $0.5 \mathrm{M} \mathrm{CaCl}_{2}$, the volume was made upto 250 $\mu \mathrm{l}$ with water and vortexed briefly. $250 \mu \mathrm{l}$ of $2 \times \mathrm{HBS}$ was pipetted dropwise into the DNA-CaCl 2 solution, air was bubbled into the solution using a sterile plugged pasteur pipette. This mixture was incubated at room temperature for $30 \mathrm{~min}$ to allow the formation of calcium phosphate crystals containing DNA. The DNA-PO complex was added dropwise onto the cells, incubated at room temperature for $30 \mathrm{~min}$ and transferred to the incubator at $37^{\circ} \mathrm{C}$.

Next day, the medium was replaced with fresh medium and the following day selection for antibiotic resistant clone was started by adding medium containing the antibiotic encoded by the co-transfected selection plasmid. Antibiotic concentration was gradually increased by $100 \mu \mathrm{g}$ per day and stopped at 500 $\mu \mathrm{g} / \mathrm{ml}$. In case of Blasticidin, a constant concentration of $5 \mu \mathrm{g} / \mathrm{ml}$ of antibiotic was maintained throughout the selection procedure and thereafter. Resistant clones were picked and cultured as described (3.2.3.6). Stable clones were always maintained in the medium containing resistant antibiotic thereafter.

\subsection{Transfection with Effectene transfection reagent (Quiagen)}

$2-8 \times 10^{5}$ cells were plated in a $6 \mathrm{~cm}$ dish one day before transfection and grown to $40-60 \%$ confluency. $1 \mu \mathrm{g}$ of DNA was diluted in DNA-condensation buffer, Buffer EC, to a total volume of $150 \mu \mathrm{l} .8 \mu \mathrm{l}$ of Enhancer was added and mixed by vortexing for a second and incubated at room temperature for 2-5 min. The mixture was centrifuged briefly, $25 \mu \mathrm{l}$ of Effectene transfection reagent was added to the DNA-Enhancer mixture and mixed by vortexing for 10 seconds. The samples were incubated for 5-10 $\mathrm{min}$ at room temperature to allow complex formation. During this incubation time, the cells were washed with PBS and fresh medium was added. $1 \mathrm{ml}$ of the medium was added to the reaction tube containing the transfection complexes and mixed by pipetting up and down. 
Immediately after mixing, the transfection complex was added dropwise onto the cells and mixed gently by swirling the dish for uniform distribution of the complexes. The cells were incubated at $37^{\circ} \mathrm{C}$ and $5 \% \mathrm{CO}_{2}$ to allow for gene expression. Clones stably expressing the protein of interest were selected as described in (3.2.3.10.1).

\subsection{Transfection with FuGENE 6 transfection reagent (Roche Diagnostics)}

2-8 $\times 10^{5}$ cells were plated in a $6 \mathrm{~cm}$ dish one day before transfection and grown to $50-80 \%$ confluency. The transfection mix (100 $\mu$ l) was prepared as follows:

Serum free DMEM $100 \mu \mathrm{l}-6 \mu \mathrm{l}-$ Volume of DNA (in $\mu \mathrm{l}$ )

FuGENE reagent $\quad 6 \mu \mathrm{l}$

DNA $2 \mu \mathrm{g}$

Selection plasmid $\quad 0.2 \mu \mathrm{g}$

The ratio of FuGENE reagent to DNA was always kept at 3:1 $(\mu \mathrm{l}: \mu \mathrm{g})$. The transfection mix was incubated at room temperature for $15 \mathrm{~min}$. After incubation the complex mixture was added dropwise onto the cells by swirling the dish to ensure uniform dispersal all over the dish. Cells were returned to the incubator and the resistant clones were selected as described (3.2.3.10.1) 


\section{$4 \quad$ Results}

\subsection{Studies on the function of $\mathrm{N}$-terminal domain of $\mu 1 \mathrm{~A}$}

\subsection{1 $\mu 2 / \mu 1$ chimeras}

We compared the sequences of the two murine $\mu$-adaptins, their hydrophilicity profiles as well as the secondary structure predictions for the formation of $\beta$ sheets and helices and for the surface probabilities to decide which sequences of $\mu 1 \mathrm{~A}$ should be exchanged by $\mu 2$ (Fig. 4.1.1). The N-terminal 159 amino acids of $\mu 2$ have been shown to form a domain almost identical to the structure of $\sigma 2-$ adaptin. The $\mathrm{N}$-terminal 159 amino acids of $\mu 2$ bind to a pocket formed by $\beta 2-$ adaptin analogous to the binding of $\mu 2$ to $\alpha$-adaptin (Figs. 4.1.1B and 5.1). The remaining C-terminal 290 amino acids form exclusively $\beta$-sheets and are oriented to create the binding site for the $Y x x Q$ sorting motifs (Owen and Evans, 1998). The sequence homology between $\mu 1 \mathrm{~A}$ and $\mu 2$ is $37 \%$ over the entire length of the proteins (Fig. 4.1.1). We decided to split the $\mathrm{N}$-terminal 159 amino acids of $\mu 2$ in two parts from amino acids 1-70 and 71-159, because the sequence homology to $\mu 1 \mathrm{~A}$ is only $25 \%$ for the former part and $49 \%$ for the latter part. The resulting $\mu 2 / \mu 1 \mathrm{~A}$ chimeras were named chimera I and II (Fig. 4.1.1). The sorting motif binding domain of $\mu 2$ was also split in two parts consisting of amino acids 160289 and $349-449$ with homologies of 52 and $35 \%$ respectively. The resulting chimeras were named chimera III and IV. The amino acids $270-329$ of $\mu 1 \mathrm{~A}$ were not replaced by the corresponding amino acids of $\mu 2$ (290-348, 24\% homology), because the anti- $\mu 1 \mathrm{~A}$ antiserum used to determine expression of the chimeras is directed against a peptide within this domain (Fig. 4.1.1). $\mu 2$ is 26 amino acids longer than $\mu 1 \mathrm{~A}$ and therefore the amino acid numbers in the chimera differ between the two proteins. All chimeras were constructed by overlap-extension PCR and they as well as the $\mu 1 \mathrm{~A}$ cDNA were cloned into the murine expression vector pMPSV. These plasmids were transfected into the $\mu 1 \mathrm{~A}$-deficient murine fibroblast cell line and stable transfectants were selected. 


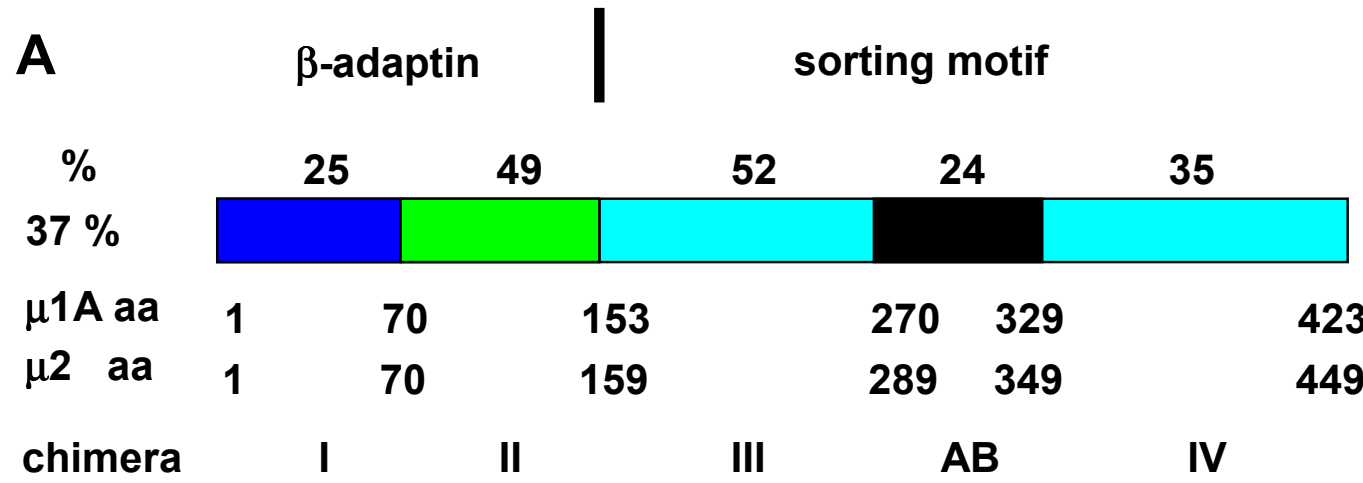

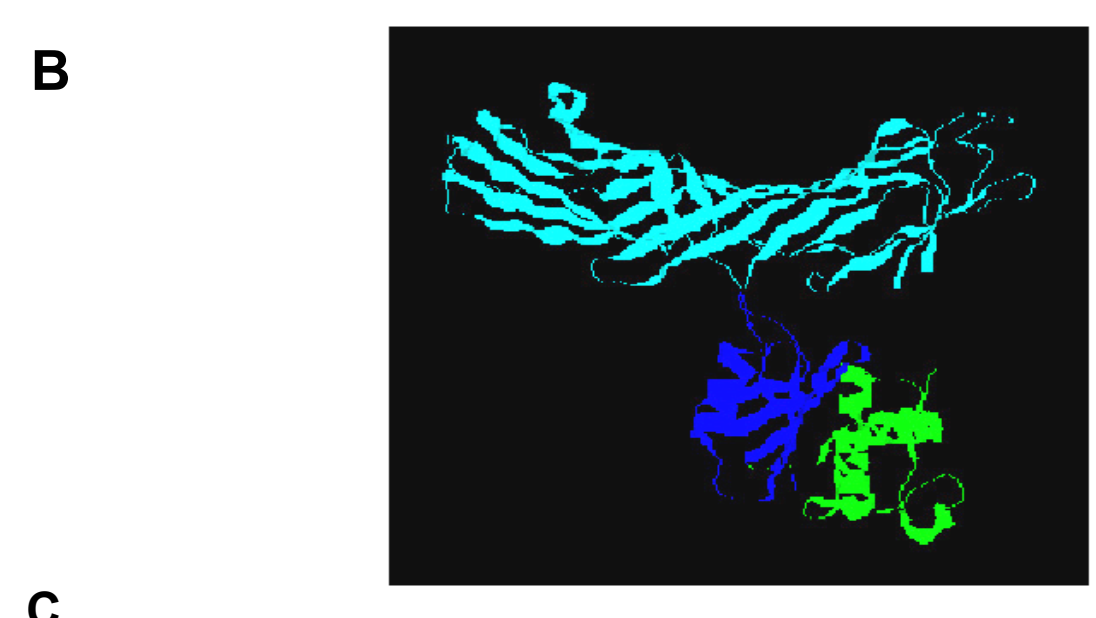

C

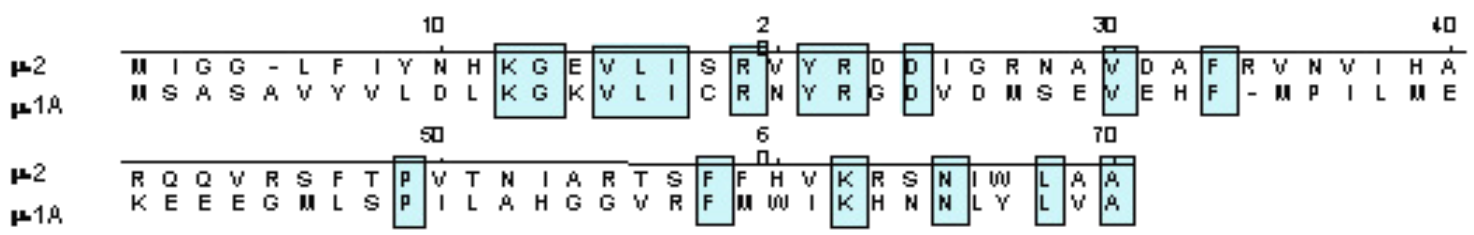

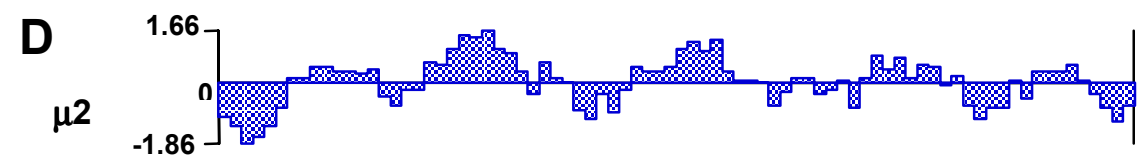

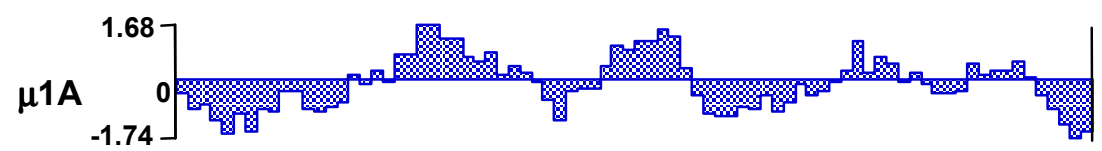

80

Figure 4.1.1 : Comparison of $\mu 1 \mathrm{~A}$ - and $\mu 2$-adaptin domains and chimera construction.

A: $\beta$-adaptin and sorting motif binding domains are indicated. Blocks in the bar indicate the $\mu 2$ domains, which have been exchanged with the corresponding $\mu 1 \mathrm{~A}$ domain. Numbers above give the sequence homologies of these domains in percent. The positions of the amino acids mark the transition between the $\mu$-sequences and these differ, because the $\mu$-adaptins differ in length by 26 amino acids. $A B$ marks the $\mu 1 \mathrm{~A}$-domain against which the antiserum is directed, used to determine expression levels of the chimeras. Colours used to label the domains correspond to those used in figure 5.1. B: Structure of $\mu 2$-adaptin coloured according to the scheme in A.

C: Sequence alignment of the $\mathrm{N}$-termini of $\mu 2$ and $\mu 1 \mathrm{~A}$. Identical residues are boxed.

D: Hydrophilicity of the N-termini calculated according to Kyte-Doolittle. 


\subsubsection{Expression of Chimera I in transfected cells}

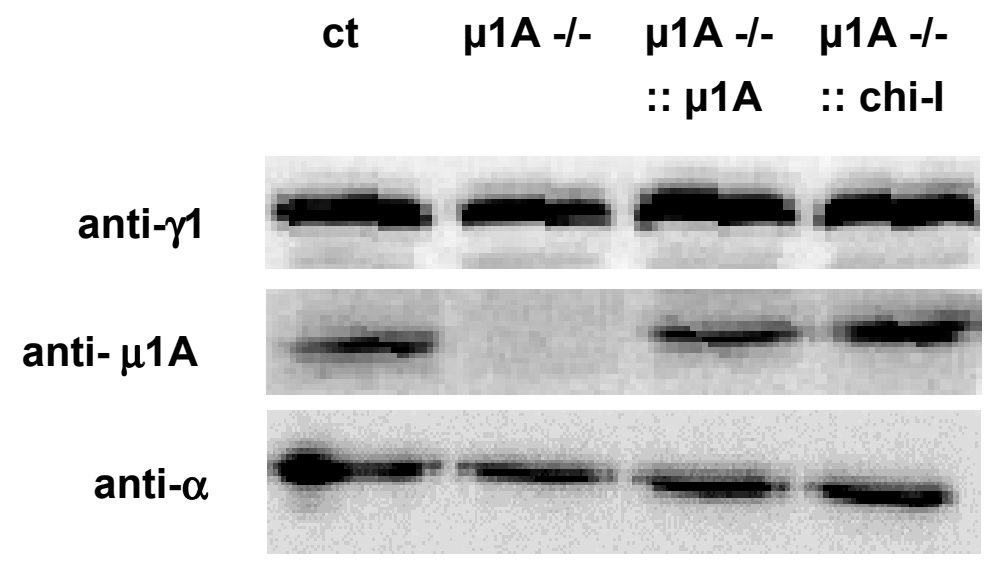

Figure 4.1.2: Expression level of $\mu 1 \mathrm{~A}$ and chimera I by ectopic expression in $\mu 1 \mathrm{~A}$-deficient cells. Post-nuclear supernatants were prepared from the cells and $50 \mu \mathrm{g}$ of protein/lane was loaded on a $10 \%$ SDS-PAGE and transferred onto a nitrocellulose membrane. Blots were probed with rabbit anti- $\mu 1 \mathrm{~A}$, monoclonal anti- $\gamma 1$ and monoclonal anti- $\alpha$ antibodies respectively. Anti- $\gamma 1-$ and anti- $\alpha$-adaptin western-blots served as controls.

Expression of $\mu 1 \mathrm{~A}$ and of the chimeras in the clones were tested by western-blot with an anti- $\mu 1 \mathrm{~A}$ antiserum. Stable transfectants with $\mu 2 / \mu 1 \mathrm{~A}$ chimera expression levels comparable to $\mu 1 \mathrm{~A}$ of control cells were only obtained from chimera I in which the N-terminal 70 amino acids of $\mu 1 \mathrm{~A}$ were replaced by those of $\mu 2$ (Fig. 4.1.2). This was surprising because these $\mu$-domains have with $25 \%$ the lowest degree of sequence identity. Hydrophilicity and surface probability profiles are however almost identical (Fig. 4.1.1C). $\mu 1 \mathrm{~A}$-adaptin is only stable, if it is incorporated into an AP-1 complex. Therefore chimeras II-IV may not fold properly, they may not be incorporated into an AP-1 complex or such complexes may be unstable.

To test for a function of this $\mathrm{N}$-terminal domain in AP-1 complex formation we cloned a $\mu 1 \mathrm{~A}$ mutant lacking the coding region for amino acids 2-70. This construct is cloned as well into pMPSV, transfected into $\mu 1 \mathrm{~A}$-deficient cells and stable transfectants were selected. We could not isolate any clone expressing 
this $\mu 1 \mathrm{~A}-\Delta \mathrm{N}^{2-70}$-adaptin. Also a truncated mutant of $\mu 1 \mathrm{~A}$-adaptin lacking the $\mathrm{C}$ terminal domain replaced in chimera IV was not stable.

\subsubsection{AP-1 complex formation in the cells expressing Chimera I}

The stability of chimera I indicated its incorporation into a heterotetrameric AP-1 complex. We controlled incorporation of chimera I into an AP-1 complex by gel filtration on a Superdex 200 column.

$\mu 1 \mathrm{~A}-/-:: \mu 1 \mathrm{~A}$

\section{$\begin{array}{llllll}\mathrm{L} & 5 & 6 & 7 & 8 & 9\end{array}$}

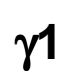

$\mu 1 \mathrm{~A}$

$\sigma 1$

$\alpha$
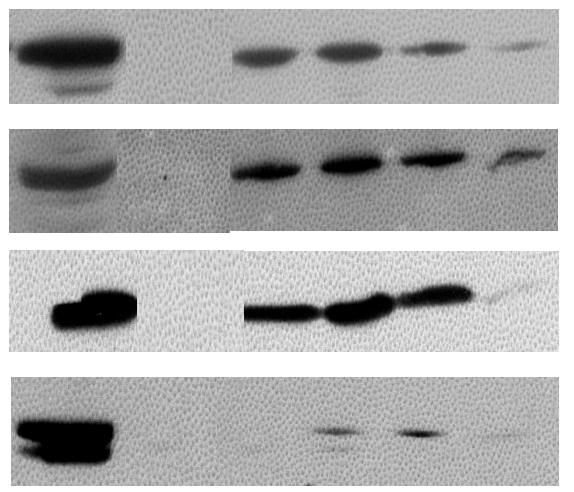

H1A -/ :: chi-I
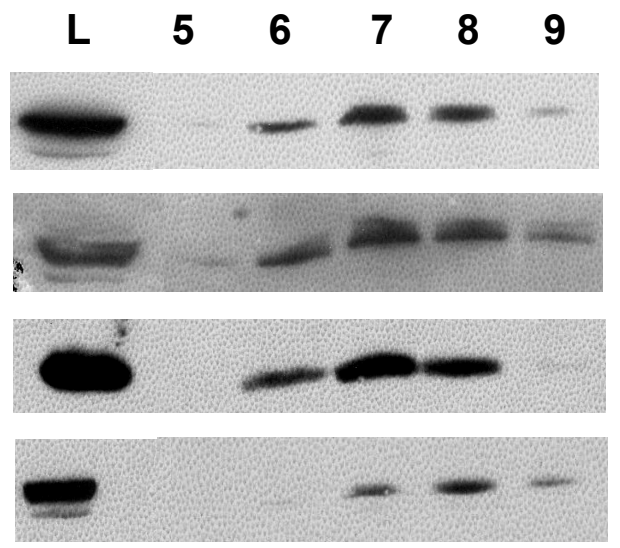

Figure 4.1.3: Gel filtration analysis of AP-1 complex formation induced by $\mu 1 \mathrm{~A}$ and chimera I expression. 100,000 g supernatants prepared from both control and Chimera I expressing cells were injected into a Superdex 200 column and the fractions collected were analyzed by western blot with the antibodies indicated. $\alpha$-adaptin fraction of the heterotetrameric AP-2 complex served as control. L: material loaded onto the column; numbers indicate column fractions.

In $\mu 1 \mathrm{~A}$-deficient cells trimeric AP- 1 complexes are formed and these elute two fractions after heterotetrameric AP-1. AP-1 fractionation was followed by anti- $\gamma 1-$, anti- $\mu 1 \mathrm{~A}$ - and anti- $\sigma 1$-adaptin western-blots. Fractionation of the AP-2 $\alpha$-adaptin served as control. In cytosol expressing chimera I all the $\gamma 1$ fractionated as in control cells, demonstrating formation of an heterotetrameric AP- ${ }^{*}$ complex to wild-type levels (Fig. 4.1.3). 


\subsubsection{Steady-state localization of AP-1 and MPRs in Chimera I expressing cells}

In $\mu 1 \mathrm{~A}$-deficient cells the trimeric AP-1 complex does not bind to membranes. The perinuclear staining for $\gamma 1$ that is observed in indirect immunofluorescence microscopy in control cells is absent. In addition the perinuclear concentration of clathrin is lost in the $\mu 1 \mathrm{~A}$-deficient cells (Fig. 4.1.4). In order to examine the distribution of $\gamma 1$ and Clathrin signal in AP-1* expressing cells we performed indirect immunoflorescence with fixed cells. We also looked for the steady-state localization of AP-1 cargo, the mannose 6-phosphate receptors, in these cells.

A:
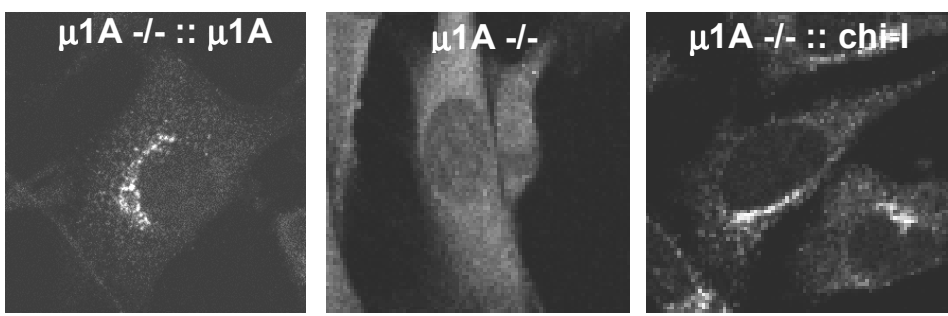

$\gamma 1$
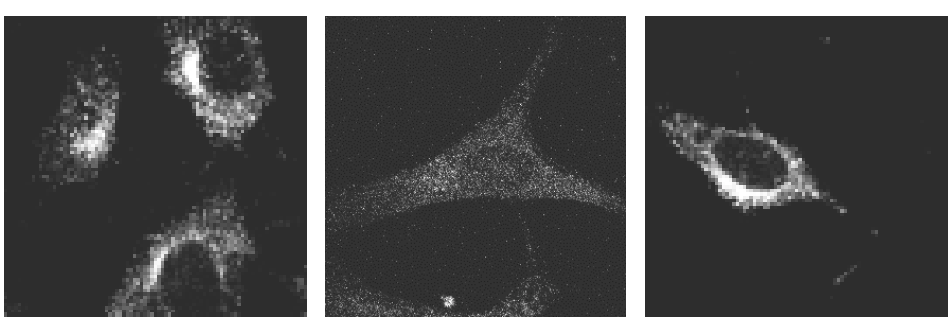

chc
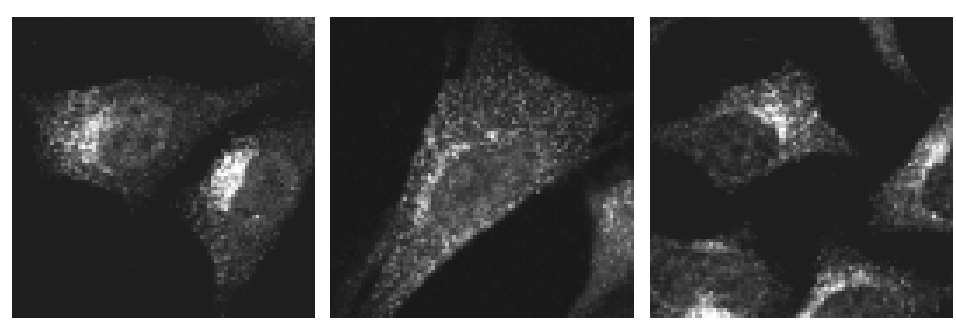

B:

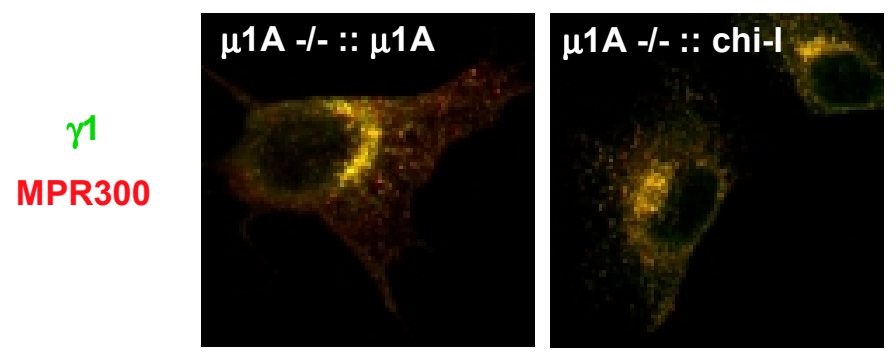

Figure 4.1.4: $\gamma 1$-adaptin, clathrin and MPR46, MPR300 steady-state distribution in control ( $\mu 1 \mathrm{~A}-/-:: \mu 1 \mathrm{~A}),(\mu 1 \mathrm{~A}-$ deficient $\mu 1 \mathrm{~A}-/-)$ and AP-1* expressing cells $(\mu 1 \mathrm{~A}-/-::$ chim-I).

A: Membrane binding of $\gamma 1$-adaptin and clathrin and subcellular distribution of MPR46. B: perinuclear co-localization of $\gamma 1$-adaptin (green) and MPR300 (red) in control ( $\mu 1 \mathrm{~A}-/-:: \mu 1 \mathrm{~A})$ and AP-1* expressing cells ( $\mu 1 \mathrm{~A}-/-::$ chim-I). 
In $\mathrm{AP}-1^{*}$-expressing cells $\gamma 1$ staining is perinuclear as in control cells demonstrating membrane binding of $\mathrm{AP}-1^{*}$. Also the perinuclear concentration of clathrin is restored by chimera I expression (Fig. 4.1.4). This indicates formation of a heterotetrameric AP-1* complex with functional membrane binding properties.

\subsubsection{MPR sorting by AP-1*}

MPR46 and MPR300 mediate TGN-to-endosome sorting of lysosomal enzymes. At steady-state the majority of the MPRs is found in the perinuclear TGN. In $\mu 1 \mathrm{~A}$ deficient cells both MPRs are redistributed to early endosomes at the expense of the TGN (Meyer et al., 2000). Expression of chimera I in these cells restored the perinuclear concentration of MPR46 and co-localization of MPRs with $\gamma 1$-adaptin as shown for MPR300 indicating correct sorting of the receptors by AP-1* (Fig. 4.1.4).

To analyze MPR-dependent sorting of lysosomal enzymes directly we followed the lysosomal sorting of its ligand cathepsin D. Cells were pulse-labelled with radioactive methionine/cysteine for one hour and chased for four hours with nonradioactive methionine/cysteine in the presence or absence of $5 \mathrm{mM}$ mannose 6phosphate. Cathepsin D immunoprecipitated from medium and cells were resolved by SDS-PAGE and analyzed by autoradiography.

Control cell lines secrete about $10-15 \%$ of the Golgi-precursor form of cathepsin $D$. This fraction is not increased by the addition of $5 \mathrm{mM}$ mannose 6-phosphate to the culture medium. $\mu 1 \mathrm{~A}$-deficient cells secrete $31 \%$ of cathepsin $D$ and this fraction is increased to $61 \%$ in the presence of mannose 6-phosphate (Fig. 4.1.5). Ectopic expression of $\mu 1 \mathrm{~A}$ in these cells restores cathepsin D sorting. Chimera I expressing cells missort $23 \%$ of the Golgi precursor form of cathepsin D into the secretions and $40 \%$ in the presence of $5 \mathrm{mM}$ mannose 6-phosphate (Fig. 4.1.5). This demonstrates impaired sorting function of AP-1*. 


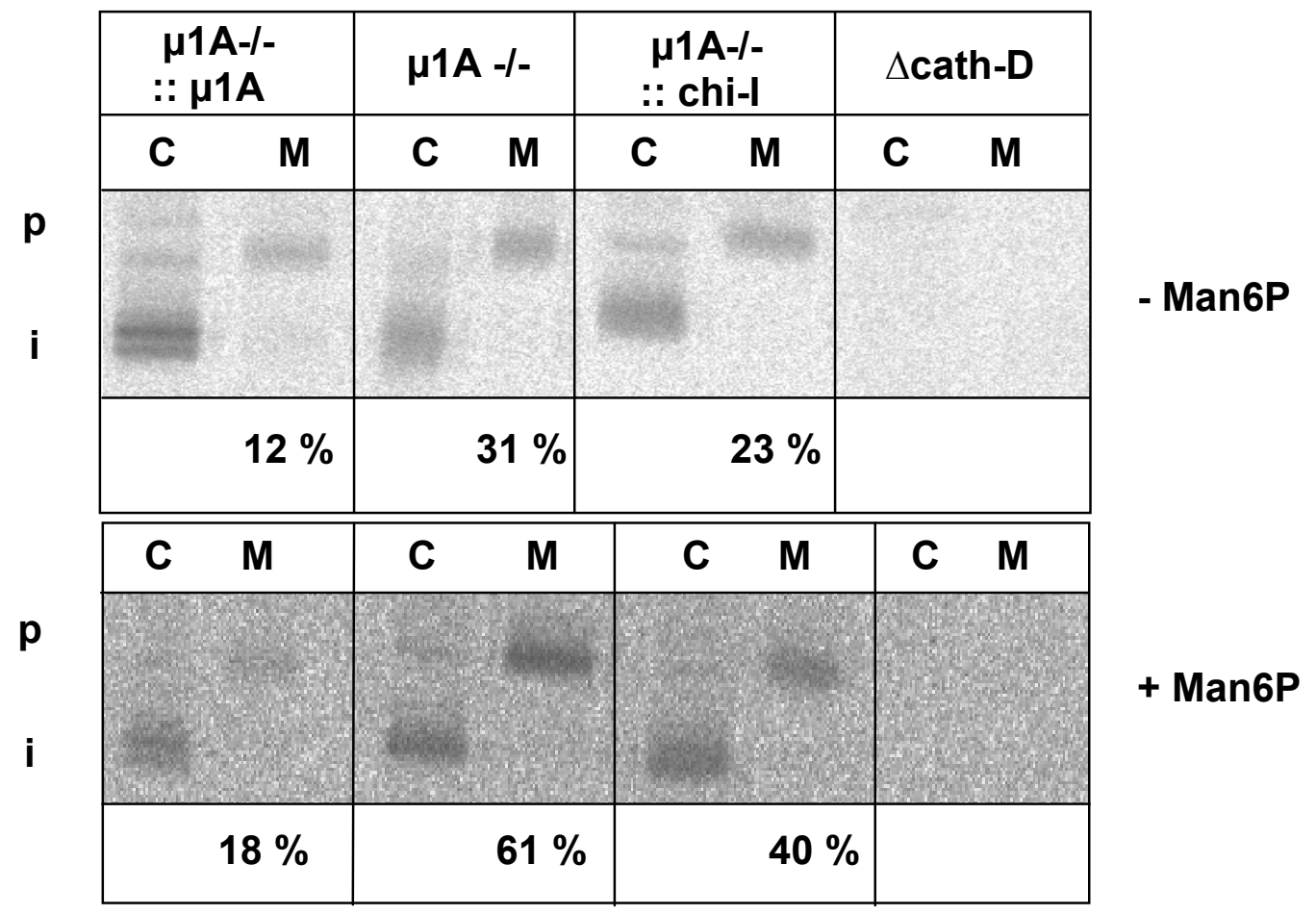

Figure 4.1.5: Cathepsin D sorting by AP-1*. Control ( $\mu 1 \mathrm{~A}-/-:: \mu 1 \mathrm{~A}), \mu 1 \mathrm{~A}$-deficient $(\mu 1 \mathrm{~A}-/-)$ and $A P-1^{*}$ expressing ( $\mu 1 \mathrm{~A}-/-::$ chim-I) cell lines were metabolically labelled with ${ }^{35} \mathrm{~S}$-methionine for 1 $\mathrm{h}$, chased for $4 \mathrm{~h}$ and cathepsin $\mathrm{D}$ was immunoprecipitated from cell extracts $(\mathrm{C})$ and the medium (M). $p$ indicates the Golgi precursor form and $i$ the endosomal/lysosomal intermediate form of cathepsin D. Cathepsin D-deficient mouse fibroblast cells $(\Delta$ cath-D) served as control for the immunoprecipitations. The numbers given are the average of two to four experiments and the s.d. was $<10 \%$ of the given numbers.

\subsubsection{Membrane binding by AP-1*}

$\mathrm{AP}-1^{*}$ is expressed to the levels of control cells and no differences in membrane binding of AP-1 and AP-1* were observed by indirect immunofluorescence microscopy (Figs. 4.1.2 and 4.1.4). In addition MPRs and $\gamma 1$-adaptin co-localized indicating $\mathrm{AP}-1^{*}$ binding to the correct TGN subdomains. A $50 \%$ reduction of AP1 expression levels does not cause missorting of cathepsin D. Missorting in the presence of $\mathrm{AP}-1^{*}$ complexes must therefore be due to impaired $\mathrm{AP}-1^{*}$ function in protein sorting or transport vesicle formation. AP-1 recycles between a membrane-bound and a cytoplasmic pool (Wu et al., 2003). Membrane binding of AP-1 requires the small GTPase ARF-1 (Robinson and Kreis, 1992; Stamnes and 
Rothman, 1993). ARF-1 GDP-exchange factors containing a Sec7-domain are inhibited by brefeldin A (Randazzo et al., 2000). Addition of this drug to the culture medium causes the redistribution of the membrane-bound pool of AP-1 into the cytoplasm. To analyze the membrane binding of $A P-1^{*}$ in more detail we added brefeldin A to the culture medium and followed AP-1 and AP-1* redistribution into the cytoplasm (Fig. 4.1.6).

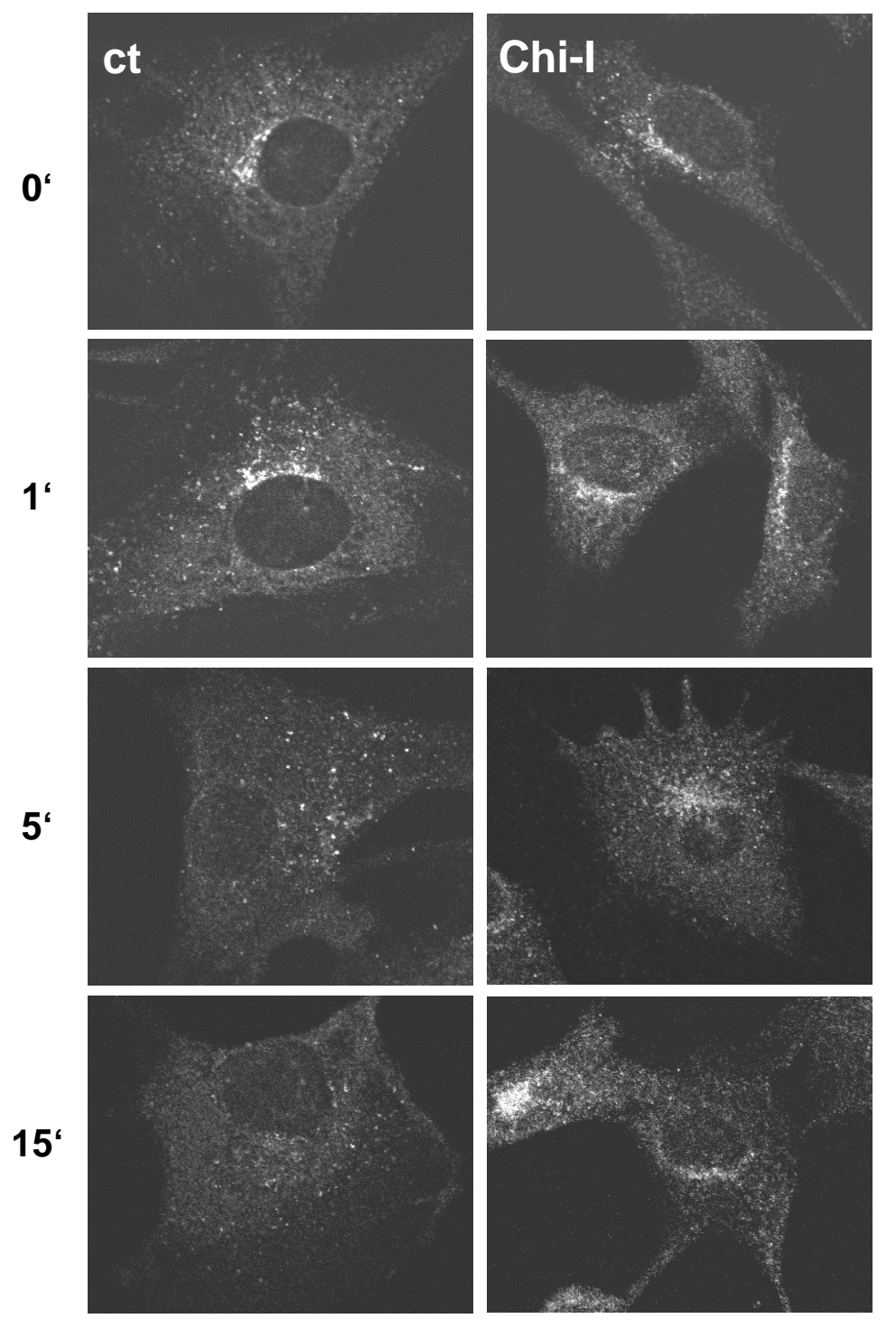

Figure 4.1.6: Redistribution of AP-1 and AP-1* between membranes and the cytoplasm. $\mu 1 \mathrm{~A}$ 'knock-out' cell line with ectopic expression of $\mu 1 \mathrm{~A}$ (control cells) and of chimera-I (chi-I) were incubated in the presence of $5 \mu \mathrm{g} / \mathrm{ml}$ brefeldin $A$ in the culture medium, moved onto ice at the indicated time points, fixed and processed for $\gamma 1$-adaptin indirect immunofluorescence microscopy. 
Compared to the AP-1 complex the rate of AP-1* redistribution was slowed down. Whereas membrane binding of AP-1 was absent after 5 min incubation, membrane binding of AP $-1^{*}$ was still detectable after 5 min and only absent after 15 min (Fig 4.1.6). This indicates either a slower ARF-1 GTPase-cycle or a slower dissociation rate of $\mathrm{AP}-1^{*}$ from membranes. 


\subsection{In vitro assay to measure the retrograde transport of MPR46}

The in vitro assay makes use of the property of a TGN-resident enzyme tyrosine sulfotransferase. When a protein containing the consensus sequence for tyrosine sulfation enters the TGN, this enzyme transfers sulfate from phosphoadenosine phosphosulfate (PAPS) onto the tyrosine residues within the consensus sequence of the protein. In order to make use of the activity of this enzyme in our transport assay, we obtained a murine MPR46 cDNA, which was modified at the 5 '-end to encode a consensus sequence for tyrosine sulfation, a hexa-histidine tag for convenient purification by nickel beads and also a myc tag for immunodetection (Itin et al., 1997)(Fig. 4.2.1). This protein is called HMY-MPR46.

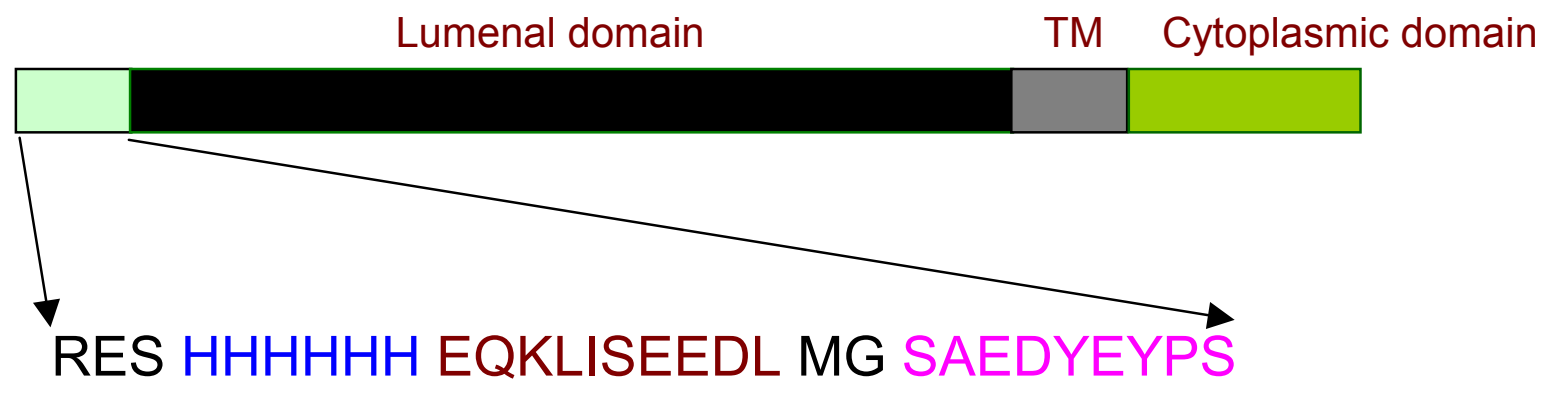

$$
\text { (HIS)6 c-myc } \quad \text { Y-sulfation }
$$

Figure 4.2.1: Schematic representation of the modified murine MPR46 (cDNA), HMYMPR46.

This construct has been used in the establishment of a similar kind of assay by Pfeffer and colleagues in chinese hamster ovary $(\mathrm{CHO})$ cells, and it has been shown that the $\mathrm{N}$-terminal tag does not affect the function of this receptor in lysosomal enzyme sorting (Itin et al., 1997). This cDNA was transfected into $\mu 1 \mathrm{~A}$ deficient cells and $\mu 1 \mathrm{~A}$-deficient cells rescued for AP-1-deficiency by ectopic expression of $\mu 1 \mathrm{~A}$. Membranes were prepared from cells grown in sulfate-free medium containing chlorate to inhibit in vivo sulfation and to accumulate a nonsulfated pool of receptors. Cells were treated with cycloheximide for two hours before membrane preparation to block the biosynthetic pathway and to minimize 
the entry of MPRs from this pathway to the TGN. So all MPRs that enter TGN under the in vitro assay conditions should be of endosomal origin. In addition, isolated membranes are incubated with non-radioactive PAPS for $15 \mathrm{~min}$ in presence of ATP to sulfate the TGN pool of HMY-MPR46. This would reduce the background labelling of pre-existing HMY-MPR46 in the TGN during the assay incubation. Membranes were collected by centrifugation on a sucrose cushion, aliquots were shock frozen on dry ice and stored at $-80^{\circ} \mathrm{C}$. These membranes could be mixed with either control cytosol or AP-1-deficient cytosol in the presence of ATP and ${ }^{35}$ S-PAPS to stimulate endosome-to-TGN transport of HMY-MPR46. Sulfated receptors were quantitated by phosphoimager analysis.

\subsubsection{Generation of Cell lines}

$\mu 1 \mathrm{~A}$-deficient mouse embryonic fibroblasts (MEFs) were stably transfected with the HMY-MPR46 construct. Positive clones were selected by western blot analysis with anti-MPR46 antibodies (Fig. 4.2.2A). Clones with 1.5 to 10 fold overexpression of HMY-MPR46 over the endogenous MPR46 were obtained. All our experiments were performed with clone 5 which had 1.5 fold HMY-MPR46 overexpression. We generated two kinds of control cell lines for our experiments. First, $\mu 1 \mathrm{~A}$-deficient cells expressing HMY-MPR46 were retransfected with $\mu 1 \mathrm{~A}$ cDNA. This has been shown to rescue the $\mu 1 \mathrm{~A}$-deficient phenotype (Meyer et al., 2000). We used the rescued cells as our control cells (Fig. 4.2.2B). We also established a HMY-MPR46 expressing control cell line with $\mu 1 \mathrm{~A}$ expression from the wild-type genomic locus (Fig. 4.2.2C), but these cells rapidly lost the expression of HMY-MPR46 and could not be used for routine experiments. 


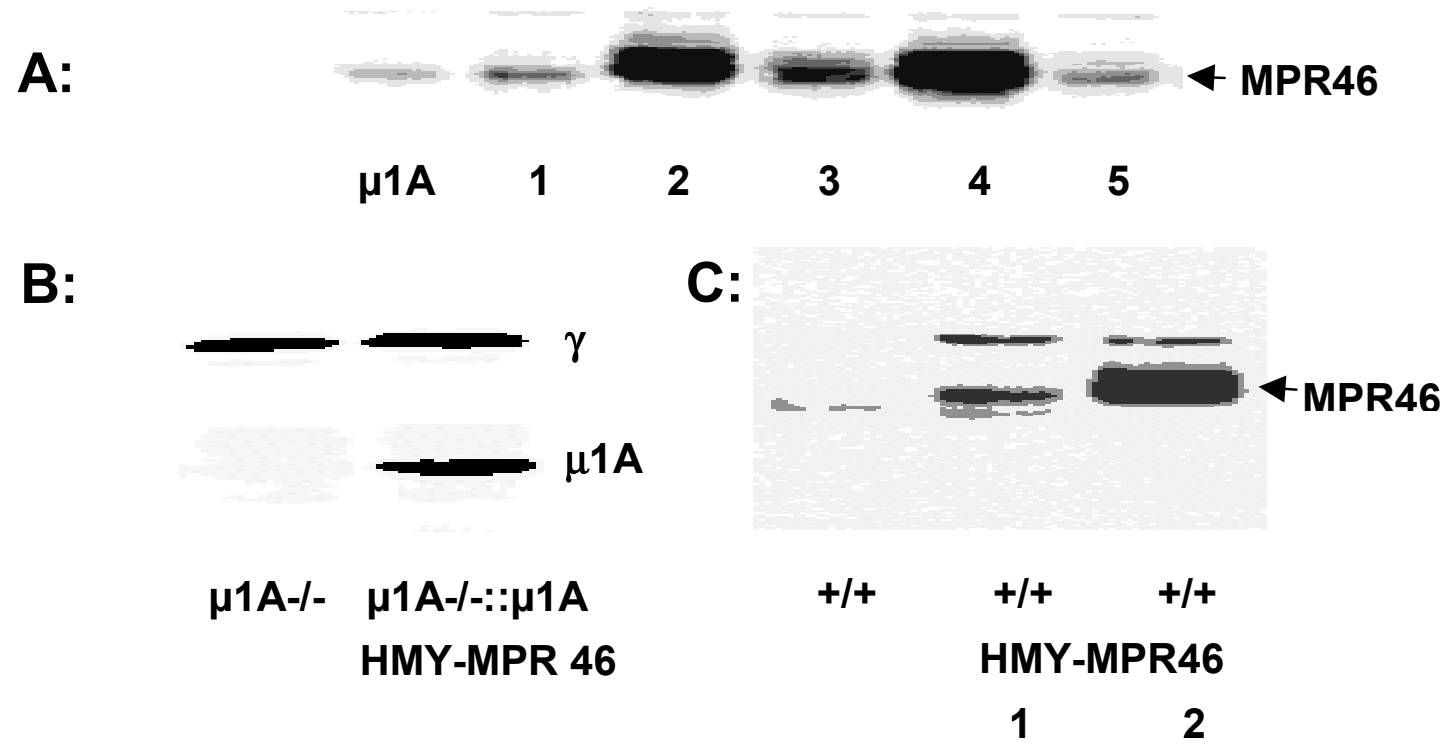

Figure 4.2.2: (A) Western blot analysis of $\mu 1 \mathrm{~A}$-deficient clones expressing HMY-MPR46. Membrane fractions from the selected clones (1 to 5) were prepared and $100 \mu \mathrm{g}$ of protein was loaded on a $12.5 \%$ SDS-PAGE. Antibodies specific to the cytoplasmic tail of MPR46 were used. (B) Western blot analysis of $\mu 1 \mathrm{~A}-/-$ HMY clone expressing $\mu 1 \mathrm{~A} .100 \mu \mathrm{g}$ of cytosolic fraction was loaded on a $10 \%$ SDS-PAGE and the blot was analyzed by anti- $\mu 1 \mathrm{~A}$ antibody and anti $\gamma$-adaptin antibody. (C) Western blot analysis of control cells expressing HMY-MPR46 as described in (A), two clones (1 \& 2) overexpressing HMY-MPR46 were obtained.

\subsubsection{Steady-state localization of HMY-MPR46}

Overexpression of HMY-MPR46 could lead to alteration of steady-state distribution of the receptor. In order to verify this, we performed indirect immunofluorescence microscopy to visualize the steady-state localization of MPR46 in control cells overexpressing HMY-MPR46. $\gamma$-adaptin was used as a marker for the TGN and LAMP1 served as a marker for late endosomes/ lysosomes.

MPR46 is concentrated in the perinuclear TGN as observed by the complete overlap with $\gamma$-adaptin staining (Fig. 4.2.3). MPR46 and LAMP1 staining was completely segregated indicating the absence of MPR46 in late endosomes or lysosomes. Thus, overexpression of HMY-MPR46 does not increase the steadystate concentration of MPR46 in these organelles. 


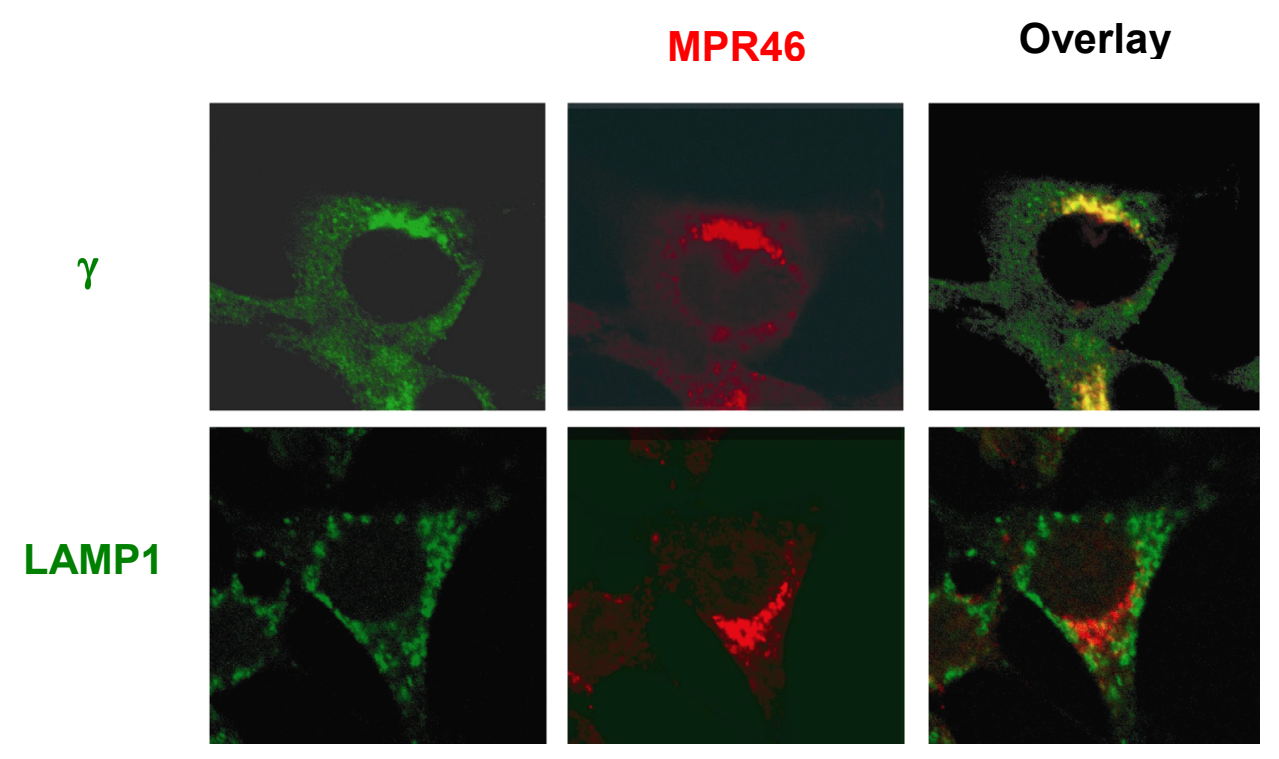

Figure 4.2.3: Steady-state localization of MPR46 in control cells overexpressing HMYMPR46. Cells were fixed using $3 \%$ paraformaldehyde and permeabilized by $0.5 \%$ saponin in PBS. These cells were incubated with antibodies against $\gamma$-adaptin or LAMP1 and MPR46 followed by secondary antibodies conjugated to FITC (green) and Texas red (red) respectively

\subsubsection{Isolation of HMY-MPR46}

Our initial plan was to rapidly quantify the transport reaction by purifying receptors with nickel beads and to determine the amount of labelled receptors by liquid scintillation counting as described in the literature (Itin et al., 1997). Many conditions were tested with metabolically labelled cell extracts to achieve purity to a single band, but even under the most stringent conditions we had contaminating bands and material which did not enter the gel. Hence we had to switch to time consuming immunoprecipitation of ${ }^{35} \mathrm{~S}$-labelled HMY-MPR46 with anti-MPR46 antibodies and analysis by SDS-PAGE and autoradiography (Fig. 4.2.4). 


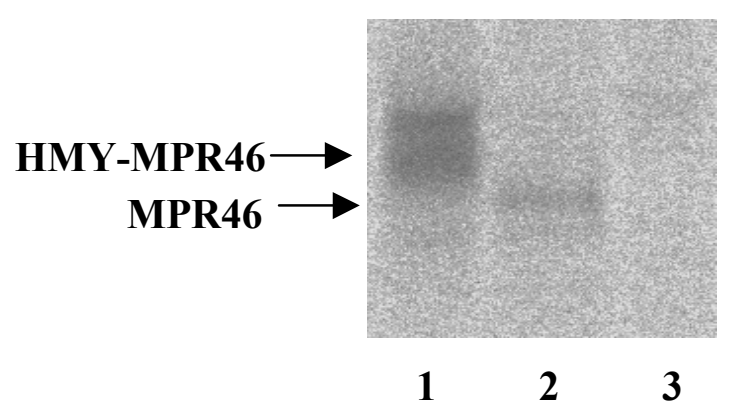

Figure 4.2.4: Immunoprecipitation of HMY-MPR46. HMY-MPR46 was immunoprecipitated by anti-MPR46 antibodies and protein-A sepharose from the cell lines which were labelled with ${ }^{35} \mathrm{~S}$ methionine/cysteine for $6 \mathrm{~h}$. Immune complexes were resolved on a $12.5 \%$ SDS-PAGE and visualized and quantitated by phosphoimager analysis. Shown is the immunoprecipitated MPR46 from $\mu 1 \mathrm{~A}$-deficient cells overexpressing HMY-MPR46 (lane 1), cells overexpressing MPR46 used as positive control (lane 2), cells deficient for MPR46 used as negative control (lane 3). HMYMPR46 is $2 \mathrm{kDa}$ larger than MPR46 and hence is seen at a slightly higher position than MPR46.

\subsubsection{In vivo ${ }^{35} \mathrm{~S}$-sulfate labelling of HMY-MPR46}

Since our transport assay is based on the sulfation of the receptor in vitro, first we had to verify if this receptor is also sulfated in vivo in MEFs. Metabolic labelling with ${ }^{35} \mathrm{~S}$-sulfate followed by immunoprecipitation revealed that HMY-MPR46 is sulfated in vivo in MEFs. (Fig. 4.2.5).

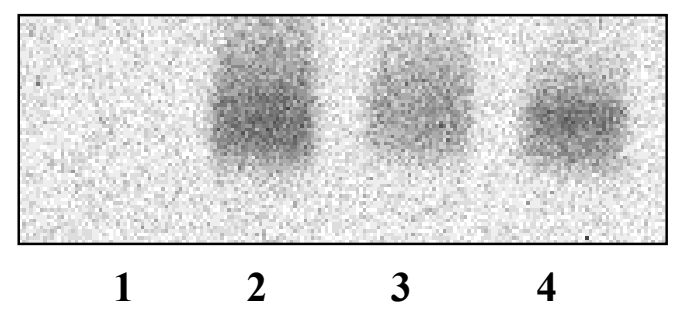

Figure 4.2.5: In vivo sulfation of HMY-MPR46. Cells were grown in sulfate-free medium and labelled with ${ }^{35} \mathrm{~S}$-sulfate for 6 hours, immunoprecipitated with anti-MPR46 antibodies, resolved by SDS-PAGE and labelled HMY-MPR46 was visualized by phosphoimager analysis.

1.Untransfected cells 2. $\mu 1 \mathrm{~A}-/-:: \mu 1 \mathrm{~A}: H M Y-M P R 46$ 3. $\mu 1 \mathrm{~A}-/-$ :HMY-MPR46 4. wt HMY-MPR46

The signals shown are not normalized to the protein content and hence labelling intensity is not directly comparable between different cell lines 


\subsubsection{Synthesis and purification of ${ }^{35}$ S-PAPS}

Our transport assay relies on the ${ }^{35} \mathrm{~S}$-sulfation of receptors that enter the TGN. PAPS is translocated from the cytosol into the TGN where it acts as the donor of the sulfate group. We had to synthesize $P A P^{35} S$ on large scale to perform assays regularly. $\mathrm{PAP}^{35} \mathrm{~S}$ is synthesized in a two step reaction:

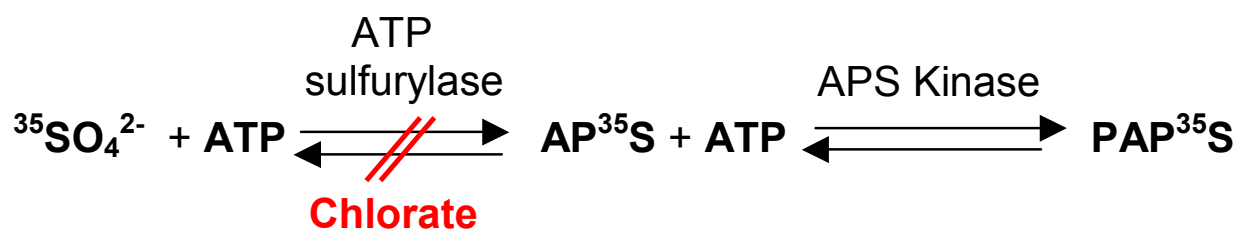

Both the enzymes required for PAPS synthesis are present in high amounts in yeast extracts and hence yeast extracts were prepared and PAPS was synthesized using these extracts as described in Materials and Methods (3.2.3.1). After a typical PAPS synthesis reaction, the reaction products were analyzed by thin layer chromatography (TLC). Since PAPS is anionic, the PAPS reaction mixture was loaded onto an anion exchanger (DEAE-Sephacel) and purified by a salt gradient (14-700 mM ammonium bicarbonate). Fractions were collected and $2 \mu \mathrm{l}$ of each fraction was counted in a scintillation counter. There were two major peaks. The peak fractions were pooled, lyophilised to dryness and then dissolved in water to obtain a final radioactivity of $0.5 \mu \mathrm{Ci} / \mu \mathrm{l}$. Aliquots were analyzed by TLC.

We were able to purify PAPS to almost $95 \%$ purity (Fig. 4.2.6). Aliquots of PAPS were stored at $-80^{\circ} \mathrm{C}$. Under these conditions $\mathrm{PAP}^{35} \mathrm{~S}$ was stable for at least $2-3$ months. 


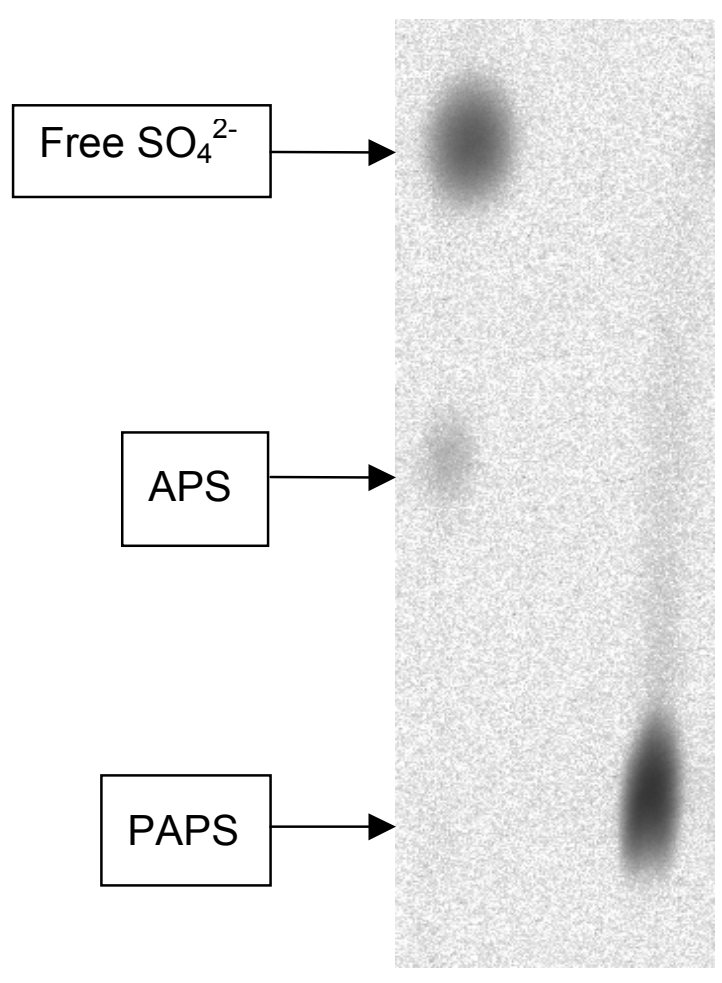

Figure 4.2.6: Thin layer chromatography of $\mathrm{PAP}^{35} \mathrm{~S}$ purified by anion-exchanger.

Lyophilised peak fractions were dissolved in water and a small amount (less than $0.5 \mu \mathrm{l}$ ) was spotted on a PEI-Cellulose F TLC sheet. Samples were resolved by 0.9 M Lithium chloride for about $45 \mathrm{~min}$ and air-dried. Radioactive spots were visualized and quantitated by phosphoimager analysis.

\subsubsection{In vitro endosome-to-TGN transport assay}

The in vitro assay mixture consisted of an ATP-regenerating system, a membrane fraction and a cytosol fraction, both of which were prepared from the different cell lines as described in (3.2.3.2 \& 3.2.3.3). The membrane and cytosol from control and adaptor-deficient cell lines could be mixed for the in vitro assay as described in Materials and Methods (3.2.3.4). In a typical transport assay, membranes were incubated with cytosol and $P A P^{35} \mathrm{~S}$ for 2 hours at $37^{\circ} \mathrm{C}$. After incubation the reaction mixes were shifted on ice, $50 \mu \mathrm{l}$ of water and $200 \mu \mathrm{l}$ of $2 x$ detergent containing buffer was added and the HMY-MPR46 was immunoprecipitated. Proteins were resolved by SDS-PAGE and the sulfated receptors were visualized and quantitated by phosphoimager analysis (Fig. 4.2.7). 
A very small amount of background labelling, independent of cytosolic proteins, was observed under our in vitro conditions and we consistently obtained about 610 fold stimulation of transport upon addition of cytosol depending on the membrane and cytosol preparations.

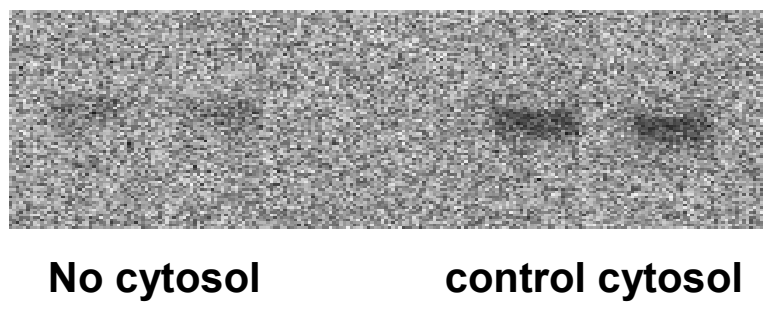

Figure 4.2.7: A typical in vitro transport reaction analysis performed in duplicates.

$25 \mu \mathrm{g}$ of control membranes were incubated with $1 \mathrm{mg} / \mathrm{ml}$ cytosol and $5 \mu \mathrm{Ci}^{35}$ S-PAPS for $2 \mathrm{~h}$ at $37^{\circ} \mathrm{C}$. Sulfated receptors were immunoprecipitated, resolved by SDS-PAGE and quantitated by phosphoimager analysis after exposure of the gels onto the phosphoimager screens for one week.

\subsubsection{Standardization of assay conditions}

\subsubsection{Time course}

In order to study the kinetics of this retrograde transport step, assay reactions were incubated for up to 150 minutes (Fig. 4.2.8). After each time point, the respective samples were shifted on ice and after the final time point all samples were processed for immunoprecipitation.

Retrograde transport increases with time till $1 \mathrm{~h}$ and after that it attains saturation (Fig. 4.2.8). As we do not see any increase in transport even after $2 \mathrm{~h}$ incubation, we performed all our assays for $2 \mathrm{~h}$ at $37^{\circ} \mathrm{C}$. 


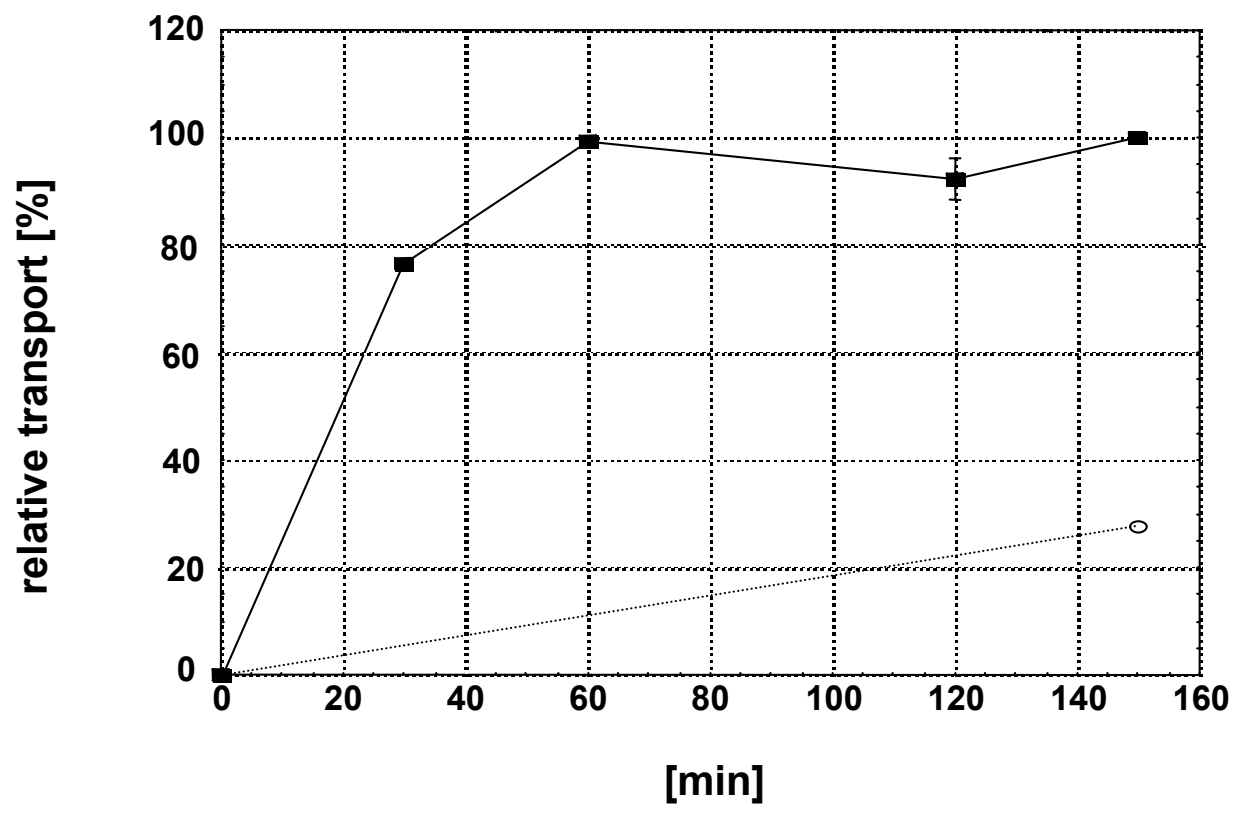

Figure 4.2.8: Time course of the in vitro transport reaction.

Assays were performed using membranes and cytosol from control cells for the indicated time points. Solid lines indicate cytosol-dependent transport, dotted line indicates background transport in the absence of cytosol. A representative figure out of two experiments is shown. Error bars indicate the maximum deviation of duplicate values from the average value.

\subsubsection{Dependence on cytosolic protein concentration}

In order to test for the requirement of cytosolic proteins, membranes from control cells were incubated with different concentrations of cytosol from control cells. To get a higher concentration of the cytosol for these assays, cells were grown in about six to eight $15 \mathrm{~cm} \phi$ dishes and cytosol was prepared as described in Materials and Methods (3.2.3.3).

The amount of HMY-MPR46 transport increases with increasing cytosol concentrations (Fig. 4.2.9). Beyond the concentration of $1 \mathrm{mg} / \mathrm{ml}$ the increase in transport is no longer in proportion to the increase in the amount of cytosolic proteins used and cytosol was even inhibitory at $2 \mathrm{mg} / \mathrm{ml}$. Therefore we performed all our assays with $1 \mathrm{mg} / \mathrm{ml}$ cytosol. 


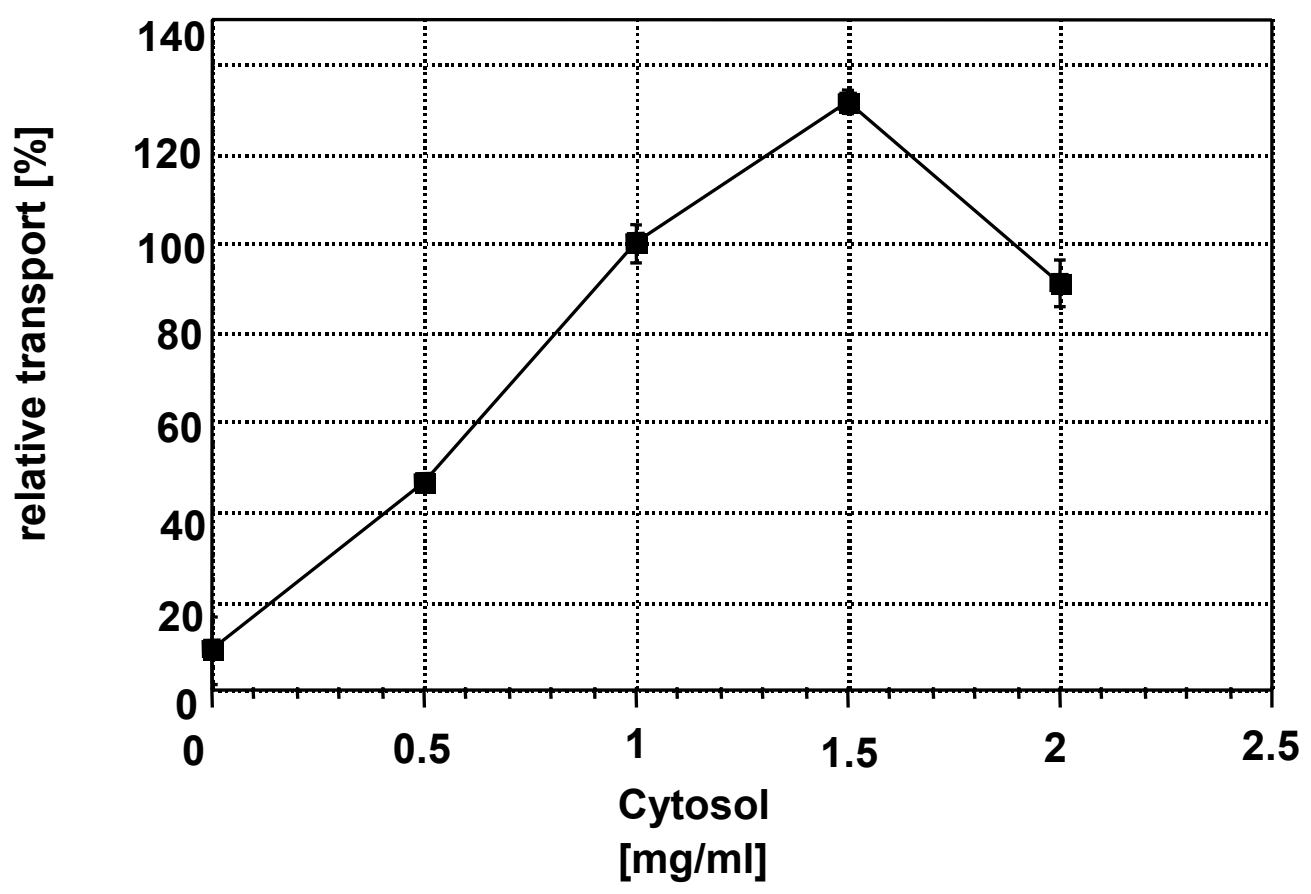

Figure 4.2.9: Cytosolic protein dependence of the tranport reaction.

Assays were performed by incubating membranes from control cells with the indicated amount of cytosol prepared from control cells. A representative figure out of two experiments is shown. Error bars indicate the maximum deviation of duplicate values from the average value.

\subsubsection{Temperature dependence}

Vesicle-mediated transport processes are functional only at physiological temperature. In order to test this aspect, in vitro assays were performed at different temperatures.

As expected, the transport reaction takes place only at physiological temperature (Fig 4.2.10) and is completely inactive at $4^{\circ} \mathrm{C}$ and minimally active at $20^{\circ} \mathrm{C}$, the temperature at which vesicle-mediated transport processes are blocked in vivo. 


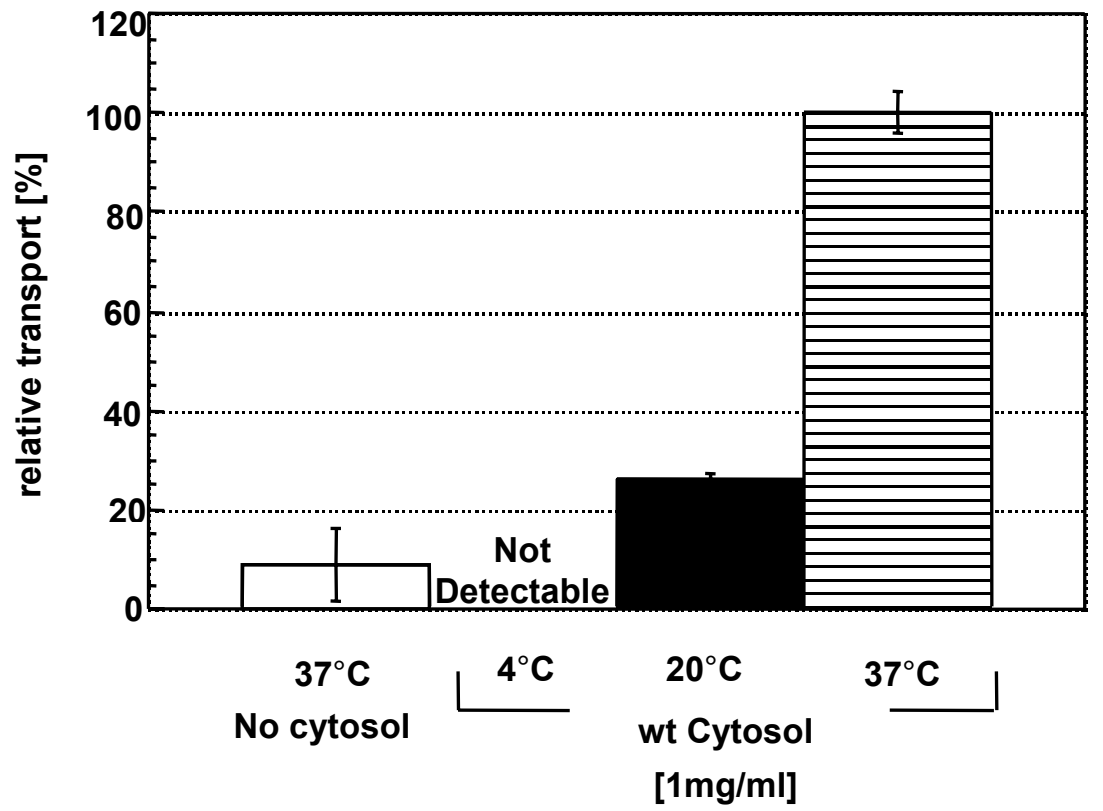

Figure 4.2.10: Temperature dependence of the transport reaction.

Assays were performed with membranes and cytosol from control cells. Reactions were incubated at the indicated temperatures and the sulfated receptors were immunoprecipitated, resolved by SDS-PAGE, visualized and quantitated by phosphoimager analysis. A representative figure out of two experiments is shown. Error bars indicate the maximum deviation of duplicate values from the average value.

\subsubsection{Assay to verify compartment intergrity}

In order to verify that the in vitro transport reactions are indeed vesicle-mediated and that the sulfation of HMY-MPR46 is a compartment-specific activity and not an in vitro artifact, assays were performed to test the sensitivity of HMY-MPR46 to trypsin treatment.

Sulfated HMY-MPR46 is sensitive to trypsin treatment only in the presence of detergent (Fig. 4.2.11, lane 4). In the absence of detergent, only the cytoplasmic tail is sensitive to trypsin treatment demonstrating that the $\mathrm{N}$-terminal domain is enclosed in a membrane compartment and hence is not accessible to trypsin. 


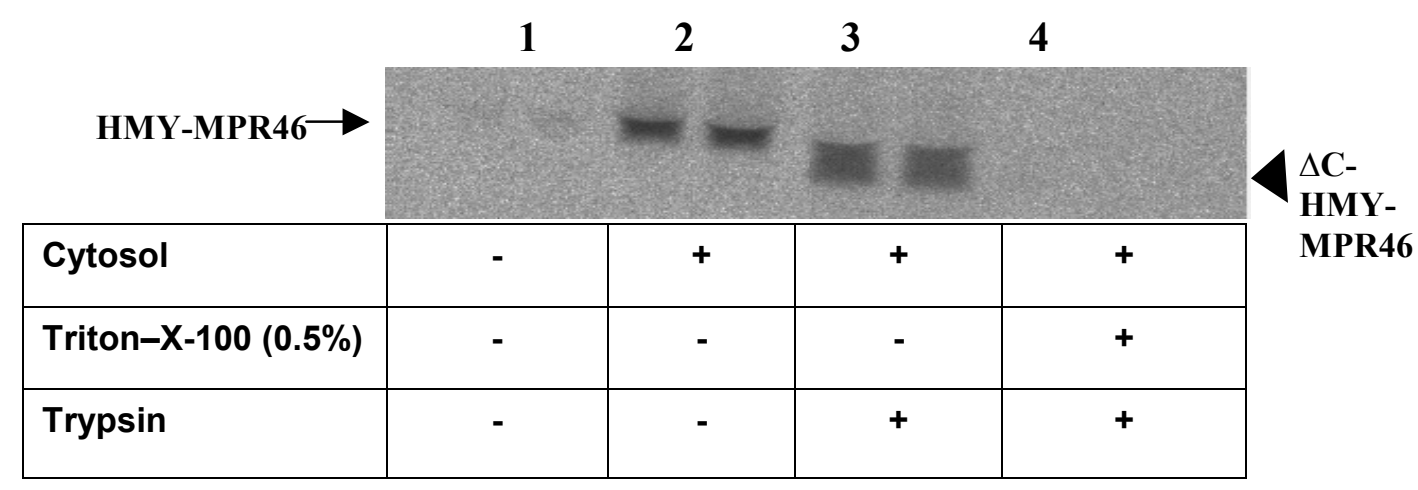

Figure 4.2.11: Assay to test for membrane integrity in the transport reaction.

Membrane and cytosol prepared from control cells were incubated for $2 \mathrm{~h}$ at $37^{\circ} \mathrm{C}$. For trypsin digestion, $25 \mu \mathrm{g}$ of trypsin was added after $1 \mathrm{~h}-45^{\prime}$ incubation and the samples were further incubated for $15 \mathrm{~min}$ at $37^{\circ} \mathrm{C}$. A final concentration of $0.5 \%$ Triton X-100 was added along with trypsin where indicated. Trypsin was inactivated by adding $25 \mu \mathrm{g}$ of trypsin inhibitor and the samples were processed for immunoprecipitation. Duplicate samples of each reaction are shown.

The tail-less MPR46 migrates at a lower molecular weight as expected (Fig. 4.2.11, lane 3). In vitro transport reaction does not function in the presence of a detergent (data not shown). This indicates that our in vitro transport reaction is a vesicular transport step and membrane integrity is necessary for the transport reaction to proceed.

\subsubsection{ATP dependence}

A typical vesicle-mediated transport process should be dependent on metabolic energy (ATP), for vesicle transport and fusion, events involving phosphorylation, for the activity of NSF etc., ATP is also required for the translocation of PAPS across the membrane of the TGN. ATP dependence can be verified by performing assays either in the presence of an ATP-regenerating system or by ATP depletion. Assay reactions were set up in the presence of an ATPregenerating system. To verify if ATP is an absolute requirement for transport of MPRs, reaction mixes included an ATP depletion system instead of ATP regeneration system. 


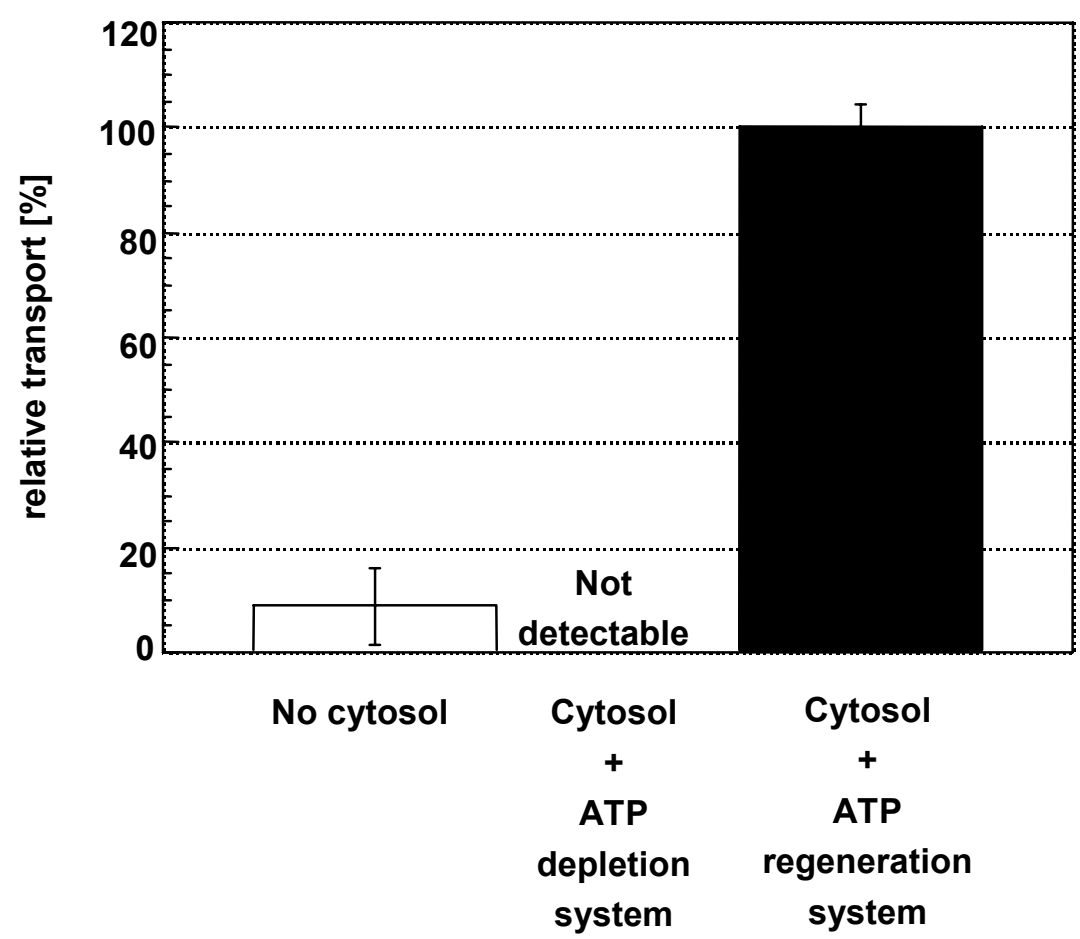

Figure 4.2.12: Assay for ATP dependence of the transport reaction.

In vitro assay reactions were performed with membranes and cytosol from control cells either in the presence of an ATP-regenerating system or ATP depletion system. The ATP depletion system consisted of a final concentration of $3 \mathrm{mM}$ glucose and $7.5 \mathrm{U} / \mathrm{ml}$ hexokinase. A representative figure out of two experiments is shown. Error bars indicate the maximum deviation of duplicate values from the average value.

ATP is necessary for the transport reaction as depletion of the ATP completely abolishes the transport reaction (Fig. 4.2.12).

\subsubsection{GTP and CAMP dependence}

With all the parameters standardized to achieve optimal transport of HMY-MPR46 to the TGN from the endosomes, we tested for the involvement of additional cytosolic factors known to be the regulators of vesicular transport.

GTPases like rab proteins, dynamin, ARFs play a major role in the vesiclemediated transport processes (Chavrier and Goud, 1999; Randazzo et al., 2000). The GTPases that regulate membrane transport processes exist in a GDP-bound inactive form and GTP-bound active form. GDP-GTP exchange activates and recruits the GTPases onto the membrane. Therefore, the GDP-GTP cycle is critical for the function of GTPases and perturbing this cycle would directly affect 
the transport processes. One way to prevent the GDP-GTP exchange is by the addition of non-hydrolyzable GTP analogs like GTP $\gamma S$ which will be exchanged for GDP and then will stay bound to the GTPases because the GTPase activating proteins (GAPs) cannot hydrolyze it. This locks the GTPases in a constitutively active state and hence would prevent the transport process.

In order to test for the involvement of GTPase(s) in our in vitro transport assay we performed assays in the presence of GTPyS (Fig. 4.2.13). Assays were also performed in the presence of a membrane permeable cAMP analog 8-(4Chlorophenylthio)adenosine 3',5'-cyclic monophosphate sodium salt (pCPTcAMP). This analog is a selective activator of cAMP dependent protein kinase (PKA) and has been shown to affect some vesicular transport pathways (Birkeli et al., 2003; Chavis et al., 1998).

The in vitro transport reaction is inhibited by GTP $\gamma S$ demonstrating the need for GTP hydrolysis and hence GDP-GTP exchange for transport to occur (Fig 4.2.13). This indicates that GTPases play a role in this transport process and supports the vesicular nature and the specificity of the in vitro reaction. The cAMP analog which activates PKA, stimulates transport by $35 \%$ over cytosol alone (Fig. 4.2.13). This demonstrates that activating PKA leads to increased transport efficiency of MPRs from endosome to the TGN. 


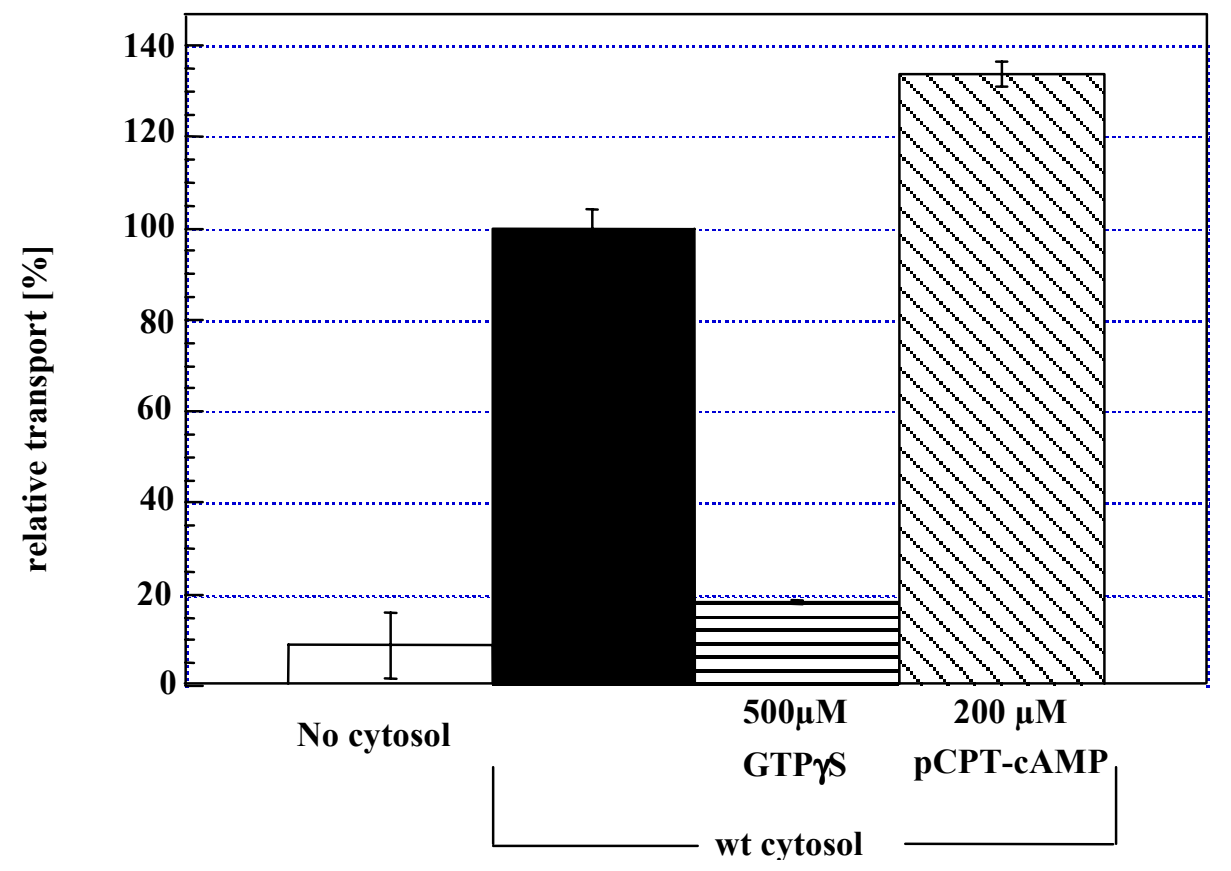

Figure 4.2.13: Assay in the presence of GTP $S$ and pCPT-cAMP.

Assays were performed with membranes and cytosol from control cells. GTP $S$ and pCPT-cAMP were added at the beginning of the in vitro assay. A representative figure out of two experiments is shown. Error bars indicate the maximum deviation of duplicate values from the average value.

\subsubsection{Analysis of the HMY-MPR46 endosome-to-TGN transport}

\subsubsection{Effect of Primaquine on the in vitro endosome-to-TGN transport}

In order to confirm about the pathway that we are measuring under our in vitro assay conditions we made use of the property of an anti-malarial drug, primaquine. Primaquine is a weak base and a lysosomotropic agent which has been shown to inhibit intra-Golgi transport (Geuze et al., 1985; Hiebsch et al., 1991). This property of primaquine has been used by previous studies to distinguish between intra-Golgi transport and endosome-to-TGN transport (Goda and Pfeffer, 1988; Hiebsch et al., 1991; Itin et al., 1997). We made use of these observations and performed assays to test for the effect of primaquine on our in vitro transport assay.

The in vitro transport reaction was not inhibited by primaquine (Fig 4.2.14) indicating that we are not measuring intra-Golgi transport and the HMY-MPR46 that is sulfated in the TGN under our in vitro condition is of endosomal origin. 


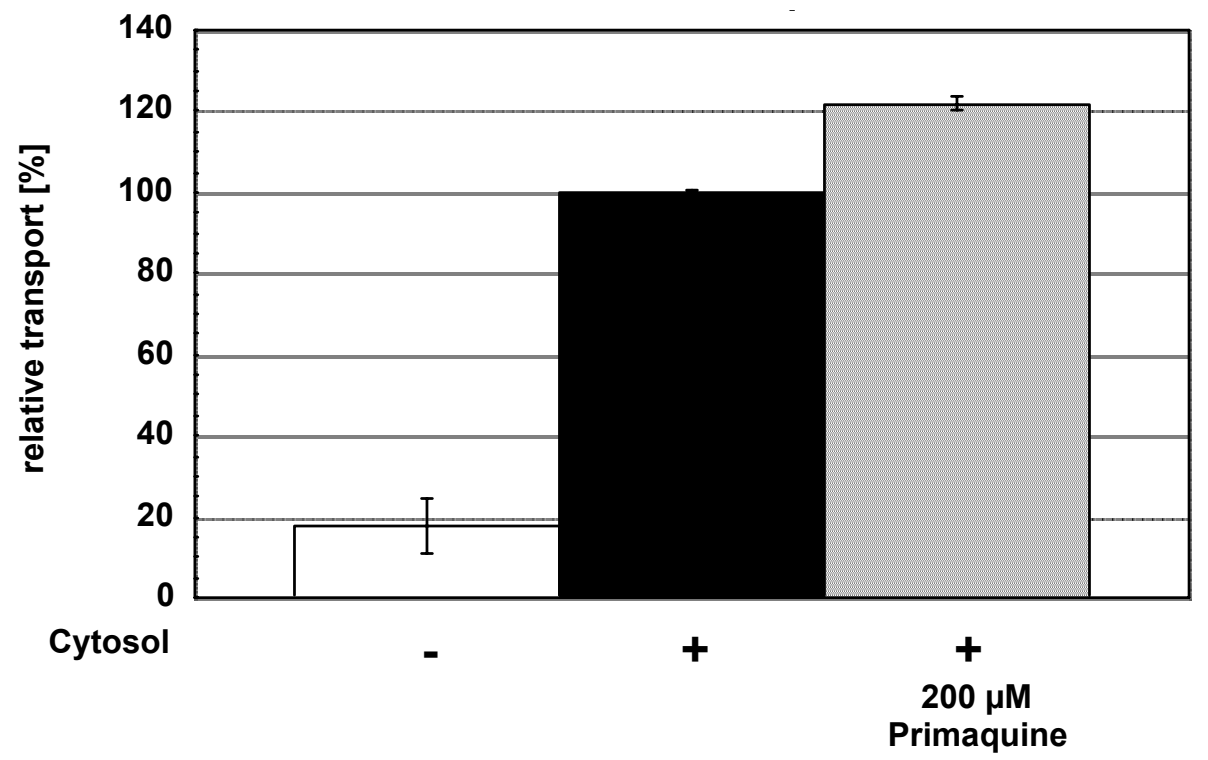

Figure 4.2.14: Assay to test the effect of primaquine.

Assays were performed with membranes and cytosol prepared from control cells. $200 \mu \mathrm{M}$ primaquine was added to the reaction mix where indicated at the beginning of the reaction. A representative figure out of two experiments is shown. Error bars indicate the maximum deviation of duplicate values from the average value.

\subsubsection{Transferrin endocytosis and immunofluorescence}

In order to further confirm that the MPRs that are sulfated in our in vitro assay are of endosomal origin, we performed immunofluorescence analysis of the control cells to visualize the localization of MPRs under the starting conditions of our membrane preparation. Cells were treated with cycloheximide for $2 \mathrm{~h}$ and transferrin which was endocytosed for 10 min served as a marker for peripheral early endosomes (Meyer et al., 2001; Shiba et al., 2002b; Waguri et al., 2003).

Tf

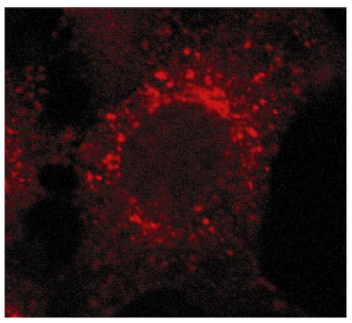

MPR46

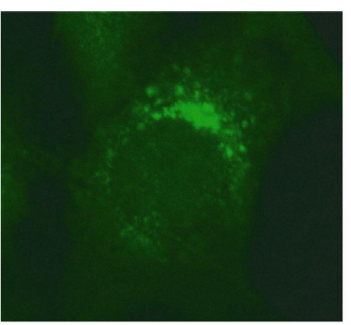

Overlay

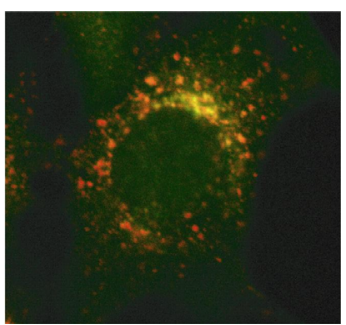

Figure 4.2.15: Localization of MPR46.

Cells were grown on cover slips, treated with $10 \mu \mathrm{g} / \mathrm{ml}$ cycloheximide for $2 \mathrm{~h}$. Transferrin endocytosis was performed as described in (3.2.2.6) for $10 \mathrm{~min}$ to label only the early endosomal structures and processed for immunoflorescence microscopy as described in (3.2.2.5.2). 
Under the starting conditions of our membrane preparation for the in vitro assay, majority of the MPR46 are at the TGN and peripheral endosomal structures (Figure 4.2.15). A significant amount of MPR46 is in peripheral endosomal structures which are most likely to be early endosomes as seen by the colocalization with endocytosed transferrin (Fig 4.2.15). Thus we propose that the HMY-MPR46 that are sulfated in the in vitro transport reaction are of endosomal origin.

\subsubsection{SNARE proteins involved in the in vitro retrograde transport reaction}

Vesicle-mediated transport events are mediated by soluble $\mathrm{N}$-ethylmaleimide sensitive factor attachment protein (SNAP) receptors (SNAREs), which are involved in the docking and fusion of vesicles to the target membranes. Intracellular membrane trafficking involves SNARE complexes consisting of SNARE proteins on the vesicle and the target membrane. Identifying a SNARE complex involved in the retrograde transport of HMY-MPR46 in our in vitro transport assay would give an indication of the endosome-to-TGN pathway that we are measuring.

Assays were performed as described in (3.2.3.4) in the presence of lgGs against the SNARE proteins, Vti1a and Syntaxin 16 which have been shown to be a part of SNARE complex that mediates early-endosome-to-TGN transport followed by 'Shiga' toxin (Monier et al., 2002). Syntaxin 16 serum was a kind gift from Dr. Gabriele Fischer von Mollard.

The antibodies against Vti1a and Syntaxin 16 inhibit the in vitro transport reaction by $40 \%$ whereas the control IgG has no effect (Fig. 4.2.16). This indicates that Vti1a and Syntaxin 16 are part of the SNARE complex that mediates retrograde transport of MPR46 from endosome to TGN. This further provides evidence that we are studying an early-endosome-to-TGN pathway in vitro. This result confirms that the in vitro assay fulfills the criteria of a specific early-endosome-to-TGN vesicular transport reaction. 


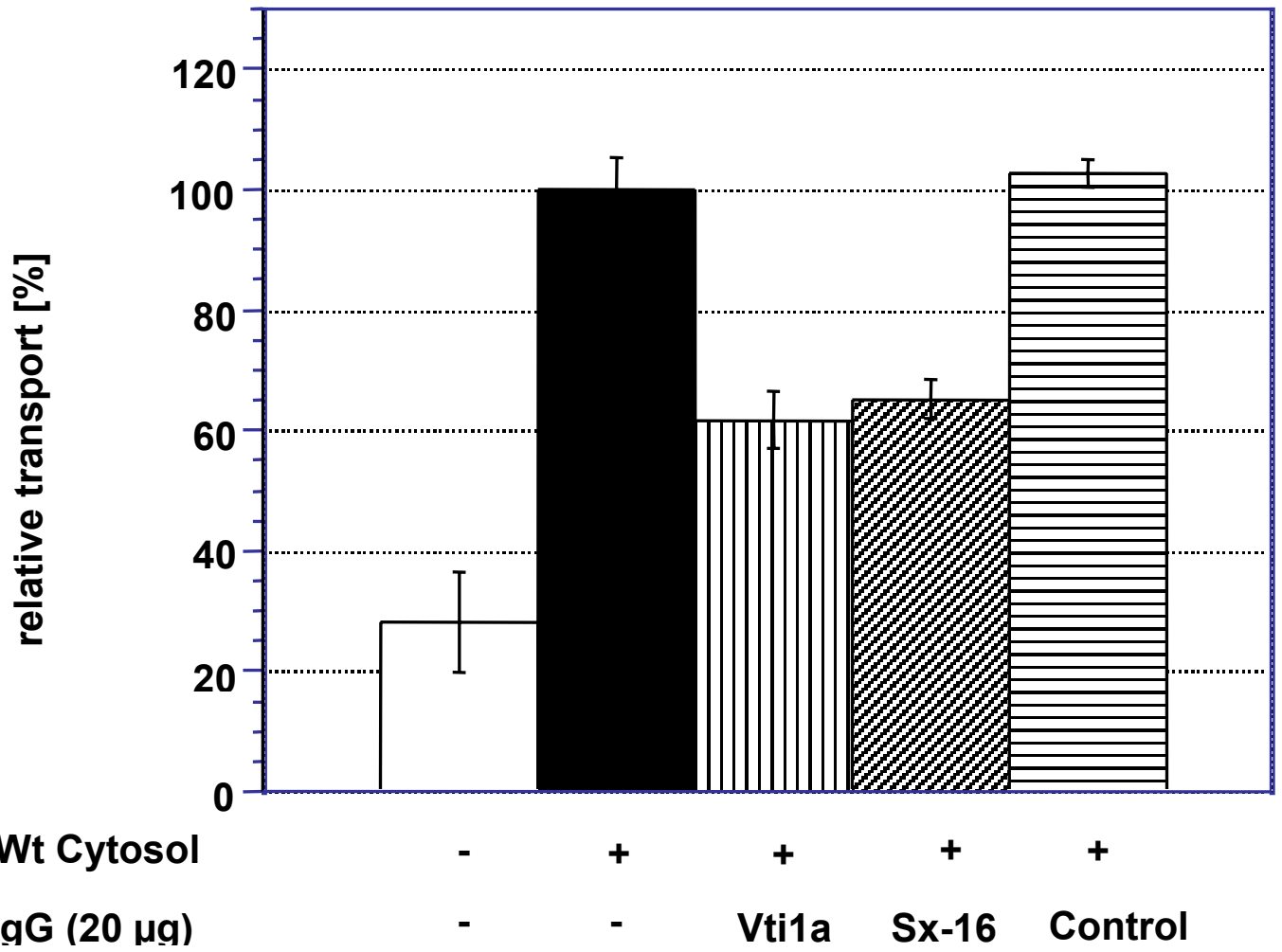

Figure 4.2.16: Effect of SNARE IgGs on in vitro transport reaction.

Membranes from control cells were incubated with control cytosol in the presence of $25 \mu \mathrm{g}$ of indicated IgGs. The sulfated receptors were immunoprecipitated, resolved by SDS-PAGE, visualized and quantitated by phosphoimager analysis. A representative figure from three experiments is shown. Error bars indicate the maximum deviation of duplicate values from the average value.

\subsubsection{Rab dependence of in vitro transport reaction}

The rab GTPases are a large family of proteins with a variety of regulatory functions in membrane trafficking. They have been shown to act in vesicle budding, targeting and tethering, regulation of late stages of vesicle fusion, and motility (Zerial and McBride, 2001). They are localized to specific organelles within the cell, many of the family members have been implicated in particular transport steps. Identifying the rab GTPase involved in the retrograde transport of MPR46 would provide further evidence to define this pathway. Rab11 and rab6a' have been shown to mediate early-endosome-to-TGN trafficking of various proteins like Shiga toxin and TGN38 (Mallard et al., 2002; Wilcke et al., 2000). Therefore we considered rab6a' and rab11 as the candidate SNAREs that could be involved in the endosome-to-TGN pathway that we are studying. We 
performed assays in the presence of rab6 and rab11 lgGs which was a kind gift from Prof. Bruno Goud.

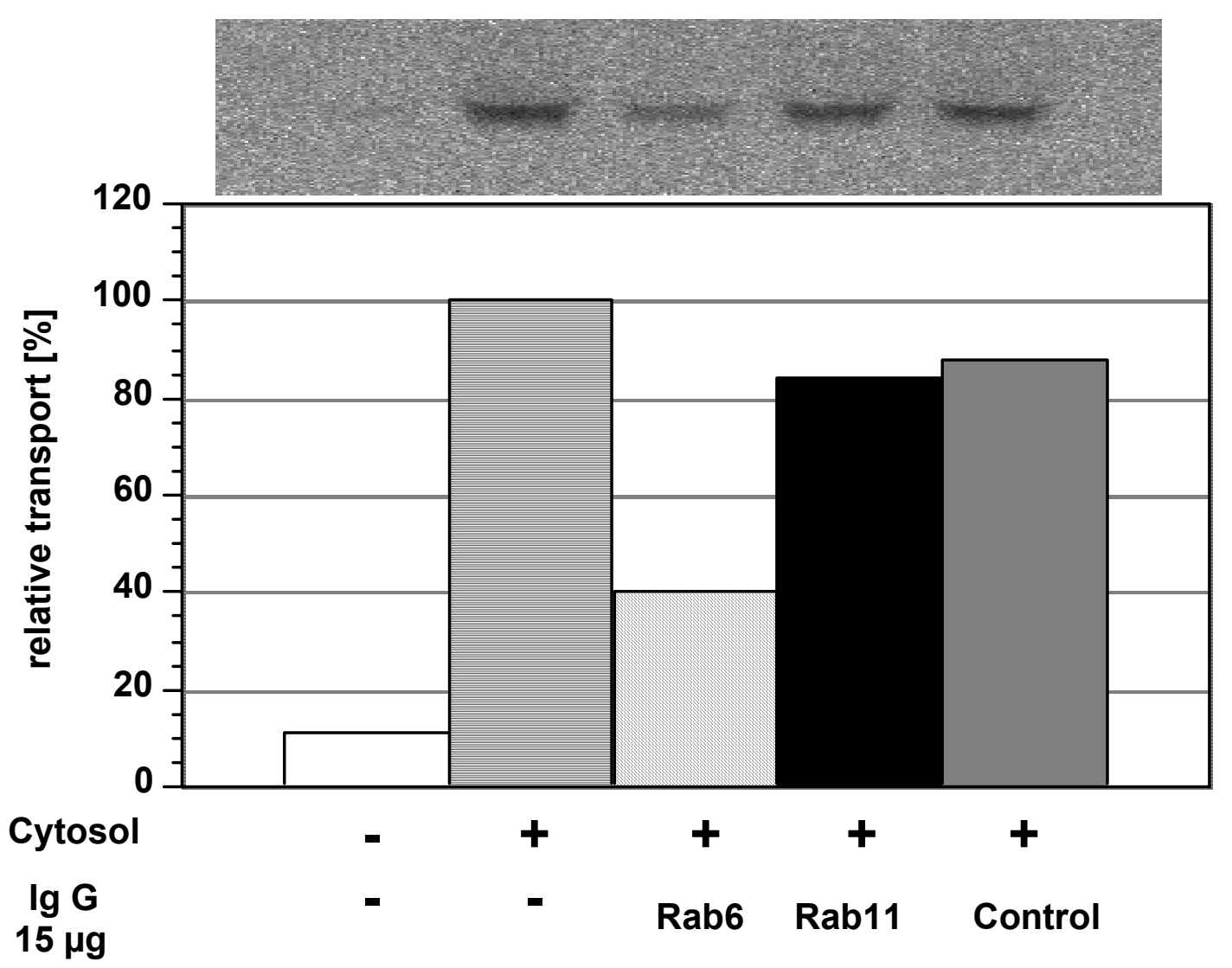

Figure 4.2.17: Rab dependence of the in vitro retrograde transport assay.

Assays were performed in the presence of $15 \mu \mathrm{g}$ of rab6, rab11 or rabbit lgGs. Sulfated HMYMPR46 was immunoprecipitated and analyzed by SDS-PAGE and phosphoimager analysis. Autoradiograph of the gel is shown and the corresponding quantitation is represented as a graph. This experiment was performed once because of the limited amount of IgGs.

Rab6 IgG inhibited transport reaction by $60 \%$ whereas rab11 IgG and control IgG did not show any inhibiition (Fig 4.2.17). This demonstrates that rab6 is involved in the retrograde transport of MPR46. The rab6 IgG that was used in the assay recognizes both the isoforms of rab6 (rab6a and rab 6a'), however it has been shown by others that rab6a' is involved in the endosome-TGN pathway (Monier et al., 2002) and rab6a is involved in the Golgi-ER pathway (Martinez et al., 1997). Therefore we conclude that we are measuring an early-endosome-TGN retrograde transport of MPR46 which is mediated by rab6a'. 


\subsubsection{Effect of AP-1-deficient cytosol on the retrograde transport of MPR46}

$\mu 1 \mathrm{~A}$-deficiency in mouse cells renders AP-1 non-functional as observed by the loss of membrane binding and defective MPR sorting phenotypes. MPRs are redistributed to early endosomes in these cells suggesting that AP-1 is required for the endosome-to-TGN transport of MPRs (Meyer et al., 2000). In vitro assays were performed as described (3.2.3.4) by incubating membranes isolated from control cells with cytosol prepared from control or AP-1-deficient cells.

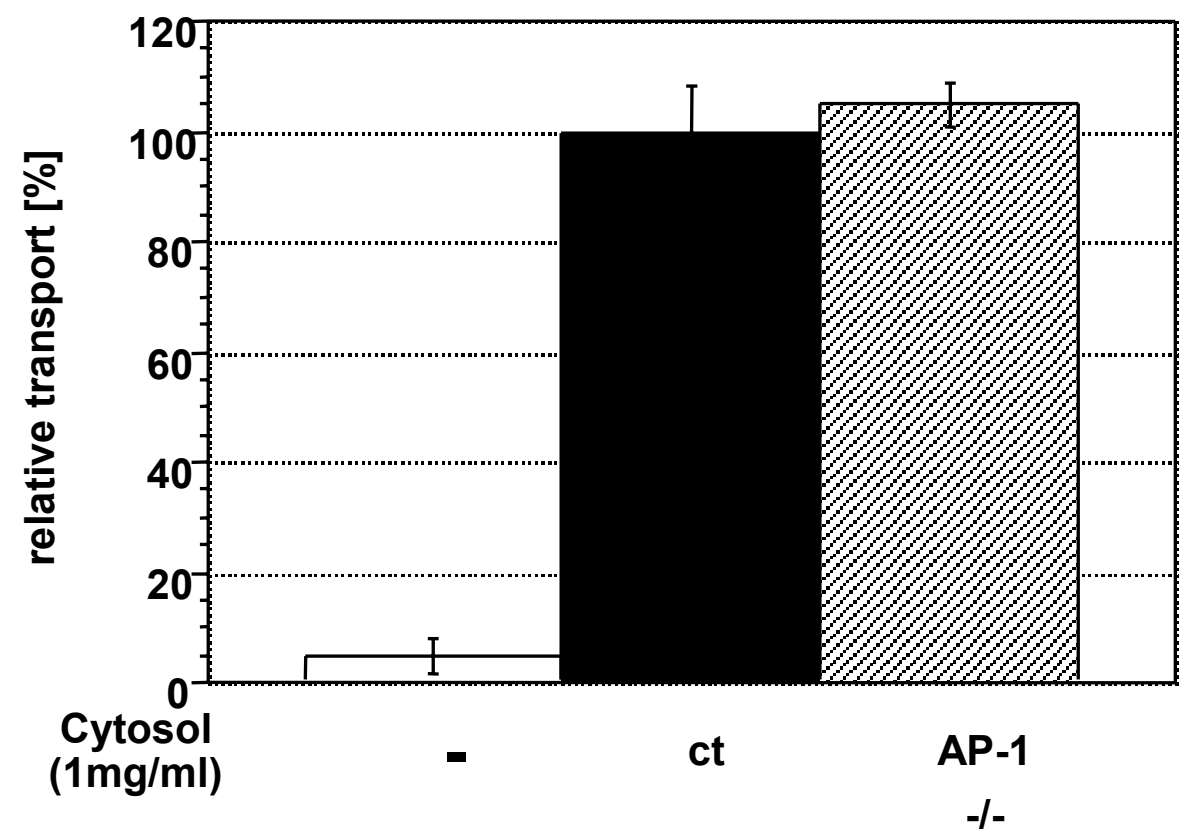

Figure 4.2.18: Assay to test the effect of AP-1-deficiency on the retrograde transport of HMY-MPR46. Membranes from control cells were incubated with control (ct) or AP-1-deficient cytosol for $2 \mathrm{~h}$ and the sulfated receptors were immunoprecipitated, resolved by SDS-PAGE, visualized and quantitated by phosphoimager analysis. A representative figure out of five experiments is shown. Error bars indicate the maximum deviation of duplicate values from the average value.

Under these in vitro conditions, cytosolic AP-1 is not required for the retrograde transport of MPRs from an endosomal compartment to the TGN (Fig. 4.2.18). Adaptor complexes are equally distributed between cytosolic and membrane fractions and hence it is possible that under these in vitro conditions the adaptors bound to the membrane of control cells are sufficient to mediate the transport reaction and thus the cytosolic fraction is not limiting for the transport reaction. 


\subsubsection{Estimation of membrane association of adaptors}

Since we did not see any effect of AP-1-deficient cytosol on the in vitro retrograde transport of MPR46, we argued that AP-1 isolated with the membrane fraction is sufficient to drive the transport reaction. In cellular subfractionation studies AP-1 fractionates $50 \% / 50 \%$ between the membrane and cytosolic fractions. The membrane preparation for the in vitro assay involves a pre-incubation step to label all TGN-resident sulfatable HMY-MPR46 with non-radioactive PAPS in presence of an ATP-regenerating system (see Materials and methods 3.2.3.2). This pre-incubation is performed at $37^{\circ} \mathrm{C}$ for $15 \mathrm{~min}$. It has been reported that a brief pre-incubation of membrane preparations in acetate buffer (used in our membrane preparation) in the presence of ATP releases AP-1 from the membranes (Traub et al., 1993; Zhu et al., 1998). We were interested to see whether or not these conditions are efficiently removing AP-1 associated with the membrane fraction during our pre-incubation step. Membranes were prepared as described (3.2.3.2) except that the pre-incubation was either done on ice or at $37^{\circ} \mathrm{C}$ for $15 \mathrm{~min}$. The amount of $\gamma$-adaptin and clathrin associated with the membrane fraction was analyzed by western blot. We also probed the blot for $\delta$ adaptin, a component of the AP-3 complex whose membrane binding is also mediated by ARF-1 (Ooi et al., 1998) and hence the mechanism of membrane association and dissociation of AP-3 could be similar to AP-1.

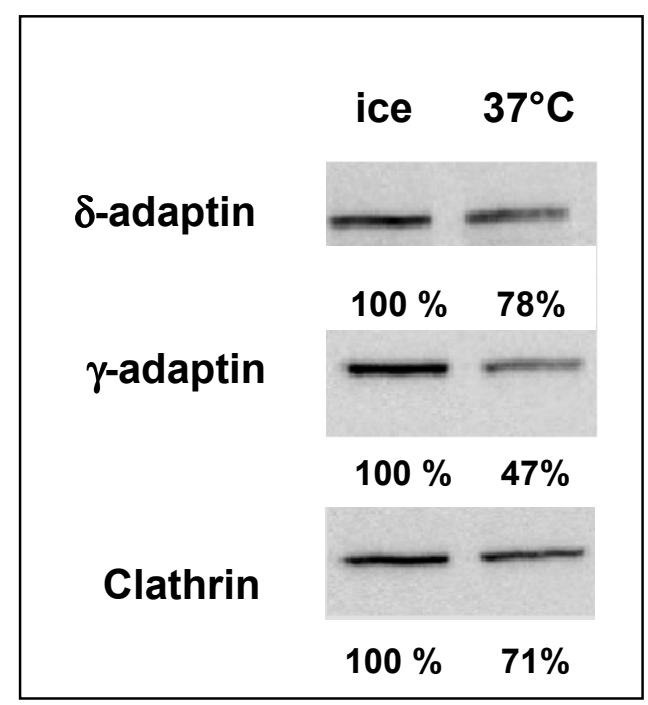

Figure 4.2.19: Analysis of the amount of membrane bound adaptors.

Membranes were prepared from control cells with pre-incubation for $15 \mathrm{~min}$ either at $37^{\circ} \mathrm{C}$ or on ice. Membrane fractions were analyzed by western blot with $\gamma$-adaptin, clathrin heavy chain and $\delta$ adaptin antibodies. Numbers indicate the amount of corresponding protein associated with the membrane fraction. 
As shown in Fig. 4.2.19, pre-incubation of membranes in the presence of an ATPregenerating system at $37^{\circ} \mathrm{C}$ releases $\mathrm{AP}-1, \mathrm{AP}-3$ and clathrin from the membrane fractions to varying extents. The amount of dissociation is more for AP-1 ( 50\%) as compared to AP-3 ( 22\%,) or clathrin ( 30\%) (Fig. 4.2.19). Considering the 50\%:50\% distribution of adaptors between membrane and cytosol at steady-state, this demonstrates that there is still 25,39 and $35 \%$ of total AP-1, AP-3 and clathrin bound to the membranes under the starting conditions of the in vitro assay and this fraction could very well be sufficient to mediate the transport reaction.

\subsubsection{Effect of BFA on the in vitro transport reaction}

As mentioned in the previous section (4.2.7.6), GDP-GTP exchange is critical for the activity of GTPases and this nucleotide exchange is brought about by the cytosolic guanine nucleotide exchange factors (GEFs). We focused on the exchange factors that bring about nucleotide exchange on ARF family of GTPases as this class of GTPases is well characterized and has been shown to play a role in AP-1-mediated transport processes (ARF1) in addition to other coated and non-coated vesicular transport events (Chavrier and Goud, 1999; Randazzo et al., 2000). AP-3 membrane association has also been shown to be ARF1-dependent, hence, the mechanism of membrane association of AP-3 could be similar to AP-1. ARF GEFs are classified into two classes based on their sensitivity to the fungal metabolite Brefeldin A (BFA). The BFA-sensitive GEFs contain a catalytic domain called Sec7-domain: a region of approximately 200 amino acids that is similar to a domain of $\mathrm{Sec} 7$, a protein required for ERthrough-Golgi transport in yeast, that is sufficient for their guanine nucleotide exchange activity. BFA is an uncompetitive inhibitor, which binds to the transient complex formed between ARF-GDP and the Sec7-domain, leading to an abortive ARF-GDP:BFA:Sec7domain complex. This way BFA traps the exchange factor and blocks the activation of other ARF molecules by this particular exchange factor (Roth, 1999; Chardin and McCormick, 1999; Cherfils and Chardin, 1999). 
The specificity of the effect of BFA on Sec7-domain-containing GEFs enabled us to easily test for the involvement of these proteins in the retrograde transport of MPR46. Assays were performed in the presence or absence of BFA and the amount of sulfated receptors was analyzed by immunoprecipitation, SDS-PAGE and autoradiography (Fig 4.2.20).

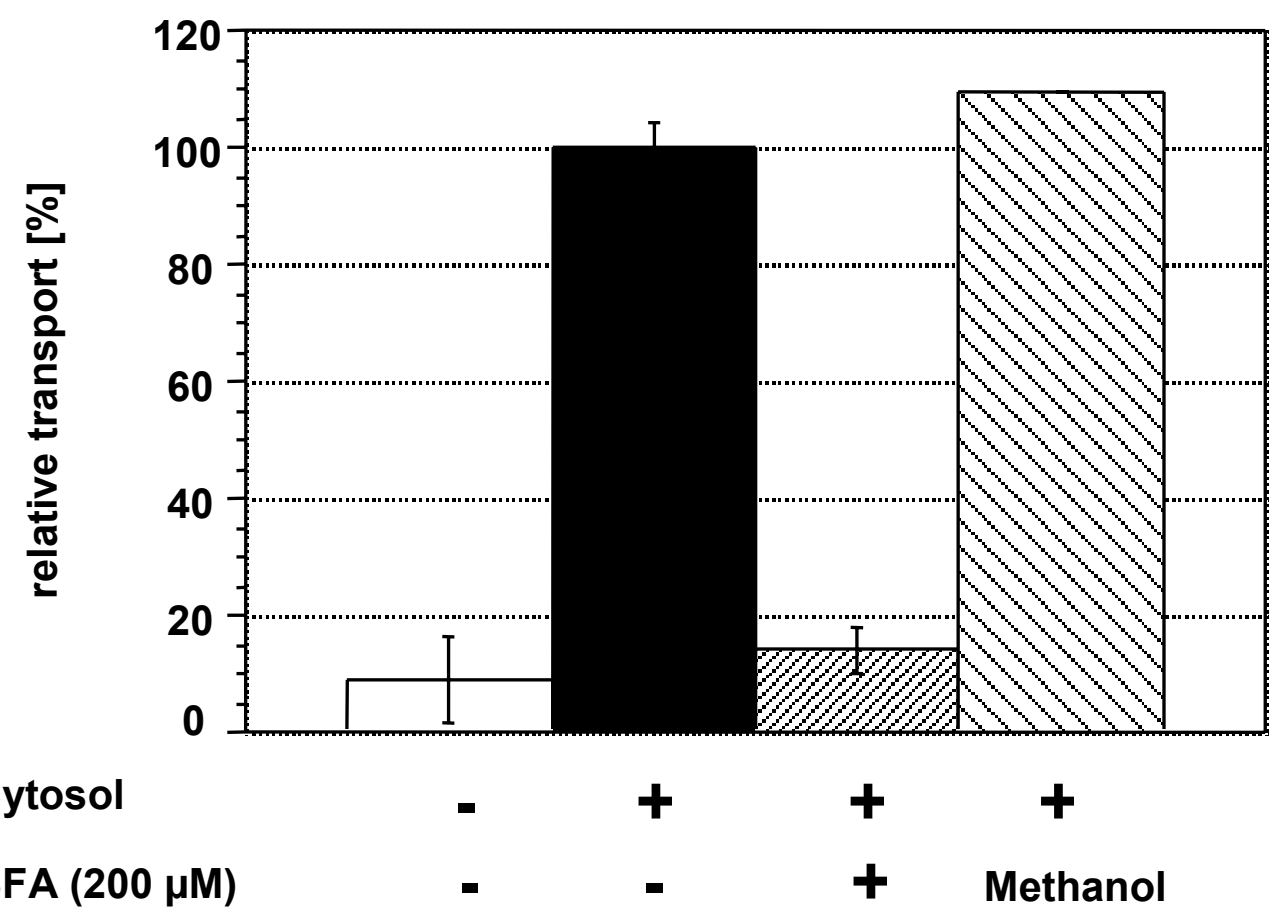

Figure 4.2.20: Assay to test the effect of Brefeldin A.

Membranes and cytosol from control cells were incubated with or without $200 \mu \mathrm{M}$ BFA for $2 \mathrm{~h}$. $B F A$ is dissolved in methanol and therefore the assay reaction with equal volume of methanol added, served as control. A representative figure out of two experiments is shown. Error bars indicate the maximum deviation of duplicate values from the average value.

Presence of BFA completely inhibits the transport reaction indicating that Sec7domain-containing GEFs are involved in the retrograde transport step of MPR46 (Fig 4.2.20). This and the inhibitory effect of GTP $\gamma S$ (Fig 4.2.13) demonstrates that GTPase cycles take place during, and are essential for the in vitro retrograde MPR46 transport. Addition of equal volume of methanol, the solvent in which BFA is dissolved, has no effect. 


\subsubsection{Effect of AP-3-deficiency on the retrograde transport of MPR46}

The inhibitory effect of BFA in the in vitro transport reaction indicated that this transport is mediated by a BFA-sensitive GEF which in turn would implicate the involvement of ARF family of GTPases. ARF1 is required for the membrane recruitment of both AP-1 and AP-3 (Crottet et al., 2002; Dittie et al., 1996; Ooi et al., 1998; Traub et al., 1993). Since AP-1-deficient cytosol had not effect on the in vitro transport reaction, it was now interesting to test the effect of AP-3-deficiency on the in vitro retrograde transport assay. A recent study has reported the interaction of $\mu 3 \mathrm{~A}$ subunit specifically with the cytoplasmic tail of MPR46 both by yeast-two-hybrid analysis and "pulll-down" assays (Storch and Braulke, 2001). This report further encouraged us to test the involvement of AP-3 in the in vitro retrograde assay. Natural mouse mutants of AP-3 exist and AP-3-deficiency leads to altered trafficking of membrane lysosomal proteins like LAMP1 and viral glycoprotein gp48 (Dell Angelica et al., 1999b; Reusch et al., 2002).

Western blot analysis was performed to verify the presence or absence of the respective subunits of AP-1 or AP-3 (Fig. 4.2.21 A). Control cells are positive for all the three subunits tested ( $\mu 1 \mathrm{~A}, \gamma$ and $\delta$-adaptin), whereas AP-1-deficient cells lack $\mu 1 \mathrm{~A}$ and AP-3-deficient cells lack $\delta$-adaptin subunits respectively (Fig. 4.2.21 A). Assays were performed by using membranes from control cells and cytosol from control, AP-1-deficient and AP-3-deficient cells (Fig 4.2.21 B).

We could see no significant difference between control and AP-1-deficient cytosols in stimulating the transport of MPR46 while AP-3-deficient cytosol was only $50 \%$ efficient as compared to the control or AP-1-deficient cytosol. (Fig 4.2.21 A). This indicates that AP-3-deficiency inhibits the transport reaction either due to lack of AP-3 itself or some other cytosolic factor whose function relies on the presence of AP-3. 
A

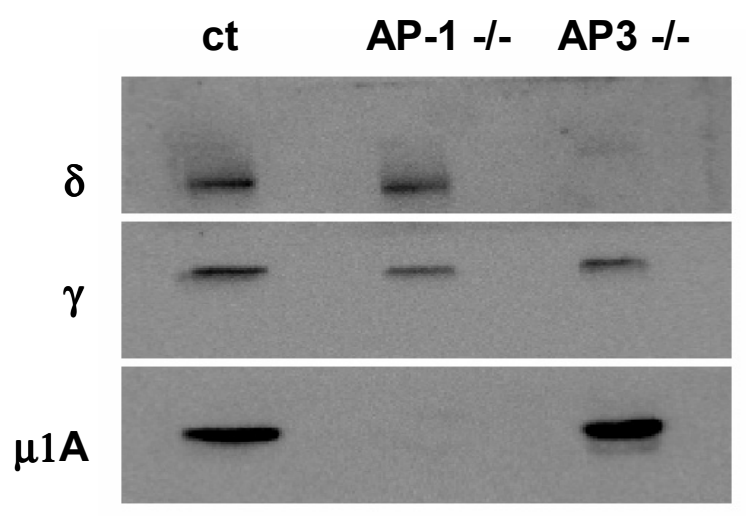

B

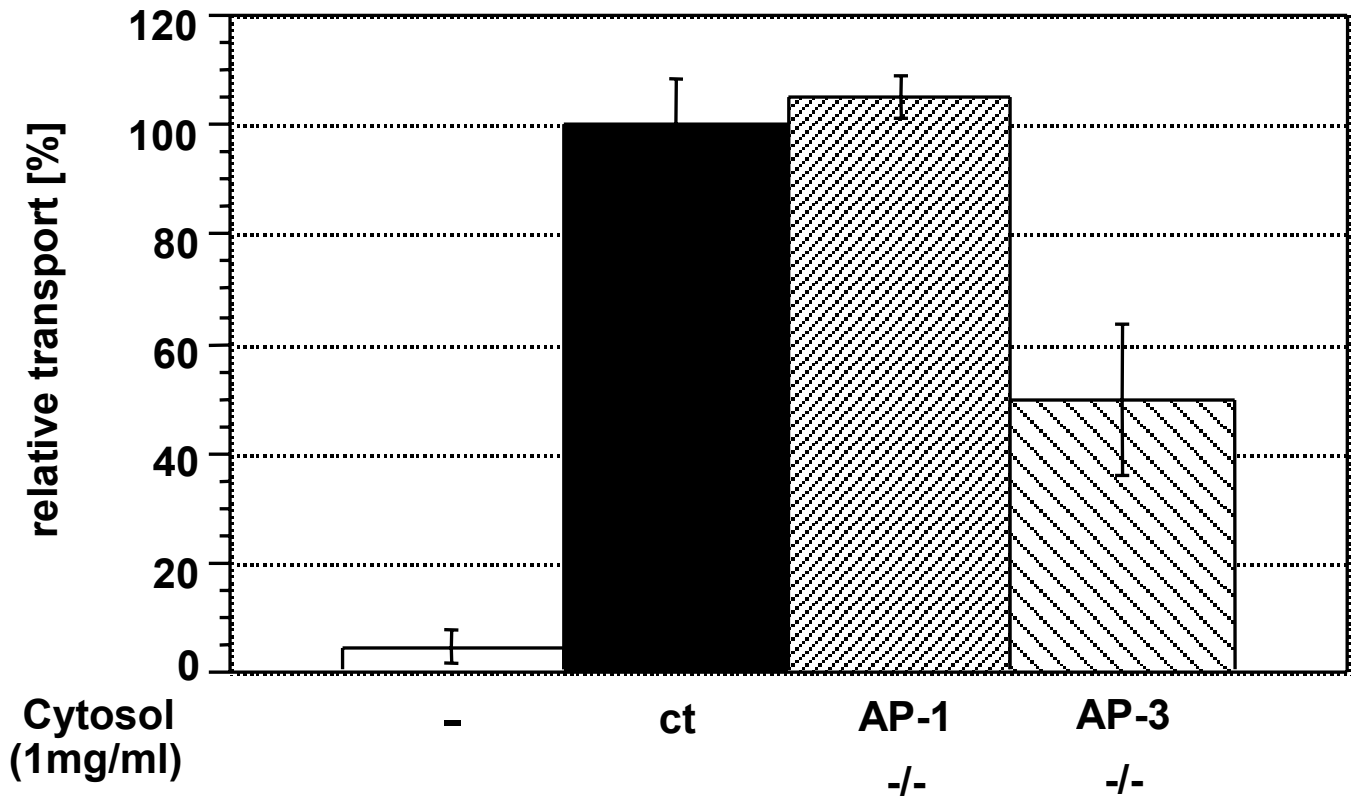

4.2.21 Effect of AP-1 and AP-3-deficiency on the retrograde transport of MPR46.

A: Western blot analysis of the cytosols used in the in vitro assay. $50 \mu \mathrm{g}$ of the cytosol fractions prepared from the control (ct), AP-1-deficient and AP-3-deficient cytosols were analyzed by SDSPAGE $(7.5 \%)$ and western blot against $\delta$-, $\gamma$ - and $\mu 1 \mathrm{~A}$-subunits. B: Assays were performed with membranes prepared from control cells and cytosol from control (ct), AP-1-deficient and AP-3deficient cells. Sulfated receptors were immunoprecipitated and analyzed by SDS-PAGE and autoradiography. A representative figure out of three experiments is shown. Error bars indicate the maximum deviation of duplicate values from the average value.

The residual transport that we observe in reactions with AP-3-deficient cytosol could be either due to the contribution of membrane-associated AP-3, thus lowering the dependence of the in vitro reaction on cytosolic AP-3 or due to another BFA-sensitive coat protein (for eg: AP-1) mediating the residual transport in the absence of AP-3. 


\subsubsection{Effect of pre-treatment of membranes with BFA}

It has been shown that BFA can prevent membrane association of AP-1 from the cytosol, both in intact and permeabilized cells (Robinson and Kreis, 1992). If the fraction of AP-1 and AP-3 associated with membranes is sufficient to mediate the retrograde transport of MPRs, a complete dependence of AP-1 or AP-3 cannot be detected by using cytosols deficient for either of these proteins. In order to get rid of the membrane-associated adaptors, membranes were pre-treated with BFA. BFA was included in all the steps of membrane preparation and these membrane fractions were analyzed by western blot to estimate the efficiency of stripping for AP-1, AP-3 and clathrin.

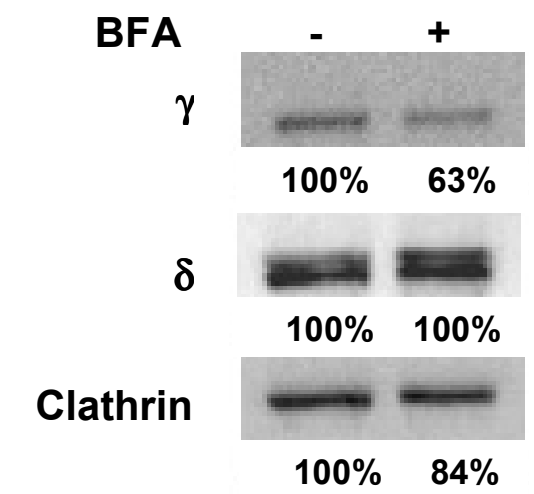

Figure 4.2.22: Western blot analysis to monitor the stripping efficiency of BFA.

Membranes from control cells were prepared by pretreating them with $200 \mu \mathrm{M}$ BFA which was present during all stages of membrane preparation. $50 \mu \mathrm{g}$ of membranes was used for western blot analysis. Blot was cut into two based on the pre-stained molecular weight markers for $\gamma$ adaptin and clathrin antibodies, clathrin blot was then again probed with $\delta$-adaptin antibody, hence the appearance of double bands, upperband is clathrin and lower band is $\delta$ adaptin.

Western blot analysis indicated that the pre-treatment of membranes with BFA dissociated AP-1 to a significant amount from the membranes whereas it has a minimal effect on clathrin and no effect on AP-3 (Fig. 4.2.22). This demonstrates that under these conditions, it is not possible to completely strip APs from membranes. But, as our membrane preparations are semi-intact cell preparations, it is possible that adaptors form aggregates and are non-specifically associated with the membranes and hence are insensitive to BFA treatment. We investigated the effect of this pre-treatment in the in vitro assay. The BFA-pretreated membranes were used in the in vitro transport reaction with cytosols from control, AP-1-deficient and AP-3-deficient cells. 


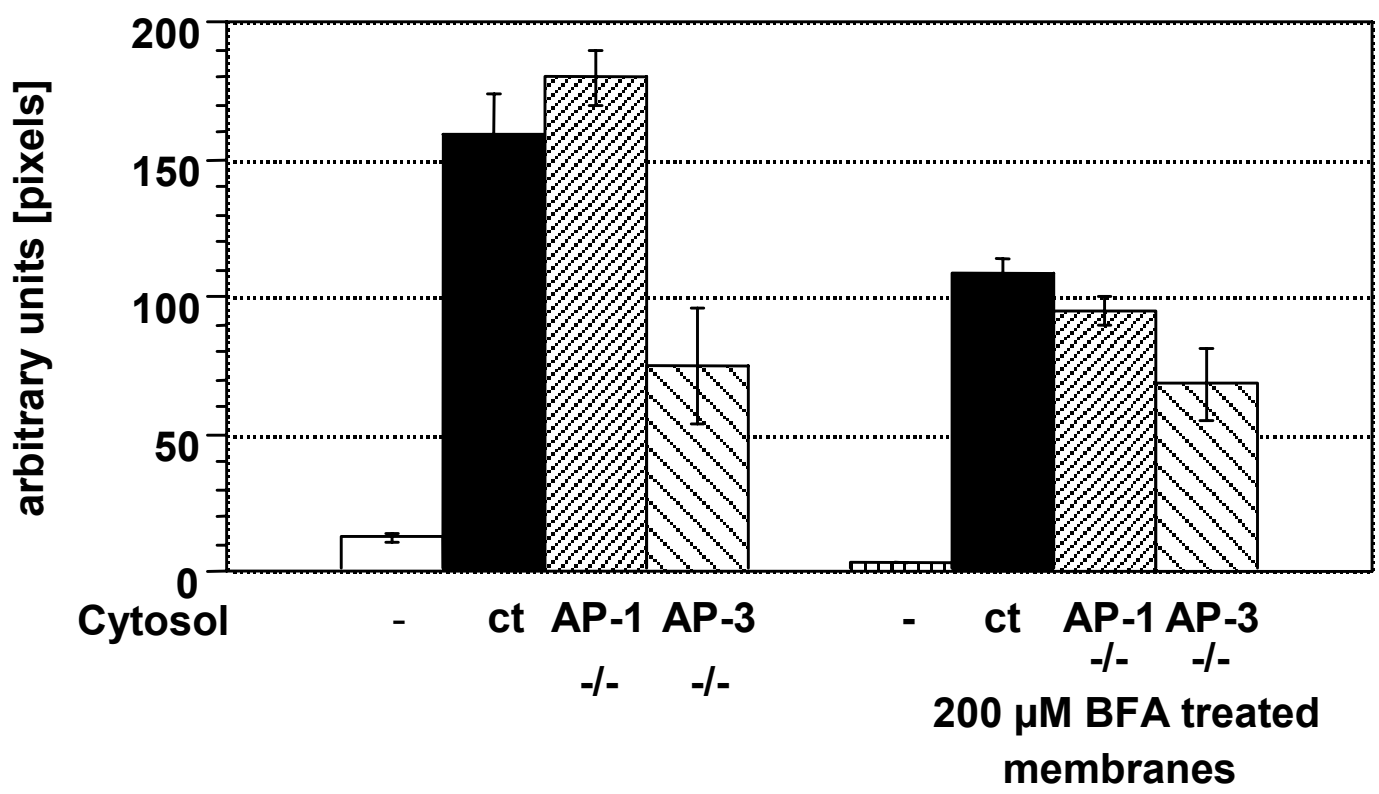

Figure 4.2.23: Efficiency of BFA pre-treated membranes in the in vitro transport reaction. Assays were performed with BFA pre-treated membranes and cytosol from control (ct), AP-1deficient and AP-3-deficient cells. A representative figure out of three experiments is shown. Error bars indicate the maximum deviation of duplicate values from the average value.

BFA pre-treatment of the membranes reduced the overall transport efficiency by $50 \%$ with both control and AP-1-deficient cytosols whereas the transport observed with AP-3-deficient cytosol was less affected (Fig 4.2.23). This indicates that a BFA-sensitive factor(s) (e.g. AP-1, which may not re-bind to the membranes during in vitro conditions), on the membrane is irreversibly altered due to the BFA pre-treatment of the membrane and this results in loss of transport competence. Cytosolic factors cannot compensate for this loss. BFA is readily washed out in cell culture experiments and thus it is unlikely that residual BFA is responsible for the reduced transport efficiency in vitro.

\subsubsection{AP-1 and AP-3 membrane association during the assay}

In order to verify if the in vitro assay conditions are appropriate for association of adaptors and clathrin with the membranes, we followed the membrane association of AP-1, AP-3 and clathrin during incubation of the assay reactions. Assays were performed with or without cytosol for the indicated periods and the 
and the membrane pellets were analyzed by SDS-PAGE and western blot analysis with $\delta$ - , $\gamma$-adaptin and clathrin antibodies (Fig. 4.2.24).

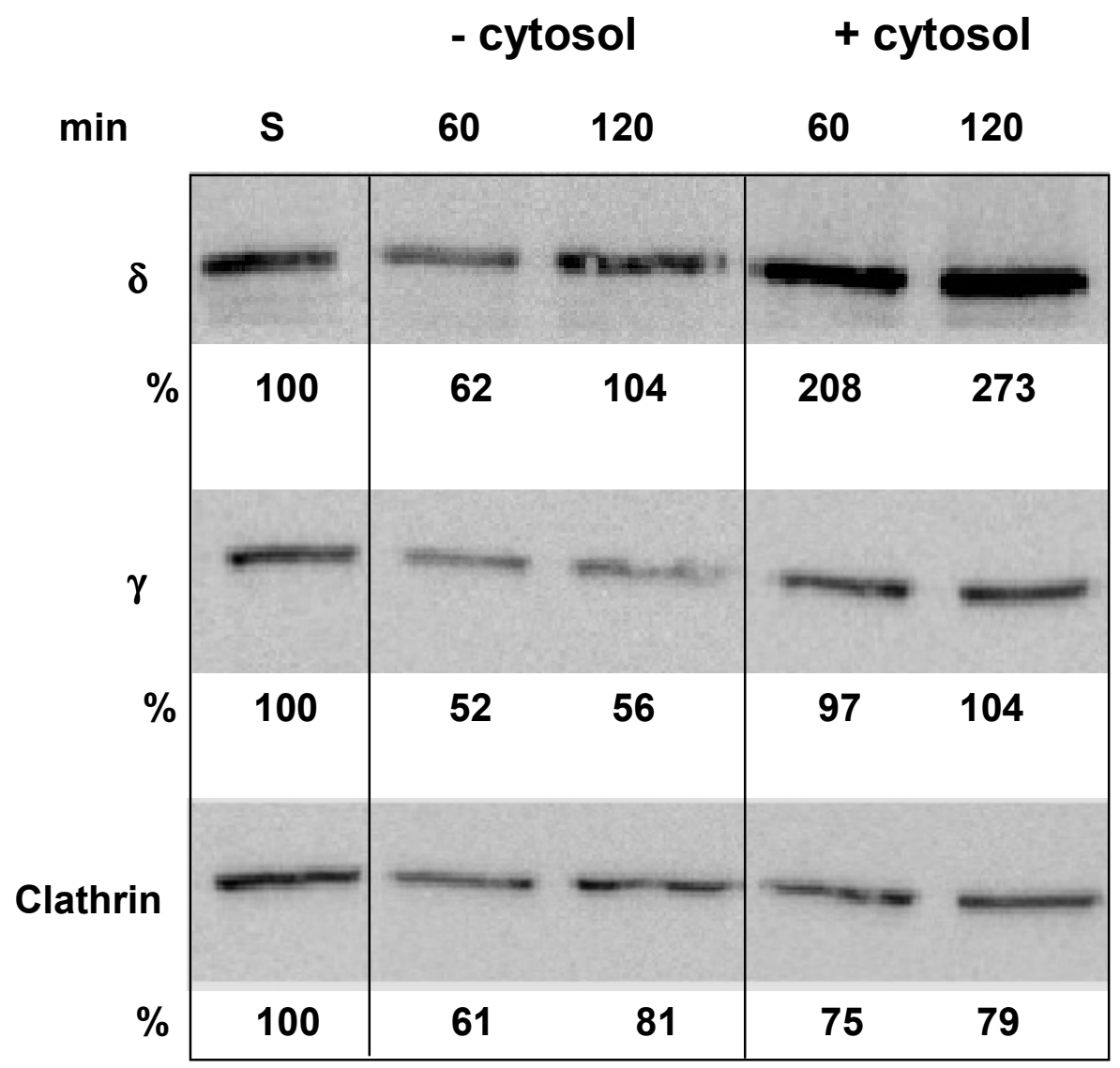

Figure 4.2.24 Membrane association of AP-3, AP-1 and clathrin during in vitro reaction.

Assays were performed with membranes and cytosol from control cells, no PAPS was added to the reaction mixes. Assay reactions were placed on ice immediately after each time point and centrifuged at $13,000 \mathrm{~g}$ for $10 \mathrm{~min}, 4^{\circ} \mathrm{C}$. Supernatant was discarded and the pellets were washed once with cold PBS by centrifuging again at $13,000 \mathrm{~g}$ for $10 \mathrm{~min}, 4^{\circ} \mathrm{C}$. The wash supernatant was discarded and the pellet was solubilized in $40 \mu \mathrm{l}$ of 1 X SDS-PAGE buffer and resolved on a $7.5 \%$ SDS-PAGE. Blots were cut based on the pre-stained molecular weight marker for $\delta$-, $\gamma$-adaptin and clathrin western blots. S-Starting material

The membrane-associated AP-1 and AP-3 dissociate from membranes in the absence of cytosol. When the incubations were performed in the presence of cytosol, membrane association of AP-3 increased by about 3 fold after $2 \mathrm{~h}$, whereas the amount of AP-1 on the membranes did not change. It has been shown that clathrin exchange between cytosolic and membrane fractions is independent of adaptors (Wu et al., 2003). Clathrin levels associated with the 
membranes also did not change under these conditions. This indicates that either AP-1 and clathrin do not recycle between the membrane and the cytosolic pool during our in vitro assay conditions or that the binding sites for AP-1 on the membranes are saturated but not for AP-3. The kinetics of association could also differ between AP-1 and AP-3 and this has to be further investigated. However, the specificity of this association of AP-1 and AP-3 with membranes under our in vitro conditions is yet to be determined. Nevertheless, this shows that there is association of cytosolic AP-3 onto the membranes during the in vitro transport reaction further indicating the involvement of AP-3 in the retrograde transport of MPR46 under these conditions.

\subsubsection{TIP47 dependence}

TIP47 is a protein which has been shown to be involved in the retrograde transport of MPRs from late endosomes to the TGN in $\mathrm{CHO}$ cells (Diaz and Pfeffer, 1998). MPRs are predominantly localized to the TGN and peripheral early endosomes in mouse embryonic fibroblasts which is the system that we are using. Hence it was interesting to investigate if TIP47 can mediate the transport of MPRs under our in vitro conditions. Assays were performed with membranes prepared from control cells and cytosols from HeLa and HeLa-TIP47 anti-sense cells (a kind gift from Dr. Stefan Hoening).

TIP47 anti-sense cytosol had no effect on the in vitro retrograde transport of MPR46 that we are measuring (Fig 4.2.25). This is in line with the steady-state localization of MPRs in our cell lines to the TGN and early endosomes, whereas TIP47 has been shown to mediate transport from late endosomes to the TGN in the $\mathrm{CHO}$ cell line. Furthermore, the TIP47-mediated pathway has been shown to be BFA-insensitive but BFA inhibits our assay completely. Thus we can conclude that the retrograde pathway of MPR46 in fibroblasts is TIP47-independent and therefore represents a new retrograde transport pathway. 


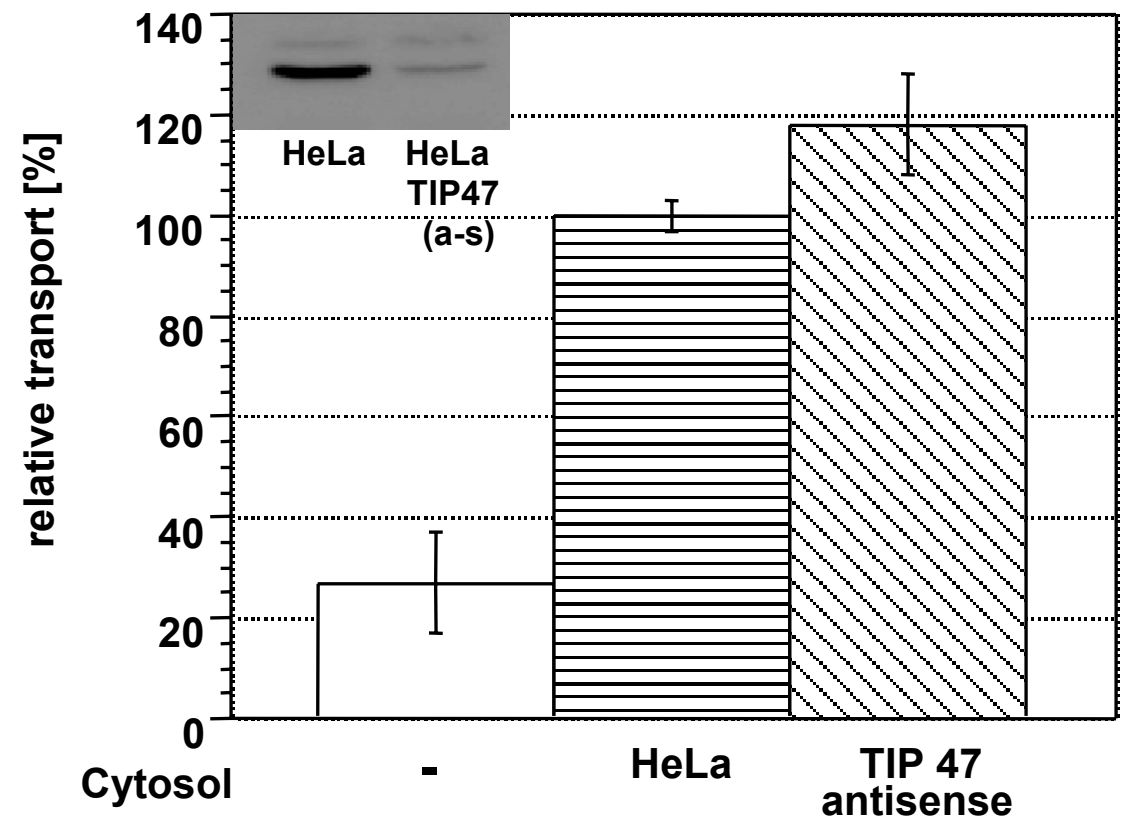

Figure 4.2.25: TIP47 dependence of the in vitro retrograde transport of MPR46.

Assays were performed with membranes prepared from control cells and cytosol from HeLa and HeLa-TIP47 antisense cells. Inset is a western blot analysis of the cytosols used in the assay. 50 $\mu \mathrm{g}$ of the cytosol was analyzed by western blot with anti-TIP47 antibody. TIP47 antisense cells expressed only $8 \%$ of the protein as compared to the wild type cells. A representative figure out of two experiments is shown. Error bars indicate the maximum deviation of duplicate values from the average value.

\subsubsection{Assays with AP-1-deficient membranes}

Assays with control cells failed to directly demonstrate a AP-1 function in the formation of transport vesicles on the endosomes to mediate the MPR46 retrograde transport. In all these reactions we cannot rule out the possibility of membrane-bound AP-1 sufficing for the requirement of the assay reaction. We reconstituted the in vitro transport reaction with membranes from AP-1-deficient cells where there is no functional AP-1 in order to address this problem. Furthermore these experiments should reveal an indirect function of AP-1 in the generation of transport-competent endosomes by its TGN-to-endosome sorting activity. 


\subsubsection{AP-1 and AP-3-depencence}

Assays were performed with membranes prepared either from control or from AP1-deficient cells and cytosols from both control and AP-1-deficient cells.

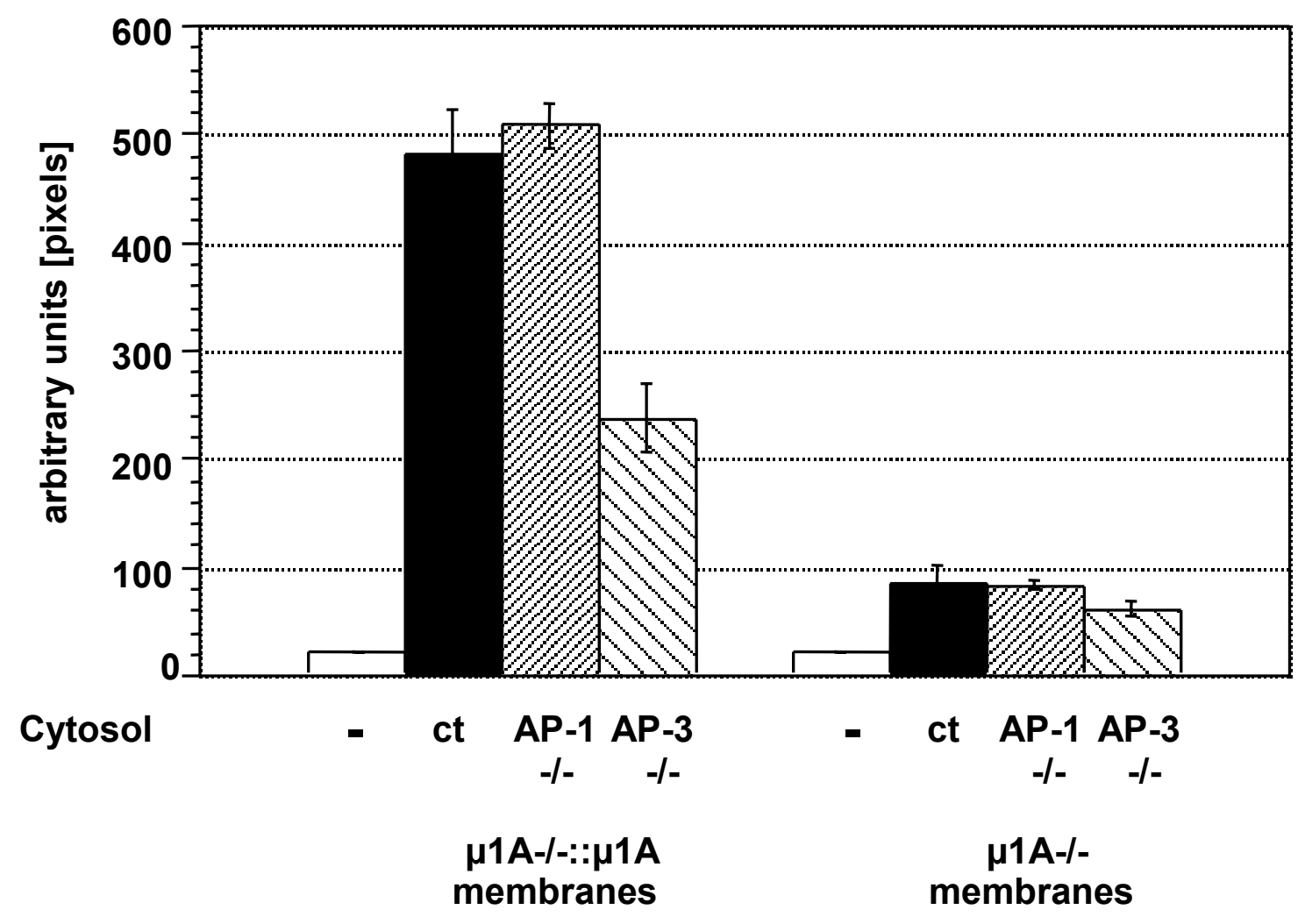

Figure 4.2.26: In vitro transport assay with AP-1-deficient cells.

Assays were performed with membranes prepared from control or AP-1-deficient cells and cytosol prepared from control (ct) or AP-1-deficient cells or AP-3-deficient cells. A representative figure out of three experiments is shown. Error bars indicate the maximum deviation of duplicate values from the average value.

The membranes prepared from AP-1-deficient cells were very inefficient in promoting the in vitro retrograde transport of MPR46 as compared to membranes prepared from control cells (Fig 4.2.26). We observed only about $20 \%$ of the transport compared to membranes prepared from control cells.

However no differences in the stimulatory effect of cytosol was observed between control, AP-1 or AP-3-deficient cytosol. Loss of even AP-3-dependence was surprising. The inefficiency is not due to high non-specific background transport. We were not able to demonstrate cytosolic AP-1 or AP-3-depencence with these 
membranes, but the drastically reduced transport efficiency of the membranes from AP-1-deficient cells indicates that AP-1 is required to maintain membrane competency for retrograde transport of MPR46. If AP-3 is involved in the retrograde transport of MPR46 (as observed with membranes from control cells, described under 4.2.8.8, also see Fig 4.2.26, $\mu 1 \mathrm{~A}-/-:: \mu 1 \mathrm{~A}$ membranes), its function depends on AP-1-mediated TGN-to-endosome sorting.

\subsubsection{Membrane-associated AP-1}

The distribution of trimeric AP-1 complex $(\gamma 1: \beta 1: \sigma 1)$ between cytosolic fraction and membrane sub-fractions in AP-1-deficient cells is comparable to the distribution of functional AP-1 complexes between these fractions in control cells. We were interested to investigate the amount of $\gamma 1$ that is still associated with the membranes at the beginning of our assay as we had done in the case of control cells. Experiment was performed as described in (4.2.8.6).

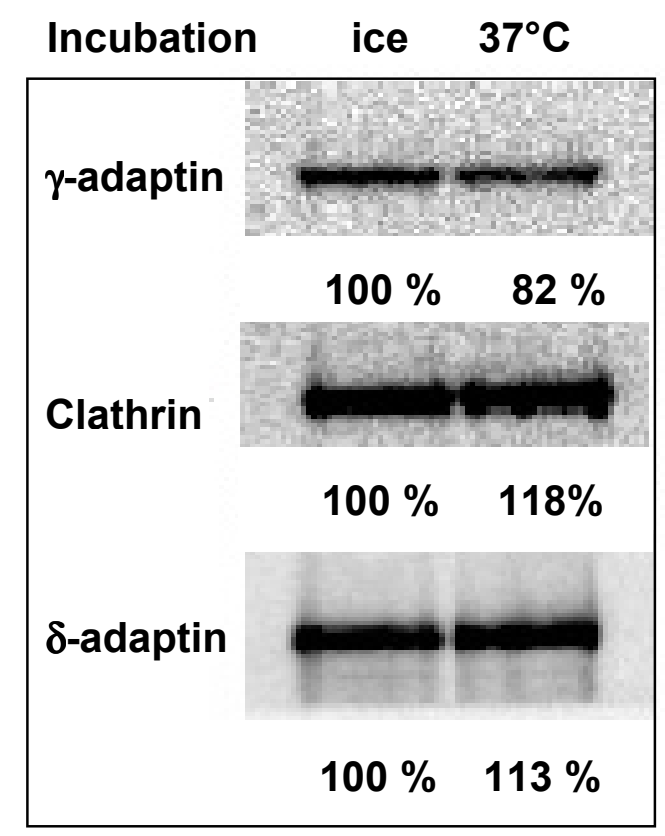

Figure 4.2.27: Analysis of the amount of membrane bound adaptors.

Membranes were prepared from AP-1deficient cells with pre-incubation for 15 min either at $37^{\circ} \mathrm{C}$ or on ice. Membrane fractions were analyzed by western blot with $\gamma$-adaptin, clathrin heavy chain and $\delta$-adaptin antibodies

When control membranes were incubated at $37^{\circ} \mathrm{C}$ in presence of ATP, about $50 \%$ of AP-1, $20 \%$ of AP-3 and $30 \%$ of clathrin dissociated from the membranes (Fig 4.2.19). None of these proteins dissociate from the membrane fractions prepared from AP-1-deficient membranes upon a similar pre-incubation (compare Fig 4.2.19 with Fig 4.2.27). This indicates that in AP-1-deficient membranes, the 
adaptors and clathrin are very tightly and therefore unspecifically associated with membranes under the in vitro assay conditions indicating that some factor essential for adaptor protein recycling is non-functional due to AP-1-deficiency. In vivo however, perinuclear concentration of clathrin and $\gamma 1$ staining is lost due to AP-1-deficiency.

\subsubsection{Effect of GTP $\gamma$ S and BFA}

We have shown earlier that GTP $\gamma$ S and BFA were inhibitory in the retrograde transport assay (Fig 4.2.13 \& 4.2.20). Assays were performed with membranes prepared from AP-1-deficient cells and cytosol from control cells. GTP $\gamma \mathrm{S}$ and BFA were added to the reaction mixes where indicated to see if this transport route has similar characteristics.

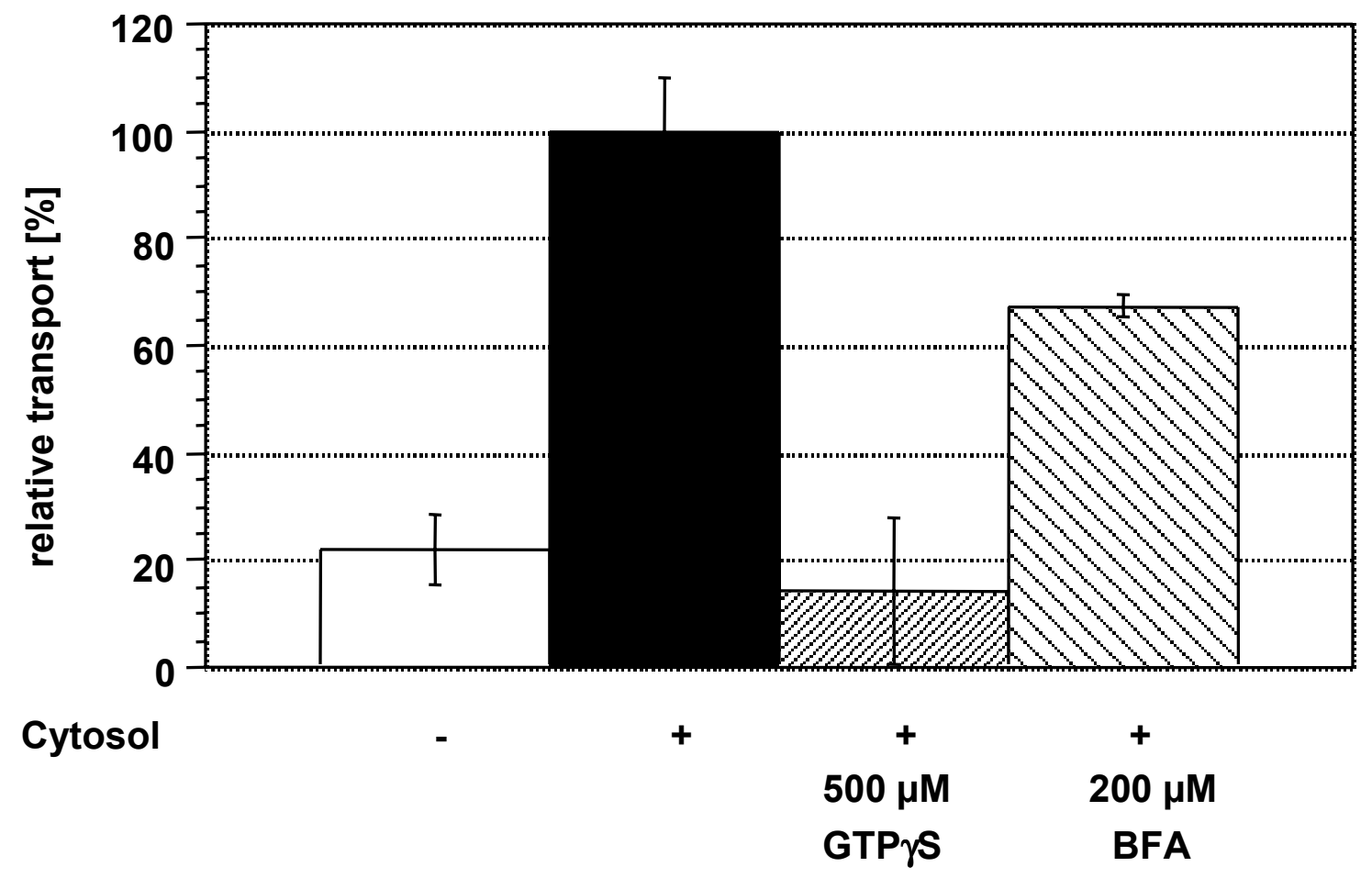

Figure 4.2.28: Effect of GTPyS and BFA.

Membranes were prepared from AP-1-deficient cells and cytosol from control cells. Assay reactions were incubated with $500 \mu \mathrm{M}$ GTP $\gamma$ and $200 \mu \mathrm{M}$ BFA where indicated. A representative figure out of two experiments is shown. Error bars indicate the maximum deviation of duplicate values from the average value. 
GTP $\gamma$ S inhibited the cytosol-dependent transport step completely indicating that GTP hydrolysis is necessary for the transport step as in control cells (compare Fig. 4.2.13 with 4.2.28). BFA only partially inhibited the transport reaction with AP-1-deficient membranes, at the concentration which was completely inhibitory in the assays with control membranes (compare Figure 4.2.20 with 4.2.28). This transport process is not entirely BFA-sensitive, but with these membranes we are measuring only $20 \%$ of the transport as compared to control membranes. This pathway represents a minor route and is only active with membranes from AP-1-deficient cells. It is also possible that these membranes lack a BFAsensitive factor, which indeed could be a functional AP-1, which is required for the retrograde transport of MPR46 and this could be the reason for their incompetence.

\subsubsection{Membrane Mixing assay}

Membranes from AP-1-deficient cells were not capable of promoting retrograde transport of MPR46 in vitro as efficiently as control membranes (Fig 4.2.26). This was in agreement with the in vivo situation in these cells (Meyer et al., 2000). We also observed adaptors and clathrin to be more tightly associated with the membrane fraction. This tight association could prevent adaptor exchange with the cytosol and make the membranes incompetent in the in vitro transport assay. There could also be an AP-1-dependent factor or a functional AP-1 itself, that is missing on these membranes and this factor could be required for the generation of transport-competent vesicles from the endosomal membranes. We decided to address this question by supplementing AP-1-deficient membranes with membranes from control cells that contain a functional AP-1 and all the factors required for retrograde transport of MPRs but which lacked HMY-MPR46. These membranes could act as donors to supply the essential factor(s) required to generate the transport vesicles from the endosomes of AP-1-deficient cells. Assays were performed using cytosol from control cells (Fig. 4.2.29). 


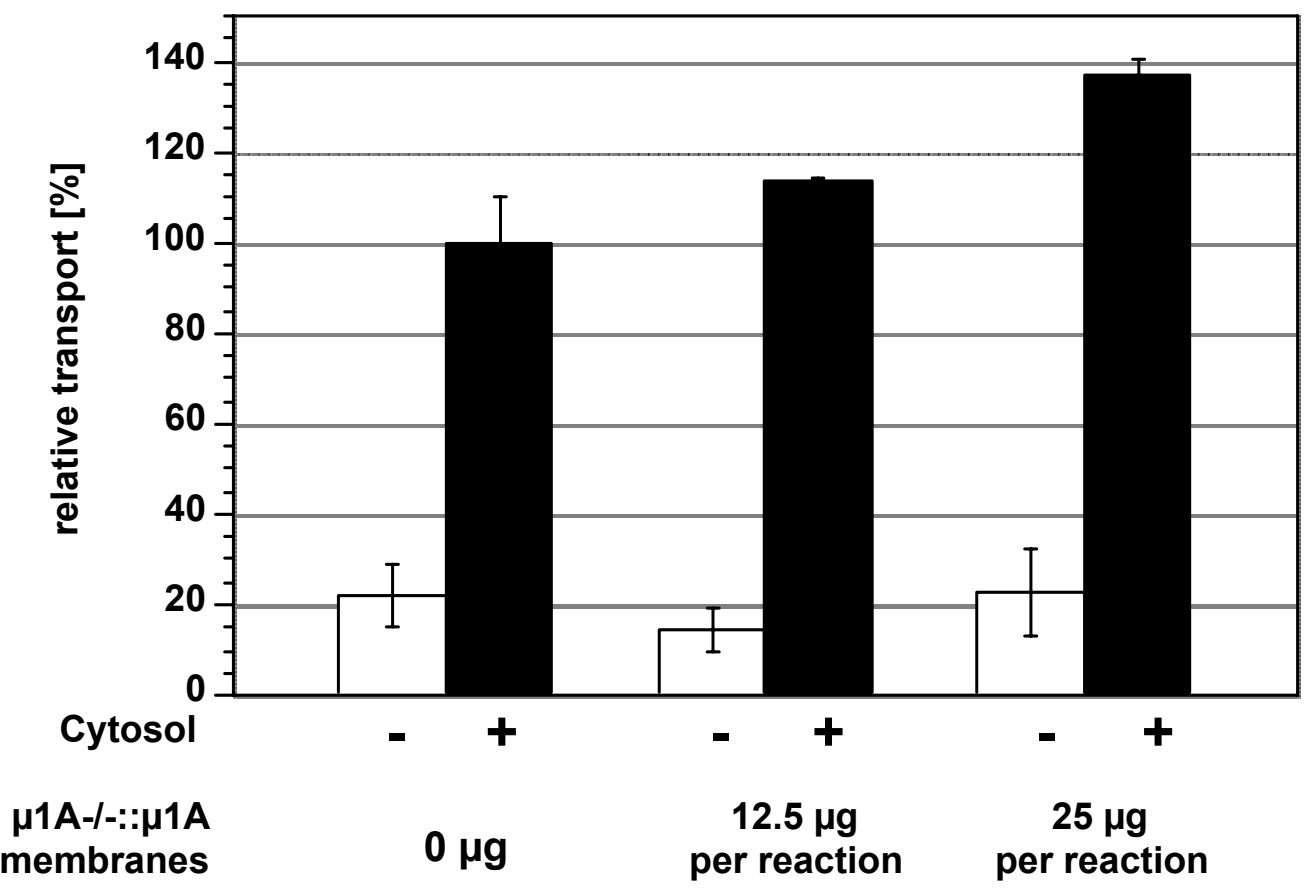

Figure 4.2.29: Assay with mixing of control and AP-1-deficient membranes.

In vitro transport assays were performed with membranes prepared from AP-1-deficient cells (25 $\mu \mathrm{g} /$ reaction) and cytosol from control cells. Indicated concentration of control membranes were added to the reaction mixes before starting the incubation. Assay reactions were analyzed by immunoprecipitation and autoradiograhy. This experiment has been performed once. Error bars indicate the maximum deviation of duplicate values from the average value.

Addition of increasing amounts of control membranes leads to a significant increase in the transport efficiency of AP-1-deficient membranes (Fig 4.2.29). This indicates that the added control membranes supply factors that can increase the efficiency of AP-1-deficient membranes either by exchange or by fusion of the control cell endosomes with the endosomes from AP-1-deficient cells. The possibility of control membranes supplying donor compartments (TGN) for sulfation is very unlikely as that should have resulted in a transport efficiency comparable to that of control membranes because the amount of control membranes added in this assay corresponds to the amount used in the assays with control membranes. 


\subsection{Role of GGA proteins in MPR transport}

GGAs are a new family of monomeric adaptor proteins which play a role in the sorting of mannose 6-phosphate receptors from the TGN to the endosomes.

There are three proteins of this family named GGA1,-2 and -3 . All three proteins have a common domain organization and are shown to mediate MPR sorting at the TGN (see 1.2.3). They interact with clathrin and AP-1, but are not isolated with CCVs. They require ARF for their recruitment onto the membranes. They bind to some of the accessory factors which bind to AP-1. They have been visualized on clathrin-coated buds containing AP-1 and it has been proposed that GGAs and AP-1 co-operate in binding to the MPR cytoplasmic tail and mediate their sorting from the TGN. However, no functional data is available to prove this mode of action. The presence of three GGA proteins raises further questions about the specific and individual functions of these proteins. The goal of our study is to analyze the function of these GGA proteins and also to test whether GGAs and AP-1 function co-operatively or independently in MPR sorting to endosomes.

\subsubsection{Generation of cell lines}

\section{1) Cells double-deficient for GGA1/AP-1 or GGA2/AP-1}

GGA cDNAs were cloned by RT-PCR using total RNA isolated from mouse embryonic fibroblast cell lines and primers designed according to mouse genomic sequences. A $2 \mathrm{~kb} E c o$ RI fragment of GGA1 and a $1.5 \mathrm{~kb} 5$ '-Eco RI fragment of GGA2 were cloned in reverse orientation in the murine expression vector pMPSV. These plasmids were transfected in a $\mu 1 \mathrm{~A}$-deficient cell line derived from "knock-out" mice, to obtain stable transfectants. Absence of the GGA mRNA was tested by northern-blot using a probe of the homologous GGA sequence as an internal control. 


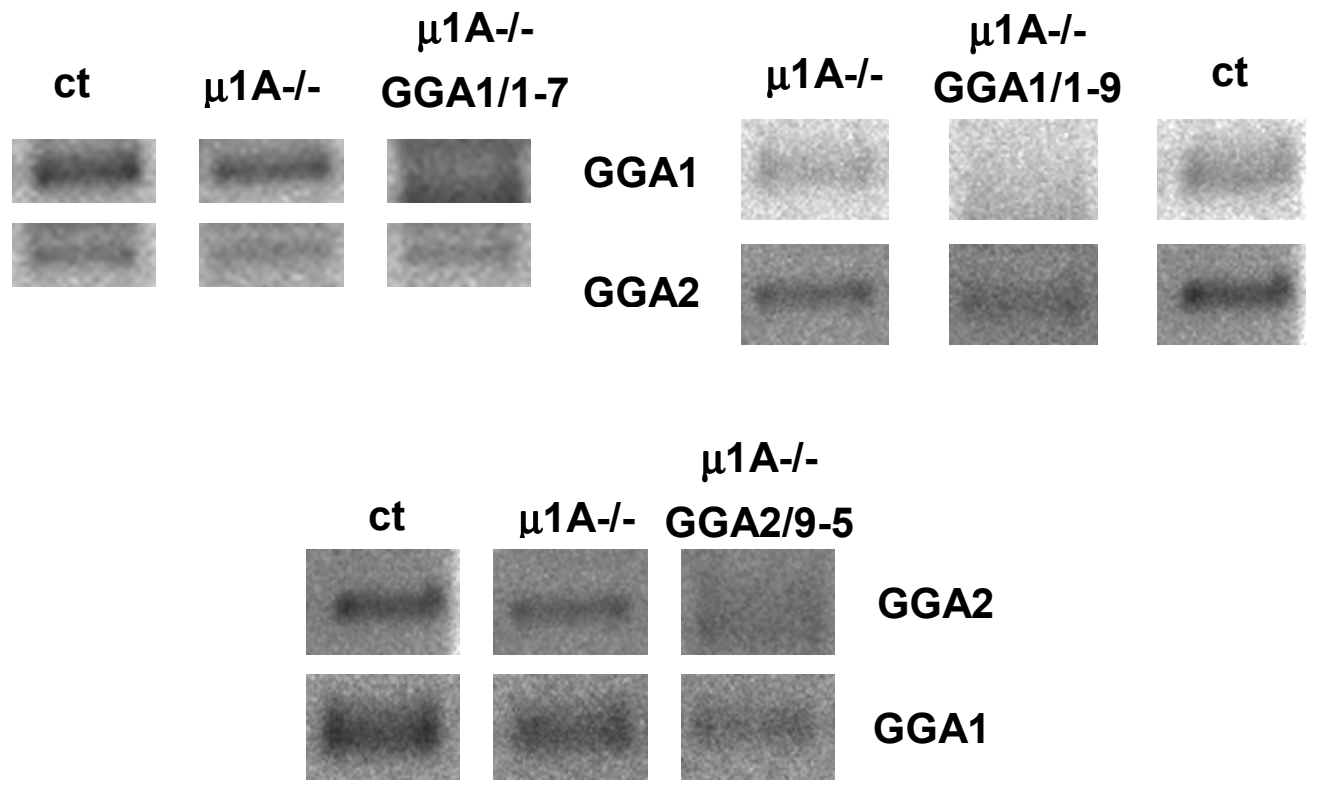

Figure 4.3.1 Generation of cells double-deficient for AP-1/GGA1 and AP-1/GGA2.

GGA cDNAs were cloned using mRNA from mouse embryonic fibroblasts. Antisense fragments were generated as described in (3.2.1.11) and transfected into $\mu 1 \mathrm{~A}$-/- MEFs. Stable transfectants which were resistant to $500 \mu \mathrm{g} / \mathrm{ml} \mathrm{Hygromycin} \mathrm{in} \mathrm{the} \mathrm{medium} \mathrm{were} \mathrm{selected} \mathrm{and} \mathrm{propagated.}$ mRNA was isolated from these cells and analyzed by northern blot as described in 4.3.1.

As shown in (Fig 4.3.1), there was no detectable GGA1 and GGA2 mRNA in clones transfected with GGA1 and GGA2 antisense respectively. The homologous GGA2 and GGA1 mRNA level in these clones was also slightly less, which was not surprising given that GGA1 and GGA2 are $45 \%$ identical to each other. So far, no antisera are available which discriminate between the GGA proteins. Nevertheless, this indicates that downregulation of one GGA could affect the other member of the family due to their high homology. These cells were used as AP-1/GGA1 and AP-1/GGA2 deficient cells in our experiments.

\section{2) GGA1 and GGA2 deficient cells}

In order to obtain cells which were deficient only for GGA1 or GGA2, the doubledeficient cells were retransfected with murine $\mu 1 \mathrm{~A}$ cDNA. This has been shown to rescue AP-1-deficiency functionally (Meyer et al., 2000). Stable clones were selected based on the expression of $\mu 1 \mathrm{~A}$ analyzed by western blot. 


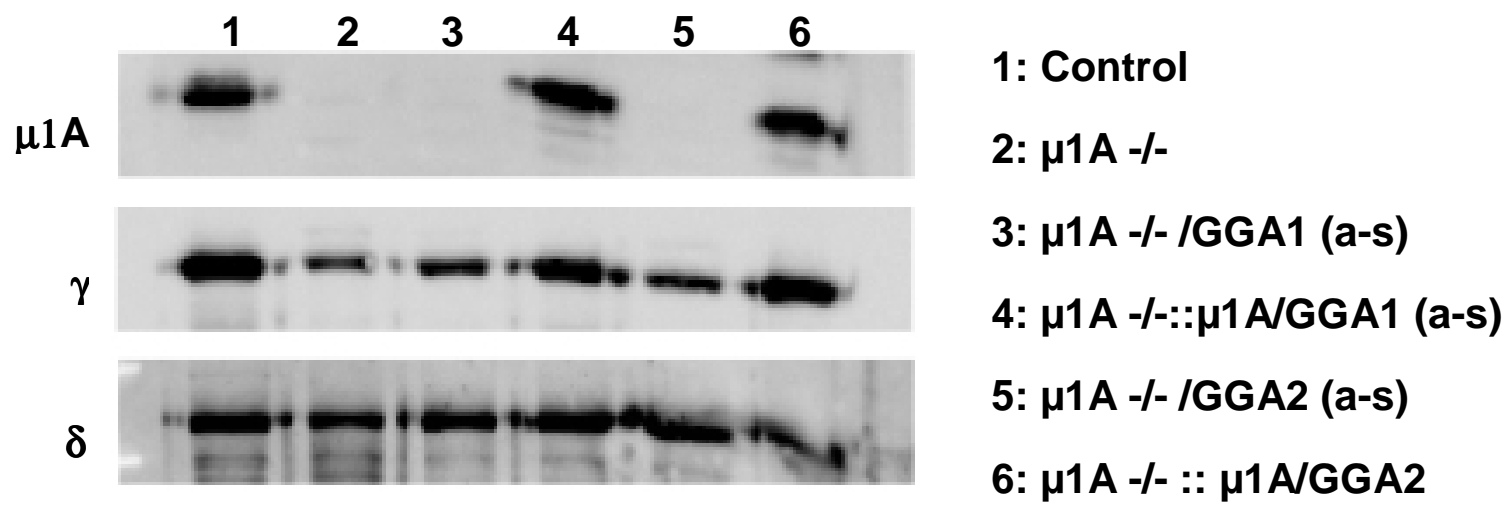

Figure 4.3.2 Generation of GGA1 and GGA2 deficient cell lines.

Murine $\mu 1 \mathrm{~A}$ cDNA was retransfected into AP-1/GGA1 and AP-1/GGA2 double-deficient cell lines to obtain cells that were deficient only for GGA1 or GGA2 respectively. $50 \mu \mathrm{g}$ of total lysates were loaded on a $10 \%$ SDS-PAGE and blots were probed with antibodies against $\mu 1 \mathrm{~A}$ - and $\gamma$ adaptin. $\delta$-adaptin blot served as a control to show that equivalent amount of proteins were loaded in all the lanes.

The $\mu 1 \mathrm{~A}$ re-transfected cells express $\mu 1 \mathrm{~A}$ as observed by western blot analysis (Fig. 4.3.2). These cells are used as the cells deficient for GGA1 and GGA2 respectively.

\subsubsection{Cathepsin D sorting}

MPRs are involved in the sorting of soluble lysosomal enzymes like cathepsin D to the lysosomes. They bind to the mannose 6-phosphate residues on the enzymes at the trans-Golgi network and sort them to the lysosomes via endosomal compartments. Cathepsin $D$ is the precursor form $(51 \mathrm{kDa})$ at the TGN and it undergoes proteolytic processing in the endosomes resulting in an intermediate form $(47 \mathrm{kDa})$ which is further converted to the mature form of 30 $\mathrm{kDa}$ and $14 \mathrm{kDa}$ fragments after delivery to the lysosomes. Impairing the function or steady-state distribution of MPRs leads to defect in processing and sorting of lysosomal enzymes like cathepsin D. The precursor form of lysosomal enzymes is missorted to the medium under such circumstances and studying this sorting is a direct functional analysis of MPRs at the TGN. 
Cells were pulse-labelled for one hour with radioactive methionine/cysteine and chased for four hours by adding non-radioactive methionine/cysteine. Cathepsin D was immunoprecipitated from the cell extracts and medium and analyzed by autoradiography.

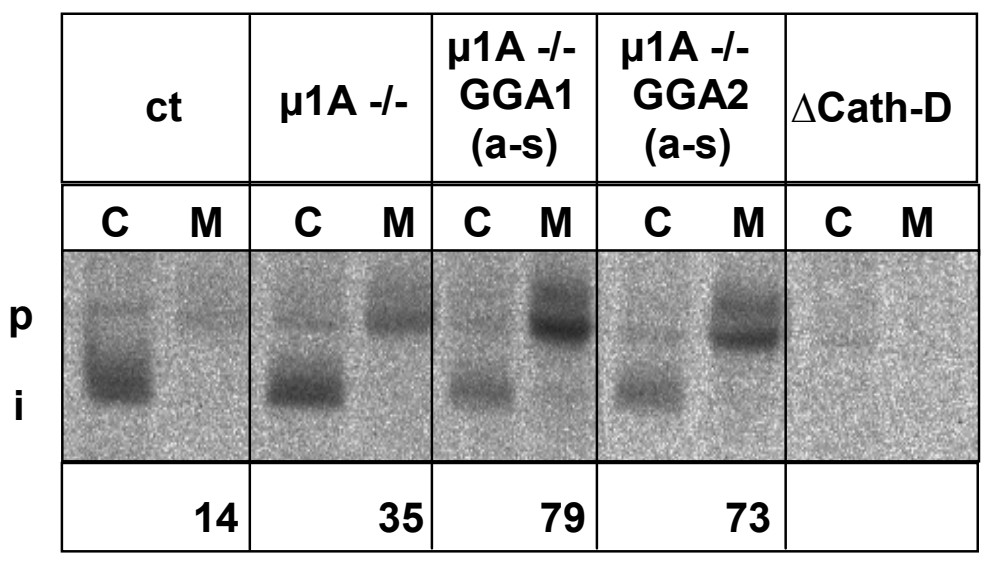

Figure 4.3.3: Cathepsin D sorting in the cells deficient for either of GGAs or doubledeficient for one of the GGAs and AP-1. Cathepsin D sorting by the indicated cell lines were analyzed by pulse-chase experiments wherein cells were pulse labelled with ${ }^{35} \mathrm{~S}$-methionine for 1 $\mathrm{h}$, chased for $4 \mathrm{~h}$ and cathepsin $\mathrm{D}$ was immunoprecipitated from cell extracts $(\mathrm{C})$ and the medium (M). $\mathbf{p}$ indicates the Golgi precursor-form and $\mathbf{i}$ the endosomal/lysosomal intermediate form of cathepsin D. Cathepsin D-deficient mouse fibroblast cells $(\Delta$ cath-D) served as control for the immunoprecipitations. Numbers given are the \% of precursor cathepsin $D$ secreted into the medium.

In $\mu 1 \mathrm{~A}$-deficient cells $35 \%$ of the cathepsin $\mathrm{D}$ is missorted into the medium [this fraction increases to $60 \%$ when mannose 6-phosphate is added to the medium, Fig. 4.3.4)] whereas the cells which are double-deficient for AP-1/GGA1 or AP1/GGA2, completely missort the precursor cathepsin D into the medium (Fig. 4.3.3). Previous studies have shown that in wild type cells about $20 \%$ of the cathepsin D is sorted in an MPR-independent manner. (von Figura and Hasilik, 1986) Therefore we can conclude from our data that there is complete missorting of cathepsin D in AP-1/GGA1 or AP-1/GGA2 deficient cells into the medium. This indicates that in AP-1-deficient cells, the residual sorting of MPRs is mediated by GGAs.

Next, we analyzed the sorting of cathepsin D in the cells which were rescued for AP-1 deficiency by ectopic expression of $\mu 1 \mathrm{~A}$ but were knocked down for GGA1 
or GGA2 expression by anti-sense DNA to the respective proteins. These experiments were done in the absence or presence of mannose 6-phosphate which would compete with cathepsin $D$ for ligand binding sites on MPRs and blocks its endocytosis. This gives a real estimate of the total amount of cathepsin $\mathrm{D}$ secreted into the medium.

A :

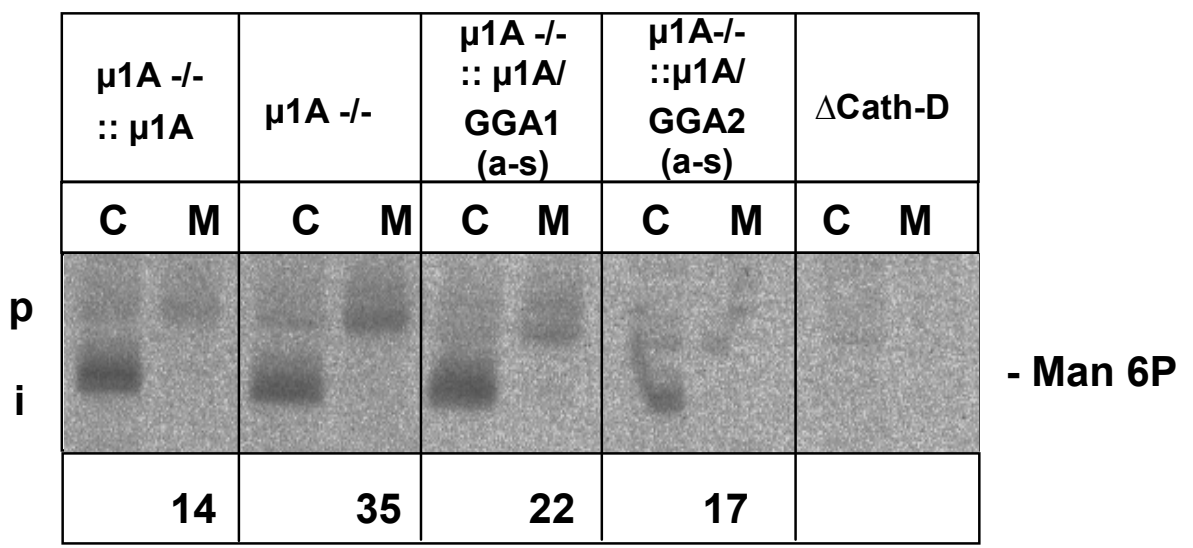

B :

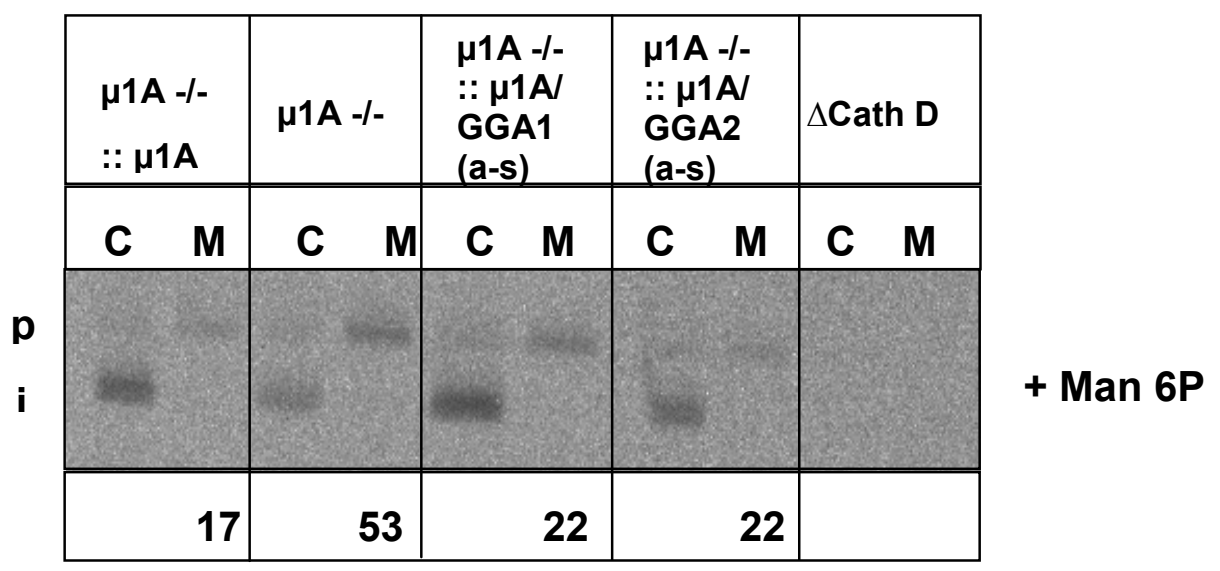

Figure 4.3.4: Cathepsin D sorting in the cells deficient for either GGA1 or GGA2.

Cathepsin $D$ sorting by the indicated cell lines were analyzed by pulse-chase experiments wherein cells were pulse labelled with ${ }^{35} \mathrm{~S}$-methionine for $1 \mathrm{~h}$, chased for $4 \mathrm{~h}$ and cathepsin $\mathrm{D}$ was immunoprecipitated from cell extracts $(C)$ and the medium $(M)$. $\mathbf{p}$ indicates the Golgi precursorform and $\mathbf{i}$ the endosomal/lysosomal intermediate form of cathepsin D. Cathepsin D-deficient mouse fibroblast cells $(\Delta$ cath-D) served as control for the immunoprecipitations. Numbers given are the $\%$ of precursor cathepsin $D$ secreted into the medium.. Pulse-chase experiments were performed either in the absence (A) or presence (B) of $5 \mathrm{mM}$ mannose 6-phosphate.

Both GGA1 and GGA2 anti-sense expressing cells do not missort cathepsin D, more than the control cells, into the medium (Fig. 4.3.4 A) whereas $\mu 1 \mathrm{~A}$-deficient cells missort $35 \%$ precursor form of cathepsin $\mathrm{D}$ as reported previously (Meyer et al., 2000). This indicates that AP-1-deficiency has much more severe effects than 
GGA-deficiency on the sorting of lysosomal enzymes. The lysosomal enzymes which are secreted into the medium re-enter the cells by endocytosis from the plasma membrane by MPR 300. Blocking this pathway would give a real estimate of total amount of cathepsin $D$ that is secreted into the medium. When cathepsin D pulse-chase experiments were performed in the presence of $5 \mathrm{mM}$ mannose 6phosphate (Fig. 4.3.4B), the amount of precursor cathepsin D secreted into the medium increased to $53 \%$ in $\mu 1 \mathrm{~A}$-deficient cells, this is in agreement with the previous observation from our lab (Meyer et al., 2000). There is no significant increase in the amount of precursor cathepsin $D$ in the medium fractions of GGA1 and GGA2 anti-sense expressing cells even in the presence of mannose 6phosphate indicating that there is no missorting of cathepsin D in these cells (Fig. 4.3.4).

\subsubsection{Steady-state localization of cathepsin D}

In order to further study if GGA-deficiency has any effect on the steady-state localization of cathepsin D, we investigated the steady-state localization of cathepsin $D$ in these cells by immunofluorescence studies.

Fixed cells were incubated with antibodies against LAMP1, a marker for late endosomes and lysosome and cathepsin D. As shown in (Fig. 4.3.5), in all the cell lines, cathepsin D staining overlapped completely with LAMP1 staining indicating that the steady-state localization of this protein is not altered due to either single deficiency of GGA1 or GGA2 or double deficiency of AP-1/GGA1 or AP-1/GGA2. 


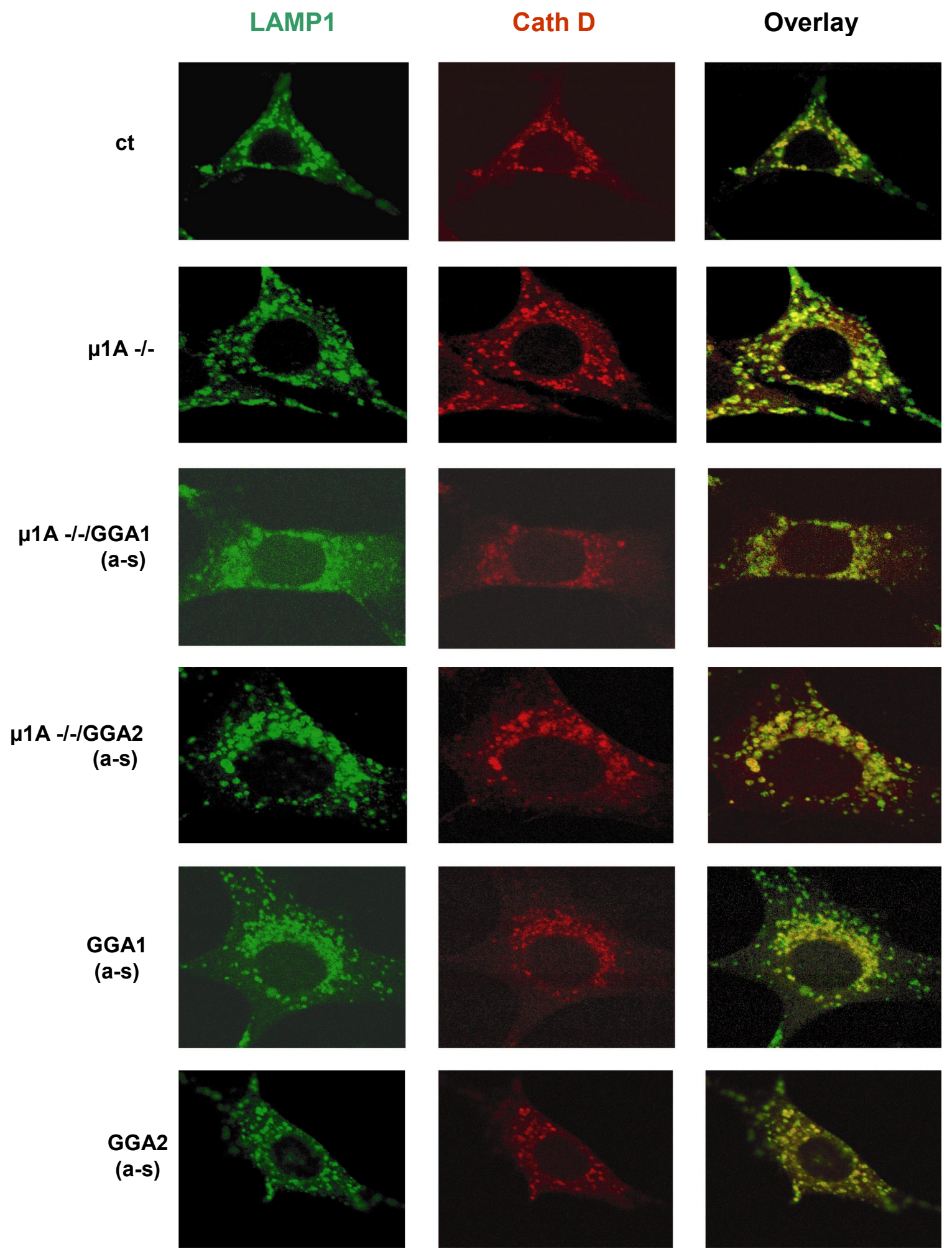

Figure 4.3.5: Steady-state localization of Cathepsin D. Cells were fixed with $3 \%$ paraformaldehyde and permeabilized by $0.5 \%$ saponin in PBS, incubated with antibodies against LAMP1 and cathepsin D followed by secondary antibodies conjugated to FITC (green) and Texas red (red) respectively. Images were processed using Leica IRE2 laser scan confocal microscope and software provided by the manufacturer. 


\subsubsection{Steady-state localization of MPRs}

Cathepsin D sorting experiments indicated that GGA1 or GGA2 do not play a major role in the sorting of MPRs. At steady-state, majority of the MPRs is localized to the TGN. AP-1 and GGAs are involved in the transport of MPRs from the TGN to the endosomes and AP-1-deficiency has been shown to alter the steady-state distribution of MPRs from the TGN into the early endosomes (Meyer et al., 2000). Therefore it was interesting to investigate the effect of GGAdeficiency on the localization of MPRs. Fixed cells were labelled with antibodies against $\gamma$-adaptin, which is localized primarily at the TGN, and MPR46 or MPR300.

As shown in (Fig. 4.3.6 and 4.3.7), in control cells MPRs are predominantly localized to the perinuclear TGN region and colocalize extensively with $\gamma$-adaptin. In $\mu 1 \mathrm{~A}$-deficient cells, the perinuclear $\gamma$-adaptin staining is lost and there is a diffused cytoplasmic staining and MPRs are redistributed to the peripheral endosomal structures which is in agreement with the previously published reports from our lab (Meyer et al., 2000). GGA1 or GGA2 anti-sense expression in $\mu 1 \mathrm{~A}$ deficient cells do not affect the redistribution of MPR46 in endosomes., however we do see a weaker staining of both MPR46 and MPR300 in AP-1/GGA1 deficient cells and this aspect has to be investigated further (see Fig. 4.3.6 and 4.3.7, AP1/GGA1 and AP-1/GGA2 double-deficient cells).

In cells which express GGA1 or GGA2 anti-sense DNA, both MPR46 and MPR300 staining is seen in the perinuclear region, but this staining is weaker as compared to control cells. In addition, some overlapping peripheral punctate staining of MPR300 and $\gamma$-adaptin could be observed in these cells (see figure 4.3.6 and 4.3.7, GGA1 (a-s) and GGA2 (a-s)). We need to confirm this data by performing immunofluorescence with markers for early and late endosomal structures to identify these peripheral compartments. 


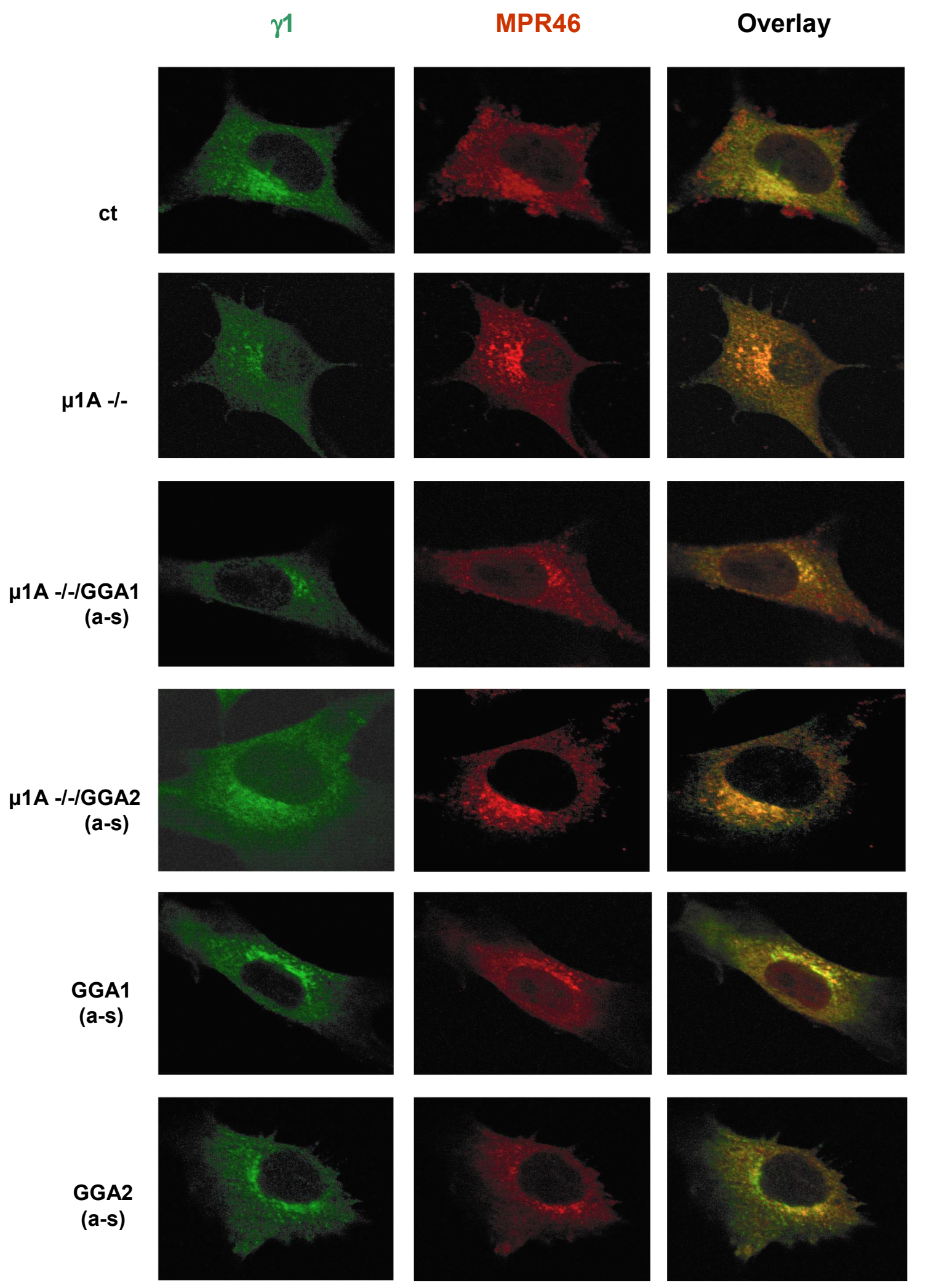

Figure 4.3.6: Steady-state localization of $\gamma$-adaptin and MPR46. Cells were fixed using 3\% paraformaldehyde and permeabilized with $0.5 \%$ Saponin in PBS, and incubated with antibodies against $\gamma$-adaptin and MPR46 followed by secondary antibodies conjugated with FITC (green) or Texas red (red) respectively. 


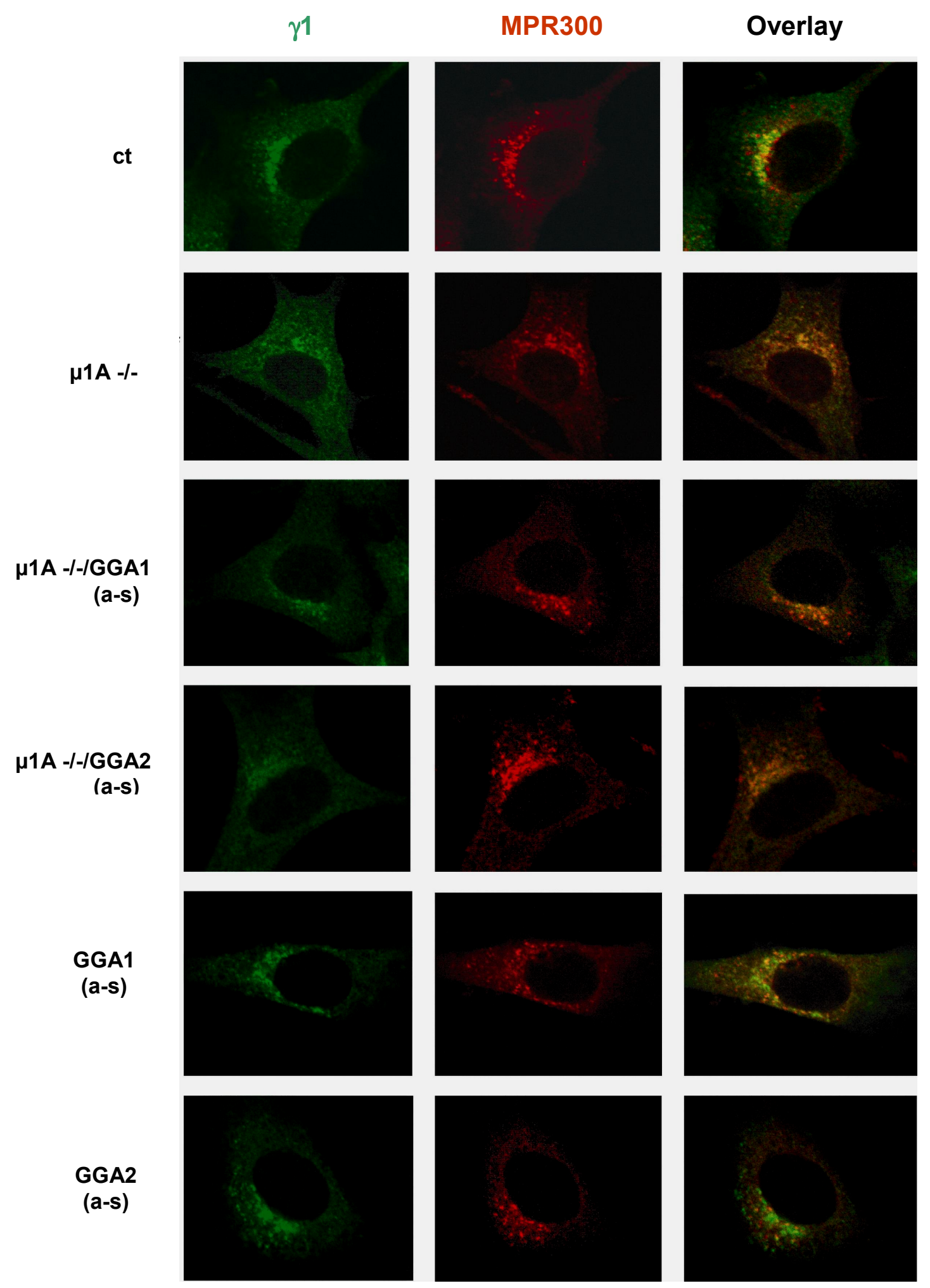

Figure 4.3.7: Steady-state localization of gamma adaptin and MPR300. Cells were fixed using $3 \%$ para-formaldehyde and permeabilized with $0.5 \%$ Saponin in PBS, incubated with antibodies against $\gamma$-adaptin and MPR300 followed by secondary antibodies conjugated with FITC (green) or Texas red (red) respectively. 


\section{Discussion}

\subsection{Studies on the function of $\mathrm{N}$-terminal domain of $\mu 1 \mathrm{~A}$}

We present data demonstrating that the $\mathrm{N}$-terminal seventy amino acids of $\mu 1 \mathrm{~A}$ play a role for the sorting/transport function of AP-1. The crystal structure of the highly homologous AP-2 complex has been solved and helps to understand also structure-function relationships of AP-1 (Collins et al., 2002). The N-terminal 150 amino acids of $\mu 2$ form a domain, whose three dimensional structure is almost identical to that of $\sigma 2$-adaptin, although both proteins have a sequence homology of only $18 \%$. Moreover $\sigma 2$ and the $\mathrm{N}$-terminal domain of $\mu 2$ bind at homologous positions to the $\alpha$ - and the $\beta 2$-adaptin respectively (see Fig. 5.1). The amino acids $151-449$ of $\mu 2$ form the domain binding the sorting motif positioned between the two dimeric structures $\alpha / \sigma 2$ and $\beta 2 / \mu 2^{\mathrm{N} 1-150}$. The $\mathrm{N}$-terminal seventy amino acids of $\mu 2$ form one helix and four $\beta$-sheets, which are accessible from the cytoplasmic face of AP-2. Amino acids 71-150 are in close contact with and hidden behind $\beta 2$. Our data indicate that the homologous domain formed by the $\mathrm{N}$-terminal seventy amino acids of $\mu 1 \mathrm{~A}$ has a double function. It serves as an anchor-structure to form a dimeric $\beta$ - $\mu$-adaptin complex as indicated by the structural analysis and has a function in protein sorting/transport.

The $\mu 1 \mathrm{~A}$ mutant protein, which lacks the first seventy amino acids of this domain is not incorporated into a AP-1 complex. Thus binding of this domain to $\beta 1$ adaptin may be essential for complex formation. While the first seventy amino acids are accessible from the cytoplasmic face of the adaptor complex, the Cterminal domain of $\mu 2$ largely covers the $\mu 2 \mathrm{~N}$-terminal domains at the membrane face of AP-2 (Fig. 5.1). However a model for AP-2 membrane binding suggests that phosphorylation of $\mu 2$ causes the C-terminal domain to flip out of the pocket formed by the two large adaptin subunits. This re-orientation would position the sorting motif binding domain in a way that it can bind to the cytoplasmic tails of 

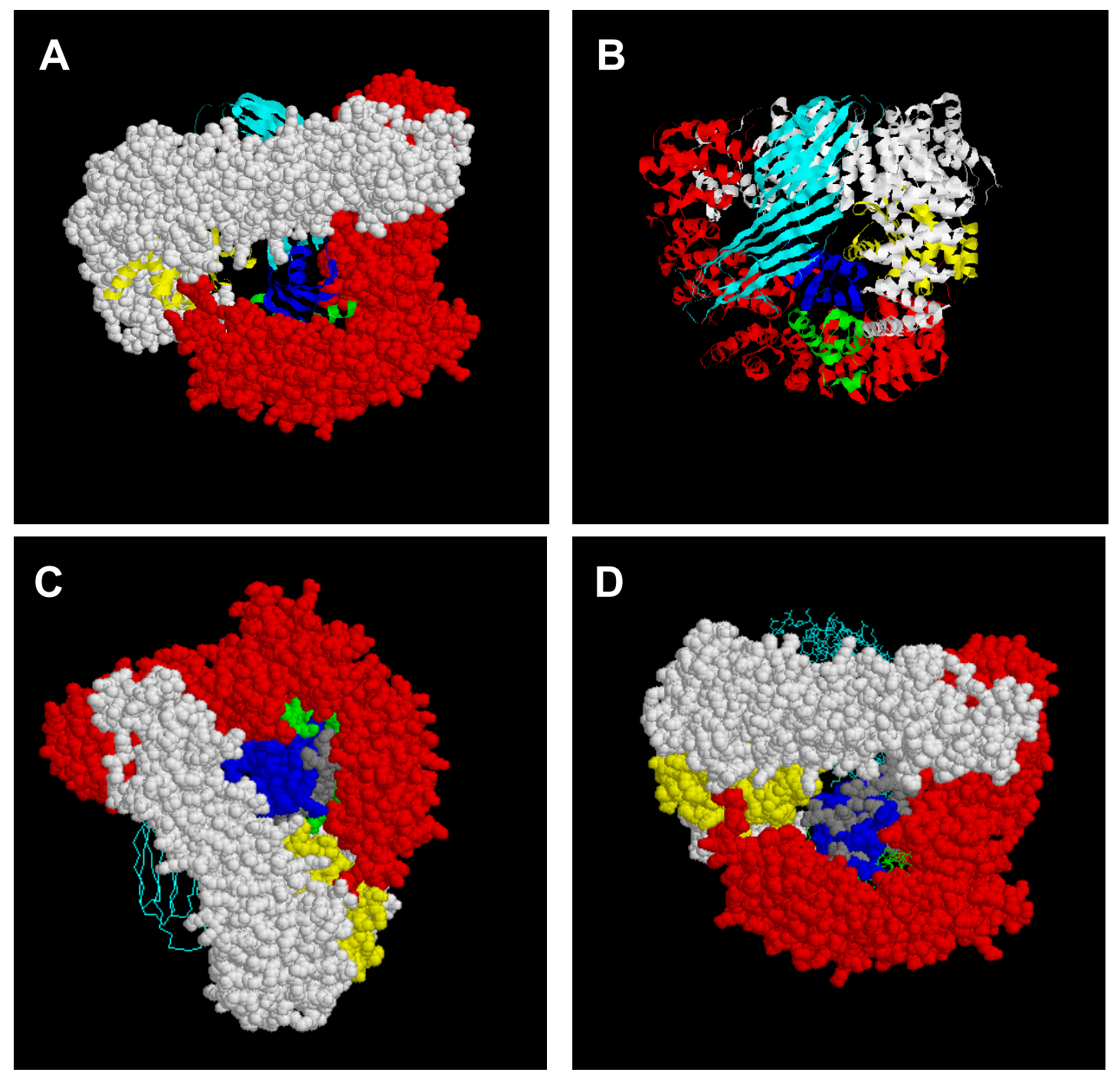

Figure 5.1: Crystal structure of the AP-2 complex. The N-terminal seventy amino acids of $\mu 2$ are shown in blue, aa 71-150 are coloured in green and the sorting motif binding domain coloured in cyan. $\sigma 2$ is shown in yellow, $\alpha$ is shown in white and $\beta 2$ is shown in red. A, C, D: Cytoplasmic face of the complex. In $C$ and $D$ amino acid residues conserved between $\mu 2$ and $\mu 1 A$ are coloured in grey; $\mathbf{B}$ : Membrane face of the complex.

cargo proteins. This flipping would render the $\mathrm{N}$-terminal domains of $\mu 2$ accessible from the membrane face of the activated AP-2 complex. The structural homology in the sorting motif binding domain between $\mu 2$ and $\mu 1 \mathrm{~A}$ predicts that such a flipping mechanism should also be involved in AP-1 binding to membranes. Whatever mechanism is operative, our data indicate proteins involved in the formation of transport vesicles bind to the $\mathrm{N}$-terminal seventy amino acids of $\mu 1 \mathrm{~A}$. 
Little is known about the mechanisms of AP-1 recruitment to the site of vesicle formation and the events leading to transport vesicle formation. It has been shown that AP-1 and AP-2 rapidly recycle between the membrane-bound and soluble state and that this recycling is independent of vesicle budding (Wu et al., 2003). ARF- $1^{\text {GTP }}$ binds to membranes and recruits AP- 1 onto membranes. ARF-1 is inactivated by ARF-GAP1. BIG2 is an ARF-1 GEF found at the TGN that is required for correct MPR transport (Shinotsuka et al., 2002a; Shinotsuka et al., $2002 \mathrm{~b}$ ). These data indicate that the binding of ARF-1 to AP-1 has to be somehow stabilized, maybe through binding of cargo proteins to AP-1 or by BIG2. These events controlling membrane binding dynamics of AP-1 could be disturbed in the case of AP-1*. ARF-1 binding sites on AP-1 have been mapped by photocrosslinking to the $\mathrm{N}$-terminal trunk domains of $\gamma 1$ and $\beta 1$ (Austin et al., 2000). This makes it unlikely that disturbed ARF-1 binding to AP-1* causes the slower AP-1 recycling and the missorting of MPR ligands. BIG2 is a $200 \mathrm{kDa}$ protein and the only characterized domain is the Sec7-domain responsible for the GEF activity, which is located in the middle of the sequence. BIG2 also lacks a $\mathrm{PH}$-domain for lipid-binding, which is found in other ARF-1 GEFs, indicating that membrane recruitment requires binding to proteins. BIG2 binds to membranes independent of AP-1 and it is thus able to establish multivalent protein-protein interactions and is one candidate, which could interact with the $\mathrm{N}$-terminus of $\mu 1 \mathrm{~A}$. However to study its subcellular localization requires overexpression leading to extensive co-localization of BIG2 and $\gamma 1$-adaptin at the TGN and interaction studies require the characterization of BIG2-domains. Transport vesicle formation is a complex process involving a number of proteins, which form complex networks as indicated by the studies on AP-2-mediated endocytosis. These proteins seem to be specific for AP-2 and thus vesicle formation by AP-1 requires a different specific set of proteins of which only a few have been identified so far, e.g. $\gamma$-synergin and EpsinR (Hirst et al., 2003; Kent et al., 2002; Liu et al., 2003). Our data indicate that one or even some of them bind to the $\mathrm{N}$-terminal seventy amino acids of $\mu 1 \mathrm{~A}$-adaptin and that this binding is essential for the fidelity of AP1-mediated protein sorting. 


\subsection{Establishment of an in vitro transport assay for MPR46 retrograde transport}

In AP-1-deficient cells, derived from $\mu 1 \mathrm{~A}$ "knock-out" mice, large fraction of lysosomal enzyme, cathepsin $D$, is missorted to the plasma membrane and there is an increased recycling of MPRs between plasma membrane and endosomes. Biochemical evidence demonstrated that there is a block in the retrograde transport of MPRs, resulting in their redistribution to early endosomes at the expense of their steady-state compartment, the TGN (Meyer et al., 2001; Meyer et al., 2000). AP-1 and GGAs are involved in the transport of MPRs from the TGN to the endosomes and the block in retrograde transport suggested a role for AP-1 also in the endosome-TGN pathway. In order to investigate the direct or indirect involvement of AP-1 in the retrograde transport of MPRs, we decided to establish an in vitro transport assay to analyze the retrograde transport of MPR46 from the endosomes to the TGN in MEFs.

The in vitro transport assay makes use of the property of a TGN-resident enzyme tyrosine sulfotransferase which mediates sulfation of tyrosine residues on the proteins with a consensus sequence for tyrosine sulfation. We obtained a murine MPR46 cDNA construct, which had been modified by inserting a consensus sequence for tyrosine sulfation at its $\mathrm{N}$-terminal end (Itin et al., 1997). This construct has been previously used to establish a late endosome-TGN MPR46 transport in a $\mathrm{CHO}$ cell line (Itin et al., 1997). AP-1-deficient and control cell lines that express this construct were generated by stable transfection and the expression levels of HMY-MPR46 were monitored by western blot analysis using anti-MPR46 antibodies (Fig. 4.2.2). A clone overexpressing 1.5 fold of HMYMPR46 over the endogenous MPR46 was used in our studies.(Fig. 4.2.2. A, clone 5). Immunofluorescence microscopy revealed a perinuclear MPR46 staining, which colocalized with $\gamma$-adaptin, a TGN marker (Fig 4.2.3). No overlap in MPR46 and LAMP1, a marker of late endosome/lysosome, staining was observed indicating that the overexpression of HMY-MPR46 does not change the steady-state distribution of the MPR46 receptors (MPR46+HMY-MPR46) in these cells. HMY-MPR46 was isolated by immunoprecipitation of the receptor from 
metabolically labelled cells and it was also demonstrated that this receptor is sulfated in vivo (Fig 4.2.5) and hence could be used for the in vitro transport assay studies. We used ${ }^{35}$ S-PAPS as the substrate for sulfation in the in vitro assays and this was synthesized from yeast extracts and purified by anion exchange chromatography (Fig 4.2.6).

\subsubsection{Assay characteristics}

We have successfully reconstituted an in vitro transport assay to measure the retrograde transport of MPR46 in membrane preparations from MEFs. Transport of MPRs in this in vitro assay is monitored by the sulfation of the receptors with ${ }^{35} \mathrm{~S}$-sulfate. Since sulfation is a TGN-specific modification there are only two possible pathways by which HMY-MPR46 can enter the TGN. First, the biosynthetic pathway and second, the endosomal pathway. Cells are treated for 2 hours with cycloheximide to block the biosynthetic pathway and deplete this pathway for any MPRs. In addition, membranes were pre-incubated with unlabelled PAPS to quench residual TGN-resident HMY-MPR46 labelling. Therefore all the MPRs that are sulfated under the in vitro assay conditions are of endosomal origin.

The endosome-to-TGN transport of HMY-MPR46 follows a time course that is typical for an in vitro vesicle-mediated transport process (Balch et al., 1984; Balch and Rothman, 1985; Goda and Pfeffer, 1988; Rothman, 1987) (Fig 4.2.8). The transport rate linearly increases with time up to one hour and attains saturation thereafter indicating limitation or saturation of factors required for vesicular transport. The transport reaction is dependent on the added cytosolic proteins up to a certain concentration and beyond that threshold level, addition of cytosolic factors becomes inhibitory (Fig 4.2.9). This could be because of a faster saturation of unknown receptor-ligand interactions on the membrane. The in vitro transport reaction proceeds only at physiological temperature (Fig 4.2.10). It has been shown that at $20^{\circ} \mathrm{C}$, vesicular transport processes cease in vivo and we indeed observe inhibition of transport reaction at this temperature (Fig 4.2.10). Integrity of membrane compartments is essential for vesicle-mediated transport 
events. We verified this in our in vitro transport assay by analysing the sensitivity of HMY-MPR46 to trypsin digestion. We observed that HMY-MPR46 was resistant to trypsin digestion and was sensitive to trypsin only upon addition of a detergent (Fig 4.2.11) and the transport reactions were non-functional when assays were performed in the presence of a detergent (data not shown). This demonstrates that the integrity of the membrane-bound compartments is essential for, and is maintained under, our assay conditions. Vesicular transport processes are absolutely dependent on ATP for a number of processes like phosphorylation of coat proteins, for the activity of NSF to which SNAP and in turn SNAREs bind, to generate force for vesicular movement, and in our assay, for the translocation of PAPS into the lumen of the TGN from the cytosol. We observe in vitro transport in the presence of an ATP-regenerating system, however this transport is completely inhibited in presence of an ATP depletion system (Fig 4.2.12). We therefore conclude that our in vitro transport assay depicts all characteristics of a specific vesicle-mediated transport process.

GTPases like ARFs, rabs, dynamin play a very important role in vesicular transport processes (Chavrier and Goud, 1999; Randazzo et al., 2000). Inhibition of an in vitro transport reaction by non-hydrolyzable GTP analogs indicates the involvement of GTPases in a given transport step. This property has been made use of by almost all in vitro assays to show the involvement of GTPases in various transport processes (Goda and Pfeffer, 1988; Jones et al., 1999; Jones et al., 1998; Mallard et al., 2002; Taylor et al., 1992). We have shown that GTP $\gamma S$ inhibits retrograde transport of HMY-MPR46 (Fig 4.2.13) and this demonstrates that GTPases are involved in this transport step. Non-hydrolyzable cAMP analogs lead to constitutive activation of PKA and this has been shown to influence some vesicular transport processes (Birkeli et al., 2003). Performing assays in the presence of this analog increases transport of HMY-MPR46 to the TGN by about $35 \%$, indicating that PKA activation upregulates this retrograde transport process (Fig 4.2.13). A complex signalling pathway mediated by PKA and its substrates could be involved in the regulation of the retrograde transport of MPR46. 


\subsubsection{Evidence for an early-endosome-to-TGN transport of MPR46}

In order to define the direction of the transport pathway that we are measuring in our in vitro transport assays we tested for the role of components that have been shown to be involved in certain specific transport pathways.

Our membrane preparation makes it difficult to definitely identify the donor compartment from which HMY-MPR46 arise. There could be three ways by which MPRs could reach the TGN. One way would be the biosynthetic pathway, second would be from early endosomes to the TGN and third would be from late endosomes to the TGN. Cells are treated with cycloheximide before membrane preparation and hence biosynthetic route is completely blocked. In order to further confirm that the HMY-MPR46 that enter the TGN under our assay conditions are of endosomal origin and not from the biosynthetic pathway, we made use of the property of the lysosomotropic agent primaquine. This drug has been shown to inhibit intra-Golgi transport and recycling of proteins from endosomes to the plasma membrane but does not affect endosome-to-TGN transport (Geuze et al., 1985; Goda and Pfeffer, 1988; Hiebsch et al., 1991). Our in vitro transport reaction is resistant to primaquine and this further confirms that we are not observing intra-Golgi transport (Fig 4.2.14).

The only two possible steps would be the late endosome-to-TGN and earlyendosome-to-TGN pathways. MPRs are predominantly localized to the TGN and also on peripheral endosomes (Fig 4.2.3) (Waguri et al., 2003). In order to further confirm the localization of MPR46 under the starting conditions of our assay, we performed immunofluorescence microscopy by using endocytosed transferrin as marker for early endosomes. Cells were treated with cycloheximide for 2 hours and transferrin was endocytosed for 10 min which is the time sufficient to label all early endosomal structures. A significant amount of MPR46 co-localized with transferrin on the perinculear/peripheral structures which are presumably early endosomes (Fig 4.2.15). Hence we propose that we are measuring an earlyendosome-to-TGN transport under our in vitro transport conditions. 
We were interested in identifying the SNARE proteins, that are part of a SNARE complex involved in the in vitro retrograde transport pathway. SNARE proteins mediate specific transport events and hence identification of the SNARE proteins involved would help us in defining the pathway that we are studying under our in vitro assay conditions. We found that antibodies against the SNARE proteins Vti1a and Syntaxin 16 inhibited the transport reaction (Fig 4.2.16). It has been shown recently that Vti1a-Syntaxin-16-VAMP4-Syntaxin-6 can form a SNARE complex (Kreykenbohm et al., 2002). This SNARE complex has been shown to be involved in early-endosome-to-TGN trafficking of Shiga toxin (Mallard et al., 2002). Our results demonstrate that the same proteins could be involved in the in vitro retrograde transport of MPR46 and this is an early-endosome-to-TGN pathway. Assays have to be performed with antibodies from Syntaxin 6 and VAMP 4 to finally conclude this result.

Rab GTPases are important regulators of vesicular trafficking pathways. They play an important role in vesicle budding, targeting and tethering, and fusion of vesicles with target organelles (Zerial and McBride, 2001). They are localized to specific compartments and mediate defined particular transport events. Therefore identifying the rab protein involved in the in vitro retrograde transport reaction would provide further evidence on the specificity of this transport step. IgGs against rab6 inhibited our in vitro transport reaction whereas rab11 or control IgG had no effect (Fig. 4.2.17). This demonstrates that rab6, which has been shown to be involved in the early-endosome-to-TGN pathway of Shiga toxin, is involved in our in vitro transport pathway. Therefore we conclude that rab6 is involved in the early-endosome-to-TGN pathway of MPR46 under our in vitro conditions. 


\subsubsection{Involvement of Adaptor complex-1 and 3 in the retrograde transport of MPR46}

AP-1 and AP-3 have been shown to play an important role in the sorting of proteins from the TGN and endosomes respectively (Dell Angelica et al., 1999b; Meyer et al., 2000; Reusch et al., 2002; Rous et al., 2002). We investigated the involvement of adaptor proteins, AP-1 and AP-3 in the in vitro retrograde transport reaction. If membranes from control cells are incubated together with cytosol from control cells, MPR46 transport to the TGN is stimulated eight to ten fold over a control incubation without cytosol added. This stimulation of transport is however also achieved, if cytosol from AP-1-deficient cells is used (Fig. 4.2.18). This indicates that the retrograde transport of MPR46, under our in vitro conditions, does not depend on cytosolic AP-1. This result can be caused by a significant amount of AP-1 associated with the membranes during the starting conditions of the assay. It has been shown that APs on membranes are in continuous exchange cycles with cytosol (Wu et al., 2003). Therefore it is possible that this membrane-associated adaptors on control membranes are sufficient to mediate the transport process under the assay conditions. We analyzed for the amount of adaptors and clathrin present on the membranes prepared for the assay and indeed observed about 25,39 and $35 \%$ of total AP-1, AP-3 and clathrin still bound to the membranes respectively (Fig. 4.2.19). It is likely that this membrane-bound adaptor fraction is lowering the dependence of the assay on cytosolic adaptor proteins.

BFA has been extensively used in the in vitro assays due to its specific action on ARF nucleotide exchange factors containing a Sec7-domain (Jackson and Casanova, 2000). We performed assays in the presence of BFA and found that it was completely inhibitory to the cytosol-dependent retrograde transport step (Fig. 4.2.20). Until now BFA has been shown to affect vesicular transport processes at the Golgi and endosome-to-plasma membrane recycling pathways (Damke et al., 1991; Hunziker et al., 1991; 1992; Ooi et al., 1998; Prydz et al., 1992; Strous et al., 1993). Here we show that it completely inhibits the endosome-to-TGN 
pathway of MPR46. The BFA-sensitive exchange factors mediate nucleotide exchange on ARF family of GTPases (Jackson and Casanova, 2000). It is possible that one of the GTPases belonging to the ARF family, which depends on the BFA-sensitive exchange factor for its nucleotide exchange, is required for the retrograde transport of MPR46. Both AP-1 and AP-3 require ARF 1 for their membrane association which is prevented by BFA (Ooi et al., 1998; Robinson and Kreis, 1992; Stamnes and Rothman, 1993). Therefore AP-1 and AP-3 are the likely candidates that could be involved in this transport pathway. BIG2 is a ARFGEF that is implicated specifically in the membrane association of AP-1 (Shinotsuka et al., 2002a; Shinotsuka et al., 2002b). It would be interesting to test the involvement of this protein in the in vitro retrograde transport reaction.

The AP-1-deficient cytosol did not show any effect in the in vitro transport reaction (Fig 4.2.18). AP-3, like AP-1, is also localized to the TGN and endosomes and it has been shown by yeast-two hybrid analysis and "pull-down" experiments in a recent study that $\mu 3 \mathrm{~A}$, the medium subunit of $\mathrm{AP}-3$, can bind specifically to MPR46 cytoplasmic tail (Storch and Braulke, 2001). This prompted us to investigate the role of AP-3 in this transport event using our in vitro transport assay. Natural AP-3-deficient mouse mutants exist and cell lines have been established and used by various groups. There is an increased trafficking of lysosomal membrane proteins via the plasma membrane in these cells (Dell Angelica et al., 1999b; Reusch et al., 2002).

Assays were performed using AP-3-deficient cytosol and this cytosol was indeed $50 \%$ as efficient as the control or AP-1-deficient cytosol (Fig. 4.2.21). The same conditions failed to show any AP-1-depencence in this transport step. This indicated that AP-3-deficiency directly or indirectly impairs the retrograde transport of MPR46. There are two ways to test the direct role of AP-3 in this transport event : 1) supplementing AP-3-deficient cytosol with purified AP-3 should restore the transport to control levels. 2) depleting cytosolic AP-3 from control cytosol should reduce its transport efficiency to the level observed by AP3-deficient cytosol. Future studies will focus on both these approaches. The 
residual transport which we still see in the absence of AP-3 could be because of two reasons, either ;

1) the membrane-bound AP-3 is lowering the dependence of the transport assay on cytosolic AP-3. This problem can be addressed by establishing this in vitro transport assay in cells lacking AP-3, which would make the assay completely dependent on the added cytosolic AP-3. This will help in demonstrating a direct or indirect role of AP-3 in the in vitro retrograde transport of MPR46

or; 2) due to the presence of another BFA-sensitive factor that can partly compensate for AP-3, the most likely candidate in this case would be AP-1. Both AP-1 and AP-3 require ARF1 for their membrane association which is prevented by BFA (Ooi et al., 1998; Stamnes and Rothman, 1993). This question can be addressed by using cytosol lacking for both AP-3 and AP-1. If AP-1 is mediating the residual transport, then the in vitro transport reaction would be completely inhibited with such a cytosol. An additional candidate, which has to be considered due to its ARF1 requirement for membrane binding is the AP-4 complex (Boehm et al., 2001). AP-4 has been proposed however to mediate sorting from the TGN to the basolateral membranes (Simmen et al., 2002).

It was important to get rid of the adaptors bound to the membranes of control cells to see cytosolic adaptor dependence. In order to achieve this, membranes were pre-treated with BFA, which has been shown to prevent association of adaptors onto the membranes both in vivo and in vitro. (Robinson and Kreis, 1992; Stamnes and Rothman, 1993). Hence the adaptors that dissociate during pre-incubation would not re-associate with the membranes in the presence of BFA. We analyzed the amount of APs and clathrin on BFA pre-treated membranes. Even in vitro BFA pre-treatment did not lead to a significant reduction in the amount of AP-1, AP-3 or clathrin on the membranes (Fig 4.2.22). It is possible that longer incubation times are required for complete dissociation, but this could result in reduced efficiency of the membranes in the in vitro transport assays. The possibility of BFA pre-treatment leading to some irreversible modifications of the factors required for efficient adaptor dissociation cannot be excluded. In order to test this, assays were performed with BFA pre- 
treated membranes and indeed the efficiency of the in vitro transport was reduced by $50 \%$ with these membranes (Fig. 3.2.20). We observed that pretreatment of BFA reversibly alters the membrane composition and makes membranes incompetent.

Next, we analyzed the association of AP-1 and clathrin with the membranes during the in vitro assay incubations and found that there is a very slow and limited association of these proteins under these in vitro conditions (Fig 4.2.24). There could be three possible explanations for this: 1) the assay conditions are not suitable for efficient exchange of AP-1 and clathrin between membrane and cytosolic fractions, 2) binding sites for AP-1 and clathrin are saturated and hence no more binding occurs, or 3) AP-1 and clathrin do not play a role in this transport event and hence no association of these with the membranes could be observed. When we followed the association of AP-3 with the membrane fractions during the in vitro incubation conditions, we found a 3 fold increase in the amount of AP3 associated with the membranes (Fig. 4.2.24). However, the specificity of this membrane association is yet to be determined. It would be interesting to study this process in the presence of BFA and GTP $\gamma S$ which would affect the membrane association-dissociation cycles and would provide some evidence for the specificity of our observation. A kinetic analysis of this membrane association process also has to be performed to further confirm these differences we observe under our in vitro conditions.

So far, there have been no reports on the effect of AP-3-deficiency on MPR trafficking. One study using $\mu 3 \mathrm{~A}$ anti-sense approach indicated no defect in lysosomal enzyme sorting in these cells (Le Borgne et al., 1998). Our cathepsin D pulse-chase experiments with AP-3-deficient cells show no missorting phenotype (data not shown) indicating that MPR trafficking is not affected in these cells. If AP-3 is involved in the retrograde transport of MPRs under our in vitro conditions, why is there no redistribution of MPRs in AP-3-deficient cells? Our in vitro retrograde transport assay is completely inhibited by BFA and hence the retrograde transport is completely ARF-dependent. It is tempting to speculate 
that under the AP-3-deficient conditions, AP-1 can compensate for AP-3 functions. This explains the reason for lack of missorting of lysosomal enzymes in AP-3-deficient cells. Recent studies from our lab have revealed that AP-1 and AP-3 mediate sequential steps of sorting, AP-1 from TGN-to-endosome and AP-3 from endosome-to-lysosome pathways respectively (Reusch et al., 2002). It is probable that AP-1 and AP-3 can function together in mediating the retrograde transport of MPR46. Therefore, cells lacking both AP-1 and AP-3 would be a good tool to address these issues. This raises further questions about the block in retrograde transport observed in vivo in AP-1-deficient cells. This aspect is discussed in section (5.2.5).

\subsubsection{TIP47 in retrograde MPR46 transport}

The only coat-protein implied in MPR46 retrograde transport characterized so far is TIP47. It has been shown to mediate the retrograde trafficking of MPRs from a late-endosomal compartment to the TGN in the $\mathrm{CHO}$ cell line (Diaz and Pfeffer, 1998). MPRs are localized to late endosomes at steady-state in $\mathrm{CHO}$ cells and this pathway is BFA-insensitive. Since our in vitro transport reaction is BFAsensitive it indicated a TIP47-independent pathway. In order to investigate TIP47 dependence directly in our in vitro transport reactions, assays were performed with cytosol prepared from cells in which TIP47 expression was knocked down by anti-sense approach. Decreased levels of TIP47 (8\% of the control) in the cytosol had no effect on our in vitro transport reaction (Fig. 4.2.25). This demonstrates that the pathway that we are studying is an early-endosome-to-TGN pathway and it does not require TIP47. This is also in agreement with our immunofluorescence results, where we did not detect any overlap in the staining of MPR46 and LAMP1, a late endosomal/lysosomal marker (Figure 4.2.3) ruling out any possibility of studying a TIP47-mediated pathway with our cells.

\subsubsection{Effect of AP-1-deficiency on MPR46 retrograde transport}

We reconstituted the in vitro transport reaction with membranes from AP-1deficient cells in order to address the direct or indirect role of AP-1 function in the retrograde transport of MPR46 in vitro. In these cells, AP-1 exists as a nonfunctional trimeric complex $(\gamma 1: \beta 1: \sigma 1)$ and hence membranes from $\mu 1 \mathrm{~A}$ "knock- 
out" mouse fibroblasts served as a source of membranes lacking any functional AP-1 associated with them. Any AP-1-mediated transport in vitro should be dependent on the exogenously added cytosolic AP-1. If AP-1 is directly required in the retrograde transport of MPR46, we could expect differences in the efficiencies of transport mediated by control and AP-1-deficient cytosols. If not, then these experiments should reveal an indirect function of AP-1 in the generation of transport-competent endosomes by its TGN-endosome sorting activity.

In vitro assays performed using AP-1-deficient membranes revealed that the transport to the TGN was very inefficient (Fig. 4.2.26). We could observe only $20 \%$ of the total transport that we observe with control membranes (Fig. 4.2.26). However, it was surprising that under these conditions, we failed to see any differences in the stimulation of retrograde transport between control, AP-1deficient or AP-3-deficient cytosol. This indicates that AP-1 is required to maintain the transport competence of the membranes but is dispensable for the transport itself. When we examined for the dissociation of coat proteins from AP-1-deficient membranes we found that the trimeric AP-1, AP-3 and clathrin are more tightly associated with membranes under these in vitro assay conditions (Figure 4.2.27, compare with 4.2.19). There may be membrane-bound factors that are necessary for the release of adaptors from the membranes and these factors could require a functional AP-1. It is possible that these factors mediate adaptor exchange between cytosol and membrane and are functional only in presence of AP-1. ARF1 is membrane-associated in its GTP bound form and promotes recruitment of AP-1 and AP-3 onto the membranes. Failure in the hydrolysis of GTP bound to ARF1 by GAPs could lead to a constitutive association of ARF1-GTP-AP-1/AP-3 on the membranes. It is possible that under our in vitro assay conditions, ARFGAP is unable to mediate GTP hydrolysis on ARF resulting in tighter association of AP-1 (trimeric) and AP-3 on the membranes. This may result in a very inefficient exchange of membrane-bound adaptors with cytosolic adaptors under the in vitro conditions and therefore could result in transport-incompetent membranes. Interestingly, it has been shown that overexpression of BIG2, an 
ARF-GEF, blocks BFA-induced redistribution of AP-1 into the cytosol (Shinotsuka et al., 2002a; Shinotsuka et al., 2002b). This condition is similar to what we observe in vitro with AP-1-deficient membranes. Hence, BIG2 is an interesting candidate protein to test in the in vitro transport reaction.

Another possibility is that AP-1-deficiency alters the endosomal membrane lipid composition or morphology. There may be factors that function on endosomes in the retrograde transport of MPRs, and these factors depend on a functional AP-1 either for their function or for their transport to the endosomes. If this is the case, then providing these factors by exogenous addition of membranes prepared from cells expressing AP-1 should make the AP-1-deficient membranes transport competent. In order to test this hypothesis, HMY-MPR46 containing membranes isolated from AP-1-deficient cells were mixed with membranes from control cells not expressing HMY-MPR46. The membranes from control cells could act as a donor for factors required to mediate the retrograde transport by endosomeendosome fusion. This could create HMY-MPR46 early endosomes containing the factors required for retrograde transport. We indeed saw a significant increase in the transport efficiency with addition of increasing concentration of control membranes to the reactions containing AP-1-deficient membranes (Fig. 4.2.29). This indicates that there are membrane-bound factors involved in the retrograde transport of MPR46 that depend on AP-1 for their function and these factors are unable to function in the absence of a functional AP-1. Hence the block in retrograde transport of MPR46 in AP-1-deficient cells is most likely to be an indirect effect of AP-1-deficiency. It is very unlikely that AP-1-deficiency has an effect on the function of TGN and under these conditions HMY-MPR46 from the early endosomes of AP-1-deficient membranes are transported to the TGN of the added control membranes. In this case, addition of 1:1 ratio of AP-1-deficient: control membranes should result in a transport efficiency comparable to the control membranes. But we observe only a $40 \%$ increase in the transport (which is $8 \%$ increase if total transport as compared to the control cells is considered). 
We propose that AP-1 could be involved in the initial steps of the retrograde transport by recruiting or transporting accessory factors, involved in the retrograde transport, to the endosomes. This function of AP-1 is necessary for AP-3 to mediate retrograde transport. However in the absence of AP-3, AP-1 can further perform the additional functions of AP-3 in the retrograde transport pathway. This explains the reason for the lack of missorting of lysosomal enzymes in AP-3-deficient cells. This also explains why despite the presence of AP-3, there is a block in retrograde transport of MPR46 in AP-1-deficient cells.

It has recently been shown that phosphorylation-dephosphorylation cycles regulate AP-1 binding, clathrin assembly and dissociation events (Ghosh and Kornfeld, 2003a). It is possible that AP-1-deficiency could alter this regulatory switch and lead to a defect in the MPR transport cycle. This aspect requires further attention in cells lacking AP-1, AP-3 or both. Thus, we propose that both AP-1 and AP-3 could be involved in the retrograde transport of MPR46. We can prove this by investigating the trafficking of MPRs in AP-3-deficient cells and cells double-deficient for both AP-1 and AP-3 which could provide some evidence in this direction. Such cell lines have been generated in our lab (Reusch et al., 2002) and establishing the in vitro assay in these cell lines should help us to answer this question in the future.

Recent live cell imaging video microscopy studies have shown that AP-1 and clathrin are present on TGN-derived vesicles and these vesicles move from the TGN to the periphery of the cell indicating that they are vesicles mediating transport steps from the TGN to the endosomes or plasma membrane (Waguri et al., 2003; Huang et al., 2001; Puertollano et al., 2003) AP-1 is undoubtedly involved in the anterograde transport of cargo proteins from the TGN to the endosomes (Reusch et al., 2002), while our data show that it's role in the retrograde transport is indirect. 


\subsection{Preliminary analysis of GGA function in MPR sorting}

GGA proteins are a recently discovered family of monomeric adaptor proteins. They have been shown to bind to the cytoplasmic tail of MPRs and mediate their sorting from the TGN to the endosomes. GGAs bind to clathrin, and to the eardomain of $\gamma$-adaptin and also to the accessory factors that bind $\gamma$-adaptin eardomain (Costaguta et al., 2001; Doray et al., 2002b; Liu et al., 2003; Puertollano et al., 2001b). GGA-deficient and clathrin-deficient yeast strains exhibit similar phenotypes suggesting that the GGAs and clathrin function either on the same pathway or on parallel pathways, transporting the same types of cargo from the TGN to an endosomal compartment. (Black and Pelham, 2000; Hirst et al., 2001; Payne et al., 1987; Seeger and Payne, 1992). GGAs colocalize with MPRs at the Golgi, and GFP-tagged versions of GGA1 and MPR46 can be observed departing together from the Golgi in tubular-vesicular structures in living cells (Puertollano et al., 2001a; Puertollano et al., 2003). Mutations in the AC-LL motif impair acid hydrolase sorting and decrease binding of the MPRs to the GGAs but not to AP1 , indicating that the GGAs have a major role in the sorting process (Chen et al., 1997; Hoening et al., 1997).

The discovery of GGAs and their role in MPR sorting further questioned the role of AP-1 at the TGN. Until recently it was believed that AP-1 exclusively mediates MPR trafficking from the TGN to the endosomes, but mouse "knock-out" studies of $\mu 1 \mathrm{~A}$ subunit of AP-1 from our lab indicated a new role for AP-1 in the endosome-to-TGN trafficking of MPRs (Meyer et al., 2000).

Deletion studies in yeast have revealed genetic interaction of GGAs with AP-1. The double deletion of GGA genes and AP-1 subunit $(\beta 1)$ genes leads not only to the increase in $\alpha$-factor secretion, but also in the strong impairment of Carboxypeptidase-S transport to the vacuole. Together, these observations indicate that, if the GGAs are missing, the AP-1 complex can to some extent compensate and vice versa (Costaguta et al., 2001). Deletion of the $\gamma$-adaptin 
gene together with the two GGA genes exacerbates the phenotype in yeast, suggesting that they function on parallel pathways. Double- and triple-labelling immunofluorescence experiments indicate that the GGAs and AP-1 are associated with distinct populations of clathrin-coated vesicles budding from the TGN (Hirst et al., 2001). However, recent electron microscopic data have found both GGAs and AP-1 on the same clathrin-coated buds suggesting that mammalian GGAs and AP-1 might cooperate to package MPRs into TGN-derived intermediates (Doray et al., 2002b). Live cell fluorescent imaging has revealed that the GGAs and AP-1 exit the TGN in the same clathrin-coated tubules (Puertollano et al., 2003). All these data do not show any functional evidence in support of the cooperative model of GGA and AP-1 function. None of the reports rules out an AP-1-independent function of GGAs in forming vesicles and cargo transport.

In order to test the cooperative model of action for GGAs and AP-1, we established cell lines that were double-deficient for one of the GGAs (GGA1 or GGA2) and AP-1. AP-1-deficient cells were transfected with GGA1 or GGA2 antisense DNA and stable clones were selected and verified for down regulation of mRNA levels in these cells by northern blot analysis (Fig. 4.3.1). No signal to the corresponding mRNA was detectable in these cells indicating a complete knock down of the GGA1 or GGA2 mRNA expression in these cells. These cells were used as double-deficient for AP-1 and GGA1 or AP-1 and GGA2. We rescued the double-deficient cells for AP-1-deficiency by transfecting $\mu 1 \mathrm{~A}$ cDNA which has been shown to functionally rescue AP-1-deficient phenotype (Meyer et al., 2000). These cells were used as cells deficient for either GGA1 or GGA2.

MPRs sort lysosomal enzymes from the TGN to the endosomes mediated by CCVs that contain AP-1 and GGAs. AP-1-deficiency leads to missorting of 55-60 $\%$ of total cathepsin $D$ in its Golgi precursor form to the medium which re-enters the cell via MPR300-mediated endocytosis. This indicates that the remaining cathepsin $D$ is sorted in an AP-1-independent manner probably by GGAs. In order to investigate this, cathepsin D pulse chase analysis was performed in AP- 
1-deficient cells expressing GGA1 or GGA2 antisense constructs. We observed complete missorting of precursor cathepsin D into the medium in these cells (Fig. 4.3.3). This demonstrates that in AP-1-deficient cells, GGAs mediate the residual sorting of cathepsin D. This provides an evidence that GGAs can function in the absence of AP-1 and a GGA-dependent pathway for lysosomal enzyme sorting may exist in MEFs. However, it is possible that GGAs and AP-1 indeed cooperate with each other and GGAs are unable to function efficiently due to the absence of $A P-1$. It is also interesting to note that knocking down the expression of either GGA1 or GGA2 in AP-1-deficient cells led to complete missorting. This shows that each of the GGAs may have a specific function and they cannot functionally compensate for each other or that the three GGAs function in a cooperative manner and $\mathrm{AP}-1$ is required for this cooperation.

If GGAs have an independent role in the sorting of lysosomal enzymes then disrupting the function of GGAs should provide additional evidence that would support such a role. Cathepsin D sorting experiments were performed in the cells that were deficient for GGA1 or GGA2 expression. Surprisingly, we did not observe any missorting of cathepsin $D$ in these cells (figure 4.3.4 A and B). We propose that when the GGA-mediated pathway is disrupted, the AP-1-mediated pathway compensates for this loss. We argue that two parallel pathways exist and that the GGA-mediated MPR sorting pathway is a minor pathway and AP-1mediated pathway is the major and most important pathway in mouse embryonic fibroblasts. This is supported by cathepsin $D$ sorting in $\mu 1 A$-deficient cells where disruption of the AP-1-dependent "major" pathway leads to missorting of $55 \%$ of the total cathepsin D (Figure 4.3.4 B and (Meyer et al., 2000)). It has to be noted that $\sim 20 \%$ of the total cathepsin D is sorted in a MPR independent manner (von Figura and Hasilik, 1986) and hence the GGA dependent "minor" pathway would be responsible for sorting of only $25 \%$ of the total cathepsin D in the cells.

The effect of double deficiency of AP-1 and GGAs or single deficiency of GGA1 or GGA2 on the distribution of MPRs was studied by immunofluorescence microscopy. In $\mu 1 \mathrm{~A}$-deficient cells, the perinuclear $\gamma$-adaptin staining is lost and 
instead a weak and diffused cytoplasmic staining can be seen (Fig 4.3.6). MPRs are redistributed to peripheral endosomal structures which have been identified as early endosomes by our previous studies (Meyer et al., 2000). Cells doubledeficient for AP-1 and GGA1 or GGA2 exhibit the same staining pattern, but in AP-1/GGA1 double-deficient cells MPR staining appears weaker than in AP-1deficient or control cells (Fig 4.3.6 and 4.3.7, $\mu 1 \mathrm{~A}-/-/ G G A 1(\mathrm{a}-\mathrm{s})$ ). This could be due to the alteration in the degradation rate of MPRs, which remains to be investigated. In cells deficient for either GGA1 or GGA2, MPR300 and $\gamma$ adaptin staining is both perinuclear and peripheral and overlapping with each other (Fig 4.3.6 and 4.3.7, GGA1 (a-s) and GGA2 (a-s)). The identification of these peripheral compartments is underway. 


\section{Conclusions}

\subsection{A function for the $\mathrm{N}$-terminal domain of $\mu 1 \mathrm{~A}$}

The data obtained from our studies on a $\mu 2 / \mu 1$ chimeric construct demonstrates that the N-terminal seventy amino acids of $\mu 1 \mathrm{~A}$ play a role for the sorting/transport function of AP-1. We propose that the domain formed by the $\mathrm{N}$ terminal seventy amino acids of $\mu 1 \mathrm{~A}$ has a double function. It serves as an anchor-structure to form a dimeric $\beta$ - $\mu$-adaptin complex as indicated by the structural analysis and has a function in protein sorting/transport as observed by the cathepsin $D$ sorting experiments. The slower rate of $A P-1^{*}$ dissociation from the membranes upon BFA treatment indicates that the events controlling membrane binding dynamics of AP-1 could be disturbed in the case of AP-1*. Transport vesicle formation is a complex process involving a number of proteins, which form complex networks, our data indicate that one or even some of them bind to the $\mathrm{N}$-terminal seventy amino acids of $\mu 1 \mathrm{~A}$-adaptin and that this binding is essential for the fidelity of AP-1-mediated protein sorting.

\subsection{In vitro MPR46 retrograde transport assay}

Vesicular transport processes involve a complex set of events involving known and unknown factors. Reconstituting this complex process in vitro is a challenging task. We have established an in vitro assay to measure the retrograde transport of MPR46, from endosomes to the TGN. The assay depicts all characteristics of a classical in vitro vesicle-mediated transport process. The in vitro transport reaction measures an endosome-to-TGN transport event as shown by resistance to primaquine which blocks intra-Golgi transport. Colocalization studies of MPR46 with endocytosed transferrin by immunofluorescence microscopy demonstrates that a significant amount of HMY-MPR46 is in the peripheral early endosomes. Involvement of SNARE proteins Vti1a and Syntaxin 16, and the GTPase rab6a supports that we are studying an early-endosome-to-TGN pathway. The in vitro retrograde pathway is TIP47-independent, therefore this is unlikely to be a lateendosome-to-TGN pathway. 
BFA inhibits the in vitro transport reaction completely indicating that the transport pathway is dependent on GEFs containing a Sec7-domain. Both AP-1 and AP-3 require the BFA-sensitive ARF 1 for their membrane association. Therefore AP-1 and AP-3 are the likely candidates that could be involved in this transport pathway. Our results from the in vitro retrograde transport assay using membranes from control cells fail to show direct dependence of this transport on cytosolic AP-1. However, the assay demonstrated a clear role for AP-3 in this pathway. There is no aberration of lysosomal enzyme sorting functions in AP-3deficient cells indicating normal MPR trafficking. It is tempting to speculate that the MPR46 retrograde transport could be mediated by AP-1 under AP-3-deficient conditions. This could only be tested in cells that lack both AP-1 and AP-3. Such a cell line has been established in our lab. It is necessary to analyze the steadystate distribution and sorting function of MPRs in cells deficient for either AP-3 or both AP-1 and AP-3 in more detail.

Results from the in vitro transport assays using AP-1-deficient membranes demonstrate that AP-1 is required to maintain the transport competence of membranes. The transport incompetence of AP-1-deficient membranes is reversed by the addition of membranes from cells expressing AP-1. This indicates that the block in the retrograde transport of MPR46 in AP-1-deficient cells is due to an indirect effect of AP-1-deficiency on the factors that regulate endosome to TGN transport and these factors depend on a functional AP-1 for their function.

Based on these data we propose that under normal conditions, AP-1 is required to maintain the transport competence of endosomes. It could be involved in transporting essential factors to the endosomes and these factors together with AP-3 mediate the retrograde transport of MPR46. Thus AP-1 plays an indirect role in the retrograde transport of MPR46. AP-1 may directly mediate the retrograde transport of MPR46 only in the absence of AP-3. A direct role for AP-1 or AP-3 can only be assigned by performing transport assays with donor and 
acceptor compartments that are free of adaptors and where transport reaction completely depends on added cytosolic adaptors.

\subsection{Analysis of the function of GGAs in MPR sorting}

GGAs are involved in the sorting of MPRs at the TGN in a clathrin and ARF1dependent manner. They interact with AP-1 and have been localized to clathrincoated buds containing AP-1. It has been proposed that GGAs and AP-1 function in a cooperative manner in the sorting of MPRs at the TGN. The aim of our study was to investigate the functions of GGA and their dependence on AP-1 for their efficient function. We generated cell lines that express anti-sense constructs for one of the GGAs in AP-1-deficient cells. We also generated cell lines which are deficient for either GGA1 or GGA2. Double deficiency of AP-1 and either GGA1 or GGA2, further enhances the severity of the cathepsin D missorting phenotype of $\mu 1 \mathrm{~A}$-deficient cells demonstrating that GGAs can mediate sorting of lysosomal enzymes to some extent in the absence of AP-1. No missorting of cathepsin D was observed with cells expressing either GGA1 or GGA2 anti-sense constructs. This demonstrates that the function of one GGA can be compensated by AP-1 or other homologous GGAs. Cells lacking all three GGAs would help us to further enhance our understanding of the function these proteins. 


\section{$7 \quad$ Literature}

Alconada, A., U. Bauer, and B. Hoflack. 1996. A tyrosine-based motif and a casein kinase II phosphorylation site regulate the intracellular trafficking of the varicella-zoster virus glycoprotein I, a protein localized in the transGolgi network. The Embo Journal. 15:6096-110.

Antonin, W., D. Riedel, and G.F. von Mollard. 2000. The SNARE Vti1a-beta is localized to small synaptic vesicles and participates in a novel SNARE complex. J Neurosci. 20:5724-32.

Austin, C., I. Hinners, and S.A. Tooze. 2000. Direct and GTP-dependent interaction of ADP-ribosylation factor 1 with clathrin adaptor protein AP-1 on immature secretory granules. The Journal of Biological Chemistry. 275:21862-9.

Balch, W.E., W.G. Dunphy, W.A. Braell, and J.E. Rothman. 1984. Reconstitution of the transport of protein between successive compartments of the Golgi measured by the coupled incorporation of $\mathrm{N}$-acetylglucosamine. Cell. 39:405-16.

Balch, W.E., and J.E. Rothman. 1985. Characterization of protein transport between successive compartments of the Golgi apparatus: asymmetric properties of donor and acceptor activities in a cell-free system. Archives of Biochemistry and Biophysics. 240:413-25.

Birkeli, K.A., A. Llorente, M.L. Torgersen, G. Keryer, K. Tasken, and K. Sandvig. 2003. Endosome-to-Golgi transport is regulated by protein kinase A type II alpha. The Journal of Biological Chemistry. 278:1991-7.

Black, M.W., and H.R. Pelham. 2000. A selective transport route from Golgi to late endosomes that requires the yeast GGA proteins. J Cell Biol. 151:587600.

Boehm, M., R.C. Aguilar, and J.S. Bonifacino. 2001. Functional and physical interactions of the adaptor protein complex AP-4 with ADP-ribosylation factors (ARFs). The Embo Journal. 20:6265-76.

Boehm, M., and J.S. Bonifacino. 2001. Adaptins: the final recount. Molecular Biology of the Cell. 12:2907-20.

Boehm, M., and J.S. Bonifacino. 2002. Genetic analyzes of adaptin function from yeast to mammals. Gene. 286:175-86.

Boll, W., H. Ohno, Z. Songyang, I. Rapoport, L.C. Cantley, J.S. Bonifacino, and T. Kirchhausen. 1996. Sequence requirements for the recognition of tyrosinebased endocytic signals by clathrin AP-2 complexes. The Embo Journal. 15:5789-95.

Boll, W., I. Rapoport, C. Brunner, Y. Modis, S. Prehn, and T. Kirchhausen. 2002. The mu2 subunit of the clathrin adaptor AP-2 binds to FDNPVY and Ypp $\tilde{A}^{\sim}$ sorting signals at distinct sites. 3:590-600. 
Brodsky, F.M., C.-Y. Chen, C. Knuehl, M.C. Towler, and D.E. Wakeham. 2001. BIOLOGICAL BASKET WEAVING: Formation and Function of ClathrinCoated Vesicles. Annu. Rev. Cell Dev. Biol. 17:517-568.

Campbell, C.H., and L.H. Rome. 1983. Coated vesicles from rat liver and calf brain contain lysosomal enzymes bound to mannose 6-phosphate receptors. The Journal of Biological Chemistry. 258:13347-52.

Carroll, K.S., J. Hanna, I. Simon, J. Krise, P. Barbero, and S.R. Pfeffer. 2001. Role of Rab9 GTPase in facilitating receptor recruitment by TIP47. Science. 292:1373-6.

Chao, H.H., A. Waheed, R. Pohlmann, A. Hille, and K. von Figura. 1990. Mannose 6-phosphate receptor dependent secretion of lysosomal enzymes. The Embo Journal. 9:3507-13.

Chardin, P., and F. McCormick. 1999. Brefeldin A: the advantage of being uncompetitive. Cell. 97:153-5.

Chavis, P., P. Mollard, J. Bockaert, and O. Manzoni. 1998. Visualization of cyclic AMP-regulated presynaptic activity at cerebellar granule cells. Neuron. 20:773-81.

Chavrier, P., and B. Goud. 1999. The role of ARF and Rab GTPases in membrane transport. Current Opinion in Cell Biology. 11:466-75.

Chen, H.J., J. Yuan, and P. Lobel. 1997. Systematic mutational analysis of the cation-independent mannose 6-phosphate/insulin-like growth factor II receptor cytoplasmic domain. An acidic cluster containing a key aspartate is important for function in lysosomal enzyme sorting. The Journal of Biological Chemistry. 272:7003-12.

Chen, W.J., J.L. Goldstein, and M.S. Brown. 1990. NPXY, a sequence often found in cytoplasmic tails, is required for coated pit-mediated internalization of the low density lipoprotein receptor. The Journal of Biological Chemistry. 265:3116-23.

Cherfils, J., and P. Chardin. 1999. GEFs: structural basis for their activation of small GTP-binding proteins. Trends in Biochemical Sciences. 24:306-11.

Claussen, M., D. Buergisser, A.G. Schuller, U. Matzner, and T. Braulke. 1995. Regulation of insulin-like growth factor (IGF)-binding protein-6 and mannose 6-phosphate/IGF-II receptor expression in IGF-IL-overexpressing NIH 3T3 cells. Molecular Endocrinology (Baltimore, Md.). 9:902-12.

Collins, B.M., A.J. McCoy, H.M. Kent, P.R. Evans, and D.J. Owen. 2002. Molecular architecture and functional model of the endocytic AP2 complex. Cell. 109:523-35.

Conner, S.D., and S.L. Schmid. 2002. Identification of an adaptor-associated kinase, AAK1, as a regulator of clathrin-mediated endocytosis. The Journal of Cell Biology. 156:921-9.

Costaguta, G., C.J. Stefan, E.S. Bensen, S.D. Emr, and G.S. Payne. 2001. Yeast Gga coat proteins function with clathrin in Golgi to endosome transport. Molecular Biology of the Cell. 12:1885-96.

Cremona, O., and P. De Camilli. 2001. Phosphoinositides in membrane traffic at the synapse. Journal of Cell Science. 114:1041-52. 
Cremona, O., G. Di Paolo, M.R. Wenk, A. Luthi, W.T. Kim, K. Takei, L. Daniell, Y. Nemoto, S.B. Shears, R.A. Flavell, D.A. McCormick, and P. De Camilli. 1999. Essential role of phosphoinositide metabolism in synaptic vesicle recycling. Cell. 99:179-88.

Crottet, P., D.M. Meyer, J. Rohrer, and M. Spiess. 2002. ARF1.GTP, Tyrosinebased Signals, and Phosphatidylinositol 4,5-Bisphosphate Constitute a Minimal Machinery to Recruit the AP-1 Clathrin Adaptor to Membranes. Molecular Biology of the Cell. 13:3672-82.

Crump, C.M., Y. Xiang, L. Thomas, F. Gu, C. Austin, S.A. Tooze, and G. Thomas. 2001. PACS-1 binding to adaptors is required for acidic cluster motif-mediated protein traffic. The Embo Journal. 20:2191-201.

Damke, H., J. Klumperman, K. von Figura, and T. Braulke. 1991. Effects of brefeldin A on the endocytic route. Redistribution of mannose 6phosphate/insulin-like growth factor II receptors to the cell surface. The Journal of Biological Chemistry. 266:24829-33.

Dell Angelica, E.C., C. Mullins, and J.S. Bonifacino. 1999a. AP-4, a novel protein complex related to clathrin adaptors. The Journal of Biological Chemistry. 274:7278-85.

Dell Angelica, E.C., R. Puertollano, C. Mullins, R.C. Aguilar, J.D. Vargas, L.M. Hartnell, and J.S. Bonifacino. 2000. GGAs: a family of ADP ribosylation factor-binding proteins related to adaptors and associated with the Golgi complex. The Journal of Cell Biology. 149:81-94.

Dell Angelica, E.C., V. Shotelersuk, R.C. Aguilar, W.A. Gahl, and J.S. Bonifacino. 1999b. Altered trafficking of lysosomal proteins in Hermansky-Pudlak syndrome due to mutations in the beta $3 \mathrm{~A}$ subunit of the AP-3 adaptor. Molecular Cell. 3:11-21.

Diaz, E., and S.R. Pfeffer. 1998. TIP47: a cargo selection device for mannose 6phosphate receptor trafficking. Cell. 93:433-43.

Dittie, A.S., N. Hajibagheri, and S.A. Tooze. 1996. The AP-1 adaptor complex binds to immature secretory granules from PC12 cells, and is regulated by ADP-ribosylation factor. The Journal of Cell Biology. 132:523-36.

Doray, B., K. Bruns, P. Ghosh, and S.A. Kornfeld. 2002a. Autoinhibition of the ligand-binding site of GGA1/3 VHS domains by an internal acidic clusterdileucine motif. Proceedings of the National Academy of Sciences of the United States of America. 99:8072-7.

Doray, B., P. Ghosh, J. Griffith, H.J. Geuze, and S. Kornfeld. 2002b. Cooperation of GGAs and AP-1 in packaging MPRs at the trans-Golgi network. Science. 297:1700-3.

Doray, B., and S. Kornfeld. 2001. Gamma subunit of the AP-1 adaptor complex binds clathrin: implications for cooperative binding in coated vesicle assembly. Molecular Biology of the Cell. 12:1925-35.

Drake, M.T., Y. Zhu, and S. Kornfeld. 2000. The assembly of AP-3 adaptor complex-containing clathrin-coated vesicles on synthetic liposomes. Molecular Biology of the Cell. 11:3723-36. 
Duncan, J.R., and S. Kornfeld. 1988. Intracellular movement of two mannose 6phosphate receptors: return to the Golgi apparatus. The Journal of Cell Biology. 106:617-28.

Erdtmann, L., K. Janvier, G. Raposo, H.M. Craig, P. Benaroch, C. Berlioz Torrent, J.C. Guatelli, R. Benarous, and S. Benichou. 2000. Two independent regions of HIV-1 Nef are required for connection with the endocytic pathway through binding to the mu 1 chain of AP1 complex. 1:871-83.

Eskelinen, E.L., C. Meyer, H. Ohno, K. von Figura, and P. Schu. 2002. The polarized epithelia-specific mu 1B-adaptin complements mu 1A-deficiency in fibroblasts. EMBO Rep. 3:471-7.

Fingerhut, A., K. von Figura, and S. Hoening. 2001. Binding of AP2 to sorting signals is modulated by AP2 phosphorylation. The Journal of Biological Chemistry. 276:5476-82.

Folsch, H., H. Ohno, J.S. Bonifacino, and I. Mellman. 1999. A novel clathrin adaptor complex mediates basolateral targeting in polarized epithelial cells. Cell. 99:189-98.

Folsch, H., M. Pypaert, P. Schu, and I. Mellman. 2001. Distribution and function of AP-1 clathrin adaptor complexes in polarized epithelial cells. The Journal of Cell Biology. 152:595-606.

Ford, M.G., I.G. Mills, B.J. Peter, Y. Vallis, G.J. Praefcke, P.R. Evans, and H.T. McMahon. 2002. Curvature of clathrin-coated pits driven by epsin. Nature. 419:361-6.

Ford, M.G.J., B.M.F. Pearse, M.K. Higgins, Y. Vallis, D.J. Owen, A. Gibson, C.R. Hopkins, P.R. Evans, and H.T. McMahon. 2001. Simultaneous Binding of Ptdlns(4,5)P2 and Clathrin by AP180 in the Nucleation of Clathrin Lattices on Membranes. Science. 291:1051-1055.

Futter, C.E., A. Gibson, E.H. Allchin, S. Maxwell, L.J. Ruddock, G. Odorizzi, D. Domingo, I.S. Trowbridge, and C.R. Hopkins. 1998. In polarized MDCK cells basolateral vesicles arise from clathrin-gamma-adaptin-coated domains on endosomal tubules. The Journal of Cell Biology. 141:611-23.

Gabel, C.A., D.E. Goldberg, and S. Kornfeld. 1983. Identification and characterization of cells deficient in the mannose 6-phosphate receptor: evidence for an alternate pathway for lysosomal enzyme targeting. Proceedings of the National Academy of Sciences of the United States of America. 80:775-9.

Gaidarov, I., M.E. Smith, J. Domin, and J.H. Keen. 2001. The class II phosphoinositide 3-kinase C2alpha is activated by clathrin and regulates clathrin-mediated membrane trafficking. Molecular Cell. 7:443-9.

Gallusser, A., and T. Kirchhausen. 1993. The beta 1 and beta 2 subunits of the AP complexes are the clathrin coat assembly components. The Embo Journal. 12:5237-44.

Gan, Y., T.E. McGraw, and E. Rodriguez Boulan. 2002. The epithelial-specific adaptor AP1B mediates post-endocytic recycling to the basolateral membrane. Nature Cell Biology. 4:605-9. 
Geuze, H.J., J.W. Slot, G.J. Strous, A. Hasilik, and K. von Figura. 1985. Possible pathways for lysosomal enzyme delivery. The Journal of Cell Biology. 101:2253-62.

Geuze, H.J., J.W. Slot, G.J. Strous, J.P. Luzio, and A.L. Schwartz. 1984. A cycloheximide-resistant pool of receptors for asialoglycoproteins and mannose 6-phosphate residues in the Golgi complex of hepatocytes. The Embo Journal. 3:2677-85.

Ghosh, P., and S. Kornfeld. 2003a. AP-1 binding to sorting signals and release from clathrin-coated vesicles is regulated by phosphorylation. J. Cell Biol. 160:699-708.

Ghosh, P., and S. Kornfeld. 2003b. Phosphorylation induced conformational changes regulate GGA1/3 function at the trans-Golgi network. J. Biol. Chem.:M212543200.

Glickman, J.N., E. Conibear, and B.M. Pearse. 1989. Specificity of binding of clathrin adaptors to signals on the mannose-6-phosphate/insulin-like growth factor II receptor. The Embo Journal. 8:1041-7.

Goda, Y., and S.R. Pfeffer. 1988. Selective recycling of the mannose 6phosphate/IGF-II receptor to the trans Golgi network in vitro. Cell. 55:30920.

Greenberg, M., L. DeTulleo, I. Rapoport, J. Skowronski, and T. Kirchhausen. 1998. A dileucine motif in HIV-1 Nef is essential for sorting into clathrincoated pits and for downregulation of CD4. Current Biology : Cb. 8:123942.

Greene, B., S.H. Liu, A. Wilde, and F.M. Brodsky. 2000. Complete reconstitution of clathrin basket formation with recombinant protein fragments: adaptor control of clathrin self-assembly. 1:69-75.

Hannan, L.A., S.L. Newmyer, and S.L. Schmid. 1998. ATP- and cytosoldependent release of adaptor proteins from clathrin-coated vesicles: $A$ dual role for Hsc70. Molecular Biology of the Cell. 9:2217-29.

Heilker, R., U. Manning Krieg, J.F. Zuber, and M. Spiess. 1996. In vitro binding of clathrin adaptors to sorting signals correlates with endocytosis and basolateral sorting. The Embo Journal. 15:2893-9.

Hemer, F., C. Korner, and T. Braulke. 1993. Phosphorylation of the human 46$\mathrm{kDa}$ mannose 6-phosphate receptor in the cytoplasmic domain at serine 56. The Journal of Biological Chemistry. 268:17108-13.

Heuser, J.E., and J. Keen. 1988. Deep-etch visualization of proteins involved in clathrin assembly. The Journal of Cell Biology. 107:877-86.

Hiebsch, R.R., T.J. Raub, and B.W. Wattenberg. 1991. Primaquine blocks transport by inhibiting the formation of functional transport vesicles. Studies in a cell-free assay of protein transport through the Golgi apparatus. The Journal of Biological Chemistry. 266:20323-8.

Hille Rehfeld, A. 1995. Mannose 6-phosphate receptors in sorting and transport of Iysosomal enzymes. Biochimica Et Biophysica Acta. 1241:177-94.

Hinshaw, J.E., and S.L. Schmid. 1995. Dynamin self-assembles into rings suggesting a mechanism for coated vesicle budding. Nature. 374:190-2. 
Hirst, J., M.R. Lindsay, and M.S. Robinson. 2001. GGAs: roles of the different domains and comparison with AP-1 and clathrin. Molecular Biology of the Cell. 12:3573-88.

Hirst, J., W.W. Lui, N.A. Bright, N. Totty, M.N. Seaman, and M.S. Robinson. 2000. A family of proteins with gamma-adaptin and VHS domains that facilitate trafficking between the trans-Golgi network and the vacuole/lysosome. The Journal of Cell Biology. 149:67-80.

Hirst, J., A. Motley, K. Harasaki, S.Y. Peak Chew, and M.S. Robinson. 2003. EpsinR: an ENTH Domain-containing Protein that Interacts with AP-1. Mol. Biol. Cell. 14:625-641.

Hirst, J., and M.S. Robinson. 1998. Clathrin and adaptors. Biochimica Et Biophysica Acta. 1404:173-93.

Hoening, S., J. Griffith, H.J. Geuze, and W. Hunziker. 1996. The tyrosine-based lysosomal targeting signal in lamp-1 mediates sorting into Golgi-derived clathrin-coated vesicles. The Embo Journal. 15:5230-9.

Hoening, S., I.V. Sandoval, and K. von Figura. 1998. A di-leucine-based motif in the cytoplasmic tail of LIMP-II and tyrosinase mediates selective binding of AP-3. The Embo Journal. 17:1304-14.

Hoening, S., M. Sosa, A. Hille Rehfeld, and K. von Figura. 1997. The 46-kDa mannose 6-phosphate receptor contains multiple binding sites for clathrin adaptors. The Journal of Biological Chemistry. 272:19884-90.

Hosobuchi, M., T. Kreis, and R. Schekman. 1992. SEC21 is a gene required for ER to Golgi protein transport that encodes a subunit of a yeast coatomer. Nature. 360:603-5.

Huang, F., A. Nesterov, R.E. Carter, and A. Sorkin. 2001. Trafficking of yellowfluorescent-protein-tagged mu1 subunit of clathrin adaptor AP-1 complex in living cells. 2:345-57.

Hunziker, W., J.A. Whitney, and I. Mellman. 1991. Selective inhibition of transcytosis by brefeldin A in MDCK cells. Cell. 67:617-27.

Hunziker, W., J.A. Whitney, and I. Mellman. 1992. Brefeldin A and the endocytic pathway. Possible implications for membrane traffic and sorting. Febs Letters. 307:93-6.

Huttner, W.B., and A. Schmidt. 2000. Lipids, lipid modification and lipid-protein interaction in membrane budding and fission--insights from the roles of endophilin A1 and synaptophysin in synaptic vesicle endocytosis. Current Opinion in Neurobiology. 10:543-51.

Itin, C., C. Rancano, Y. Nakajima, and S.R. Pfeffer. 1997. A novel assay reveals a role for soluble $\mathrm{N}$-ethylmaleimide-sensitive fusion attachment protein in mannose 6-phosphate receptor transport from endosomes to the trans Golgi network. The Journal of Biological Chemistry. 272:27737-44.

Itoh, T., S. Koshiba, T. Kigawa, A. Kikuchi, S. Yokoyama, and T. Takenawa. 2001. Role of the ENTH domain in phosphatidylinositol-4,5-bisphosphate binding and endocytosis. Science. 291:1047-51.

Jackson, C.L., and J.E. Casanova. 2000. Turning on ARF: the Sec7 family of guanine-nucleotide-exchange factors. Trends in Cell Biology. 10:60-7. 
Johnson, K.F., and S. Kornfeld. 1992a. The cytoplasmic tail of the mannose 6phosphate/insulin-like growth factor-Il receptor has two signals for lysosomal enzyme sorting in the Golgi. The Journal of Cell Biology. 119:249-57.

Johnson, K.F., and S. Kornfeld. 1992b. A His-Leu-Leu sequence near the carboxyl terminus of the cytoplasmic domain of the cation-dependent mannose 6-phosphate receptor is necessary for the lysosomal enzyme sorting function. The Journal of Biological Chemistry. 267:17110-5.

Jones, A., D. Spiro, T. Kirchhausen, P. Melancon, and M. Wessling-Resnick. 1999. Studies on the inhibition of endosome fusion by GTPgammaSbound ARF. J Cell Sci. 112:3477-3485.

Jones, S.M., K.E. Howell, J.R. Henley, H. Cao, and M.A. McNiven. 1998. Role of Dynamin in the Formation of Transport Vesicles from the Trans-Golgi Network. Science. 279:573-577.

Jost, M., F. Simpson, J.M. Kavran, M.A. Lemmon, and S.L. Schmid. 1998. Phosphatidylinositol-4,5-bisphosphate is required for endocytic coated vesicle formation. Current Biology : Cb. 8:1399-402.

Kent, H., H. McMahon, P. Evans, A. Benmerah, and D. Owen. 2002. gammaAdaptin Appendage Domain. Structure and Binding Site for Eps15 and gamma-Synergin. 10:1139.

Kirchhausen, T. 1999. Adaptors for clathrin-mediated traffic. Annual Review of Cell and Developmental Biology. 15:705-32.

Kirchhausen, T. 2000. Clathrin. Annual Review of Biochemistry. 69:699-727.

Kirchhausen, T., K.L. Nathanson, W. Matsui, A. Vaisberg, E.P. Chow, C. Burne, J.H. Keen, and A.E. Davis. 1989. Structural and functional division into two domains of the large (100- to 115-kDa) chains of the clathrin-associated protein complex AP-2. Proceedings of the National Academy of Sciences of the United States of America. 86:2612-6.

Klumperman, J., A. Hille, T. Veenendaal, V. Oorschot, W. Stoorvogel, K. von Figura, and H.J. Geuze. 1993. Differences in the endosomal distributions of the two mannose 6-phosphate receptors. The Journal of Cell Biology. 121:997-1010.

Klumperman, J., R. Kuliawat, J.M. Griffith, H.J. Geuze, and P. Arvan. 1998. Mannose 6-phosphate receptors are sorted from immature secretory granules via adaptor protein AP-1, clathrin, and syntaxin 6-positive vesicles. The Journal of Cell Biology. 141:359-71.

Kongsvik, T.L., S. Hoening, O. Bakke, and D.G. Rodionov. 2002. Mechanism of interaction between leucine-based sorting signals from the invariant chain and clathrin-associated adaptor protein complexes AP1 and AP2. The Journal of Biological Chemistry. 277:16484-8.

Korner, C., A. Herzog, B. Weber, O. Rosorius, F. Hemer, B. Schmidt, and T. Braulke. 1994. In vitro phosphorylation of the 46-kDa mannose 6phosphate receptor by casein kinase II. Structural requirements for efficient phosphorylation. The Journal of Biological Chemistry. 269:1652932. 
Kornfeld, S., and I. Mellman. 1989. The biogenesis of lysosomes. Annual Review of Cell Biology. 5:483-525.

Koster, A., P. Saftig, U. Matzner, K. von Figura, C. Peters, and R. Pohlmann. 1993. Targeted disruption of the $M(r) 46,000$ mannose 6-phosphate receptor gene in mice results in misrouting of lysosomal proteins. The Embo Journal. 12:5219-23.

Koster, A., K. von Figura, and R. Pohlmann. 1994. Mistargeting of lysosomal enzymes in $M(r)$ 46,000 mannose 6-phosphate receptor-deficient mice is compensated by carbohydrate-specific endocytotic receptors. European Journal of Biochemistry. 224:685-9.

Kreitzer, G., A. Marmorstein, P. Okamoto, R. Vallee, and E. Rodriguez Boulan. 2000. Kinesin and dynamin are required for post-Golgi transport of a plasma-membrane protein. Nature Cell Biology. 2:125-7.

Kreykenbohm, V., D. Wenzel, W. Antonin, V. Atlachkine, and G.F. von Mollard. 2002. The SNAREs vti1a and vti1b have distinct localization and SNARE complex partners. European Journal of Cell Biology. 81:273-80.

Kuehn, M.J., J.M. Herrmann, and R. Schekman. 1998. COPII-cargo interactions direct protein sorting into ER-derived transport vesicles. Nature. 391:18790.

Kyle, J.W., C.M. Nolan, A. Oshima, and W.S. Sly. 1988. Expression of human cation-independent mannose 6-phosphate receptor cDNA in receptornegative mouse P388D1 cells following gene transfer. The Journal of Biological Chemistry. 263:16230-5.

Le Borgne, R., A. Alconada, U. Bauer, and B. Hoflack. 1998. The mammalian AP3 adaptor-like complex mediates the intracellular transport of lysosomal membrane glycoproteins. The Journal of Biological Chemistry. 273:2945161.

Le Borgne, R., and B. Hoflack. 1997. Mannose 6-phosphate receptors regulate the formation of clathrin-coated vesicles in the TGN. The Journal of Cell Biology. 137:335-45.

Le Borgne, R., A. Schmidt, F. Mauxion, G. Griffiths, and B. Hoflack. 1993. Binding of AP-1 Golgi adaptors to membranes requires phosphorylated cytoplasmic domains of the mannose 6-phosphate/insulin-like growth factor II receptor. The Journal of Biological Chemistry. 268:22552-6.

Lemansky, P., V. Gieselmann, A. Hasilik, and K. von Figura. 1985. Synthesis and transport of lysosomal acid phosphatase in normal and I-cell fibroblasts. The Journal of Biological Chemistry. 260:9023-30.

Lemansky, P., A. Hasilik, K. von Figura, S. Helmy, J. Fishman, R.E. Fine, N.L. Kedersha, and L.H. Rome. 1987. Lysosomal enzyme precursors in coated vesicles derived from the exocytic and endocytic pathways. The Journal of Cell Biology. 104:1743-8.

Lemmon, S.K. 2001. Clathrin uncoating: Auxilin comes to life. Current Biology: Cb. 11:R49-52. 
Liu, W.W.Y., B.M. Collins, J. Hirst, A. Motley, C. Millar, P. Schu, D.J. Owen, and M.S. Robinson. 2003. Binding Partners for the COOH-terminal Appendage Domains of the GGAs and \{gamma\}-Adaptin. Mol. Biol. Cell:E02-11-0735.

Lobel, P., K. Fujimoto, R.D. Ye, G. Griffiths, and S. Kornfeld. 1989. Mutations in the cytoplasmic domain of the $275 \mathrm{kd}$ mannose 6-phosphate receptor differentially alter lysosomal enzyme sorting and endocytosis. Cell. 57:78796.

Lombardi, D., T. Soldati, M.A. Riederer, Y. Goda, M. Zerial, and S.R. Pfeffer. 1993. Rab9 functions in transport between late endosomes and the trans Golgi network. The Embo Journal. 12:677-82.

Ludwig, T., H. Munier Lehmann, U. Bauer, M. Hollinshead, C. Ovitt, P. Lobel, and B. Hoflack. 1994. Differential sorting of lysosomal enzymes in mannose 6phosphate receptor-deficient fibroblasts. The Embo Journal. 13:3430-7.

Ludwig, T., C.E. Ovitt, U. Bauer, M. Hollinshead, J. Remmler, P. Lobel, U. Ruther, and B. Hoflack. 1993. Targeted disruption of the mouse cation-dependent mannose 6-phosphate receptor results in partial missorting of multiple lysosomal enzymes. The Embo Journal. 12:5225-35.

Mallard, F., B.L. Tang, T. Galli, D. Tenza, A. Saint Pol, X. Yue, C. Antony, W. Hong, B. Goud, and L. Johannes. 2002. Early/recycling endosomes-toTGN transport involves two SNARE complexes and a Rab6 isoform. The Journal of Cell Biology. 156:653-64.

Mallet, W.G., and F.M. Brodsky. 1996. A membrane-associated protein complex with selective binding to the clathrin coat adaptor AP1. Journal of Cell Science. 109 ( Pt 13):3059-68.

Martinez, O., C. Antony, G. Pehau Arnaudet, E.G. Berger, J. Salamero, and B. Goud. 1997. GTP-bound forms of rab6 induce the redistribution of Golgi proteins into the endoplasmic reticulum. Proceedings of the National Academy of Sciences of the United States of America. 94:1828-33.

Meyer, C., E.L. Eskelinen, M.R. Guruprasad, K. von Figura, and P. Schu. 2001. Mu $1 \mathrm{~A}$ deficiency induces a profound increase in MPR300/IGF-II receptor internalization rate. Journal of Cell Science. 114:4469-76.

Meyer, C., D. Zizioli, S. Lausmann, E.L. Eskelinen, J. Hamann, P. Saftig, K. von Figura, and P. Schu. 2000. mu1A-adaptin-deficient mice: lethality, loss of AP-1 binding and rerouting of mannose 6-phosphate receptors. The Embo Journal. 19:2193-203.

Misra, S., R. Puertollano, Y. Kato, J.S. Bonifacino, and J.H. Hurley. 2002. Structural basis for acidic-cluster-dileucine sorting-signal recognition by VHS domains. Nature. 415:933-7.

Miwako, I., A. Yamamoto, T. Kitamura, K. Nagayama, and M. Ohashi. 2001. Cholesterol requirement for cation-independent mannose 6-phosphate receptor exit from multivesicular late endosomes to the Golgi. Journal of Cell Science. 114:1765-76.

Molloy, S.S., E.D. Anderson, F. Jean, and G. Thomas. 1999. Bi-cycling the furin pathway: from TGN localization to pathogen activation and embryogenesis. Trends in Cell Biology. 9:28-35. 
Monier, S., F. Jollivet, I. Janoueix Lerosey, L. Johannes, and B. Goud. 2002. Characterization of novel Rab6-interacting proteins involved in endosometo-TGN transport. 3:289-97.

Munier Lehmann, H., F. Mauxion, U. Bauer, P. Lobel, and B. Hoflack. 1996. Reexpression of the mannose 6-phosphate receptors in receptor-deficient fibroblasts. Complementary function of the two mannose 6-phosphate receptors in lysosomal enzyme targeting. The Journal of Biological Chemistry. 271:15166-74.

Nakagawa, T., M. Setou, D. Seog, K. Ogasawara, N. Dohmae, K. Takio, and N. Hirokawa. 2000. A novel motor, KIF13A, transports mannose-6-phosphate receptor to plasma membrane through direct interaction with AP-1 complex. Cell. 103:569-81.

Nathke, I.S., J. Heuser, A. Lupas, J. Stock, C.W. Turck, and F.M. Brodsky. 1992. Folding and trimerization of clathrin subunits at the triskelion hub. Cell. 68:899-910.

Neufeld, E.F. 1991. Lysosomal storage diseases. Annual Review of Biochemistry. 60:257-80.

Newman, L.S., M.O. McKeever, H.J. Okano, and R.B. Darnell. 1995. Beta-NAP, a cerebellar degeneration antigen, is a neuron-specific vesicle coat protein. Cell. 82:773-83.

Nogi, T., Y. Shiba, M. Kawasaki, T. Shiba, N. Matsugaki, N. Igarashi, M. Suzuki, R. Kato, H. Takatsu, K. Nakayama, and S. Wakatsuki. 2002. Structural basis for the accessory protein recruitment by the gamma-adaptin ear domain. Nature Structural Biology. 9:527-31.

Ohno, H., J. Stewart, M.C. Fournier, H. Bosshart, I. Rhee, S. Miyatake, T. Saito, A. Gallusser, T. Kirchhausen, and J.S. Bonifacino. 1995. Interaction of tyrosine-based sorting signals with clathrin-associated proteins. Science. 269:1872-5.

Ohno, H., T. Tomemori, F. Nakatsu, Y. Okazaki, R.C. Aguilar, H. Foelsch, I. Mellman, T. Saito, T. Shirasawa, and J.S. Bonifacino. 1999. Mu1B, a novel adaptor medium chain expressed in polarized epithelial cells. Febs Letters. 449:215-20.

Olson, L.J., J. Zhang, Y.C. Lee, N.M. Dahms, and J.J. Kim. 1999. Structural basis for recognition of phosphorylated high mannose oligosaccharides by the cation-dependent mannose 6-phosphate receptor. The Journal of Biological Chemistry. 274:29889-96.

Ooi, C.E., E.C. Dell Angelica, and J.S. Bonifacino. 1998. ADP-Ribosylation factor 1 (ARF1) regulates recruitment of the AP-3 adaptor complex to membranes. The Journal of Cell Biology. 142:391-402.

Owen, D.J., and P.R. Evans. 1998. A structural explanation for the recognition of tyrosine-based endocytotic signals. Science. 282:1327-32.

Owen, D.J., Y. Vallis, M.E. Noble, J.B. Hunter, T.R. Dafforn, P.R. Evans, and H.T. McMahon. 1999. A structural explanation for the binding of multiple ligands by the alpha-adaptin appendage domain. Cell. 97:805-15. 
Owen, D.J., Y. Vallis, B.M. Pearse, H.T. McMahon, and P.R. Evans. 2000. The structure and function of the beta 2-adaptin appendage domain. The Embo Journal. 19:4216-27.

Payne, G.S., T.B. Hasson, M.S. Hasson, and R. Schekman. 1987. Genetic and biochemical characterization of clathrin-deficient Saccharomyces cerevisiae. Molecular and Cellular Biology. 7:3888-98.

Peden, A.A., G.Y. Park, and R.H. Scheller. 2001. The Di-leucine motif of vesicleassociated membrane protein 4 is required for its localization and AP-1 binding. The Journal of Biological Chemistry. 276:49183-7.

Pevsner, J., W. Volknandt, B.R. Wong, and R.H. Scheller. 1994. Two rat homologs of clathrin-associated adaptor proteins. Gene. 146:279-83.

Pohlmann, R., M.W. Boeker, and K. von Figura. 1995. The two mannose 6phosphate receptors transport distinct complements of lysosomal proteins. The Journal of Biological Chemistry. 270:27311-8.

Prasad, K., J. Heuser, E. Eisenberg, and L. Greene. 1994. Complex formation between clathrin and uncoating ATPase. The Journal of Biological Chemistry. 269:6931-9.

Prydz, K., S.H. Hansen, K. Sandvig, and B. van Deurs. 1992. Effects of brefeldin A on endocytosis, transcytosis and transport to the Golgi complex in polarized MDCK cells. The Journal of Cell Biology. 119:259-72.

Puertollano, R., R.C. Aguilar, I. Gorshkova, R.J. Crouch, and J.S. Bonifacino. 2001a. Sorting of mannose 6-phosphate receptors mediated by the GGAs. Science. 292:1712-6.

Puertollano, R., P.A. Randazzo, J.F. Presley, L.M. Hartnell, and J.S. Bonifacino. 2001b. The GGAs promote ARF-dependent recruitment of clathrin to the TGN. Cell. 105:93-102.

Puertollano, R., N.N. van der Wel, L.E. Greene, E. Eisenberg, P.J. Peters, and J.S. Bonifacino. 2003. Morphology and Dynamics of Clathrin/GGA1Coated Carriers Budding from the Trans-Golgi Network. Mol. Biol. Cell:0207-0109.

Randazzo, P.A., Z. Nie, K. Miura, and V.W. Hsu. 2000. Molecular aspects of the cellular activities of ADP-ribosylation factors. 2000:RE1.

Rapoport, I., Y.C. Chen, P. Cupers, S.E. Shoelson, and T. Kirchhausen. 1998. Dileucine-based sorting signals bind to the beta chain of AP-1 at a site distinct and regulated differently from the tyrosine-based motif-binding site. The Embo Journal. 17:2148-55.

Reusch, U., O. Bernhard, U. Koszinowski, and P. Schu. 2002. AP-1A and AP-3A lysosomal sorting functions. 3:752-61.

Ricotta, D., S.D. Conner, S.L. Schmid, K. von Figura, and S. Hoening. 2002. Phosphorylation of the AP2 mu subunit by AAK1 mediates high affinity binding to membrane protein sorting signals. The Journal of Cell Biology. 156:791-5.

Roberts, D.L., D.J. Weix, N.M. Dahms, and J.J. Kim. 1998. Molecular basis of lysosomal enzyme recognition: three-dimensional structure of the cationdependent mannose 6-phosphate receptor. Cell. 93:639-48. 
Robinson, M.S., and J.S. Bonifacino. 2001. Adaptor-related proteins. Current Opinion in Cell Biology. 13:444-53.

Robinson, M.S., and T.E. Kreis. 1992. Recruitment of coat proteins onto Golgi membranes in intact and permeabilized cells: effects of brefeldin $A$ and $G$ protein activators. Cell. 69:129-38.

Rodionov, D.G., and O. Bakke. 1998. Medium chains of adaptor complexes AP-1 and AP-2 recognize leucine-based sorting signals from the invariant chain. The Journal of Biological Chemistry. 273:6005-8.

Rohde, G., D. Wenzel, and V. Haucke. 2002. A phosphatidylinositol $(4,5)-$ bisphosphate binding site within mu2-adaptin regulates clathrin-mediated endocytosis. The Journal of Cell Biology. 158:209-14.

Rosenthal, J.A., H. Chen, V.I. Slepnev, L. Pellegrini, A.E. Salcini, P.P. Di Fiore, and $P$. De Camilli. 1999. The epsins define a family of proteins that interact with components of the clathrin coat and contain a new protein module. The Journal of Biological Chemistry. 274:33959-65.

Roth, M.G. 1999. Snapshots of ARF1: implications for mechanisms of activation and inactivation. Cell. 97:149-52.

Rothman, J.E. 1987. Transport of the vesicular stomatitis glycoprotein to trans Golgi membranes in a cell-free system. The Journal of Biological Chemistry. 262:12502-10.

Rous, B.A., B.J. Reaves, G. Ihrke, J.A. Briggs, S.R. Gray, D.J. Stephens, G. Banting, and J.P. Luzio. 2002. Role of adaptor complex AP-3 in targeting wild-type and mutated CD63 to lysosomes. Molecular Biology of the Cell. 13:1071-82.

Salamero, J., R. Le Borgne, C. Saudrais, B. Goud, and B. Hoflack. 1996. Expression of major histocompatibility complex class II molecules in HeLa cells promotes the recruitment of AP-1 Golgi-specific assembly proteins on Golgi membranes. The Journal of Biological Chemistry. 271:30318-21.

Scales, S.J., M. Gomez, and T.E. Kreis. 2000. Coat proteins regulating membrane traffic. International Review of Cytology. 195:67-144.

Schekman, R., and I. Mellman. 1997. Does COPI go both ways? Cell. 90:197200.

Schlossman, D.M., S.L. Schmid, W.A. Braell, and J.E. Rothman. 1984. An enzyme that removes clathrin coats: purification of an uncoating ATPase. The Journal of Cell Biology. 99:723-33.

Schu, P. 2001. Vesicular protein transport. 1:262-71.

Schulze Lohoff, E., A. Hasilik, and K. von Figura. 1985. Cathepsin D precursors in clathrin-coated organelles from human fibroblasts. The Journal of Cell Biology. 101:824-9.

Schweizer, A., S. Kornfeld, and J. Rohrer. 1996. Cysteine34 of the cytoplasmic tail of the cation-dependent mannose 6-phosphate receptor is reversibly palmitoylated and required for normal trafficking and lysosomal enzyme sorting. The Journal of Cell Biology. 132:577-84.

Schweizer, A., S. Kornfeld, and J. Rohrer. 1997. Proper sorting of the cationdependent mannose 6-phosphate receptor in endosomes depends on a 
pair of aromatic amino acids in its cytoplasmic tail. Proceedings of the National Academy of Sciences of the United States of America. 94:144716.

Seeger, M., and G.S. Payne. 1992. A role for clathrin in the sorting of vacuolar proteins in the Golgi complex of yeast. The Embo Journal. 11:2811-8.

Shiba, T., H. Takatsu, T. Nogi, N. Matsugaki, M. Kawasaki, N. Igarashi, M. Suzuki, R. Kato, T. Earnest, K. Nakayama, and S. Wakatsuki. 2002a. Structural basis for recognition of acidic-cluster dileucine sequence by GGA1. Nature. 415:937-41.

Shiba, Y., H. Takatsu, H.W. Shin, and K. Nakayama. 2002b. Gamma-adaptin interacts directly with Rabaptin-5 through its ear domain. 131:327-36.

Shih, W., A. Gallusser, and T. Kirchhausen. 1995. A clathrin-binding site in the hinge of the beta 2 chain of mammalian AP-2 complexes. The Journal of Biological Chemistry. 270:31083-90.

Shinotsuka, C., S. Waguri, M. Wakasugi, Y. Uchiyama, and K. Nakayama. 2002a. Dominant-negative mutant of BIG2, an ARF-guanine nucleotide exchange factor, specifically affects membrane trafficking from the trans-Golgi network through inhibiting membrane association of AP-1 and GGA coat proteins. Biochemical and Biophysical Research Communications. 294:254-60.

Shinotsuka, C., Y. Yoshida, K. Kawamoto, H. Takatsu, and K. Nakayama. 2002b. Overexpression of an ADP-ribosylation factor-guanine nucleotide exchange factor, BIG2, uncouples brefeldin A-induced adaptor protein-1 coat dissociation and membrane tubulation. The Journal of Biological Chemistry. 277:9468-73.

Simmen, T., S. Hoening, A. Icking, R. Tikkanen, and W. Hunziker. 2002. AP-4 binds basolateral signals and participates in basolateral sorting in epithelial MDCK cells. Nature Cell Biology. 4:154-9.

Stamnes, M.A., and J.E. Rothman. 1993. The binding of AP-1 clathrin adaptor particles to Golgi membranes requires ADP-ribosylation factor, a small GTP-binding protein. Cell. 73:999-1005.

Stein, M., J.E. Zijderhand Bleekemolen, H. Geuze, A. Hasilik, and K. von Figura. 1987. Mr 46,000 mannose 6-phosphate specific receptor: its role in targeting of lysosomal enzymes. The Embo Journal. 6:2677-81.

Storch, S., and T. Braulke. 2001. Multiple C-terminal Motifs of the 46-kDa Mannose 6-Phosphate Receptor Tail Contribute to Efficient Binding of Medium Chains of AP-2 and AP-3. J. Biol. Chem. 276:4298-4303.

Strous, G.J., P. van Kerkhof, G. van Meer, S. Rijnboutt, and W. Stoorvogel. 1993. Differential effects of brefeldin A on transport of secretory and lysosomal proteins. The Journal of Biological Chemistry. 268:2341-7.

Subtil, A., I. Gaidarov, K. Kobylarz, M.A. Lampson, J.H. Keen, and T.E. McGraw. 1999. Acute cholesterol depletion inhibits clathrin-coated pit budding. Proceedings of the National Academy of Sciences of the United States of America. 96:6775-80. 
Sugimoto, H., M. Sugahara, H. Folsch, Y. Koide, F. Nakatsu, N. Tanaka, T. Nishimura, M. Furukawa, C. Mullins, N. Nakamura, I. Mellman, and H. Ohno. 2002. Differential Recognition of Tyrosine-based Basolateral Signals by AP-1B Subunit \{micro\}1B in Polarized Epithelial Cells. Mol. Biol. Cell. 13:2374-2382.

Takatsu, H., Y. Katoh, Y. Shiba, and K. Nakayama. 2001. Golgi-localizing, gamma-adaptin ear homology domain, ADP-ribosylation factor-binding (GGA) proteins interact with acidic dileucine sequences within the cytoplasmic domains of sorting receptors through their Vps27p/Hrs/STAM (VHS) domains. The Journal of Biological Chemistry. 276:28541-5.

Taylor, T.C., R.A. Kahn, and P. Melancon. 1992. Two distinct members of the ADP-ribosylation factor family of GTP-binding proteins regulate cell-free intra-Golgi transport. Cell. 70:69-79.

ter Haar, E., S.C. Harrison, and T. Kirchhausen. 2000. Peptide-in-groove interactions link target proteins to the beta-propeller of clathrin. Proceedings of the National Academy of Sciences of the United States of America. 97:1096-100.

ter Haar, E., A. Musacchio, S.C. Harrison, and T. Kirchhausen. 1998. Atomic structure of clathrin: a beta propeller terminal domain joins an alpha zigzag linker. Cell. 95:563-73.

Teuchert, M., W. Schafer, S. Berghofer, B. Hoflack, H.D. Klenk, and W. Garten. 1999. Sorting of furin at the trans-Golgi network. Interaction of the cytoplasmic tail sorting signals with AP-1 Golgi-specific assembly proteins. The Journal of Biological Chemistry. 274:8199-207.

Tikkanen, R., S. Obermuller, K. Denzer, R. Pungitore, H.J. Geuze, K. von Figura, and S. Hoening. 2000. The dileucine motif within the tail of MPR46 is required for sorting of the receptor in endosomes. 1:631-40.

Traub, L.M., M.A. Downs, J.L. Westrich, and D.H. Fremont. 1999. Crystal structure of the alpha appendage of AP-2 reveals a recruitment platform for clathrin-coat assembly. Proceedings of the National Academy of Sciences of the United States of America. 96:8907-12.

Traub, L.M., S. Kornfeld, and E. Ungewickell. 1995. Different domains of the AP-1 adaptor complex are required for Golgi membrane binding and clathrin recruitment. The Journal of Biological Chemistry. 270:4933-42.

Traub, L.M., J.A. Ostrom, and S. Kornfeld. 1993. Biochemical dissection of AP-1 recruitment onto Golgi membranes. The Journal of Cell Biology. 123:56173.

Ungewickell, E., H. Ungewickell, S.E. Holstein, R. Lindner, K. Prasad, W. Barouch, B. Martin, L.E. Greene, and E. Eisenberg. 1995. Role of auxilin in uncoating clathrin-coated vesicles. Nature. 378:632-5.

van der Bliek, A.M., T.E. Redelmeier, H. Damke, E.J. Tisdale, E.M. Meyerowitz, and S.L. Schmid. 1993. Mutations in human dynamin block an intermediate stage in coated vesicle formation. The Journal of Cell Biology. 122:553-63.

von Figura, K., and A. Hasilik. 1986. Lysosomal enzymes and their receptors. Annual Review of Biochemistry. 55:167-93. 
Waguri, S., F. Dewitte, R. Le Borgne, Y. Rouille, Y. Uchiyama, J.-F. Dubremetz, and B. Hoflack. 2003. Visualization of TGN to Endosome Trafficking through Fluorescently Labeled MPR and AP-1 in Living Cells. Mol. Biol. Cell. 14:142-155.

Wan, L., S.S. Molloy, L. Thomas, G. Liu, Y. Xiang, S.L. Rybak, and G. Thomas. 1998. PACS-1 defines a novel gene family of cytosolic sorting proteins required for trans-Golgi network localization. Cell. 94:205-16.

Wilcke, M., L. Johannes, T. Galli, V. Mayau, B. Goud, and J. Salamero. 2000. Rab11 regulates the compartmentalization of early endosomes required for efficient transport from early endosomes to the trans-golgi network. The Journal of Cell Biology. 151:1207-20.

Wilde, A., and F.M. Brodsky. 1996. In vivo phosphorylation of adaptors regulates their interaction with clathrin. The Journal of Cell Biology. 135:635-45.

Wu, X., X. Zhao, R. Puertollano, J.S. Bonifacino, E. Eisenberg, and L.E. Greene. 2003. Adaptor and Clathrin Exchange at the Plasma Membrane and transGolgi Network. Mol. Biol. Cell. 14:516-528.

Ybe, J.A., F.M. Brodsky, K. Hofmann, K. Lin, S.H. Liu, L. Chen, T.N. Earnest, R.J. Fletterick, and P.K. Hwang. 1999. Clathrin self-assembly is mediated by a tandemly repeated superhelix. Nature. 399:371-5.

Zaremba, S., and J.H. Keen. 1985. Limited proteolytic digestion of coated vesicle assembly polypeptides abolishes reassembly activity. Journal of Cellular Biochemistry. 28:47-58.

Zerial, M., and H. McBride. 2001. Rab proteins as membrane organizers. 2:10717.

Zhdankina, O., N.L. Strand, J.M. Redmond, and A.L. Boman. 2001. Yeast GGA proteins interact with GTP-bound Arf and facilitate transport through the Golgi. Yeast (Chichester, West Sussex). 18:1-18.

Zhu, Y., B. Doray, A. Poussu, V.P. Lehto, and S. Kornfeld. 2001. Binding of GGA2 to the lysosomal enzyme sorting motif of the mannose 6-phosphate receptor. Science. 292:1716-8.

Zhu, Y., M.T. Drake, and S. Kornfeld. 1999a. ADP-ribosylation factor 1 dependent clathrin-coat assembly on synthetic liposomes. Proceedings of the National Academy of Sciences of the United States of America. 96:5013-8.

Zhu, Y., L.M. Traub, and S. Kornfeld. 1998. ADP-ribosylation factor 1 transiently activates high-affinity adaptor protein complex AP-1 binding sites on Golgi membranes. Molecular Biology of the Cell. 9:1323-37.

Zhu, Y., L.M. Traub, and S. Kornfeld. 1999b. High-affinity binding of the AP-1 adaptor complex to trans-golgi network membranes devoid of mannose 6phosphate receptors. Molecular Biology of the Cell. 10:537-49.

Zizioli, D., C. Meyer, G. Guhde, P. Saftig, K. von Figura, and P. Schu. 1999. Early embryonic death of mice deficient in gamma-adaptin. The Journal of Biological Chemistry. 274:5385-90. 


\section{Acknowledgement}

I thank Prof. Dr. Kurt von Figura, for giving me an opportunity to work in this institute and helping me with his supervision and guidance in the completion of this project. I thank Prof. Dr. G. Braus, for agreeing to be my co-referee.

I thank Dr. Peter Schu for his constant support, patience and guidance in this project. His insistence on proper planning of the experiments, accurate and reproducible data generation, analysis of the results has taught me the way to approach and tackle a scientific problem. With his help during the preparation of this thesis I have learnt to present a scientific work in a manner understandable to everyone. Thanks a lot for all your help Peter.

I thank Boehringer Ingelheim Foundation for their financial support.

Olaf, Monika, Inga, Angelika, Chitkala, Ira, I was lucky to have such wonderful colleagues who created an enthusiastic working atmosphere. Thank you all for your cooperation. Thank you Rekha for always being there to take care of my gels and blots! Thank you very much Constanze for the criticial reading of my thesis and for many useful discussions that we had.

My special thanks to Anna for all her software support without which it would have been an impossible to finish this thesis. Thank you Dr.Torben Lübke, Annegret, Ellen, Vera, Vadim, Mals, Subbulakshmi, Alfred, Byörn, Martin Hasilik and Jens for many lively interactions.

I thank Dr. Thomas Dierks for all his help during my experiments with the SMART system. I thank Dr. Stefan Hoening who always had time for me for scientific discussions and provided me with many reagents that was of great use in my experiments. I also would like to thank Dr. Christian Korner, Dr. Gabriele Fischer von Mollard and Dr. Bernhard Schmidt for their help with reagents and equipments for the experiments.

I thank my family and friends in India for their moral support and encouragement from overseas at all the times in these three years.

I thank all my colleagues in the institute with whom I had lively interactions, with whom I picked up my "Deutsch" and who helped me with many day to day to things.

This thesis would never have seen its completion without my best friend, Dr. Meik Dilcher's help from the beginning till the end in critical reading, correcting, organising, formatting, printing, binding etc etc., My whole hearted thanks to you Meik. 


\section{Lebenslauf:}

Name:

Date of Birth:

Geburtsort:

$1990-1992$

1992-1995

1995-1997

M.Sc Project

April 1998-Nov. 1999

Dec. 1999 - present
Guruprasad Medigeshi Ramarao

20.03.1975

Bangalore, Indien

Pre-universtiy education, Government College for Boys, Mandya. India.

Bachelor of Science in Botany, Biochemistry and Microbiolgy, at the Yuvaraja's college, University of Mysore, India.

Master of Science in Biotechnology at the Dept. Of Applied Botany and Biotechnology, University of Mysore, India.

"Studies on the plasmid determined multiple antibiotic resistance in Klebsiella pneumoniae"

At Vittal Mallya Scientific Research Foundation,

Bangalore, India

Worked as Project Assistant with Prof. Sandhya S. Visweswariah, Indian Institute of Science, Banglaore, India.

Joined the "Zentrum Biochemie und Molekulare Zell Biologie" (Biochemie) to pursue doctoral studies under the supervision of PD. Dr. Peter Schu to work on the research project "Role of Adaptor Proteins in MPR sorting" 